DOE/NASA/0335-5

NASA CR-191088

GARRETT NO. 31-8071(05)

\title{
ADVANCED TURBINE TECHNOLOGY APPLICATIONS PROJECT (ATTAP)
}

1992 ANNUAL REPORT

Engineering Staff of Garrett Auxiliary Power Division A Unit of Allied-Signal Aerospace Company

March 1993

Prepared for

NATIONAL AERONAUTICS AND SPACE

ADMINISTRATION

Lewis Research Center

Cleveland, Ohio 44135

Under Contract DEN3-335

for

U.S. DEPARTMENT OF ENERGY

Office of Transportation Technologies

Advanced Propulsion Division

Washington, D.C. 20585 


\section{Disclaimer}

This report was prepared as an account of work sponsored by an agency of the United States Government. Neither the United States Government nor any agency thereof, nor any of their employees, makes any warranty, express or implied, or assumes any legal liability or responsibility for the accuracy, completeness, or usefulness of any information, apparatus, product or process disclosed, or represents that its use would not infringe privately owned rights. Reference herein to any specific commercial product, process, or service by trade name, trademark, manufacturer, or otherwise, does not necessarily constitute or imply its endorsement, recommendation, or favoring by the United States Government or any agency thereof. The views and opinions of authors expressed herein do not necessarily state or reflect those of the United States Government or any agency thereof.

Printed in the United States of America

Available from

National Technical Information Service

U.S. Department of Commerce

5285 Port Royal Road

Springfield, Virginia 22161

NTIS Price Codes ${ }^{1}$

Printed copy: $\quad A 07$

Microfiche copy: A01

1 Codes are used for pricing all publications. The code is determined by the number of pages in the publication. Information pertaining to the pricing codes can be found in the current issues of the following publications, which are generally available in most libraries: Energy Research Abstracts (ERA); Government Reports Announcements and Index (GRA and I); Sclentific and Technical Abstract Reports (STAR); and publication, NTIS-PR-360 available from NTIS at the above address 


\section{TABLE OF CONTENTS}

Page

ACRONYMS AND ABBREVIATIONS $\quad$ x

$\begin{array}{ll}1.0 \text { SUMMARY } & 1\end{array}$

1.1 Test Bed Engine Design, Analysis, And Materials Assessment 1

1.2 Ceramic Component Design 1

1.3 Materials Characterization And Ceramic Component Fabrication 2

1.4 Component Rig Testing $\quad 3$

1.5 Engine Test Bed Trials $\quad 4$

$\begin{array}{lll}2.0 & \text { INTRODUCTION } & 5\end{array}$

3.0 TEST BED ENGINE DESIGN, ANALYSIS, AND MATERIALS ASSESSMENT 8

$\begin{array}{llr}3.1 & \text { Materials Assessment } & 8\end{array}$

3.2 Reference Powertrain Design (RPD) $r$

3.3 Reference Powertrain Design Cost Analysis 18

$\begin{array}{llc}3.4 & \text { Test Bed Improvements } & 8\end{array}$

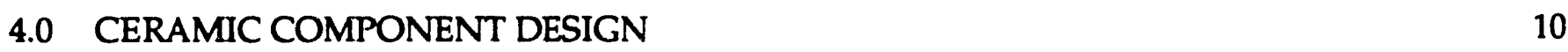

$\begin{array}{lll}\text { 4.1 Design Methods For Impact Damage Resistance } & 10\end{array}$

$\begin{array}{ll}\text { 4.1.1 Local Impact Damage Model } & 10\end{array}$

$\begin{array}{ll}\text { 4.1.2 Structural Impact Damage Model } & 10\end{array}$

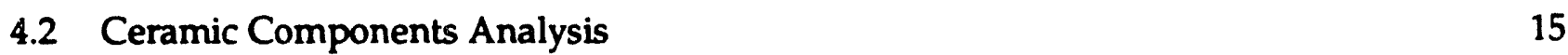

4.2.1 Peak Stress Evaluation Of IRT Rotor $\quad 17$

$\begin{array}{ll}\text { 4.2.2 Probabilistic Life Analysis } & 19\end{array}$

$\begin{array}{lll}\text { 4.2.3 Room Temperature Burst Analysis } & 21\end{array}$

4.2.4 Fast Fracture During Engine Operation $\quad 21$

4.2.5 Slow Crack Growth During Engine Steady-State Operation 22

5.0 MATERIALS CHARACTERIZATION AND CERAMIC COMPONENT FABRICATION 24

$\begin{array}{llr}5.1 & \text { Materials Characterization } & 24\end{array}$

$\begin{array}{lll}\text { 5.1.1 Property Measurements } & 24\end{array}$

$\begin{array}{ll}\text { 5.1.2 Nondestructive Evaluation (NDE) } & 35\end{array}$ 
5.2 Ceramic Component Fabrication 36

5.2.1 Norton Advanced Ceramics (NAC) 37

5.2.2 Garrett Ceramic Components (GCC) 37

5.2.3 The Carborundum Company (CBO) 39

\begin{tabular}{ll}
5.3 & Ceramic Component Preparation \\
\hline
\end{tabular}

6.0 COMPONENT RIG TESTING

6.1 Hot Spin Pit Testing 40

6.2 Combustor Rig Testing 42

6.3 Regenerator Rig Testing $\quad 42$

6.4 Structural Proof Testing 43

6.4.1 Thermal Furnace Proof Testing $\quad 44$

6.4.2 Spring Seal Proof Test 45

$\begin{array}{lll}6.5 & 2500 \mathrm{~F}(1371 \mathrm{C}) \text { Test Rig } & 47\end{array}$

6.6 Turbine Stage Aerodynamic Test Rig 47

$\begin{array}{lll}7.0 & \text { ENGINE TEST BED TRIALS } & 50\end{array}$

7.1 Metal Engine Testing 51

7.2 All-Ceramic Engine Testing 51

7.2.1 Milestone 4 Testing $\quad 52$

$\begin{array}{ll}7.2 .2 & \text { Milestone } 5 \text { Testing }\end{array}$

$\begin{array}{lll}7.3 & \text { Engine Test Summary } & 60\end{array}$

$\begin{array}{lll}8.0 & \text { PROJECT MANAGEMENT AND REPORTING } & 62\end{array}$

REFERENCES

$\begin{array}{lll}\text { APPENDIX I } & -\quad \text { ANNUAL TECHNICAL PROGRESS REPORT } & \\ \text { APPENDIX II }-\quad & \text { GARRETT CERAMIC COMPONENTS } & 64 \\ \text { ANNUAL TECHNICAL PROGRESS REPORT } & \text { NORTON ADVANCED CERAMICS COMPANY }\end{array}$ 


\section{LIST OF FIGURES}

3 New Combustor Cap Design Lowers Spring Operating Temperature

Three Ceramic Blade Design Parameters Were Found To Have The Greatest Influence On Impact Resistance

Two Ceramic Subelement Models Were Fabricated For Impact

Verification Tests

$7 \quad$ IRI Plot Shows Significant Improvement In Impact Resistance Was Achieved With New Design Method

Calculated Strains Using Elastic Mociel Are Much Higher Than The Measured Strains

9 Macromechanical Impact Model Produces Better Agreement Between Analytical And Experimental Results

10 Cross Section Of Redesigned Turbine And Supporting Structures Shows Five Modified Components (Shaded)

11 3-D Finite Element Analysis Results Were Used For Probabilistic Stress Predictions

12 Milestone 5 Durability Test Cycle

13 Weibull Parameters For NT154 And GN-10 Used In Rotor Failure Probability Analysis

14 GN-10 Stress Rupture Data Used For Slow Crack Growth Predictions

Fast Fracture Life Prediction For ATTAP Milestone 5 Durability Cycle Testing 


\section{LIST OF FIGURES (Contd)}

Figure

18

19

20

21

22

23

24

Comparison Of NT154 And GN-10 Slow Crack Growth Lives At

$2400 \mathrm{~F}(1318 \mathrm{C})$ TIT And 90,000 rpm

Comparison Of NT154 Flexural And Tensile Stress Rupture Test Results

NT154 Test Specimen Flaw Originating From Pit In As-Processed Surface

NT230 Flexural Stress Rupture Test Results

NT164 Flexural Strength Test Results

NT164 Specimen Failure Originating From Machined Surface

NT164 Specimen Failure Originating From Iron Particle Inclusion

SN-88 Flexural Strength Test Results

As-Processed SN-88 Specimen Failure Originating From Surface Pit

SN-88 Specimen Failure Originating From Silicon Nitride Grain

SN-88 High-Temperature Stress Rupture Test Results

ATTAP Hot Regenerator Test Rig Incorporates A Ceramic Valve Replacing The Rotating Group

Anti-Tilt Roller Reduced Regenerator Core Tilt And Torque

Ceramic Component Furnace Proof Test Fixture Was Designed

And Fabricated

Component Thermal Proof Test Cycles Were Analytically Defined And

Experimentally Verified

Spring Seal Proof Test Fixtures Simulate Deflections In The AGT101 Engine

The 2500F (1371C) Test Rig Exposes Ceramic Hardware To High

Temperature To Verify Suitability For Engine Testing 


\section{LIST OF FIGURES (Contd)}

AGT101 Impact-Resistant Turbine Stage Performance Map Was Derived From Aerodynamic Rig Test Results

Milestone 4 Emissions Volume Versus Engine Speed (Commercial Ethanol Fuel)

Milestone 4 Emissions Index (EI) Versus Engine Speed (Commercial Ethanol Fuel)

Milestone 4 Specific Fuel Consumption

Milestone 4 Corrected Aerodynamic Horsepower

Engine Candidate AGT101 IRT Rotors For Second and Final Scheduled Delivery

Comparison of Fast Fracture Strength and Slow Crack Growth

Threshold For Revs. 15 and 17 GN-10 Slip

Significant Improvements in GN-10 Rotor Properties Achieved During the ATTAP Program

NT154 Process Flow Chart 


\section{LIST OF FIGURES (Contd)}

\section{Figure}

\section{Title}

Page

Aqueous-Milled, Agglomerated NT154 Weibull Distribution For Room Temperature And 1370C MOR

1370C MOR Statistical Process Control Chart For Aqueous-Milled, Agglomerated NT154 Slip Batches 30 Through 58

Aqueous-Milled NT154 And NT164 Stress Rupture Characteristics

Aqueous-Milled, Agglomerated NT164 Weibull Distribution For Room Temperature And 1370C MOR

1370C MOR Statistical Process Control Chart For Aqueous-Milled, Agglomerated NT164 Slip Batches 1 Through 25

Second-Generation AGT101 Stator Casting Pattern Design

Engine-Quality AGT101 Rotors

AGT101 Rotor Deliverable Set No. 1 Process Yields

AGT101 Rotor Deliverable Set No. 2 Process Yields

AGT101 Rotor Deliverable Set No. 3 Process Yields

AGT101 Rotor Process Losses By Defect Type

Engine-Quality AGT101 Stators

AGT101 Stator Deliverable Set No. 1 Process Yields

AGT101 Stator Deliverable Set No. 2 Process Yields

AGT101 Stator Deliverable Set No. 3 Process Yields

AGT101 Stator Deliverable Set No. 4 Process Yields

AGT101 Stator Deliverable Set No. 4 - Histogram Of Z-Section CMM Data

AGT101 Stator Deliverable Set No. 3 - Histogram Of L-Section CMM Data

AGT101 Stator Set 1 Versus Set 3 Quality Comparison Green Casting

AGT101 Stator Set 1 Versus Set 3 Quality Comparison Green Casting 


\section{LIST OF FIGURES (Contd)}

Figure

Title

Page

76 AGT101 Stator Set 1 Versus Set 3 Quality Comparison Dense Casting Visual Inspection

77 AST101 Stator Set 1 Versus Set 3 Quality Comparison Sense Casting FPI Inspection

78 AGT101 Stator Set 1 Versus Set 3 Quality Comparison Dense Machined Visual Inspection

79 AGT101 Stator Set 1 Versus Set 3 Quality Comparison Dense Machined FPI Inspection

80 AGT101 Stator Set 1 Versus Set 3 Quality Comparison Dense Machined MFXR Inspection 


\section{LIST OF TABLES}

Tabie

Title

Page KEY PARAMETERS FOR TWO IMPACT-RESISTANT CERAMIC
TURBINE BLADE DESIGNS

SUBELEMENT IMPACT TEST RESULTS SHOWED SUBSTANTIAL IMPROVEMENT FOR IMPROVED BLADE DESIGN

ATTAP CERAMIC MATERIAL FLEXURAL STRENGTH AND STRESS RUPTURE TEST PARAMETERS

ATTAP CERAMIC MATERIAL TENSILE STRESS RUPTURE TEST PARAMETERS NOTABLE GAINS WERE ACHIEVED IN GCC GN-10 SILICON NITRIDE
ROTOR PROPERTIES

ROOM TEMPERATURE FAST FRACTURE SPIN BURST TEST RESULTS

HIGH-TEMPERATURE FAST FRACTURE SPIN BURST TEST RESULTS

1992 ATTAP ENGINE BUILDS AND TEST RESULTS

ATTAP ENGINE TEST STATUS

METAL AGT101 ENGINE TEST SUMMARY

AGT101 ENGINE S/N 002C TEST SUMMARY

ATTAP MILESTONE 4 AGT101 ENGINE TEST DATA

AGT101 ENGINE S/N 002C BUILD 23 TEST SUMMAK:

MECHANICAL PROPERTIES OF AGT101 ROTORS

MECHANICAL PROPERTIES OF 1992 AGT101 ROTORS

PROPERTIES OF NT154 AND NT164 $\mathrm{Si}_{3} \mathrm{~N}_{4}$ PHYSICAL, THERMAL, AND MECHANICAL PROPERTIES OF
NT230 Si-SiC

AQUEOUS-MILLED, PRESSURE-CAST NT154 TENSILE FAST

FRACTURE AND STRESS RUPTURE QUALIFIC.ATION RESULTS 


\section{LIST OF TABLES (Contd)}

Table

Title

Page

20 AS-FIRED SURFACE IMPROVEMENT TRIAL RESULTS

21 COMBINED CO-PROCESS MECHANICAL PROPERTY RESULTS FOR ALL ENGINE-QUALITY AGT101 ROTOR, ENGINE-QUALITY STATOR, AND NT164 SPECIMEN DELIVERABLES

CO-PROCESS MECHANICAL PROPERTIES FOR DELIVERABLE ROTOR SET NO. 2

MECHANICAL PROPERTIES FOR ROTOR CUT-UP FROM SET NO. 2

CO-PROCESSED MECHANICAL PROPERTIES FOR DELIVERABLE STATOR SET NO. 1 


\section{ACRONYMS AND ABBREVIATIONS}

\begin{tabular}{|c|c|}
\hline $\begin{array}{l}\text { AGT } \\
\text { AP } \\
\text { APU } \\
\text { ASEA }\end{array}$ & $\begin{array}{l}\text { Advanced Gas Turbine } \\
\text { As-Processed Surface } \\
\text { Auxiliary Power Unit } \\
\text { Swedish Subcontractor to GCC } \\
\text { (HIP Encapsulation Process) }\end{array}$ \\
\hline ASME & American Society of Mechanical Engineers \\
\hline $\begin{array}{l}\text { ASTM } \\
\text { ATTAP }\end{array}$ & $\begin{array}{l}\text { American Society for Testing and Materials } \\
\text { Advanced Turbine Technology Applications Project }\end{array}$ \\
\hline $\begin{array}{l}\text { BF } \\
\text { Btu }\end{array}$ & $\begin{array}{l}\text { Backface } \\
\text { British Thermal Units }\end{array}$ \\
\hline $\begin{array}{l}\mathrm{C} \\
\mathrm{CBO} \\
\mathrm{CL} \\
\mathrm{cm} \\
\mathrm{CO} \\
\mathrm{CO}\end{array}$ & $\begin{array}{l}\text { Celsius } \\
\text { Carborundum Company } \\
\text { Centerline } \\
\text { Centimeter } \\
\text { Carbon Monoxide } \\
\text { Carbon Dioxide }\end{array}$ \\
\hline $\begin{array}{l}\text { DF-2 } \\
\text { DOE }\end{array}$ & $\begin{array}{l}\text { No. } 2 \text { Diesel Fuel } \\
\text { Department of Energy }\end{array}$ \\
\hline EI & Emissions Index \\
\hline $\begin{array}{l}\text { F } \\
\text { FE } \\
\text { FF } \\
\text { FPI } \\
\text { FSH } \\
\mathrm{ft}\end{array}$ & $\begin{array}{l}\text { Fahrenheit } \\
\text { Finite Element } \\
\text { Fast Fracture } \\
\text { Fluorescent Penetrant Inspection } \\
\text { Flow Separator Housing } \\
\text { Foot }\end{array}$ \\
\hline $\begin{array}{l}\text { G } \\
\text { GCC }\end{array}$ & $\begin{array}{l}\text { Gram } \\
\text { Garrett Auxiliary Power Division } \\
\text { Garrett Ceramic Components }\end{array}$ \\
\hline $\begin{array}{l}\text { HIP } \\
\text { hp } \\
\text { hr }\end{array}$ & $\begin{array}{l}\text { Hot Isostatic Pressing } \\
\text { Yorsepower } \\
\text { Hour }\end{array}$ \\
\hline IR & $\begin{array}{l}\text { Inch } \\
\text { Impact Resistance Index } \\
\text { Impact-Resistant Turbine }\end{array}$ \\
\hline un & $\begin{array}{l}\text { Kilogram } \\
\text { Thousands of Revolutions Per Minute } \\
\text { Thousands of Pounds Per Square Inch } \\
\text { KiloWatt }\end{array}$ \\
\hline
\end{tabular}




\section{ACRONYMS AND ABBREVIATIONS (Contd)}

\begin{tabular}{|c|c|}
\hline $\begin{array}{l}1 \\
\text { LAS } \\
\text { lb }\end{array}$ & $\begin{array}{l}\text { Liter } \\
\text { Lithium Aluminosilicate } \\
\text { Pounds }\end{array}$ \\
\hline $\begin{array}{l}\text { m } \\
\text { MFXR } \\
\text { mm } \\
\text { mil } \\
\text { min } \\
\text { MOR } \\
\text { MPa } \\
\text { mpg } \\
\text { MS }\end{array}$ & $\begin{array}{l}\text { Meter; Weibull modulus } \\
\text { Microfocus X-Ray Radiography } \\
\text { Millimeter } \\
\text { Thousandths of an inch } \\
\text { Minute } \\
\text { Modulus of Rupture } \\
\text { MegaPascal } \\
\text { Miles Per Gallon } \\
\text { Machiried Surface }\end{array}$ \\
\hline $\begin{array}{l}\text { N/A } \\
\text { NAC } \\
\text { N.ASA } \\
\text { NDE } \\
\text { NOX } \\
\text { NTC }\end{array}$ & $\begin{array}{l}\text { Not Applicable } \\
\text { Norton Advanced Ceramics } \\
\text { National Aeronautics and Space Administration } \\
\text { Nondestructive Evaluation } \\
\text { Nitrous Oxides } \\
\text { Norton/TRW Ceramics }\end{array}$ \\
\hline ORNL & Oak Ridge National Laboratory \\
\hline $\begin{array}{l}\text { PF } \\
\text { Ppm } \\
\text { PS } \\
\text { psig }\end{array}$ & $\begin{array}{l}\text { Probability of Failure } \\
\text { Parts Per Million } \\
\text { Pressure Surface } \\
\text { Pounds Per Square Inch Gage }\end{array}$ \\
\hline $\begin{array}{l}\text { RTT } \\
\text { RPD } \\
\text { RT } \\
\text { rpm }\end{array}$ & $\begin{array}{l}\text { Regenerator Inlet Temperature } \\
\text { Reference Powertrain Design } \\
\text { Room Temperature } \\
\text { Revolutions Per Minute }\end{array}$ \\
\hline $\begin{array}{l}\text { SAE } \\
\text { SCG } \\
\text { seC } \\
\text { SFC } \\
\text { shp } \\
\text { SEM } \\
\text { Si3N4 } \\
\text { S/N } \\
\text { SS }\end{array}$ & $\begin{array}{l}\text { Society of Automotive Engineers } \\
\text { Slow Crack Growth } \\
\text { Second } \\
\text { Specific Fuel Consumption } \\
\text { Shaft Horsepower } \\
\text { Scanning Electron Microscope } \\
\text { Silicon Nitride } \\
\text { Serial Number } \\
\text { Suction Surface }\end{array}$ \\
\hline $\begin{array}{l}\text { TBD } \\
\text { TET } \\
\text { TIT }\end{array}$ & $\begin{array}{l}\text { To Be Determined } \\
\text { Turbine Exit Temperature } \\
\text { Turbine Inlet Temperature }\end{array}$ \\
\hline
\end{tabular}




\section{ACRONYMS AND ABBREVIATIONS (Contd)}

\begin{tabular}{ll}
$\begin{array}{ll}\text { UDRI } \\
\text { UHC }\end{array}$ & $\begin{array}{l}\text { University of Dayton Research Institute } \\
\text { Unburned Hydrocarbons } \\
\text { U.S. }\end{array}$ \\
VOL & United States \\
W & Wolume \\
$\mathbf{X}$ & Times Magnification \\
Hm & $\begin{array}{l}\text { Microns (Thousandths of a Millimeter) } \\
\text { 3-D }\end{array}$ \\
\hline
\end{tabular}




\subsection{SUMMARY}

This report summarizes work performed by Garrett Auxiliary Power Divisiun (GAPD), a unit of Allied-Signal Aerospace Company, during calendar year 1992, toward development and demonstration of structural ceramic technology for automotive gas turbine engines. This work was performed for the U.S. Department of Energy (DOE) under National Aeronautics and Space Administration (NASA) Contract DEN3-335, Advanced Turbine Technology Applications Project (ATTAP).

GAPD utilized the AGT101 regenerated gas turbine engine developed under the previous DOE/NASA Advanced Gas Turbine (AGT) program as the ATTAP test bed for ceramic engine technology demonstration. ATTAP focussed on improving AGT101 test bed reliability, development of ceramic design methodologies, and improvement of fabrication and materials processing technology by domestic U.S. ceramics fabricators. A series of durability tests was conducted to verify technology advancements. This is the fifth in a series of technical summary reports published annually over the course of the five-year contract.

\subsection{Test Bed Engine Design, Analysis, And Materials Assessment}

During 1992, two additional improvements to the AGT101 engine were successfully developed and implemented, making it a more reliable and robust test bed for verification of the ATTAP ceramic technologies. The following improvements were incorporated into the AGT101 test bed engine:

- Combustor cap spring baffle configuration

- Anti-tilt roller configuration for the regenerator system.

\subsection{Ceramic Component Design}

Significant progress has been made in the development of design methods for predicting impact damage to ceramic components in gas turbine engines. The design methods development has been pursued in two parallel paths: modeling of local impact damage (near the point of impact), which was completed in 1991; and modeling of structural damage (failure away from point of impact), which was the focus during 1992. The impact methods development work has been performed in collaboration with the University of Dayton Research Institute (UDRI) in Dayton, Ohio. 
In 1992, a significantly improved impact-resistant ceramic turbine wheel configuration was tested and the results compared against the current impact-resistant wheel and the previous radial wheel designs. This testing evaluated the key parameters associated with the design and generated an impact resistance index (IRI) for comparison of the results. Based on this analysis, additional work modeling the pulverization process for impacting carbon particles was completed, improving the predictive capabilities of the structural impact model.

Significant effort was also expended in performing a risk analysis of the impact-resistant turbine design. The risk analysis efforts included investigating the peak stresses in the turbine rotor, evaluating stresses for cold rotation, steady-state, and transient operation; and conducting a probabilistic life analysis, calculating the probability of failure for room temperature spin burst conditions, fast fracture during engine operation, and slow crack growth during steady-state operation.

\subsection{Materials Characterization And Ceramic Component Fabrication}

During 1992, mechanical property test data was acquired to characterize the following ceramic materials:

- Norton Advanced Ceramics NT154 silicon nitride

- Norton Advanced Ceramics NT164 silicon nitride

- Norton Advanced Ceramics NT230 siliconized silicon carbide

- NGK SN-88 silicon nitride

- Garrett Ceramic Components GN-10 silicon nitride

Characterization of ceramic components from cut up bars was shifted to the ceramics subcontractors, thereby avoiding significant duplication of effort. Historically, comparison of GAPD and vendor data has shown good correlation.

Nondestructive evaluation (NDE) efforts by GAPD concentrated on component inspections and detection of test bar flaws for correlation with destructive test results.

As planned, two of the three selected ATTAP U.S. ceramic subcontractors, Norton Advanced Ceramics (NAC, formerly Norton/TRW Ceramics, NTC) and Garrett Ceramic Components (GCC), successfully delivered ceramic engine-candidate components during 1992. NAC delivered impactresistant turbine rotors and stators, and GCC delivered turbine rotors. 
Rotor process development at NAC included a new mold system and an aqueous-based slip system, providing better dimensional control and a simplified process. A centering problem in the machining setup was solved, for better location of the geometric center and the mass center of the machined rotor.

Stator forming issues addressed by NAC pertained to casting problems. Anisotropic shrinkage of the initial stators resulted in pieces that were undersized. A second pattern was fabricated, successfully solving the shrinkage problem. Later deliveries of stators showed dimensional conformance satisfactory for use in engine testing.

GCC sought to improve the strength of GN-10 as-processed hot isostatic pressed (as-HIPped) surfaces. Approaches tried included: modifications to the existing process; improvements in the calcining process, and utilization of an alternative higher-purity ceramic starting powder. Some strength improvements resulted from these efforts.

\subsection{Component Rig Testing}

Hot spin burst testing of ceramic disks was completed in 1992. An arbor attachment scheme employing a compliant ring was designed, tested, and put into use. A test rig capable of operation at temperatures up to $2500 \mathrm{~F}$ was developed and utilized for the high-temperature creep, fast fracture, and slow crack growth tests.

Regenerator rig testing was continued, to evaluate new component designs prior to implementation in the AGT101 test bed engines, and to assess regenerator system durability and performance. Two new designs, the combustor cap spring baffle configuration and the anti-tilt roller were evaluated in the regenerator rig.

Structural proof tests were conducted to screen ceramic hardware for engine testing. These tests were of two types: thermal furnace proof tests, and mechanical deflection tests. The thermal proof test was developed as a less-expensive method of qualifying individual ceramic components. Ceramic hardware qualified with the furnace proof rig included: the turbine shroud, baffle, and inner and outer diffusers. A mechanical deflection proof test was employed for the inner and outer spring seals. This rig simulated the interfaces between the seals and the engine hardware and permitted the seals to be stressed to 125 percent of the anticipated operating level in the engine. 
The $2500 \mathrm{~F}$ (1371C) test rig was utilized to expose engine structural components to the high pressures and temperatures found in the actual test bed engine. This rig was used in 1992 to evaluate the behavior of certain materials for oxidation and sticking, and the interfaces between a variety of materials.

\subsection{Engine Test Bed Trials}

A series of engine bed trials was completed during 1992, culminating in successful completion of Milestone 4, demonstration of AGT101 operation at Reference Powertrain Design (RPD) conditions (90,000 rpm and 1800F regenerator inlet temperature); and initiation of Milestone 5, the 100-hour endurance test. A metal AGT101 test bed engine was used to proof test the ceramic rotors received from Norton Advanced Ceramics and Garrett Ceramic Components. These rotors were then integrated into two fully-ceramic AGT101 engines for testing. Eight all-ceramic engine tests were completed in 1992, and the maximum operating conditions achieved during these tests were a speed of $90,000 \mathrm{rpm}$ and a turbine inlet temperature (TIT) of $2315 \mathrm{~F}(1268 \mathrm{C})$. Over 67 hours of testing were accomplished in 1992, with approximately 38 hours of engine testing completed towards the Milestone 5 100-hour endurance test. These 38 hours of testing were conducted with a TIT in excess of $2200 \mathrm{~F}(1204 \mathrm{C})$.

Milestone 5 testing was terminated after two builds of the all-ceramic AGT101 engine, due to failures of the Flow Separator Housing (FSH). The FSH is constructed from lithium aluminosilicate (LAS) ceramic material, and is susceptible to contact damage in the fillet radius, which was the primary cause of failure in the two Milestone 5 engine builds.

Due to system problems encountered during testing of the AGT101 engine, specifically the FSH, the regenerator seals and core, and the fuel and engine control system, a decision was made to discontinue testing of the AGT101 engine. The 1993 ATTAP efforts to advance structural ceramics towards commercial engine applications will continue with a demonstration program involving the AlliedSignal Model 331-200[CT] Auxiliary Power Unit (APU). The 331-200[CT] APU will provide a reliable, proven test bed engine for integration of ceramic blades and stator vanes in the first-stage turbine. This change is planned to eliminate engine system problems, permitting more efficient accumulation of ceramic engine test data towards commercial engine application. 


\subsection{INTRODUCTION}

This report is the fifth in a series of Annual Technical Summary Reports for ATTAP, prepared by Garrett Auxiliary Power Division under the DOE-sponsored NASA Contract DEN3-335. The project is administered by Mr. Thomas Strom, Project Manager, NASA-Lewis Research Center, Cleveland, Ohio. This report presents work plans and progress for calendar year 1992. Project efforts conducted under this contract are part of the DOE Gas Turbine Highway Vehicle System Program. This program is oriented to provide the United States automotive industry with the high-risk, long-range technology necessary to produce gas turbine engines for automobiles with reduced fuel consumption and reduced environmental impact.

The Garrett Model AGT101 ATTAP test bed engine (Figure 1) is designed such that, when installed in a $3000 \mathrm{lb}(1361 \mathrm{~kg})$ inertia weight automobile, it will provide:

- Low emissions

- Fuel economy of $42 \mathrm{mpg}(17.9 \mathrm{~km} / \mathrm{l})$ on diesel fuel

- Multifuel capability

- Competitive costs with current spark-ignition engines

- Noise and safety characteristics that meet U.S. federal standards.

The AGT101 is nominally a 100-shp $(74.6 \mathrm{~kW})$ engine, capable of speeds up to $100,000 \mathrm{rpm}$ and turbine operation at inlet temperatures to $1371 \mathrm{C}(2500 \mathrm{~F})$ with a specific fuel consumption (SFC) level of $0.3 \mathrm{lb} / \mathrm{hp}-\mathrm{hr}(0.2 \mathrm{~kg} / \mathrm{kW}-\mathrm{hr})$ over much of the operating range.

ATTAP is oriented toward developing the high-risk technology of ceramic structural component design and fabrication, such that industry can carry this technology forward to production in the 1990s. The AGT101 engine, continued in use from the prior DOE-sponsored AGT Project, is being used as the Garrett ATTAP test bed engine for verification of the durability of ceramic components, and their suitability for service over the full engine operating envelope.

The ATTAP milestone schedule is depicted in Figure 2. This report reviews the efforts conducted in the fifth full year of ATTAP in development of ceramic technology, and improvements made to the test bed engine and test rigs. Appendices include progress reports prepared by the major ATTAP subcontractors to GAPD: Garrett Ceramic Components and Norton Advanced Ceramics (formerly Norton/TRW Ceramics). 


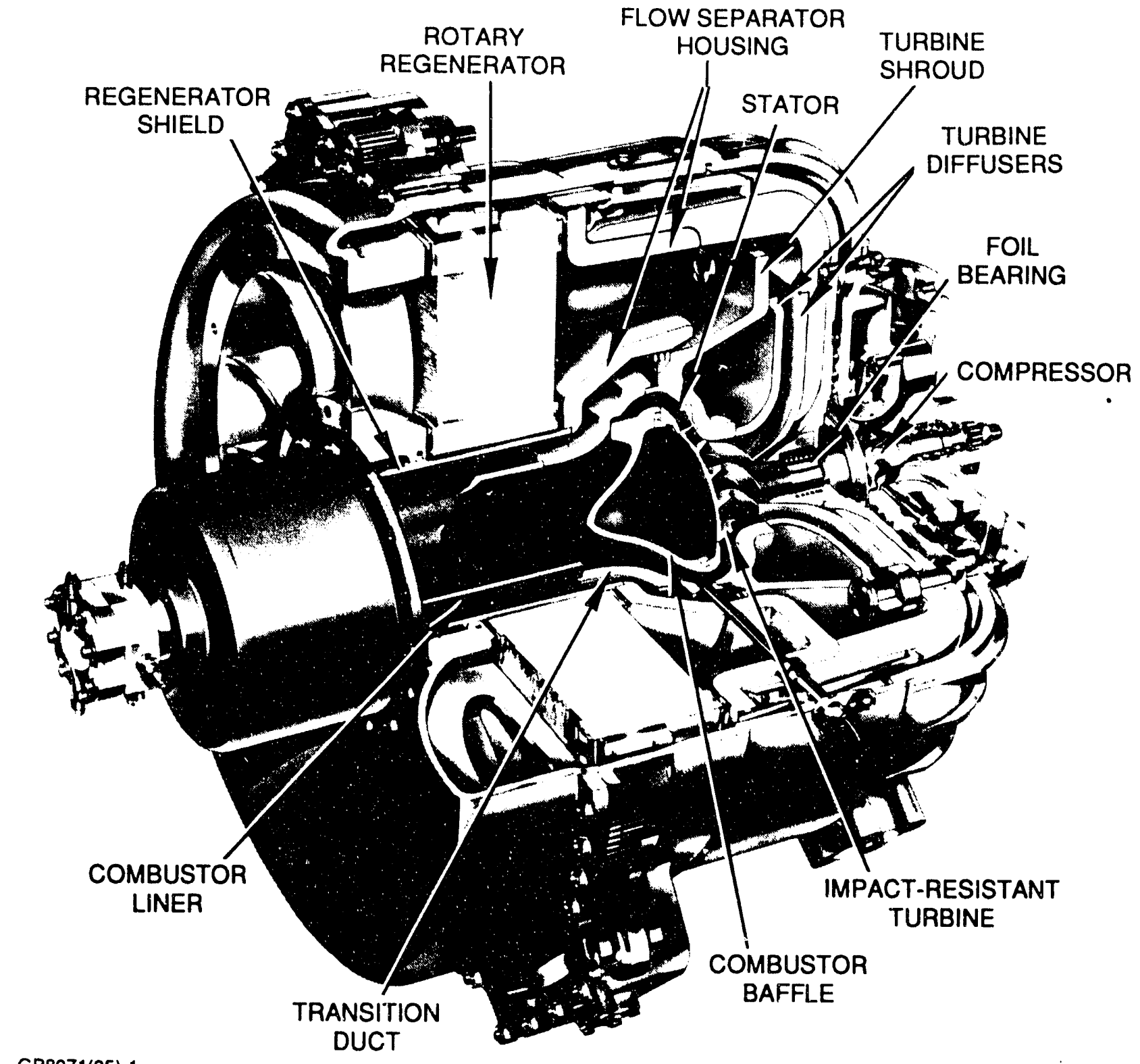

GB8071(05)-1

Figure 1. Garrett Model AGT101 ATTAP Test Bed Engine. 


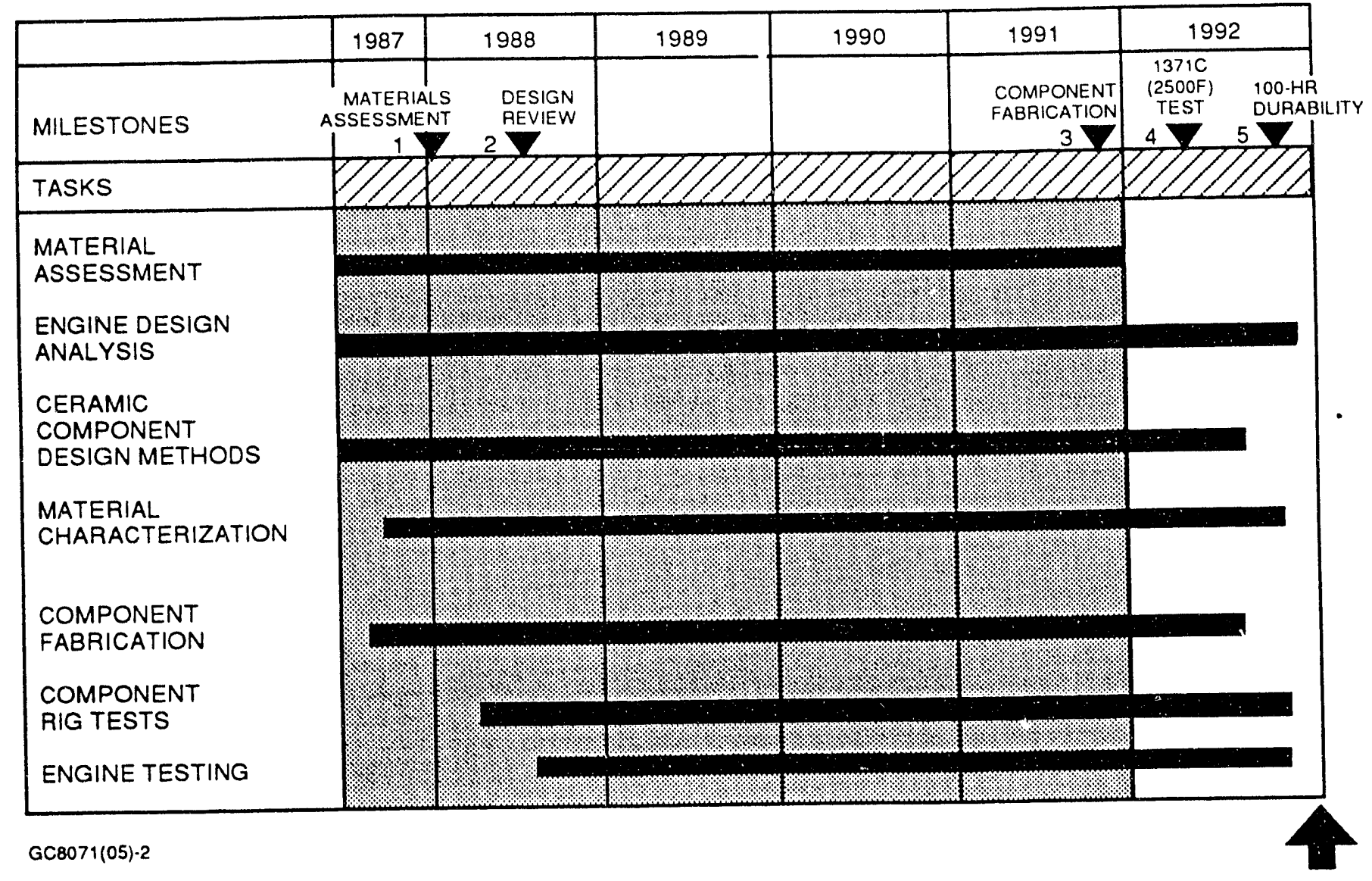

Figure 2. ATTAP Milestone Schedule. 


\subsection{TEST BED ENGINE DESIGN, ANALYSIS, AND MATERIALS ASSESSMENT}

\subsection{Materials Assessment}

No material assessments were conducted during 1992.

\subsection{Reference Powertrain Design (RPD)}

No modifications were made to the RPD during 1992.

\subsection{Reference Powertrain Design Cost Analysis}

No modifications to the RPD Cost Analysis were performed during 1992.

\subsection{Test Bed Improvements}

Improvements to the AGT101 engine were developed to provide a more reliable test bed for evaluation of ATTAP ceramic components. Two changes were implemented in 1992. The first was a combustor cap spring baffle modification, and the second was the addition of an anti-tilt roller to the regenerator support system.

The combustor cap spring configuration (Figure 3) was designed to keep the combustor load springs cool throughout the range of engine operation. Prior regenerator rig tests showed spring operating temperatures ranged up to $1300 \mathrm{~F}(704 \mathrm{C})$, which is above the acceptable operating level for the spring material. The springs apply the compressive load needed to maintain the ceramic combustor hardware stack and the seal of the flow separator housing seal rings. Operation at the elevated temperature causes the spring material to creep over an extended time period and lose its compressive load capability. Incorporation of the new design lowered the temperature of the springs to under $1000 \mathrm{~F}(538 \mathrm{C})$, which provides acceptable operation.

The second design evaluated in the regenerator rig was the anti-tilt roller for the regenerator support system. Prior rig tests indicated displacement and tilting of the regenerator core occurred during engine operation. Measurements indicated a maximum deflection of 0.028 inch $(0.072 \mathrm{~cm})$ at the outer periphery of the core at maximum rig temperature and pressure. The regenerator core tilt increased the leakage across the face of the hot seal, and increased the load on the cold seal, causing an increase in the regenerator core torque. The anti-tilt roller (Figure 4) was designed to react the pressure forces of the airflow through the regenerator core ring gear, thus reducing the leakage and torque. 


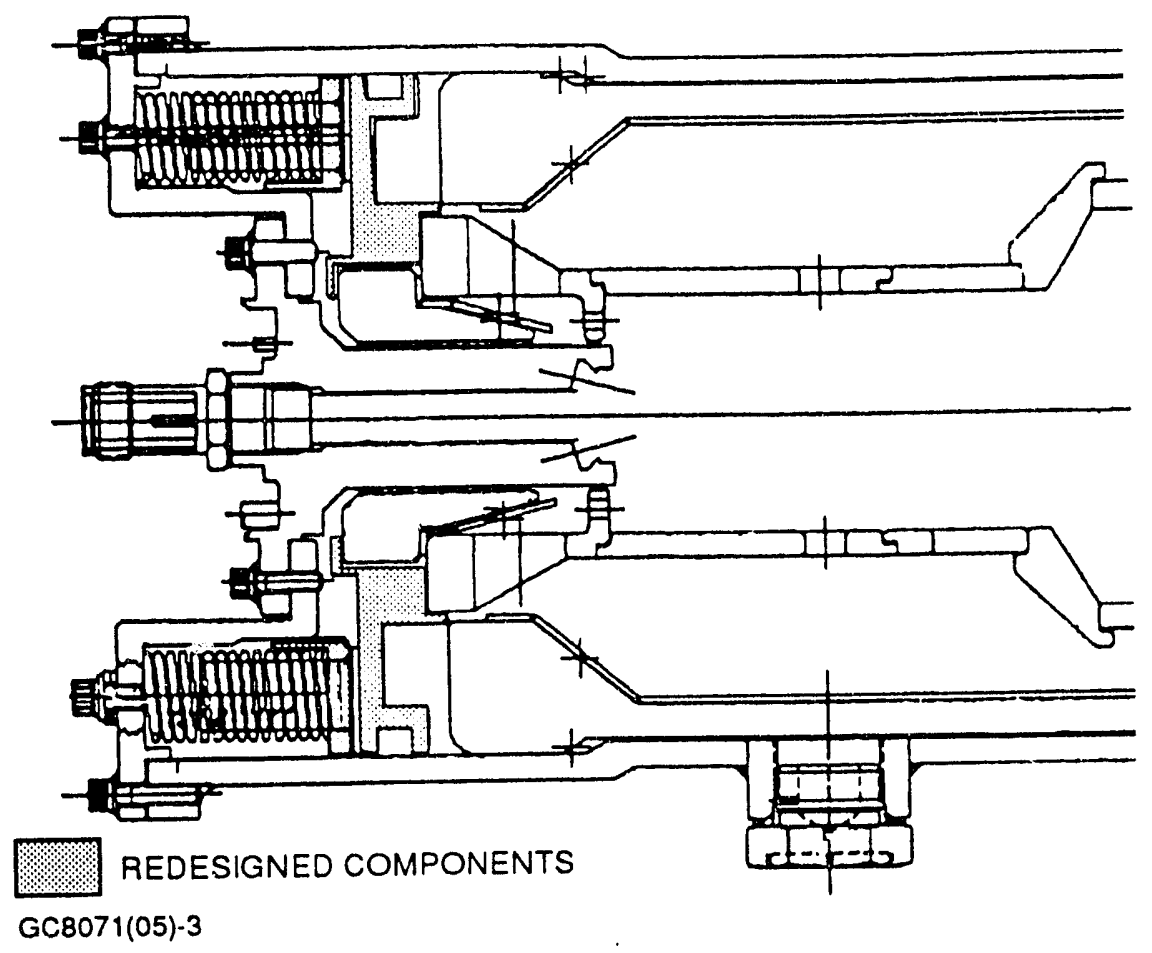

Figure 3. New Combustor Cap Design Lowers Spring Operating Temperature.

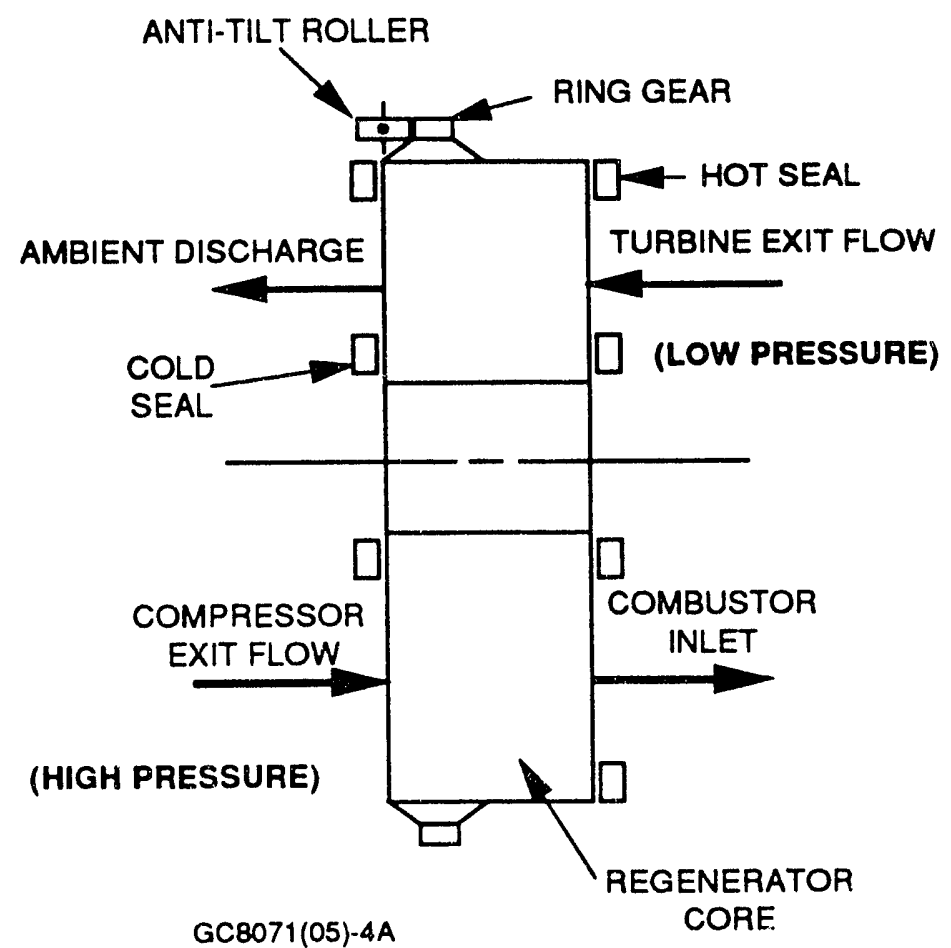

Figure 4. Anti-Tilt Roller Design Reduces Seal Leakage And Regenerator Torque. 


\subsection{CERAMIC COMPONENT DESIGN}

\subsection{Design Methods For Impact Damage Resistance}

The brittle nature of ceramic materials requires sophisticated and rigorous methods capable of addressing the design requirements of ceramic engine components. To provide robust component design for gas turbine use, methods are needed to address the numerous failure modes of ceramics, including fast fracture, slow crack growth, creep, impact, contact, oxidation and corrosion, and thermal fatigue.

GAPD has formulated a romprehensive plan to develop verified methods to address near-term and future ceramic component design needs. The most urgently needed design systems are being developed now at GAPD under ATTAP and at the DOE/Oak Ridge National Laboratory (ORNL) under the Life Prediction Methodology for Ceramic Components of Advanced Heat Engines programs. The ORNL program efforts are addressing fast fracture, slow crack growth and creep ${ }^{(1) *}$.

ATTAP has focused on design needs to minimize impact damage. Impact damage is a concern in turbine rotors and stators due to their vulnerability to impact from debris and/or combustion products. Design methods development, under both ATTAP and the ORNL ceramic life prediction program, utilizes analytical and experimental work to develop models of material behavior, stress states, and material failure criteria. These efforts are concluded by verifying the design approach with simulated component evaluations.

\subsubsection{Local Impact Damage Model}

The ATTAP efforts in local impact model development were completed in 1991.

\subsubsection{Structural Impact Damage Model}

The structural impact model developed under ATTAP has been used in a parametric study to identify the design variables which strongly affect component impact resistance and to find a new ceramic blade configuration with lower impact stress. In the first phase of this study, Taguchi methods were used for the screening process. The most sensitive design variables identified were blade thickness, inlet (Beta) angle, and fillet radius (Figure 5).

*Numbered references in parentheses are listed at the end of this report. 


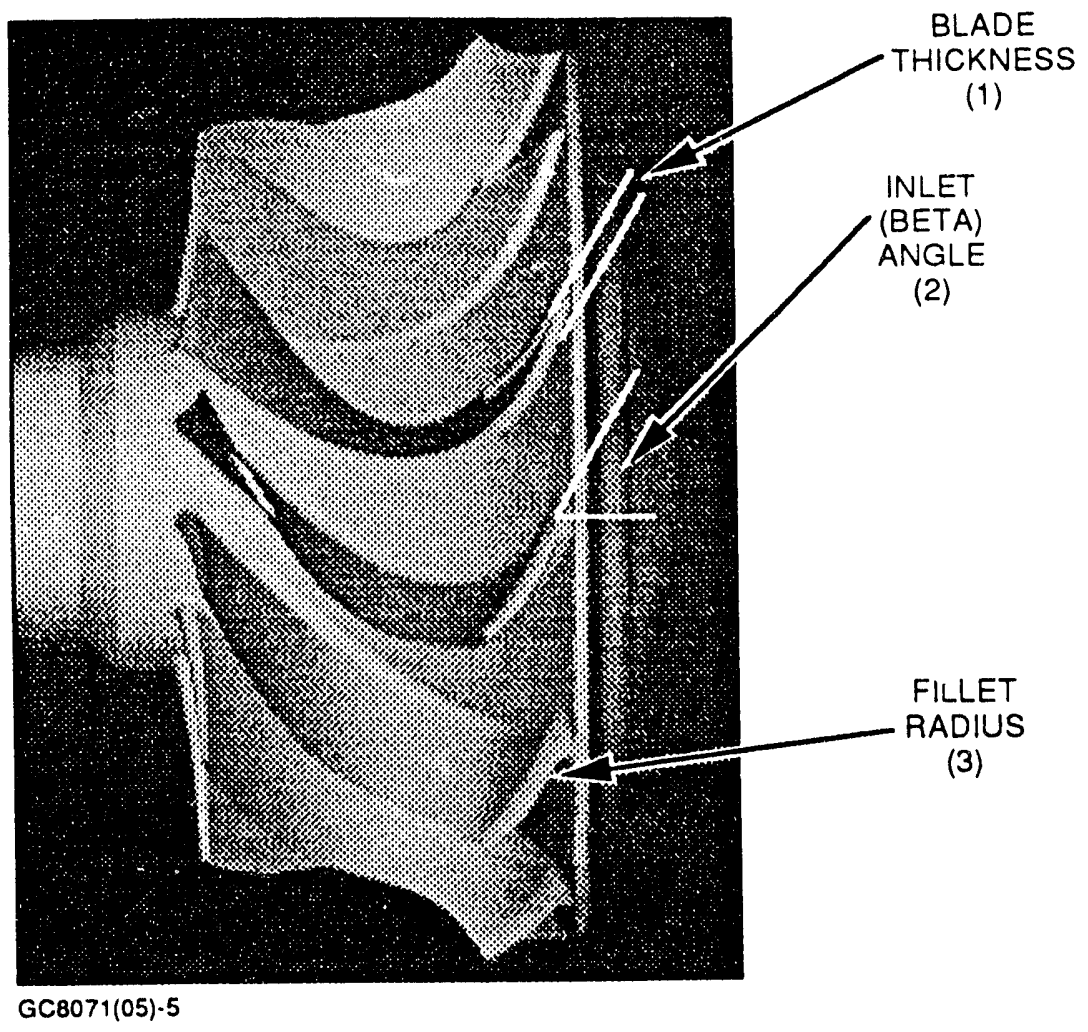

Figure 5. Three Ceramic Blade Design Parameters Were Found To Have The Greatest Influence On Impact Resistance.

In the second phase, a parametric study was conducted to determina the optimal combination of these parameters providing the most impact-resistant blade design, while still accommodating turbine aerodynamic requirements. The current impact-resistant turbine (IRT) blade design and the improved blade design were used to fabricate subelements for particle impact testing. The subelements (Figure 6) consist of a single blade attached to a segment of the hub. Subelement 1 (left side in Figure 6) is the blade from the current IRT design, and Subelement 2 (right side in Figure 6) is the improved blade geometry identified in the parametric study using impact analysis. The values of the key blade design parameters are listed in Table 1.

The third phase consisted of performing impact testing on the ceramic subelements and analyzing the results, to verify the design improvement. Ten specimens of each design were divided into two groups of five specimens. The two groups were tested with either 0.10 -inch $(0.25-\mathrm{cm})$ or 0.20 -inch $(0.51-\mathrm{cm})$ diameter graphite balls, respectively, and the critical impact velocity was established for each impact condition (Table 2). The improvement in impact resistance for the improved blade design (Subelement 2) was substantial. 

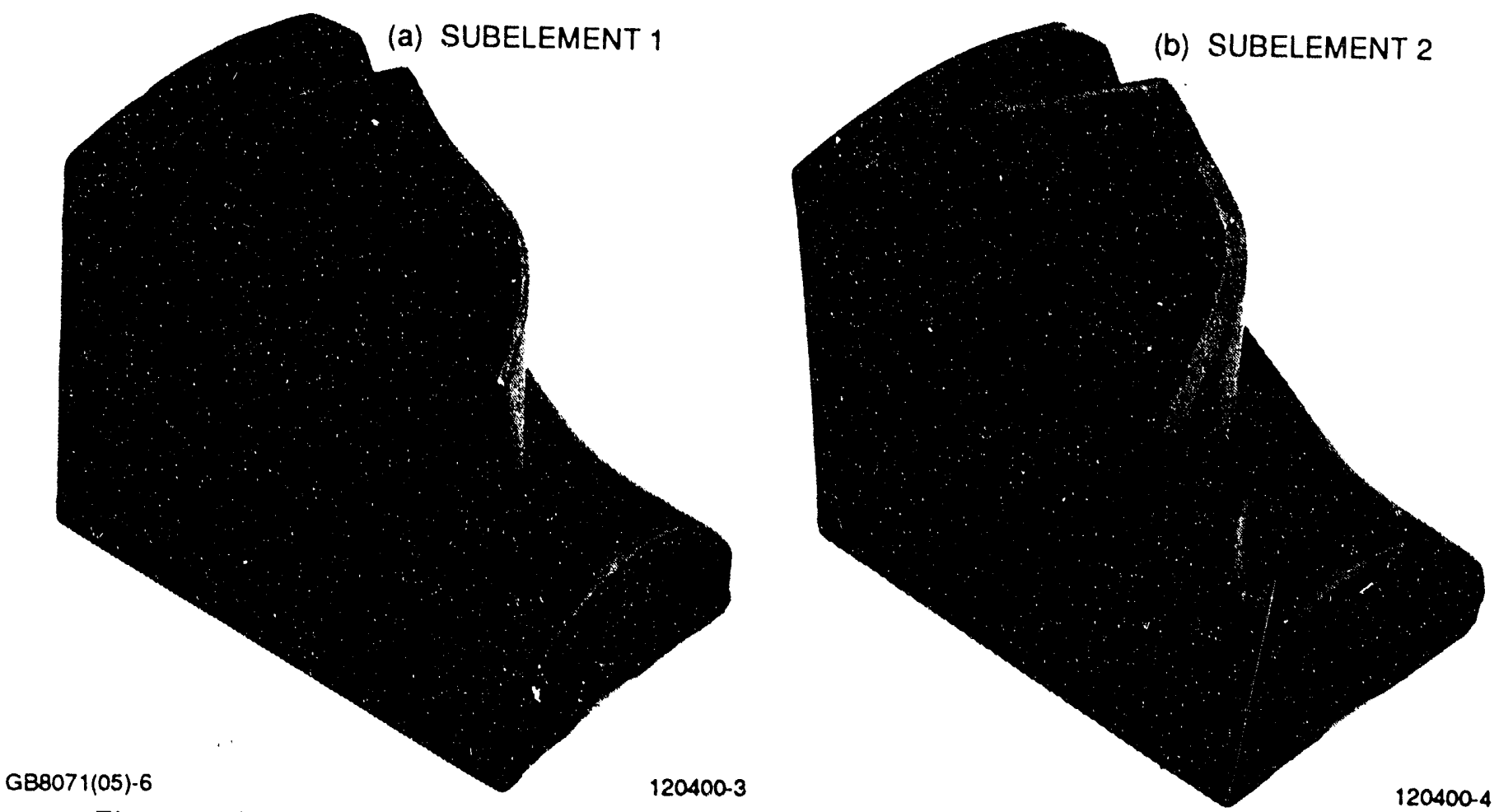

Figure 6. Two Ceramic Subelement Models Were Fabricated For Impact Verification Tests.

TABLE 1. KEY PARAMETERS FOR TWO IMPACT-RESISTANT CERAMIC TURBINE BLADE DESIGNS

\begin{tabular}{|c|c|c|c|}
\cline { 2 - 4 } \multicolumn{1}{c|}{} & $\begin{array}{c}\text { Thickness, } \\
\text { Inch (cm) }\end{array}$ & $\begin{array}{c}\text { Inlet (Beta) Angle, } \\
\text { Degrees }\end{array}$ & $\begin{array}{c}\text { Fillet Radius, } \\
\text { Inch (cm) }\end{array}$ \\
\hline Subelement 1 & $\begin{array}{c}0.07 \\
(0.18)\end{array}$ & 51 & $\begin{array}{c}0.045 \\
(0.114)\end{array}$ \\
\hline Subelement 2 & $\begin{array}{c}0.15 \\
(0.38)\end{array}$ & 61 & $\begin{array}{c}0.045 \\
(0.114)\end{array}$ \\
\hline
\end{tabular}

TABLE 2. SUBELEMENT IMPACT TEST RESULTS SHOWED SUBSTANTIAL IMPROVEMENT FOR IMPROVED BLADE DESIGN

\begin{tabular}{|c|c|c|}
\hline Specimen & $\begin{array}{c}\mathbf{0 . 1 0} \text { Inch }(0.25 \mathrm{~cm}) \\
\text { Projectile }\end{array}$ & $\begin{array}{c}\mathbf{0 . 2 0} \text { Inch }(0.51 \mathrm{~cm}) \\
\text { Projectile }\end{array}$ \\
\hline \hline Subelement 1 & $\begin{array}{c}482 \mathrm{ft} / \mathrm{sec} \\
(147 \mathrm{~m} / \mathrm{sec})\end{array}$ & $\begin{array}{c}152 \mathrm{ft} / \mathrm{sec} \\
(46.3 \mathrm{~m} / \mathrm{sec})\end{array}$ \\
\hline Subelement 2 & $\begin{array}{c}2256 \mathrm{ft} / \mathrm{sec} \\
(688 \mathrm{~m} / \mathrm{sec})\end{array}$ & $\begin{array}{c}593 \mathrm{ft} / \mathrm{sec} \\
(181 \mathrm{~m} / \mathrm{sec})\end{array}$ \\
\hline
\end{tabular}


A more meaningful comparison of impact resistance for different blade designs employs the impact resistance index (IRI), defined as the ratio of the critical impact velocity for a particle impact divided by the actual turbine blade velocity at the engine design condition for a given particle size. The IRI values for the original AGT101 radial turbine blade, the current ATTAP IRT blade (Subelement 1), and the optimal IRT blade (Subelement 2) from the parametric study are shown in Figurs 7. In the IRI plot, one unit corresponds to the threshold level at which a blade can survive for a particular particle size. A particle size of 0.20 inch $(0.51 \mathrm{~cm})$ is used to calculate this IRI index, because it is the largest particle able to pass through the stator opening of the AGT101 engine.

To improve the structural impact model, a material model was developed to simulate the carbon particle pulverization phenomena during impact. Without a pulverization model, projectiles must be treated as elastic even though they pulverize during real impact events. Experiments established that graphite spheres impacting a silicon nitride target break up into several large fragments at an impact velocity of approximately $250 \mathrm{ft} / \mathrm{sec}(76.2 \mathrm{~m} / \mathrm{sec})$. Beyond an impact velocity of $300 \mathrm{ft} / \mathrm{sec}(91.4$ $\mathrm{m} / \mathrm{sec}$ ), graphite balls pulverize into powder. An impact analysis using the elastic material model for the graphite balls generates higher then real stresses and this discrepancy worsens with increasing impact velocity.

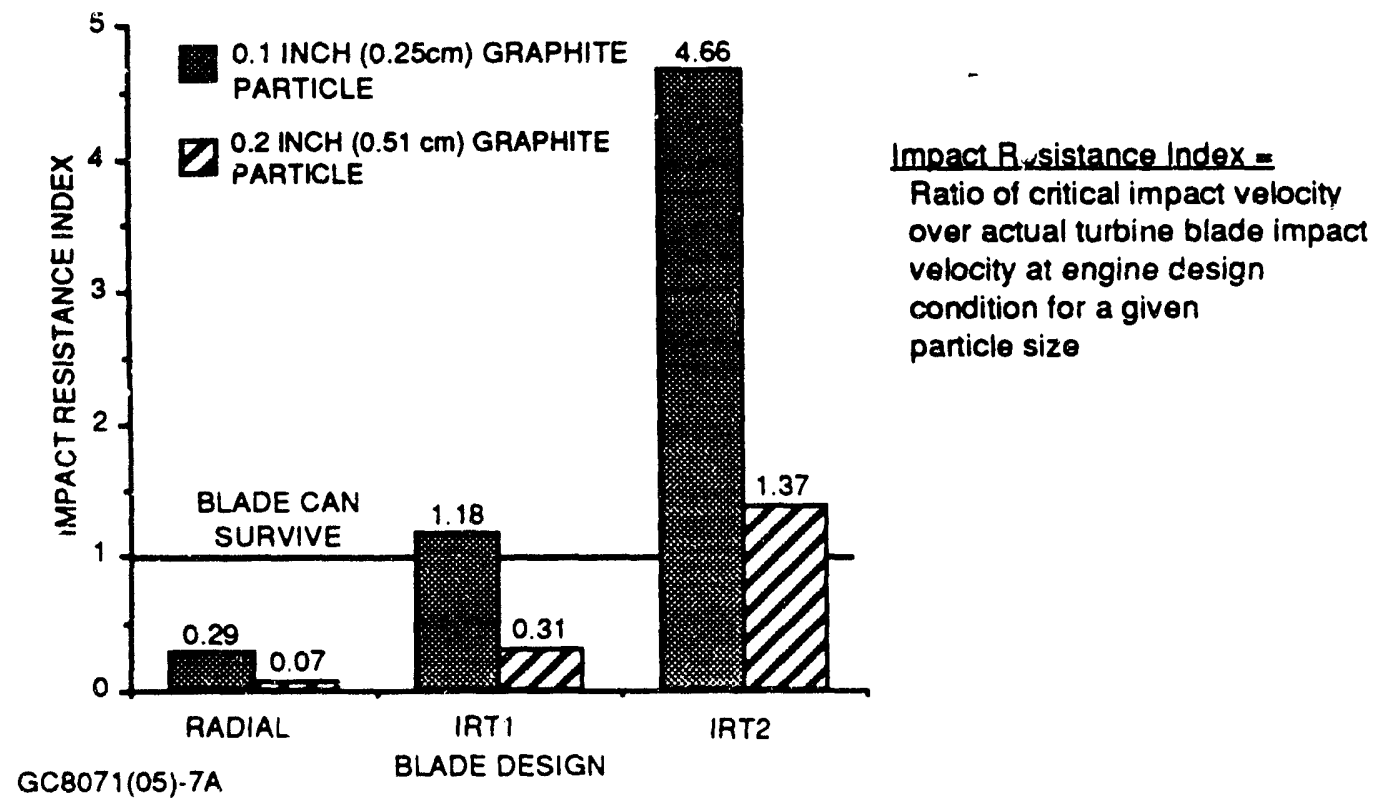

Figure 7. IRI Plot Shows Significant Improvement In Impact Resistance Was Achieved With New Design Method. 
The instrumented particle impact tests conducted earlier in the ATTAP program provided important data for the development of this model. Strain gage measurements of surface tensile strain along the longitudinal direction for eight different impact velocities verified this phenomena. When the peak values of the tensile strain from the strain gage recordings and the analytical results using the elastic material model are plotted (Figure 8), it is clear that the elastic analysis does not generate the impact strain with any reasonable accuracy.

There are two basic approaches to modeling the pulverization phenomena: micromechanical and macromechanical. The micromechanical approach models the physics of the material breakup and models the process at the powder particle scale. Due to the complex details of the fracture process during pulverization and the time and expense required to numerically simulate the powder particles, this approach was not chosen. The macromechanical model makes no attempt to represent the small-scale physics of the pulverization, but rather captures the essential effects of the breakup in integrated quantities, such as energy dissipation and inelastic deformation. Therefore, this method was chosen to model the pulverization of a graphite particle during an impact event.

A complete material pulverization model should include the definition of elastic behavior at lowstress conditions and inelastic responses at stress conditions that exceed the threshold. Without specific experimental data to suggest otherwise, the selected model assumes isotropic elastic behavior following Hooke's law at low stress levels. At higher impact velocities, the pulverization process

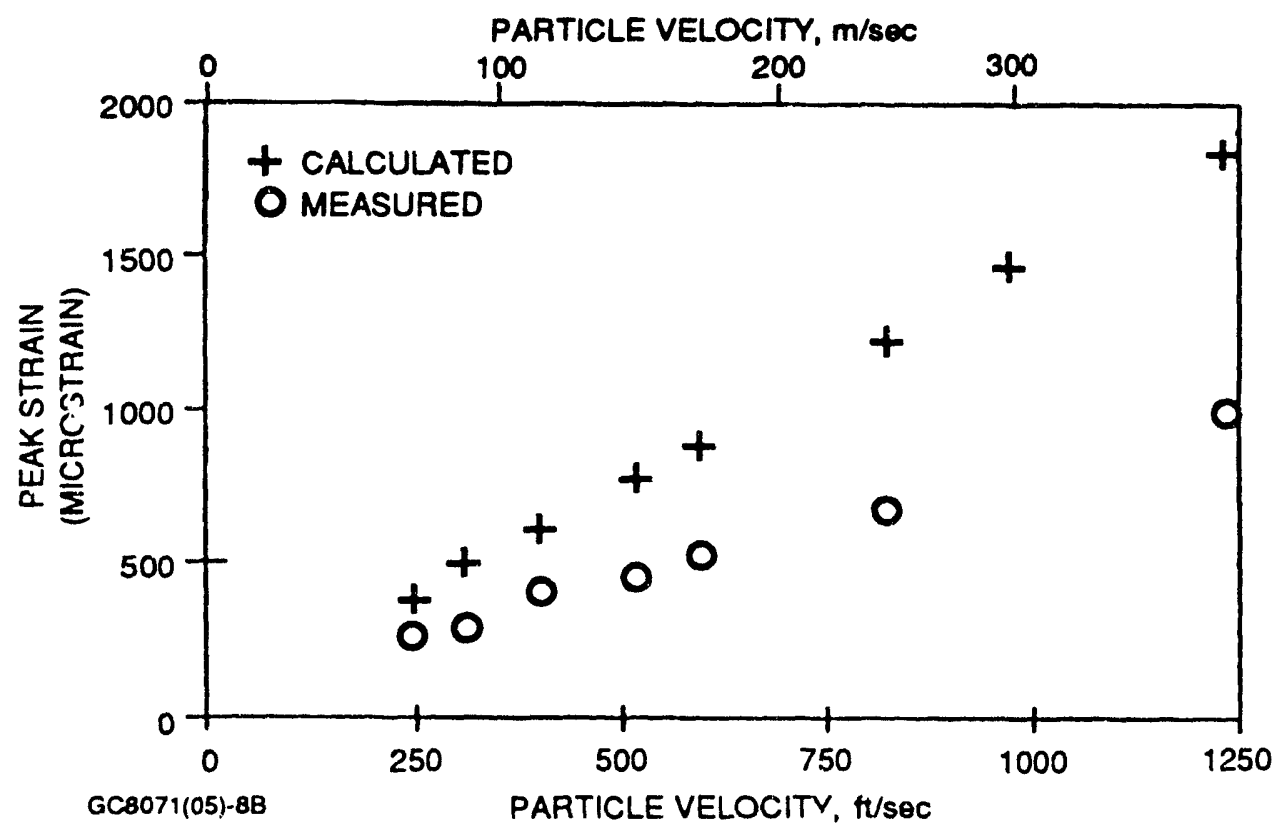

Figure 8. Calculated Strains Using Elastic Model Are Much Higher Than The Measured Strains. 
occurs in the projectile, as a very large number of brittle fractures. Based on these observations, a principal stress criterion is established at the limit of the elastic region. Furthermore, the test data shows a substantial difference in the tensile and compressive failure strengths for graphite. Therefore, the model adopted different limiting values of principal stress for the tensile and compressive regimes.

To model the inelastic behavior of the pulverizing projectile, the macromechanical model uses a linear hardening inelastic flow formulation. The main reasons behind this choice are as follows: the main emphasis was in a ruodel that can account for the energy dissipation during pulverization and provide an increased contact area as pulverization takes place. Within the time and budget constraints of the ATTAP program, this model can at least provide an engineering solution to this complicated problem.

For the model to be a valid analytical tool, it must predict impact stress and strain for the selected ceramic material (NT154 silicon nitride) under different conditions (geometry, impact velocity, impact angle, etc.). To prove the validity of the model, ceramic material constants were calibrated with instrumented subelement impact test results. These material constants were then used to compare the analytical strain results with actual strain results from other subelement impact tests.

A strain-gaged specimen was impacted with a 0.10 -inch $(0.25-\mathrm{cm})$ diameter graphite ball at eight different velocities. The strain gage records for velocities of $246 \mathrm{ft} / \mathrm{sec}(75 \mathrm{~m} / \mathrm{sec})$ and $12.36 \mathrm{ft} / \mathrm{sec}$ $(376.7 \mathrm{~m} / \mathrm{sec})$ were used to calibrate the material constants. These constants were then held fixed in simulations of six different impact velocities. The peaks of the strain from the two sources at each impact velocity are plotted in Figure 9 for comparison. The discrepancy is within 12 percent.

A thicker specimen, 0.05 inch $(0.13 \mathrm{~cm})$ vs. 0.075 inch $(0.19 \mathrm{~cm})$ thick, was also impacted with a 0.10 -inch $(0.25-\mathrm{cm})$ diameter graphite ball at eight different velocities. The predictions of peak strain for each impact velocity showed a maximum discrepancy of only 13 percent. It was shown from the comparison that the model works reasonably well in predicting the actual impact stress and strain for the given ceramic material under different conditions.

\subsection{Ceramic Components Analysis}

Previous durability testing of the AGT101 engine showed the ceramic radial turbine design to be susceptible to impact damage from combustor-generated carbon ${ }^{(2)}$. Inducer blade damage from carbon ingestion was the cause of an engine shutdown after 85 hours of testing. Tests performed 


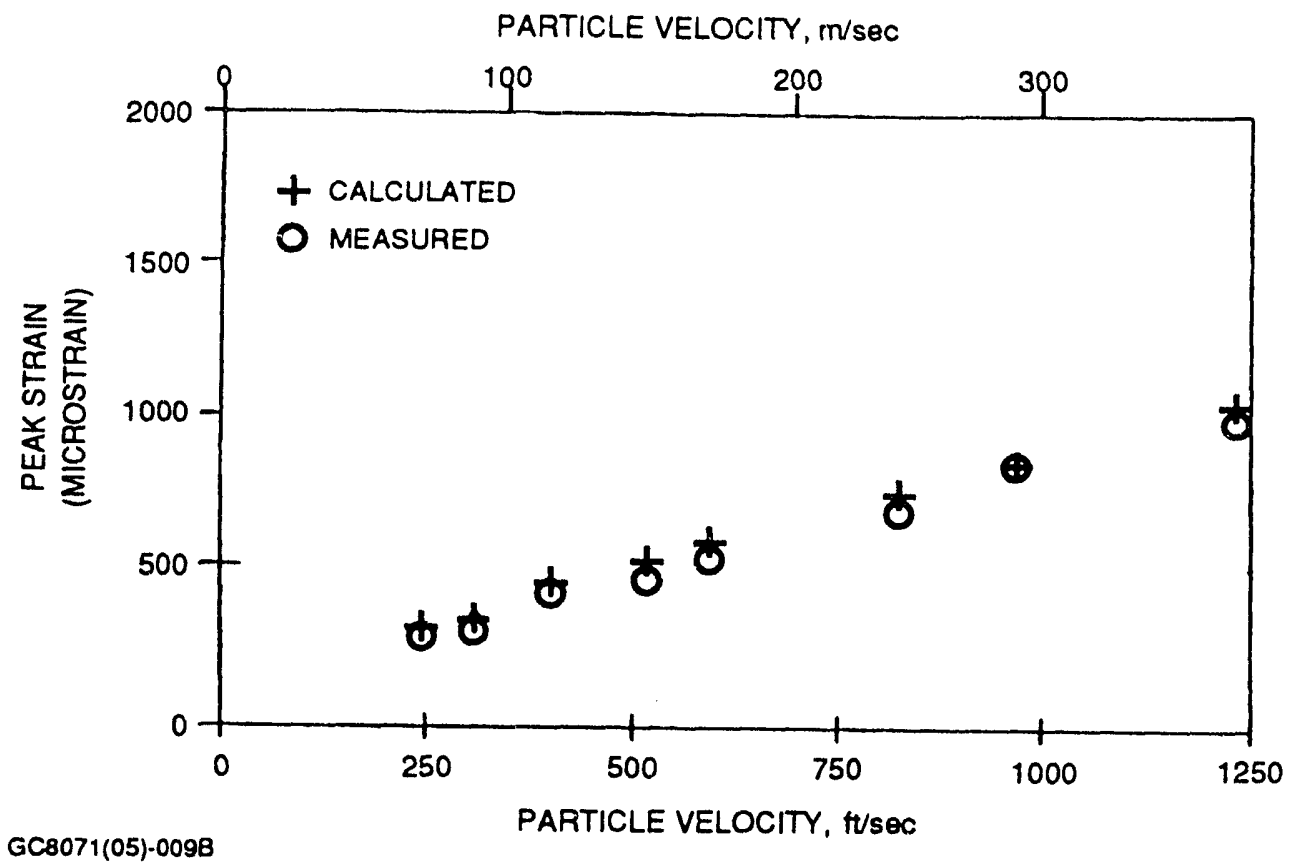

Figure 9. Macromechanical Impact Model Produces Better Agreement Between Analytical And Experimental Results.

with the Garrett AGT101 combustor rig also indicated that Number 2 diesel fuel (DF-2) used in ATTAP testing promoted formation of carbon deposits in the combustor. To address this, concurrent efforts were initiated to eliminate carbon formation in the combustor and to improve the impact resistance of the turbine rotor. The combustor development was successfully completed in 1991 (previously reported).

The impact-resistant turbine was designed to meet ATTAP criteria for aerodynamic performance, mechanical integrity, and fabricability. The engine structures surrounding the turbine stage were also redesigned, to accommodate the necessary changes in the flowpath. A partial engine cross section (Figure 10) shows the redesigned turbine and surrounding structures.

To maintain AGT101 engine compatibility and minimize the number of components requiring modification, the new turbine design was constrained to operate within the $90,000 \mathrm{rpm}$ speed and existing compressor pressure ratio and mass flow characteristics. The design for the improved, impact-resistant ATTAP turbine included:

- Reduced turbine blade tip speed

- Redesigned blades with impact-resistant geometry

- Ceramic material of improved strength 


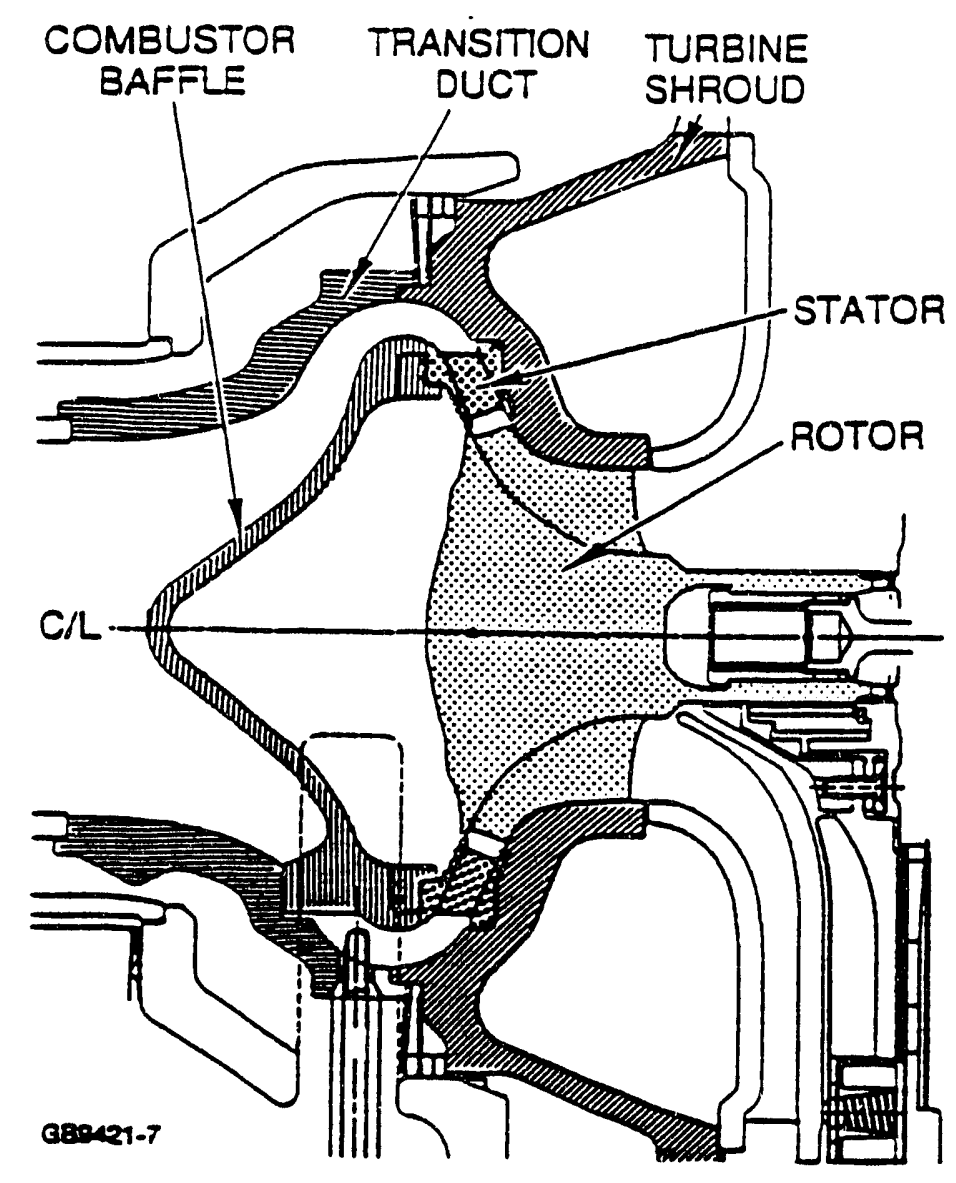

Figure 10. Cross Section Of Redesigned Turbine And Supporting Structures Shows Five Modified Components (Shaded).

The efforts for 1992 concentrated on performing the risk analysis, and calculating peak stresses and probabilistic life for the impact-resistant turbine (IRT) design.

\subsubsection{Peak Stress Evaluation Of IRT Rotor}

In performing risk analysis of mechanical components, it is the combination of the stress and temperature fields that determine the survival probabilities for fast fracture and slow crack growth. Three-dimensional (3-D) finite element (FE) analysis techniques were used to predict the thermomechanical stress fields for the IRT rotor. The FE mesh, shown in Figure 11, denotes the four critical regions of the rotor: centerline (CL), backface (BF), blade suction surface (SS), and blade pressure surface (PS). Stress analyses were accomplished for several different operating modes, including cold rotation, and steady-state and transient engine operation. 


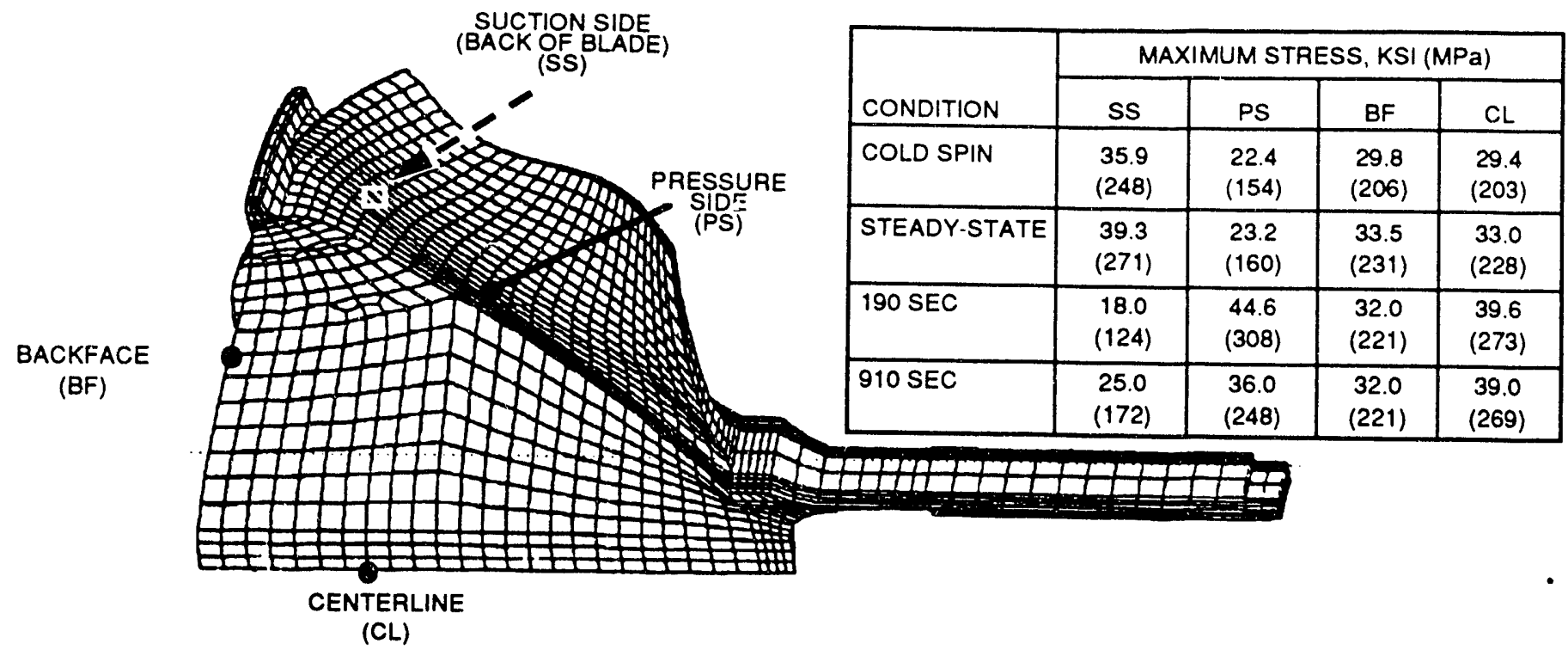

GC8071(05)-11

Figure 11. 3-D Finite Element Analysis Results Were Used For Probabilistic Stress Predictions.

The calculated peak steady-state stresses for cold rotation $(100,000 \mathrm{rpm})$, and at the design point [90,000 rpm, 2404F (1318C) TIT] are $44.5 \mathrm{ksi}(307 \mathrm{MPa})$ and $39.3 \mathrm{ksi}$ (271 MPa), respectively, both occurring on the blade SS. Peak transient stresses occur during engine accelerations, 190 and 910 seconds into the start cycle (Figure 12) defined for the ATFAP Milestone 5 100-hour durability test. At 190 seconds after start, a peak stress of $44.5 \mathrm{ksi}(307 \mathrm{MPa})$ occurs on the blade PS, whereas at 910 seconds, the rotor $\mathrm{CL}$ stress peaks at $39 \mathrm{ksi}(269 \mathrm{MPa})$.

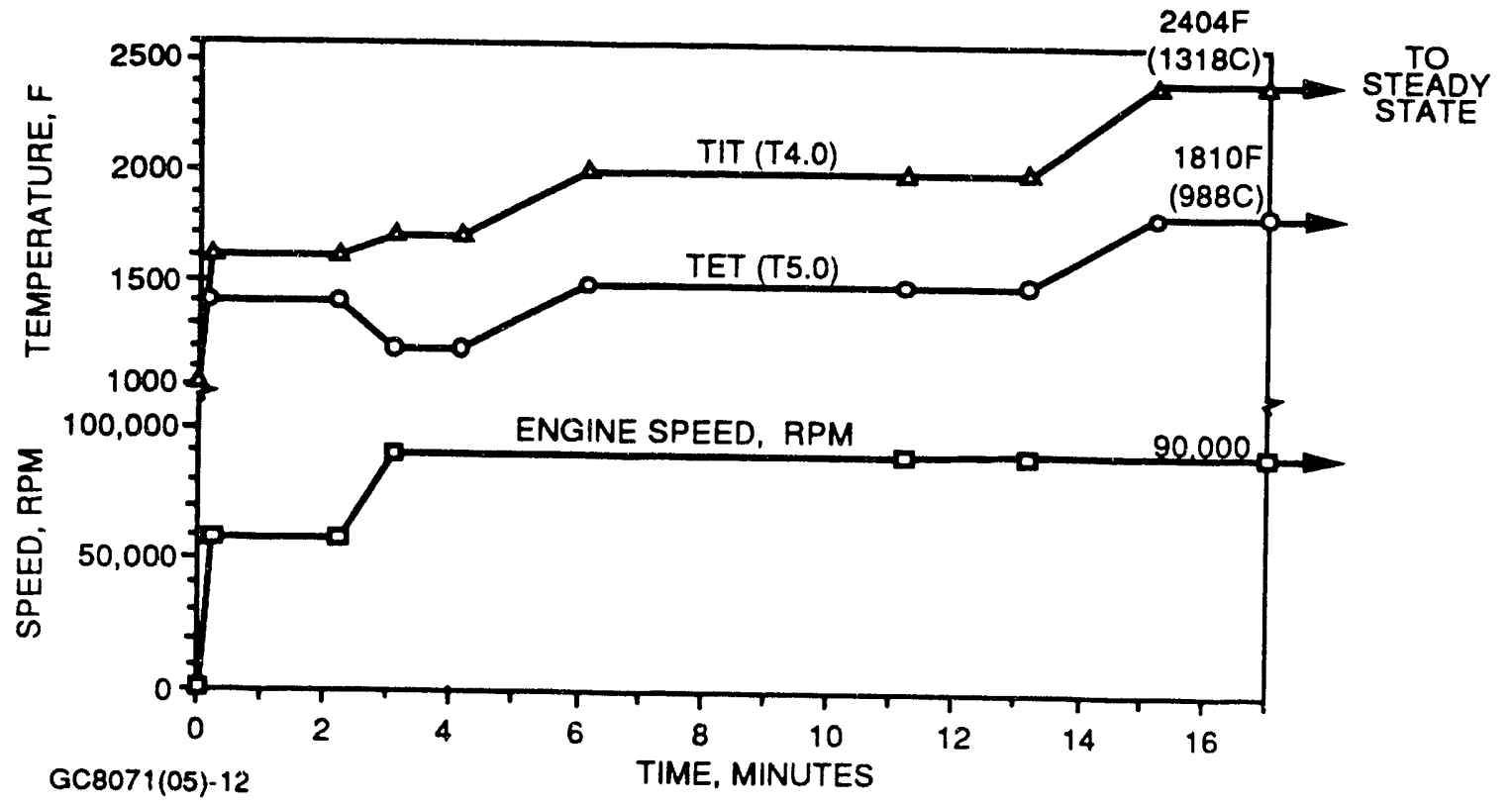

Figure 12. Milestone 5 Durability Test Cycle. 


\subsubsection{Probabilistic Life Analysis}

The objective of performing probabilistic life analysis in the ATTAP program was to advance the state-of-the-art while predicting the life of the IRT rotor when subjected to realistic engine conditions. A convenient way of evaluating portions of the methodology is to compare results of room temperature spin burst tests with analytical predictions. Such comparisons were made for rotors fabricated from GCC GN-10 and NTC NT154 silicon nitride.

Some notable features of the probabilistic life analysis include: (a) placing confidence bands around the fast fracture predictions, (b) use of pooled data sets and censoring to estimate the Weibull parameters, and (c) computation of total reliability determined from independent failure modes [volume (VOL), as-processed surface (AP), and machined surface (MS)].

Two sets of mechanical property data were used to generate the statistical properties required for the fast fracture and slow crack growth life analyses. The first set utilized NT154 and GN-10 Mil-B test specimens, size-scaled to reflect Weibull data for unit size, to generate the mechanical properties values (Figure 13) needed to calculate the fast fracture (FF) probability of failure. The second set of test specimens was used to generate mechanical property data (Figures 14 and 15) to predict the slow crack growth (SCG) probability of failure.

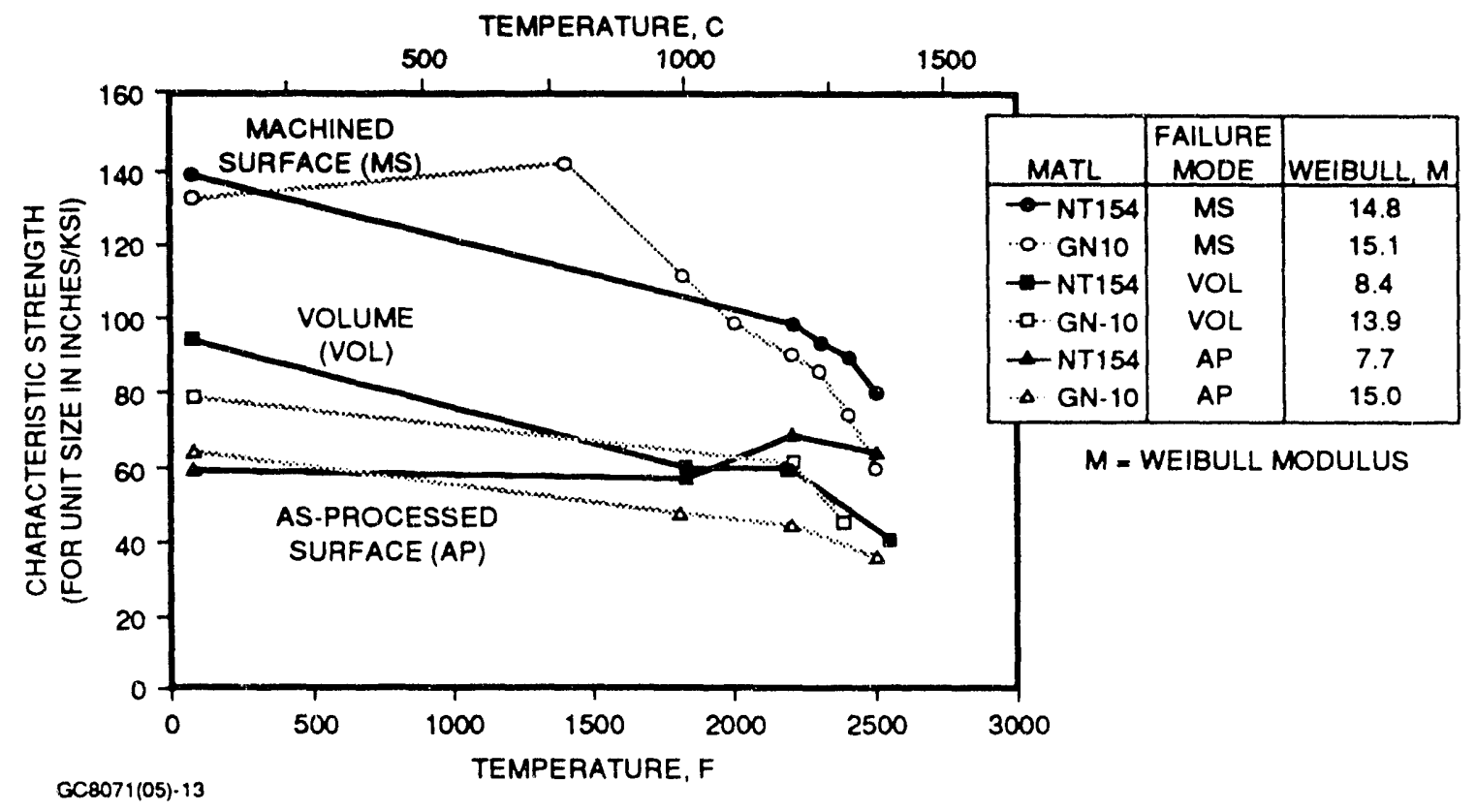

Figure 13. Weibull Parameters For NT154 And GN-10 Used In Rotor Failure Probability Analysis. 


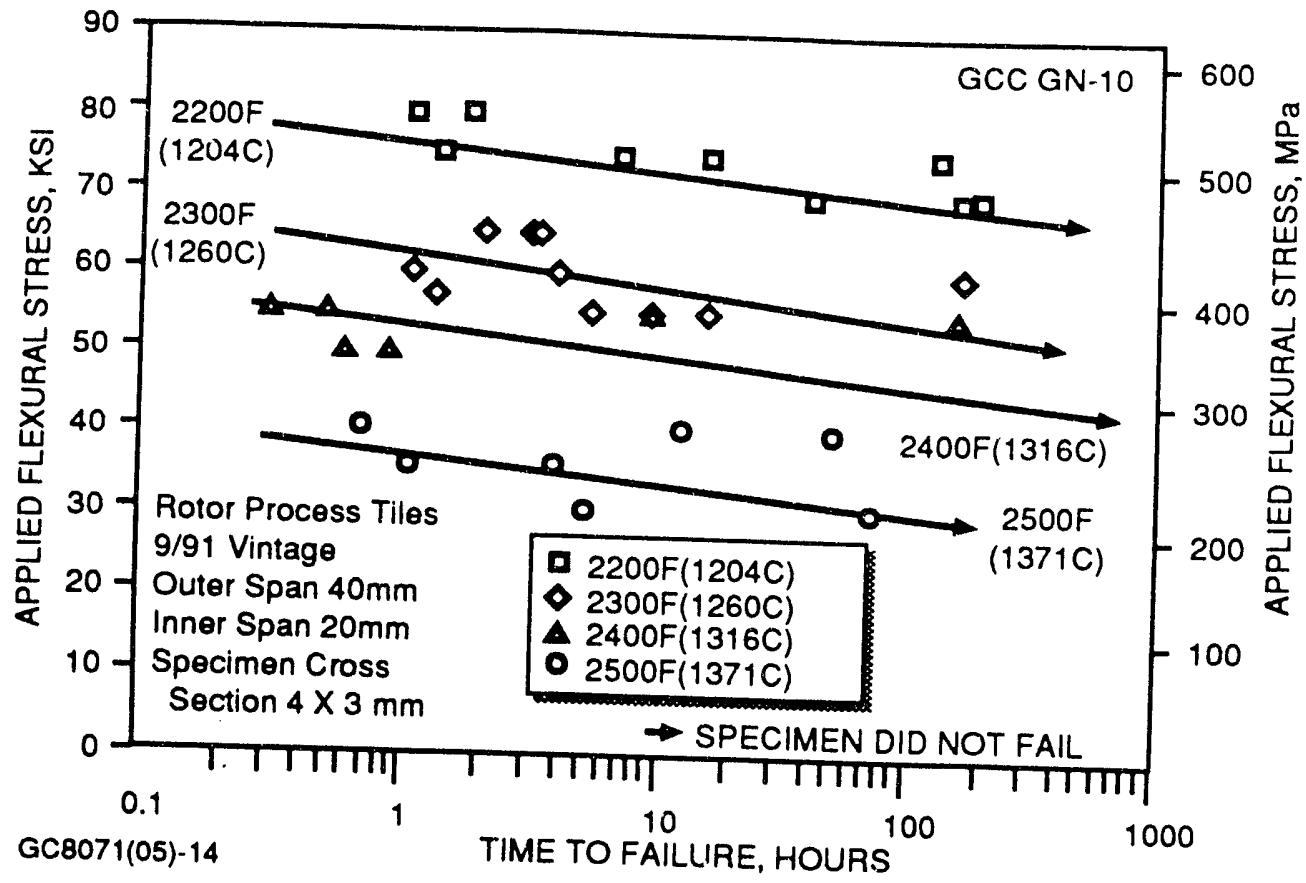

Figure 14. GN-10 Stress Rupture Data Used For Slow Crack Growth Predictions.

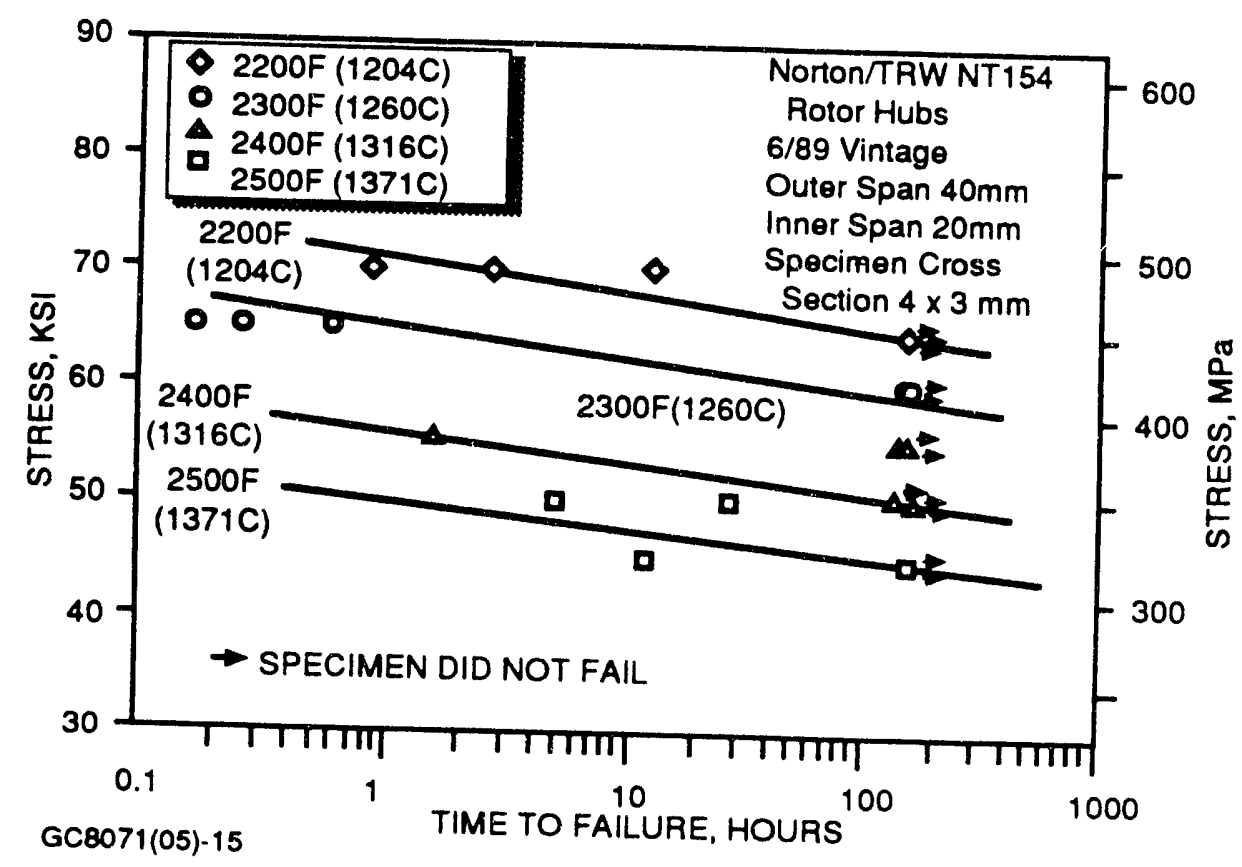

Figure 15. NT154 Stress Rupture Data Used For Slow Crack Growth Predictions. 


\subsubsection{Room Temperature Burst Analysis}

Confidence intervals were calculated for fast fracture failure, and the results were compared with actual rotor burst test data. The analysis is designed to predict that 90 percent of the time, the actual data should fall within the confidence bands. When analytical results were compared with the rotor burst test data available (from six GN-10 rotors and two NT154 rotors), the outcome was encouraging (Figure 16). Whatever discrepancies that exist between observed and predicted behavior are attributable to either the quality of the test data, prediction methodology, or both. The capabilities of the methodologies are being thoroughly evaluated in the DOE/ORNL Ceramic Life Prediction Program.

\subsubsection{Fast Fracture During Engine Operation}

Fast fracture (FF) methodology was applied to predict the reliability under thermomechanical loading for the ATTAP 100-hour durability test cycle load and unload transients. The results are shown in Figure 17. The scatter bands in Figure 17 depict the confidence intervals at the two critical timepoints for both materials. It is predicted that at 910 seconds after engine lightoff, with a 90 percent confidence calculation, the FF probability of failure (PF) for NT154 lies within 3 and 25 percent,

(a) GN-10

ROTOR SPEED, krpm

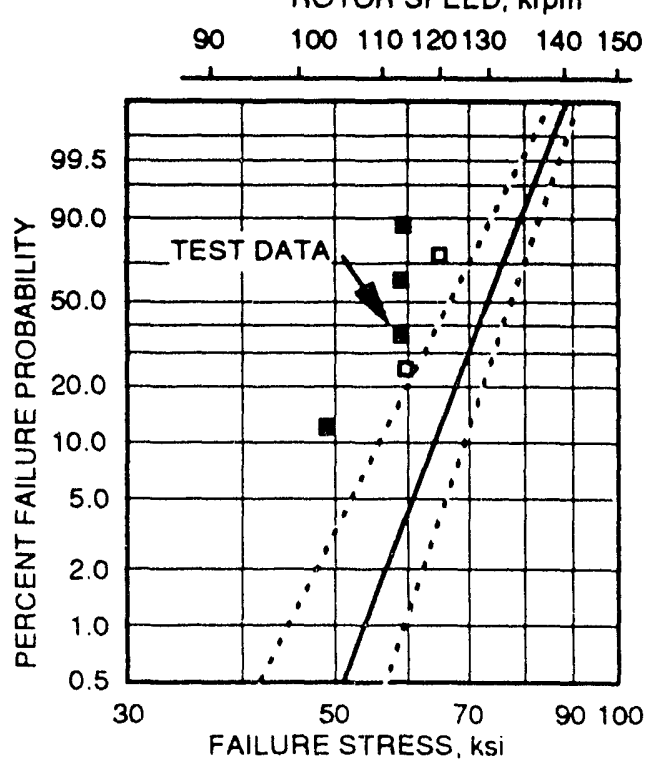

GC8071(05)-16A (b) NT 154

ROTOR SPEED, krpm

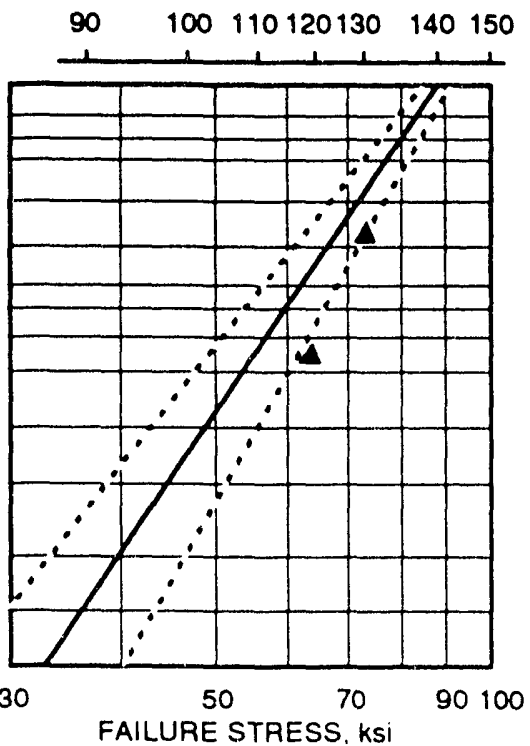

Figure 16. GN-10 (Left Plot) And NT154 (Right Plot) Failure Predictions Compared With Spin Test Results. 


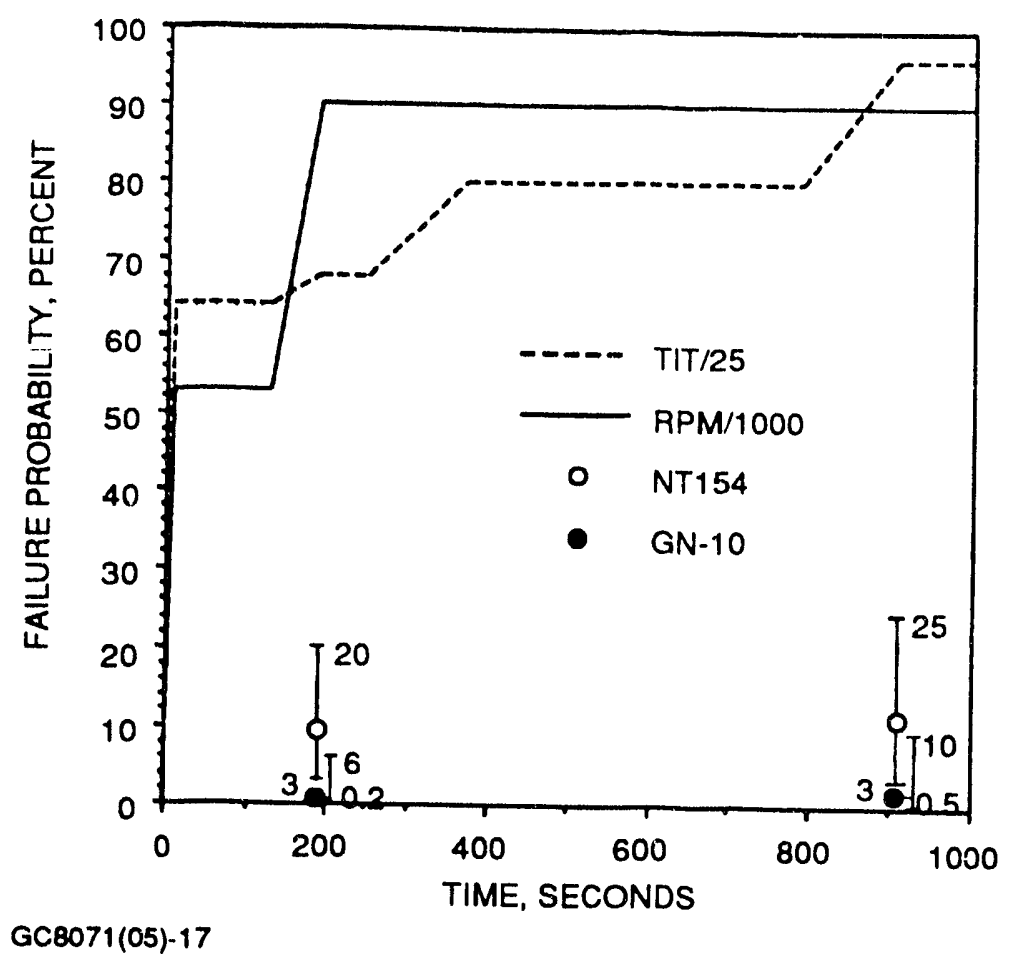

Figure 17. Fast Fracture Life Prediction For ATTAP Milestone 5 Durability Cycle Testing .

with the nominal being 11.7 percent. Likewise for GN-10, the corresponding range is between 0.5 and 10.0 percent, with the nominal being 2.1 percent. Thus NT154 has a significantly higher PF compared to GN-10 (analytically). However, the experimental cold burst spin test data does not support this position. This discrepancy may be attributed to inherent assumptions in the probabilistic life analysis or the quality of the test data used to generate the Weibull and characteristic strength properties of GN-10 and NT154.

\subsubsection{Slow Crack Growth During Engine Steady-State Operation}

Slow crack growth (SCG) behavior was investigated for the AGT101 rotor at the steady-state operating conditions of $2404 \mathrm{~F}(1318 \mathrm{C})$ turbine inlet temperature (TIT) and $90,000 \mathrm{rpm}$. The prediction methodology so far cannot establish a measure of confidence for SCG, as has been done for FF. The SCG results for GN-10 and NT154 rotors are shown in Figure 18. Here again, GN-10 is predicted to be superior to NT154. This is attributed to the higher Weibull modulus of the GN-10. 


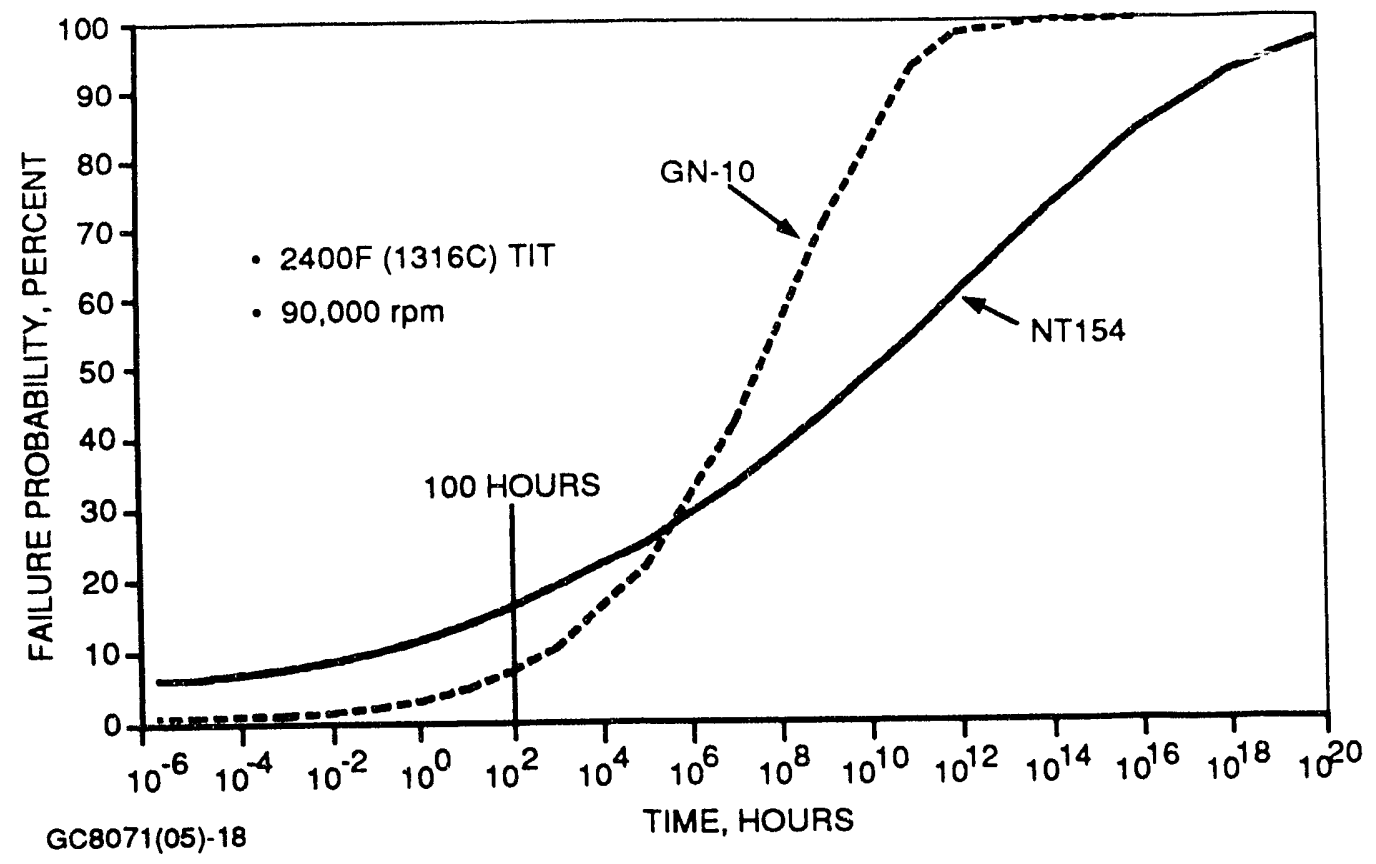
Figure 18. Comparison Of NT154 And GN-10 Slow Crack Growth Lives At 2400F (1318C) TIT
And 90,000 rpm.

The results plotted in Figure 18 apply to rotors that have not been proof tested. If a rotor is proof spin tested to withstand the stresses of steady-state operation prior to being used in an engine, then its FF risk (SCG at time zero) reduces to zero. Thus, the SCG probability of failure of a proof-tested rotor after 100 hours operation is approximately six percent for GN-10 and approximately nine percent for NT154.

The failure mode for SCG is predicted to be from the as-processed surface for GN-10, and from volume failure for NT154. Even though NT154 is predicted to have a higher SCG probability of failure compared to GN-10, it has a more favorable SCG curve, as shown in Figure 18. After 100 hours of operation, the data for GN-10 lies very close to the knee of the S-shaped curve; whereas, for NT154, the knee is very soft. This trend puts NT154 in a better position against uncertainties in the analytical predictions. 


\subsection{MATERIALS CHARACTERIZATION AND CERAMIC COMPONENT FABRICATION}

\subsection{Materials Characterization}

The ATTAP materials characterization activity focused on testing materials fabricated using the same process path used for the respective ATTAP components. This provides a more accurate database for component design and design methodology development. Additionally, since all ATTAP ceramic components are fabricated near-net-shape, each having a combination of machined and unmachined (as-processed) surfaces, evaluations include fully-machined and as-processed test specimens so properties for both surface conditions are available to support the design activities.

\subsubsection{Property Measurements}

Flexural strength and stress rupture tests performed during 1992 used test specimens and support spans in accordance with American Society for Testing and Materials (AŚTM) Specification C1161, Configuration B. The nominal test parameters are listed in Table 3.

\section{TABLE 3. ATTAP CERAMIC MATERIAL FLEXURAL STRENGTH AND STRESS RUPTURE TEST PARAMETERS}

\begin{tabular}{|ll|}
\hline Specimen Dimensions: & $\begin{array}{l}\text { Width }=4.0 \mathrm{~mm}(0.157 \mathrm{inch}) \\
\text { Thickness }=3.0 \mathrm{~mm}(0.118 \mathrm{inch}) \\
\text { Length }=50.0 \mathrm{~mm}(2.0 \mathrm{inch})\end{array}$ \\
Support Spans: & $\begin{array}{l}\text { Inner }=20.0 \mathrm{~mm}(0.787 \mathrm{inch}) \\
\text { Outer }=40.0 \mathrm{~mm}(1.574 \mathrm{inch})\end{array}$ \\
Displacement Rate: & $0.5 \mathrm{~mm} / \mathrm{min}(0.02 \mathrm{inch} / \mathrm{min})$ \\
\hline
\end{tabular}

Some flexural strength evaluations included specimens with the test surface left in the as-processed (unmachined) condition. The as-processed surface strength data is important for reliability analyses of components with highly stressed, as-processed surfaces.

The flexural testing was performed at room and elevated temperatures. All elevated temperature tests were conducted in a static air furnace environment.

The Weibull modulus for analysis of four-point flexural strength data was calculated for sample sizes of 20 and greater using a spreadsheet developed by Professor M. Ferber of the University of Illinois. The reported Weibull values were calculated using the maximum likelihood method. 
The fracture surfaces of all specimens were visually examined at 40X magnification to identify the fracture origin locations. Selected specimens were evaluated further using scanning electron microscopy (SEM) to document the typical fracture-originating flaw types.

Tensile stress rupture testing of the ATTAP rotor material candidates, NT154 and GN-10 silicon nitrides, was performed at the DOE Oak Ridge National Laboratory (ORNL) under the direction of Mr. K. Lui. Tensile stress rupture testing provides more accurate slow crack growth and creep data than that obtainable using flexure testing. The test data supports rotor life analyses. The nominal test parameters are listed in Table 4.

TABLE 4. ATTAP CERAMIC MATERIAL TENSILE STRESS RUPTURE TEST PARAMETERS

\begin{tabular}{ll}
\hline Specimen Type: & ORNL Buttonhead \\
Gage Dimensions: & $\begin{array}{l}\text { Diameter }=6.35 \mathrm{~mm}(0.250 \mathrm{inch}) \\
\text { Length }=63.5 \mathrm{~mm}(2.50 \text { inch })\end{array}$
\end{tabular}

\subsubsection{Norton Advanced Ceramics NT754 Silicon Nitride Material Characterization}

Norton Advanced Ceramics (NAC) NT154 silicon nitride is currently used for the AGT101 turbine rotor and statcr. Since a combination of porous and nonporous mold materials are used in pressure slip casting these components, the flexural strength of as-processed surface test specimens cast using both mold materials was characterized.

The flexural strength results are plotted as a function of temperature in Figure 19. The results show that both mold materials yield equivalent as-processed surface properties. The as-processed surface strengths averaged approximately $75 \mathrm{ksi}(517 \mathrm{MPa})$ from room temperature up to $2500 \mathrm{~F}$ (1371C). The strength is low compared to NT154 machined strength properties, which typically average better than $120 \mathrm{ksi}(827 \mathrm{MPa})$ at room temperature and $80 \mathrm{ksi}(552 \mathrm{MPa})$ at $2500 \mathrm{~F}(1371 \mathrm{C})$, respectively.

Up to $2200 \mathrm{~F}$ (1204C), all NT154 specimen failures originated from the as-processed surface. The predominate fracture-originating flaws were pits in the as-processed surface (Figure 20). At 2500F (1371C), a few internal failures originating from iron-based inclusions were noted. 


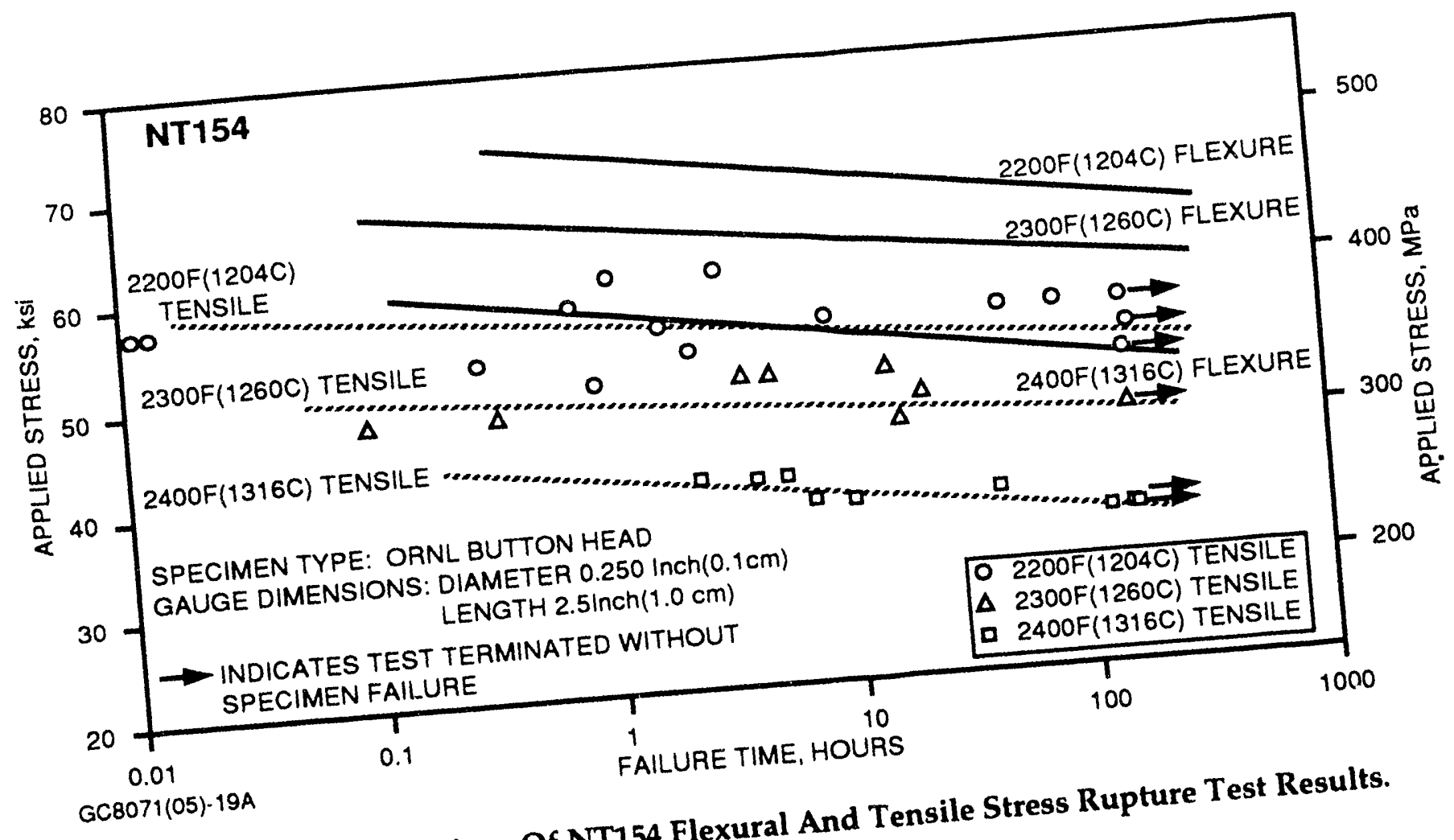

Figure 19. Comparison Of NT154 Flexural And Tensile Stress

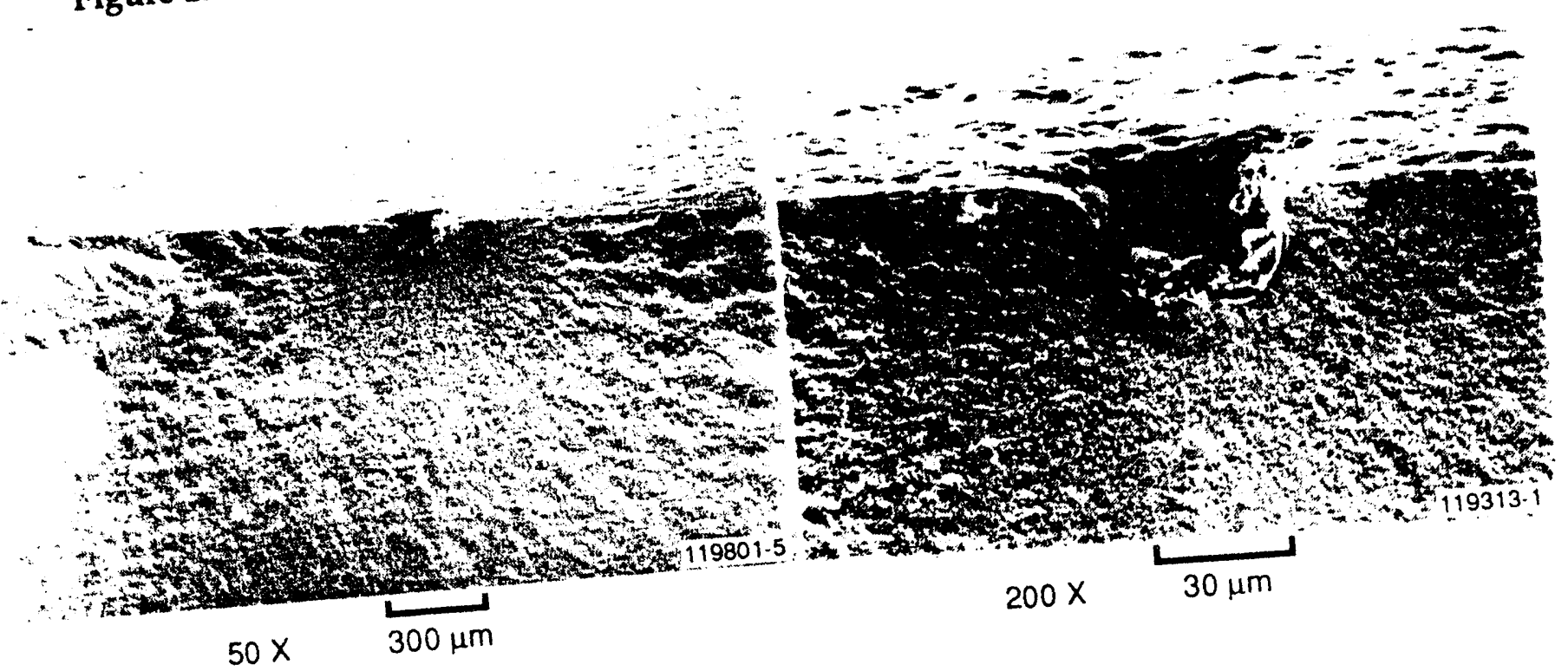

GB8071(04)-27

Figure 20. NT154 Test Specimen Flaw Originating From Pit In As-Processed Surface. 


\subsubsection{Norton Advanced Ceramics_NT230 Siliconized Silicon Carbide Material Characterization}

Flexural stress rupture testing of Nurton Advanced Ceramics NT230 siliconized silicon carbide was performed at temperatures between $2200 \mathrm{~F}$ to $2500 \mathrm{~F}$ ( $1204 \mathrm{C}$ to $1371 \mathrm{C}$ ). Tests performed at $2200 \mathrm{~F}$ and $2300 \mathrm{~F}(1204 \mathrm{C}$ and $1260 \mathrm{C}$ ) ran out to 150 hours with no failures at maximum test stress levels of 60 and $52.5 \mathrm{ksi}$ ( 1414 and $362 \mathrm{MPa}$ ), respectively. At slightly higher test stress levels, the tests resulted in a mixture of runouts and specimens failing upon load application. The stress rupture test results for tests performed at $2400 \mathrm{~F}$ and $2500 \mathrm{~F}$ (1316C and 1171C) are plotted in Figure 21. NT230 exhibited 100hour stress rupture capability of greater than $40 \mathrm{ksi}(276 \mathrm{MPa})$ at $2400 \mathrm{~F}(1316 \mathrm{C})$ and greater than 50 ksi (345 MPa) stress rupture capability at 2500F (1371C).

\subsubsection{Norton Advanced Ceramics NT164 Silicon Nitride Materials Characterization}

Flexural strength testing of NT164 silicon nitride (pressure slip cast and HIPped) flexure test specimens was performed during 1992. The test results are plotted as a function of temperature in Figure 22.

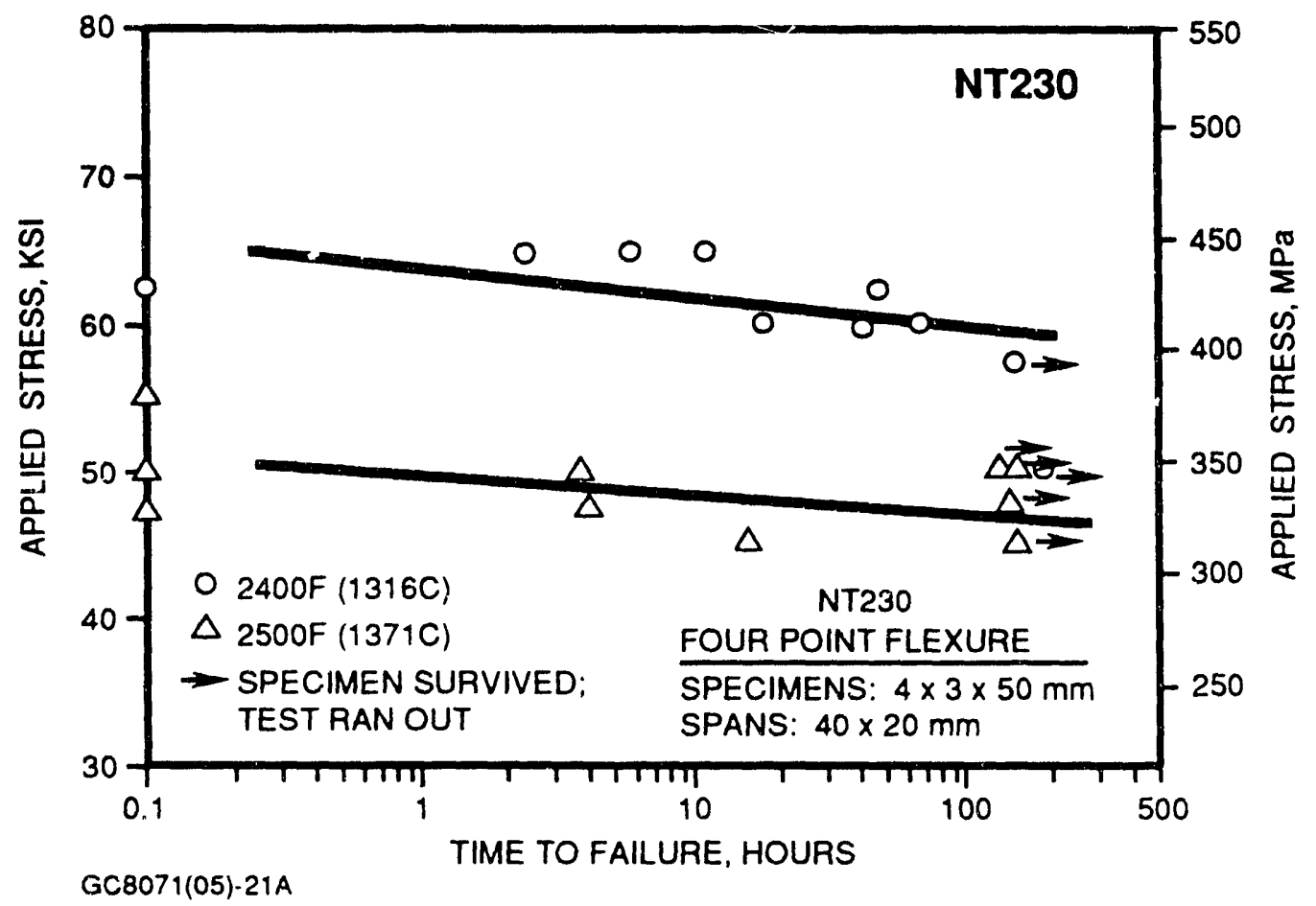

Figure 21. NT230 Flexural Stress Rupture Test Results. 


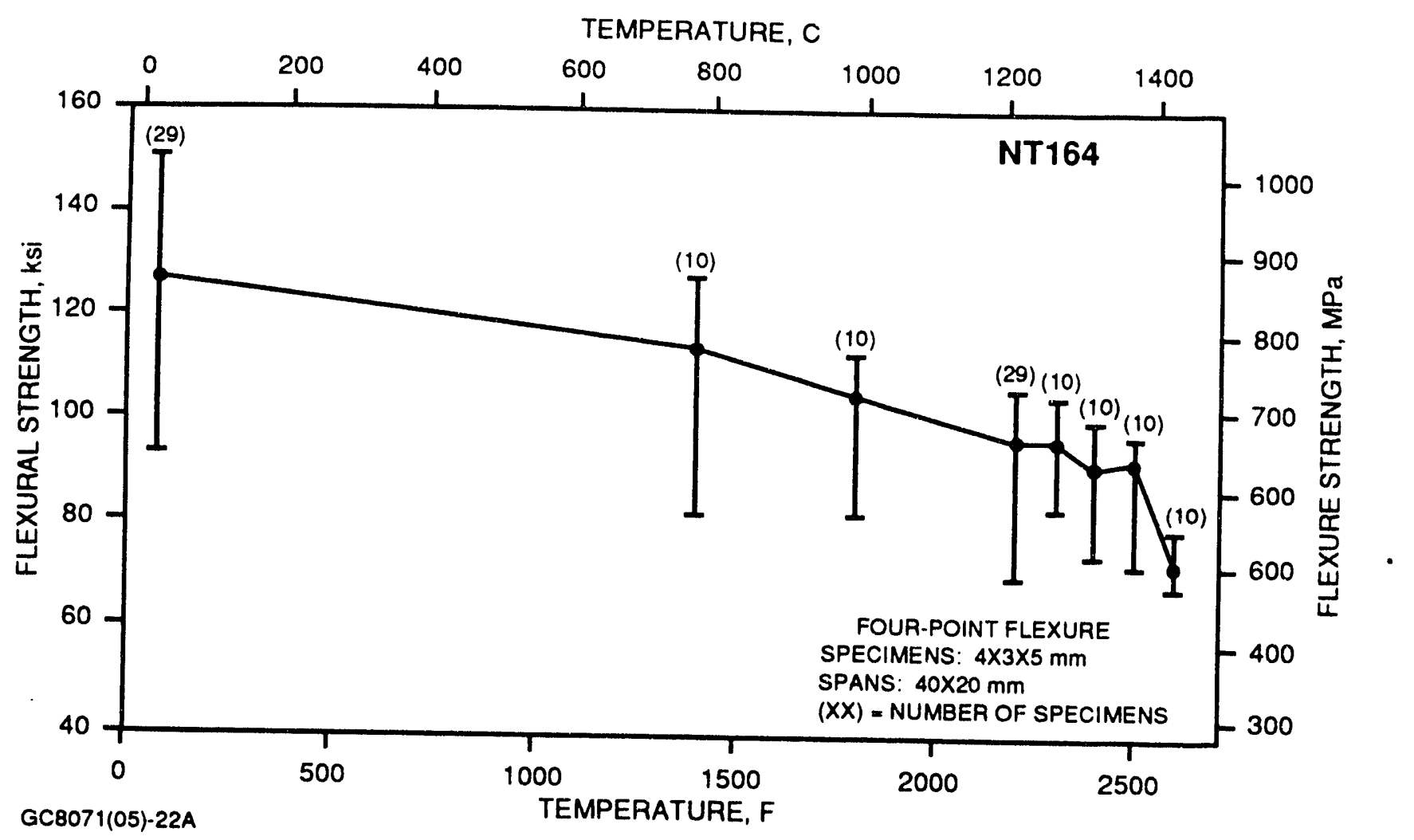

Figure 22. NT164 Flexural Strength Test Results.

At room temperature, the average strength and the Weibull modulus of NT164 was $127.7 \mathrm{ksi}$ (880 $\mathrm{MPa}$ ) and 13.2, respectively. At elevated temperatures, as-processed NT164 exhibits a gradual decrease in flexural strength to $91.9 \mathrm{ksi}(634 \mathrm{MPa})$ average at $2500 \mathrm{~F}$ (1371C). NT164 strength drops to $71.7 \mathrm{ksi}(494 \mathrm{MPa})$ at $2600 \mathrm{~F}(1427 \mathrm{C})$, accompanied by nonlinearity in the load-deflection curves, which suggests the onset of creep or slow crack growth.

The NT164 specimen fractures originated predominately from the machined surfaces (Figure 23), although a notable quantity of specimens failed from iron particle inclusions (Figure 24). Failures originating at the inclusions accounted for virtually all of the low-strength breaks in this evaluation.

\subsubsection{NGK SN-88 Silicon Nitride Material Characterization}

Flexural strength testing of NGK SN-88 silicon nitrice (isopressed and green machined) flexure test specimens with the test surface left in the as-processed condition was performed. The as-processed and machined surface strength properties are plotted as a function of temperature in Figure 25 for comparison. 

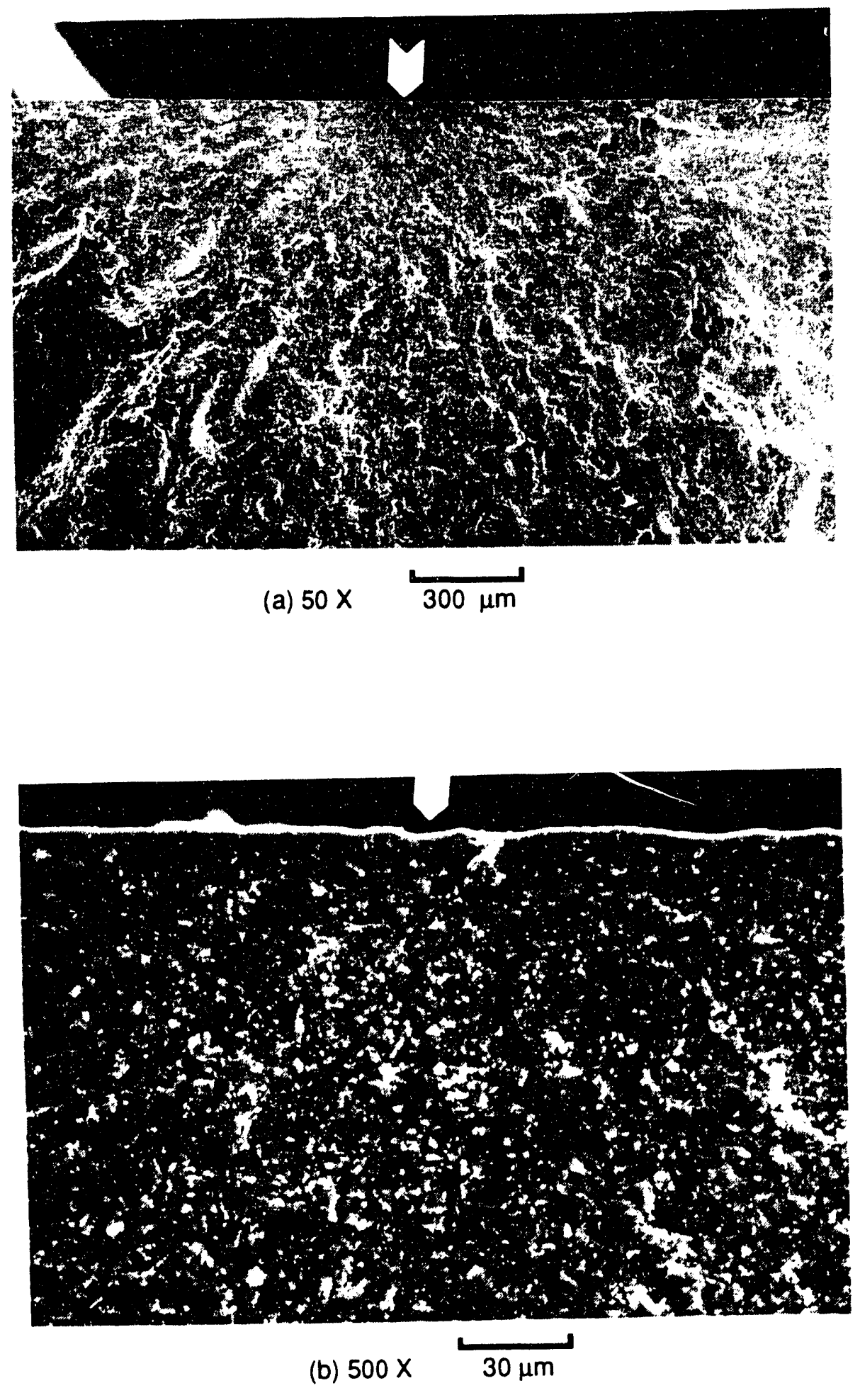

GB6990(31)-2

Figure 23. NT164 Specimen Failure Originating From Machined Surface. 

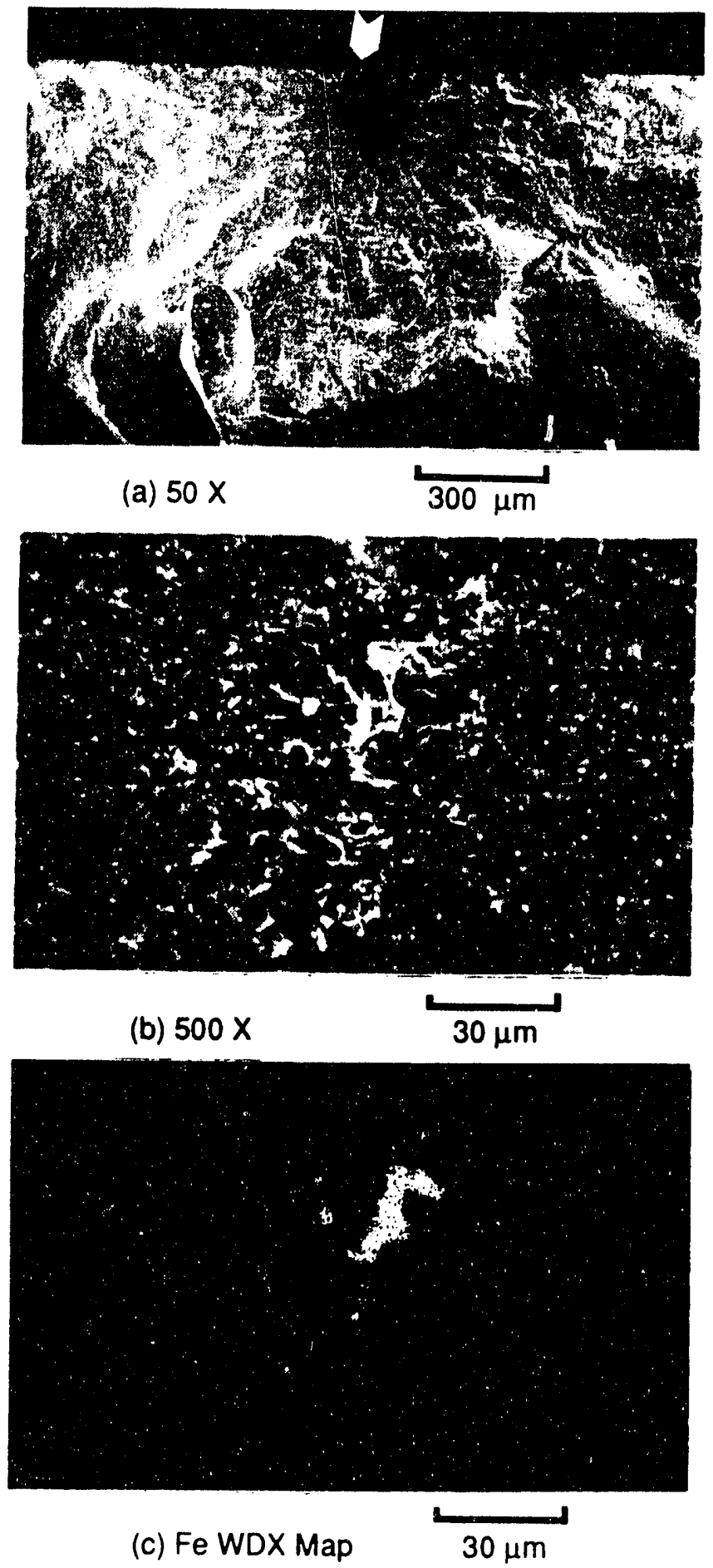

GB6990(31)-3

Figure 24. NT164 Specimen Failure Originating From Iron Particle Inclusion. 


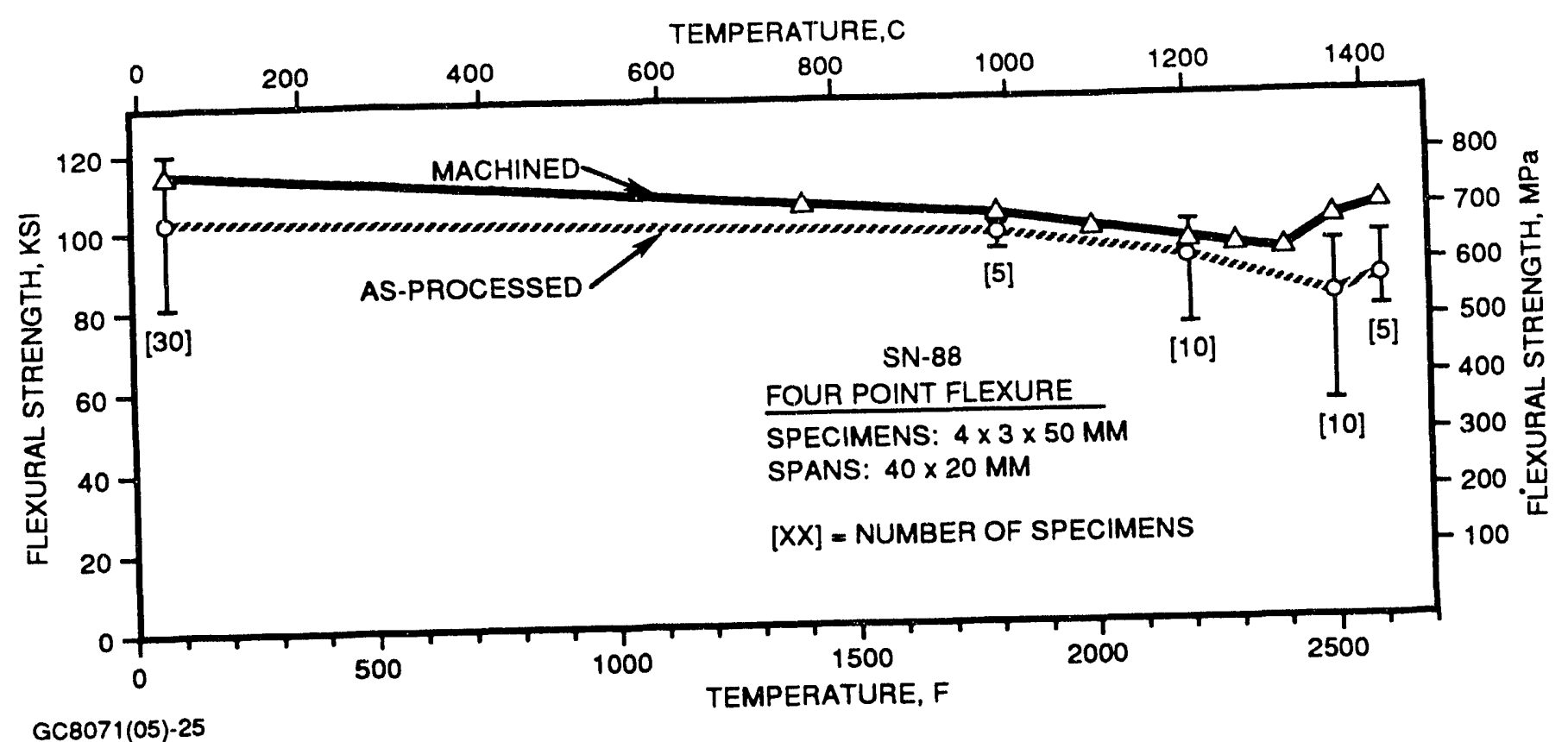

Figure 25. SN-88 Flexural Strength Test Results.

The flexural strength of as-processed surface SN-88 specimens is slightly less than measured for fully-machined SN-88 specimens. At room temperature, the average strength and the Weibull modulus for as-processed SN-88 specimens was $101.8 \mathrm{ksi}(702 \mathrm{MPa}$ )and 13.3, respectively, compared to $114.2 \mathrm{ksi}(787 \mathrm{MPa})$ and 21.5 , respectively, for machined SN-88. At elevated temperatures, as-processed SN-88 exhibits a gradual decrease in flexural strength to $80.3 \mathrm{ksi}$ (554 MPa) average at $2500 \mathrm{~F}$ (1371C). SN-88 exhibits some strength recovery to $84.7 \mathrm{ksi}(584 \mathrm{MPa})$ average at $2600 \mathrm{~F}(1427 \mathrm{C})$. The strength increase at $2600 \mathrm{~F}(1427 \mathrm{C})$ was accompanied by some nonlinearity in the load-deflection curves, which suggests the onset of creep or slow crack growth.

The SN-88 specimen fractures originated predominately from the as-processed surface. The primary fracture-originating flaws were pits in the as-processed surface (Figure 26). Several surface failures from large silicon nitride grains, usually associated with a surface pit, were also noted (Figure 27). A few specimens exhibited internal failure origins. In these instances, the fracture-originating flaws were either silicon nitride grains or porous areas, similar to the internal failure origins documented previously for the machined SN-88 flexural strength specimens. 

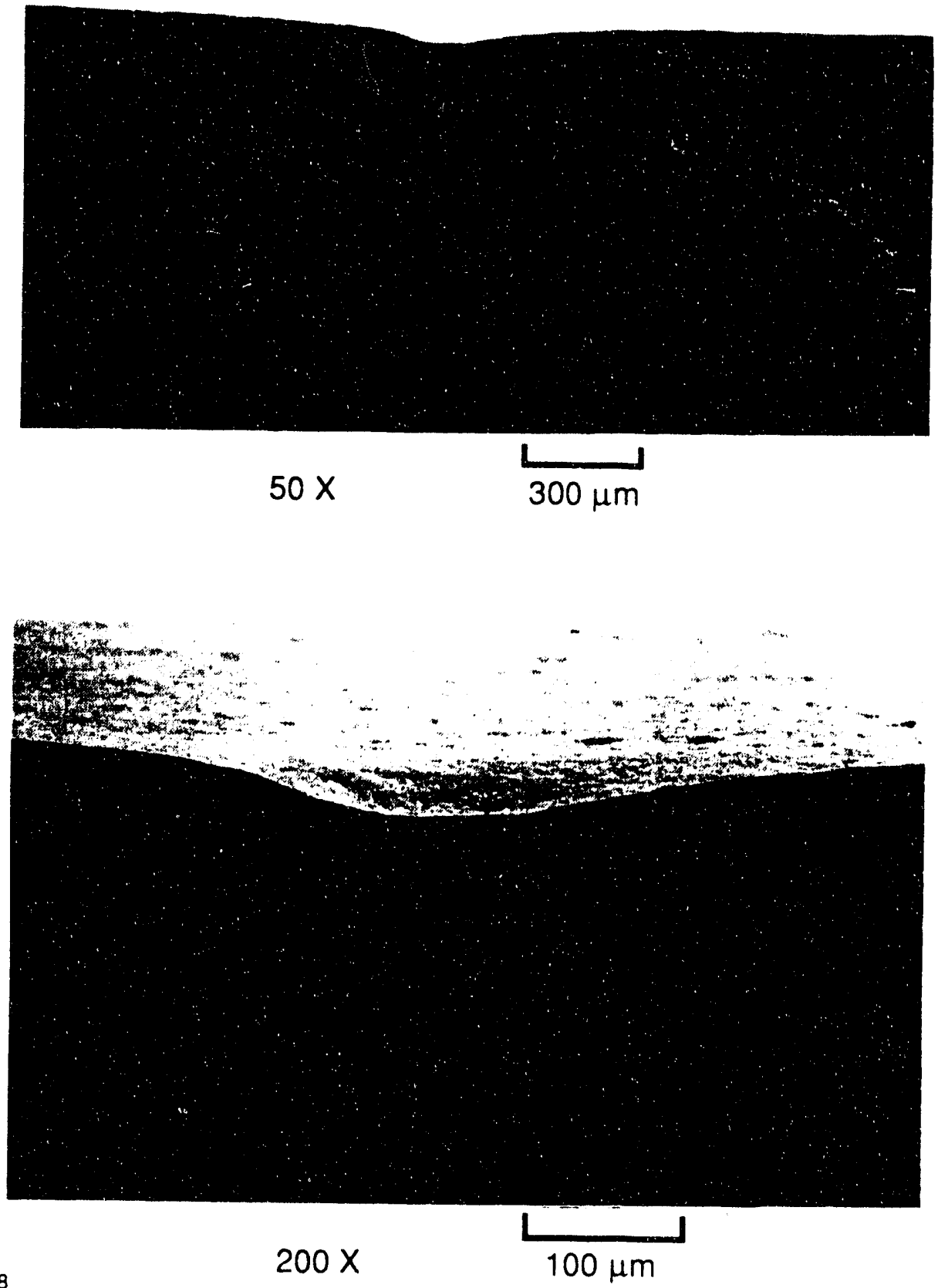

Figure 26. As-Processed SN-88 Specimen Failure Originating From Surface Pit. 

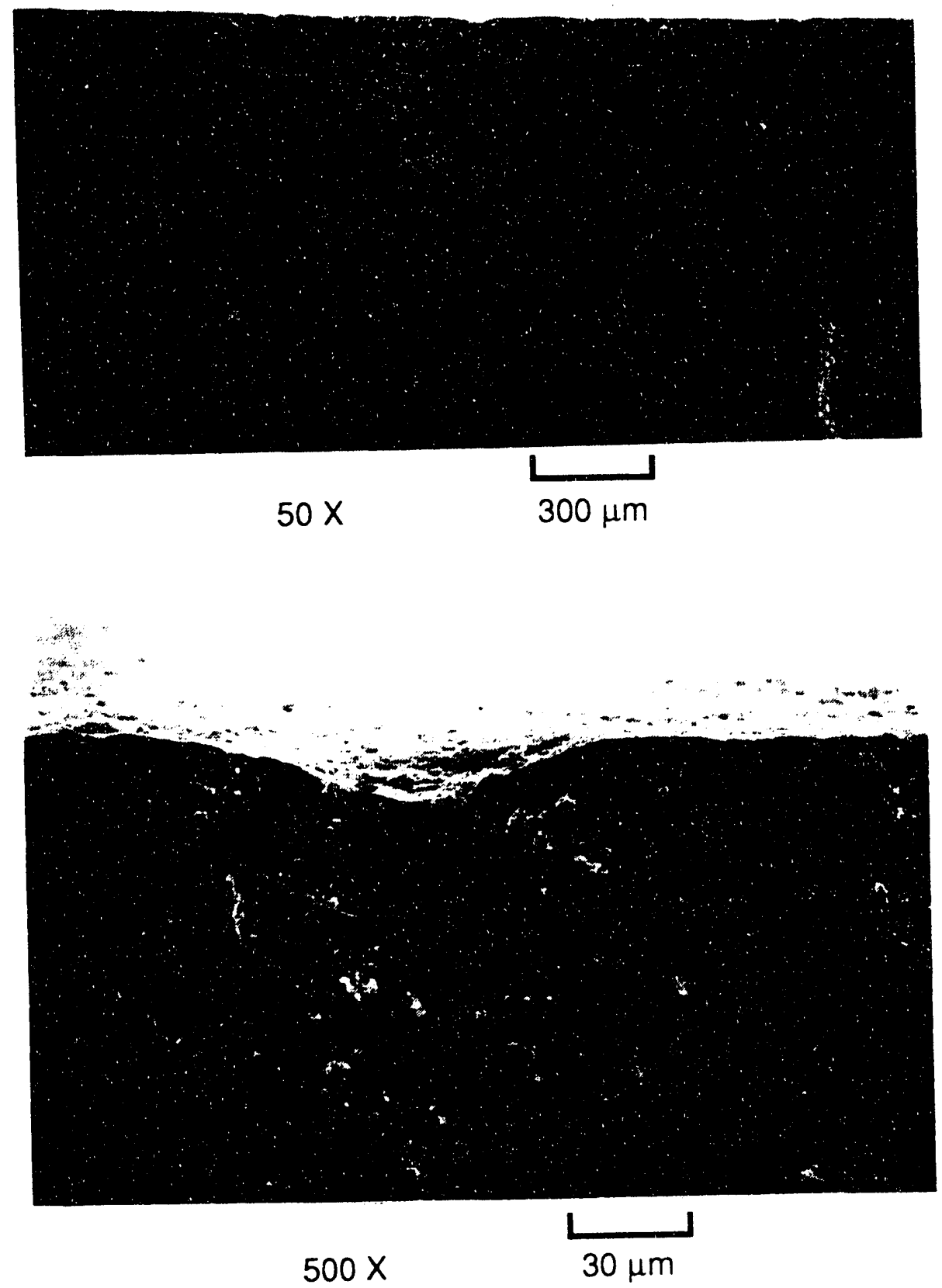

GB6990(30)-9

Figure 27. SN-88 Specimen Failure Originating From Silicon Nitride Grain. 
Flexural stress rupture testing for SN-88 (machined surface) was performed at temperatures between $2200 \mathrm{~F}$ to $2500 \mathrm{~F}$ ( $1204 \mathrm{C}$ to $1371 \mathrm{C}$ ). Tests performed at $2200 \mathrm{~F}$ and $2300 \mathrm{~F}$ (1204C and $1260 \mathrm{C}$ ) ran out to 150 hours with no failures, at stresses approaching fast fracture strength levels. At higher stresses, within the fast fracture strength range, the tests resulted in a mixture of runouts and specimens failing upon load application. The stress rupture test results for tests performed at $2400 \mathrm{~F}$ and 2500F (1316C and 1371C) are plotted in Figure 28. SN-88 exhibited 100-hour stress rupture capability greater than $80 \mathrm{ksi}(552 \mathrm{MPa})$ at $2400 \mathrm{~F}(1316 \mathrm{C})$ and greater than $70 \mathrm{ksi}(483 \mathrm{MPa})$ at $2500 \mathrm{~F}(1371 \mathrm{C})$.

\subsubsection{Carborundum Co. Hexoloy SA Materials Characterization}

The Hexoloy SA materials characterization effort with Carborundum Co. was completed in 1991.

\subsubsection{Norton/TRW Ceramics NT154 and Garrett Ceramic Components GN-10 Silicon Nitride Component Characterizations}

The responsibilities for NT154 rotor and stator characterizations and GN-10 rotor characterizations were assigned to the respective ATTAP ceramic subcontractors for completion in 1992.

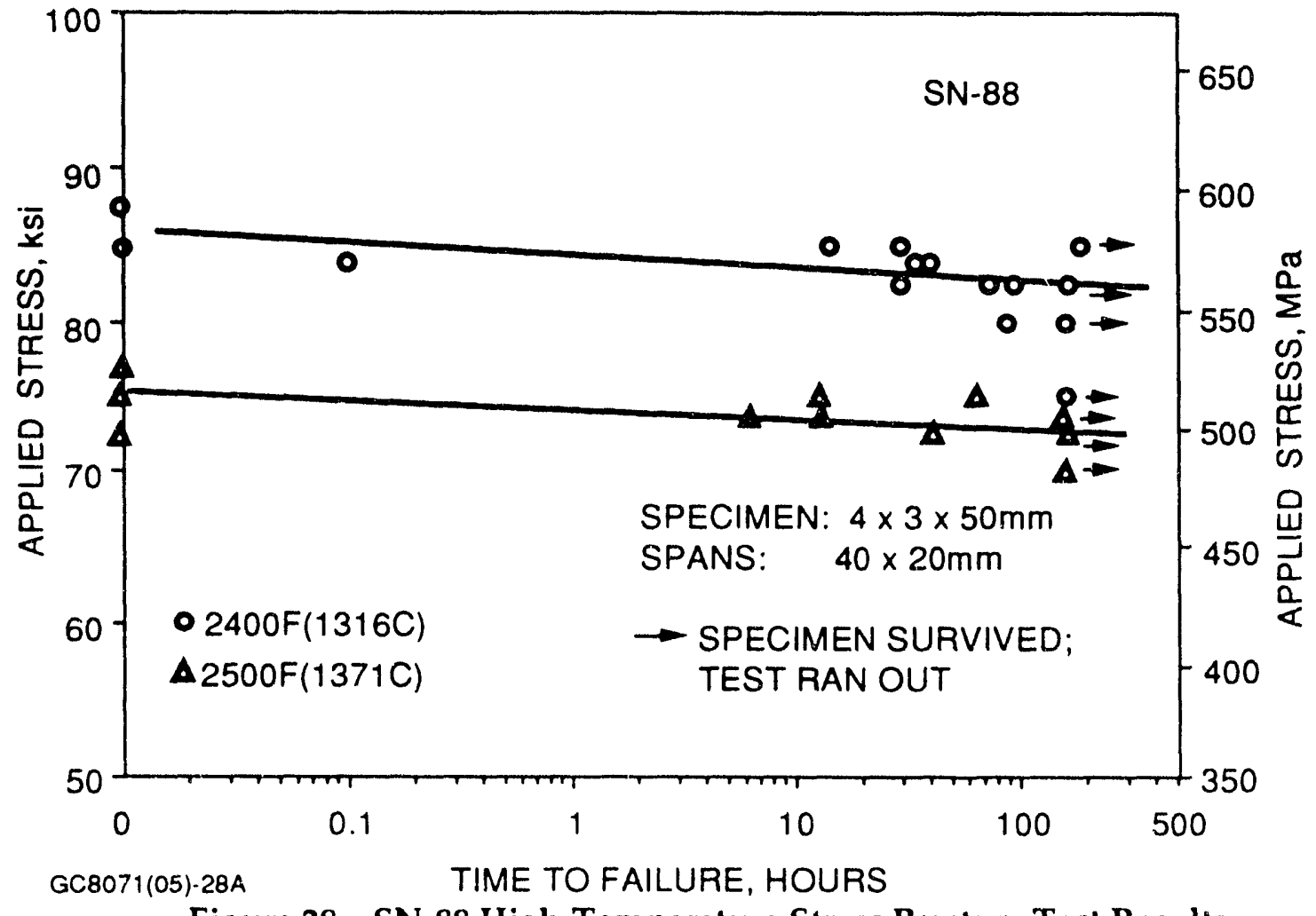

Figure 28. SN-88 High-Temperature Stress Ruf iure Test Results. 


\subsubsection{Miscellaneous Materials Issues}

Gradient furnace evaluations of candidate AGT101 engine component ceramic materials were performed to screen for intermediate temperature [1200F to $2000 \mathrm{~F}$ (649C to 1093C)] oxidation stability problems. Five materials were evaluated:

- Norton/TRW Ceramics NT154 silicon nitride

- Norton/TRW Ceramics NT230 siliconized silicon carbide

- Garrett Ceramic Components GN-10 silicon nitride

- NGK SN-88 silicon nitride (flash oxidized)

- Kyocera SN-252 (flash oxidized)

The gradient furnace studies included fully-machined and as-processed flexural strength test specimens of each material. The test specimens were exposed in a gradient furnace (static air environment) for 100 hours. Test specimens were exposed at approximately 200F (94C) intervals, spanning a $1000 \mathrm{~F}$ to $2400 \mathrm{~F}$ ( $538 \mathrm{C}$ to $1316 \mathrm{C}$ ) gradient. Weight change, dimensional change, and retained strength were measured to screen for intermediate temperature oxidation problems.

The results of the gradient furnace evaluation indicate that none of the current AGT101 ceramic material candidates exhibit intermediate temperature oxidation stability problems. Other materials previously found to have intermediate temperature oxidation problems exhibited short-term exposure (10-100 hours) oxidation weight gains greater than $0.5 \mathrm{~g} / \mathrm{cm}^{2}$. All of the ceramic materials in the current study exhibited less than $0.1 \mathrm{~g} / \mathrm{cm}^{2}$ weight increase from $1200 \mathrm{~F}$ to $2000 \mathrm{~F}$ (649C to $1093 \mathrm{C}$ ). Even at higher temperatures, most of the materials exhibited less $0.1 \mathrm{~g} / \mathrm{cm}^{2}$ weight gain. Similarly, no dimensional change or strength loss was observed for specimens exposed at intermediate temperatures. The specimens were returned to GAPD for fractography.

\subsubsection{Nondestructive Evaluation (NDE)}

During 1992, a total of more than 400 components received fluorescent penetrant (FPI) and/or radiographic inspection. These inspections proved highly successful in screening out discrepant hardware prior to engine test. Lessons learned from these inspections included:

- For ceramic components, the use of $10 \mathrm{X}$ magnification visual inspection in conjunction with FPI is a more viable surface inspection method when compared to FPI alone, as the latter rejects many components for indications which are later determined to be nondetrimental to component performance. 
- Because the use of microfocus radiographic (MFXR) techniques is mandated by the high image quality required in the inspection of ceramics, radiography of ceramics is time consuming when compared to that for metallics. However, exposure times can be significantly reduced through the use of multiple-speed film exposures and optimization of exposure energies.

Also completed during 1992 was a comparison of radiographic detection capabilities for seeded, calcined and HIPped, ceramic specimens. Detection capabilities of 50 microns $(0.002$ inch) for calcined specimens and 125 microns (0.005 inch) for HIPped specimens were demonstrated. The increase in detectable flaw size for the HIPped specimens was caused by diffusion of the seeded defects into the ceramic matrix.

\subsection{Ceramic Component Fabrication}

In recognition of the need to maintain a competitive position for domestic U.S. suppliers in critical ceramics technologies, the ATTAP program has placed heavy emphasis on the role played by the ceramics subcontractors. The development of fabrication techniques to produce high-quality, reliable ceramic engine components is critical to the growth of ceramic applications. Under ATTAP, the U.S. suppliers are concentrating on fabrication technologies for the complex ceramic shapes needed for gas turbines. This forming technology must not sacrifice the temperature capability and the strength, reliability, and durability which make ceramic materials so desirable for engine applications.

Three U.S. subcontractors were selected by GAPD to develop fabrication methods for highquality ceramic engine components: Norton Advanced Ceramics (NAC), Garrett Ceramic Components (GCC), and The Carborundum Company (CBO). These suppliers have demonstrated the process and fabrication capabilities to produce ceramic components with material properties suitable for gas turbine use.

Activities of the ATTAP ceramic component subcontractors for 1992 are detailed in the Appendices to this report. A brief synopsis of 1992 activities is presented in the following paragraphs. 


\subsubsection{Norton Adyanced Ceramics (NAC)}

NAC was contracted to develop fabrication processes for rotors and stators with their NT154 silicon nitride, and to deliver components to support engine testing. Pressure slip casting followed by hot isostatic press (HIP) densification was the fabrication approach used.

Rotor process development included development of a mold system incorporating both porous and nonporous surfaces to define casting behavior, and development of an aqueous-based slip sys'em to simplify the overall process and afford better dimensional control of the final part, due to increased green densities over the previous system.

Further rotor issues that were addressed included initial difficulty in balancing rotor components within specification. Improvements to the machining setup were made to better locate the geometric center of the machined rotor in line with the rotor mass center. NAC also was able to define machining parameters which allowed relatively rapid stock removal without any apparent damage to the underlying subsurface material. Machining time for a rotor component in the range of eight hours was achieved. A total of nine engine-quality rotors were delivered to GAPD for evaluation in the AGT101 engine test bed.

Issues concerning stator fabrication had primarily to do with casting methods. The initial stators produced showed anisotropic shrinkage, with the result that dimensions across the stator vane (platform-to-platform distance) were undersized. This presented a challenge for machining setup of this part, which has a rather complex geometry. Fixturing made to the print specification required adjustments to accommodate the decreased vane width. This condition also decreased the flowpath area below the design specification.

A second pattern was made to address the anisotropic shrinkage for subsequent deliveries. Stators delivered later in 1992 showed better conformance with print dimensions and allowed for straight-forward machining without adjustments to the fixturing. A total of 177 stator segments were delivered to GAPD for evaluation in the AGT101 engine test bed.

\subsubsection{Garrett Ceramic Components (GCC)}

GCC was contracted to develop fabrication processes for rotors with their GN-10 silicon nitride, and to deliver components to support engine testing. As with NTC, pressure slip casting followed by HIPping was the fabrication approach employed. 
GCC sought specifically to improve the strength of as-HIPped surfaces of their GN-10 material. GN-10 surface strength typically falls short of the strength of machined surfaces of other HIPped silicon nitrides by $40 \mathrm{ksi}$ or more. Other property improvements were sought as well and the results are listed in Table 5. The approaches to achieving these improvements fell into the following three areas:

(a) Modifications to the existing process, including:

- HIP and post-HIP heat treatment

- Modification to the calcining cycle or the drying cycle

- Abrasive machining to remove the surface reaction layer

(b) Improvements to the slip process

(c) Use of an alternative, higher-purity ceramic powder.

TABLE 5. NOTABLE GAINS WERE ACHIEVED IN GCC GN-10 SILICON NITRIDE ROTOR PROPERTIES

\begin{tabular}{|c|c|c|c|c|}
\hline & Units & Previous & Target & Current \\
\hline $\begin{array}{l}\text { As-Processed Flexure Strength } \\
\text { - RT } \\
\text { - } 2200 \mathrm{~F}(1204 \mathrm{C})\end{array}$ & $\begin{array}{l}\text { ksi (MPa) } \\
\text { ksi (MPa) }\end{array}$ & $\begin{array}{l}73(503) \\
58(400) \\
\end{array}$ & $\begin{array}{l}100(689) \\
85(586) \\
\end{array}$ & $\begin{array}{c}75(517) \\
\text { N/A } \\
\end{array}$ \\
\hline $\begin{array}{l}\text { Tensile Strength } \\
\text { - } \mathrm{RT} \\
\text { - } 2500 \mathrm{~F}(1204 \mathrm{C}) \\
\end{array}$ & $\begin{array}{l}\text { ksi (MPa) } \\
\text { ksi (MPa) }\end{array}$ & $\begin{array}{c}92.7(639) \\
38(262) \\
\end{array}$ & $\begin{array}{l}110(758) \\
60(414) \\
\end{array}$ & $\begin{array}{l}\text { Testing Scheduled } \\
\text { Testing Scheduled }\end{array}$ \\
\hline $\begin{array}{cl}\text { Stress Rupture Life } \\
\qquad & 70 \mathrm{ksi} \text { and } 2200 \mathrm{~F} \\
& (483 \mathrm{MPa} \text { and } 1204 \mathrm{C}) \\
\end{array}$ & Hours & $\cong 80$ & $>80$ & $>100$ \\
\hline Weibull Modulus (RT) & - & 18.6 & 20 & 22 \\
\hline
\end{tabular}

$\mathrm{RT}=$ Room Temperature. $\mathrm{N} / \mathrm{A}=$ Not Applicable.

Modifications by GCC to the GN-10 HIP process and post-HIP heat treatments did not produce the desired improvements in mechanical properties. Neither did modification of the slip process, which produced high-density gradients in the "green" part. Alternative powder trials at first gave problems with cracking during drying, but subsequent trials proved more successful, and the alternative powder was adopted by GCC as part of their updated process for GN-10. A refinement to the calcining cycle, while unfortunately providing a softer, more delicate "green" part, did yield some improvement in surface strength, but not to the degree desired. 
In the trials performed by C,CC, flow machining was unable to penetrate the HIP surface reaction layer by an amount sufficient to restore material bulk properties. With the exception of the goal for surface properties, all target GN-10 mechanical properties were successfully achieved by GCC.

GCC delivered five GN-10 rotors to GAPD for evaluation in the AGT101 test bed engine. Some of these exhibited an excessive unbalance condition, due to disparities between the mass center and the geometric center of the machined parts. Stricter machining setups were implemented to address this concern, with subsequent machined rotors exhibiting less stock removal for balance.

\subsubsection{The Carborundum Company (CBO)}

No ceramic fabrication work was performed by CBO during 1992.

\subsection{Ceramic Component Preparation}

New ceramic hardware received was processed through an inspection loop consisting of visual, dimensional, fluorescent penetrant (FPI), and radiographic inspections as necessary. Certain items were also subjected to proof testing, discussed in Section 6.4 .

Some ceramic hardware machining was necessary, to correct certain dimensional features or otherwise alter the parts to meet test requirements. Selected ceramic items were sent to outside machining vendors to develop alternate out-of-house machining sources. 


\subsection{COMPONENT RIG TESTING}

\subsection{Hot Spin Pit Testing}

The objective of this effort was to use burst test data generated from ceramic spin iest specimens to formulate methods of analytically predicting ceramic component life, and to apply these methods to successfully predict the life of ceramic disks of like material, spin tested under room temperature and heated conditions.

The spin tests are necessary to acquire biaxial stress field test data to demonstrate successful life prediction under more than just a uniaxial state of stress (as generated in ordinary test specimens). Such spin testing at high rotational speeds is normally accomplished in a near-complete vacuum to eliminate viscous drag effects limiting the spin speed achievable and affecting stability of the spinning member. However, spin testing silicon nitride $\left(\mathrm{Si}_{3} \mathrm{~N}_{4}\right)$ specimens in a near-complete vacuum for prolonged time periods (more than one hour) can cause dissociation of the $\mathrm{Si}_{3} \mathrm{~N}_{4}$ test material; thus, spin testing under atmospheric conditions is required.

A test rig was successfully developed to accommodate spin burst testing of ceramic disks in air, at temperatures up to $2500 \mathrm{~F}$ ( $1371 \mathrm{C}$ ), and for test durations up to 100 hours. A titanium disk of a geometry nearly identical to the ceramic spin disk was used to evaluate the ceramic-to-metal shaft at-tachment design and to determine the torque requirements of the motor to overcome windage while spin testing in the air environment.

The ceramic-to-metal shaft attachment was accomplished using a compliant ring which acts as an elastic shim to position and frictionally hold the ceramic shaft and metal arbor together. The compliant ring compensates for large radial differential growth between the shaft and arbor under elevated temperatures and speeds while maintaining component positioning, bending stiffness, and torque transfer capacity.

A preliminary hot spin test to determine the thermal continuity of the ceramic spin disks was conducted. Five thermocouples were embedded in a disk at various radial locations and depths. The disk was spun at low speed (approximately $450 \mathrm{rpm}$ ) and steady-state data was taken at five increments of $200 \mathrm{~F}$ ( $94 \mathrm{C}$ ) from $2100 \mathrm{~F}$ to $2500 \mathrm{~F}$ (1149C to $1371 \mathrm{C}$ ). Isothermal heating of the spin disk was successfully confirmed. 
Nondes'ructive evaluation (NDE) has been completed on all 42 ceramic spin disks. All disks underwent visual, radiographic, and fluorescent penetrant examinations. Twelve of the disks underwent computed tomography and eight of the disks underwent internal acoustic microscopy at the General Electric Aviation Component Service Center. Surface acoustic microscopy was conducted on seven disks at GAPD.

Fourteen room temperature fast fracture spin burst tests were conducted, spinning the ceramic disks in a vacuum. The test results are listed in Table 6. Five high-temperature fast fracture spin tests were successfully completed. The results are listed in Table 7.

TABLE 6. ROOM TEMPERATURE FAST FRACTURE SPIN BURST TEST RESULTS

\begin{tabular}{|c|c|c|l|}
\hline $\begin{array}{c}\text { Test } \\
\text { Number }\end{array}$ & $\begin{array}{c}\text { Burst Speed, } \\
\text { rpm }\end{array}$ & \multicolumn{1}{|c|}{$\begin{array}{c}\text { Failure } \\
\text { Location }\end{array}$} & \multicolumn{1}{|c|}{ Type } \\
\hline \hline 1 & 102,700 & Surface & Transverse machining \\
2 & 43,100 & Surface & Deep scratches on shaft \\
3 & 89,200 & Surface & Transverse machining \\
4 & 80,600 & Surface & Transverse machining \\
5 & 82,800 & Surface & Longitudinal machining \\
6 & 99,100 & Surface & 20 degrees transverse machining \\
7 & 92,800 & Surface & Transverse machining \\
8 & 107,100 & TBD & TBD \\
9 & 90,200 & Volume & Internal inclusion \\
10 & 96,600 & TBD & TBD \\
11 & 105,000 & TBD & TBD \\
12 & 102,600 & TBD & TBD \\
13 & 88,500 & TBD & TBD \\
14 & 46,800 & Surface & Shaft Failure \\
\hline TBD $=$ To be determined. &
\end{tabular}

TABLE 7. HIGH-TEMPERATURE FAST FRACTURE SPIN BURST TEST RESULTS

\begin{tabular}{|c|c|c|l|}
\hline $\begin{array}{c}\text { Test } \\
\text { Number }\end{array}$ & $\begin{array}{c}\text { Burst Speed, } \\
\text { rpm }\end{array}$ & \multicolumn{1}{|c|}{$\begin{array}{c}\text { Failure } \\
\text { Location }\end{array}$} & \multicolumn{1}{c|}{ Type } \\
\hline \hline 1 & 93,000 & Volume & Internal inclusion \\
2 & 80,400 & Volume & Internal inclusion \\
3 & 60,800 & TBD & TBD \\
4 & $83, C 00$ & TBD & TBD \\
5 & 85,800 & TBD & TBD \\
\hline
\end{tabular}




\subsection{Combustor Rig Testing}

Combustor rig testing was completed in 1991.

\subsection{Regenerator Rig Testing}

Regenerator rig testing was conducted to evaluate new component designs prior to implementation into the AGT101 engine test bed and to assess regenerator system durability and performance. The ATTAP regenerator rig utilized the metallic and ceramic structures of the AGT101 ceramic engine, except for replacement of the rotating group with an adjustable ceramic valve (Figure 29). During 1992 testing, an improved regenerator hot seal was developed, and test bed improvements were developed prior to incorporation into engine testing. Four regenerator rig tests were performed, totalling 187 hours of rig operation.

The regenerator rig was successfully used to test the mechanical design of the improved regenerator hot seal and to demonstrate durability of the hot seal ceramic coating. The improved hot seal mechanical design allows for thermal expansion without buckling. The baseline hot seal coating completed over 100 hours of testing at maximum regenerator inlet temperature without failure or spalling.

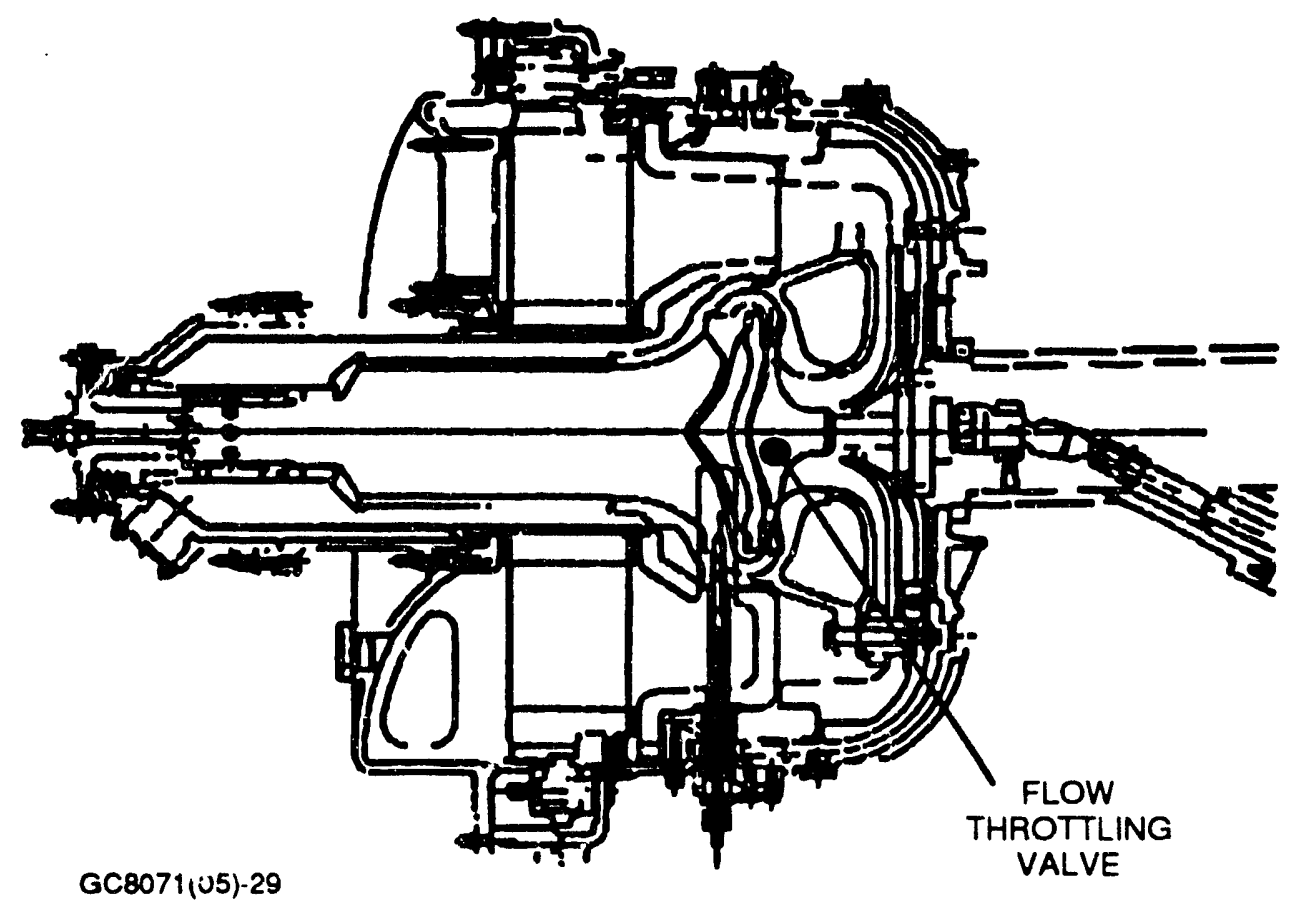

Figure 29. ATTAP Hot Regenerator Test Rig Incorporates A Ceramic Valve Replacing The Rotating Group. 
Validation of two new component designs was also accomplished (discussed in section 3.4). A new combustor cap spring configuration was designed, to ensure adequate cooling of the combustor load springs during engine operation. Rig testing showed incorporation of the new design lowered the spring operating temperature to an acceptable level.

A second component design evaluated was the regenerator core anti-tilt roller. The results of rig tests at five combinations of experimental conditions showed incorporation of the anti-tilt roller had a positive effect on lowering regenerator core tilt and torque values (Figure 30).

\subsection{Structural Proof Testing}

NDE techniques required to assure high reliability of ceramic components have not yet been fully identified or developed and it remains necessary to perform component proof tests to qualify ceramic hardware for use in the ATTAP test bed engine. These tests generally simulate a worst-case stress condition with a 25-percent overstress margin. Information from these proof tests, when combined with results of prior NDE testing, can be valuable in determining critical flaw characteristics and will aid in estahliching specifications for ceramic components.

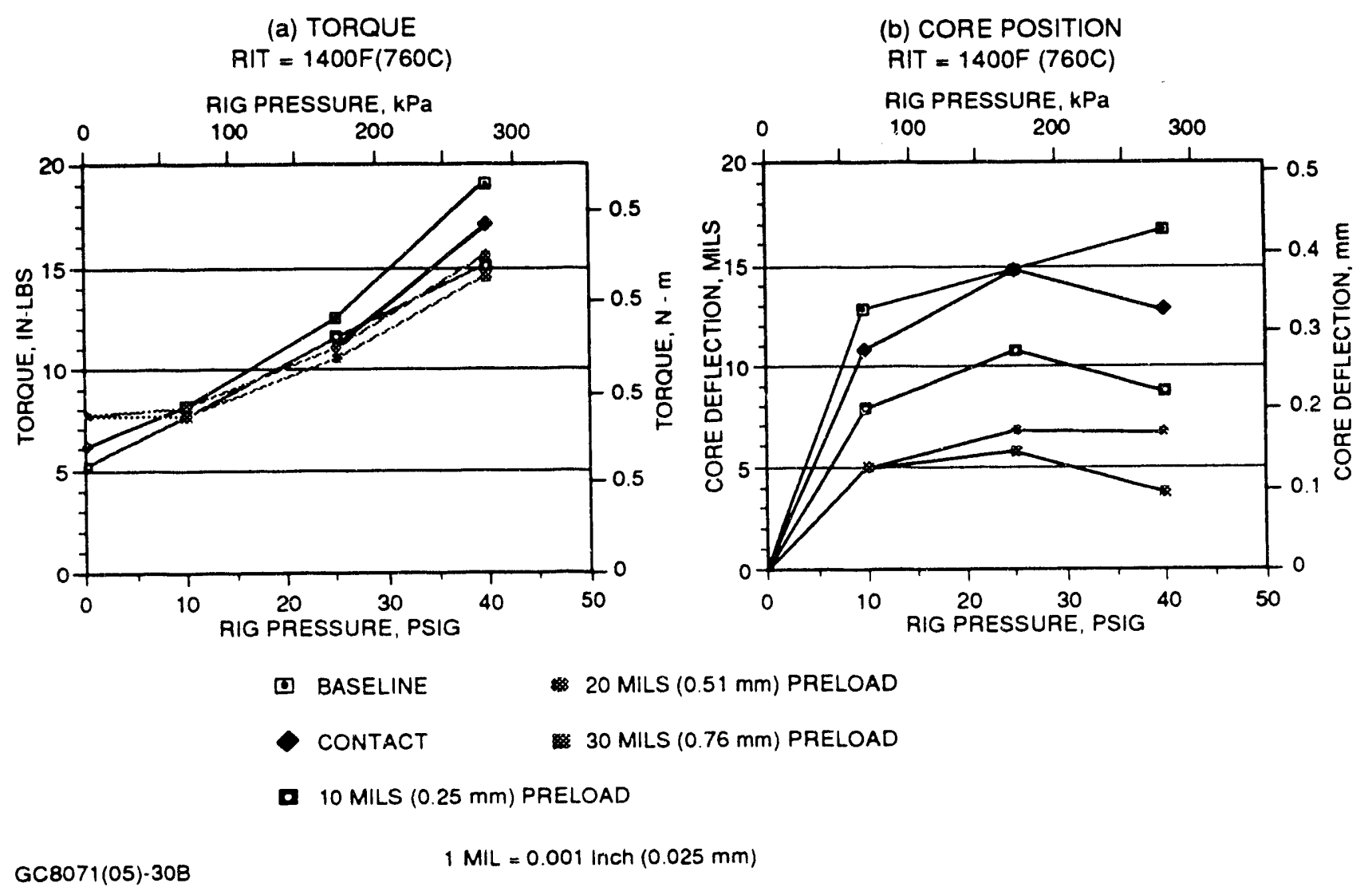

Figure 30. Anti-Tilt Roller Reduced Regenerator Core Tilt And Torque. 


\subsubsection{Thermal Furnace Proof Testing}

Previously, hot combustion flow rigs were utilized to simulate engine operation for the purpose of proof testing/qualifying components. However, because of the expense and difficulties of controlling and calibrating the hot flow rig to simulate engine characteristics, a new proof test method and rig was devised. The primary goals of this new test rig were: 1) to achieve the desired stress fields and maximum stress without an elaborate controller to adjust rig input parameters based on temperature feedback; and 2) to test one component at a time rather than a subassembly, thus providing better control over the test.

Figure 31 shows the basic components of the new furnace proof test rig. The proof test cycle for a given component is a function of the preset furnace temperature, the exposure time, and the insulation configuration. The component is selectively insulated such that the maximum stress distribution during the proof cycle will simulate 125 percent of the actual engine operating stress. Furnace proof cycles and fixtures were developed and utilized for the following AGT101 engine structures:

- Turbine shroud

- Baffle

- Inner Diffuser

- Outer Diffuser.

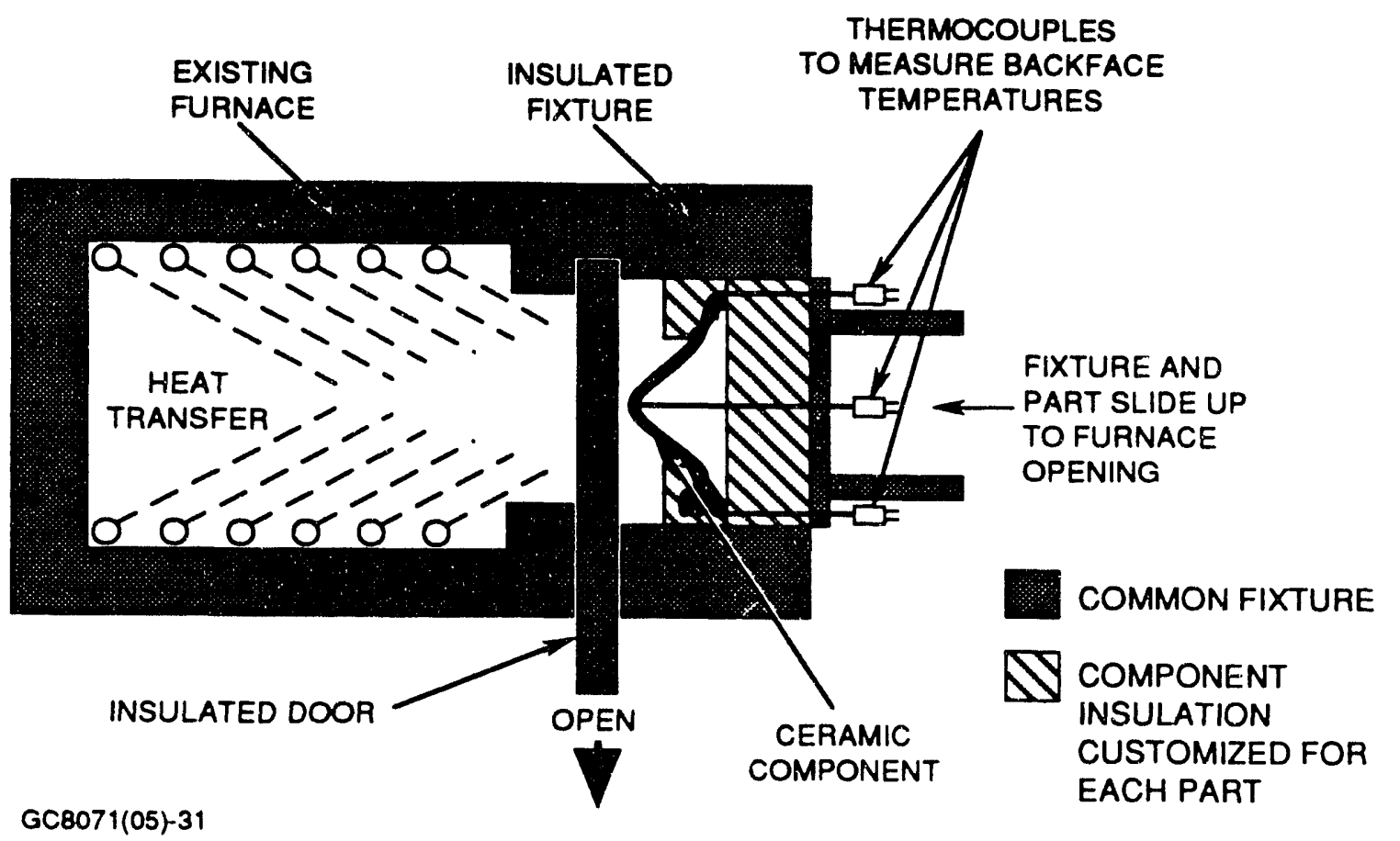

Figure 31. Ceramic Component Furnace Proof Test Fixture Was Designed And Fabricated. 
The furnace proof test method has significant advantages over the use of hot flow rigs. The proof test fabrication effort was significantly reduced, since a single furnace is utilized for all components. The component insulation is the only portion of thie fixture customized for each part, which significantly reduces the costs associated with the proof tests. The furnace proof test is also easily controlled, thus reduring the risk of hardware damage due to rig malfunctions.

A calibration test of the furnace was initially accomplished to characterize the furnace heat flux at various setpoint temperatures. This enabled definition of a stress cycle for each component. Temperature measurements during the initial proof test for each component type verified the accuracy of the analytical predictions (Figure 32).

\subsubsection{Spring Seal Proof Test}

A proof test fixture was designed for the new inner and outer spring seals which are utilized on the impact-resistant configuration of the AGT101 test bed. The fixture was designed to simulate the interface between the seals and the actual engine hardware (Figure 33). The deflection provided by each fixture creates a peak stress of 125 percent of the actual worst-case engine condition. The upper plate bottoms out when the maximum deflection and stress is attained. The bottom plate is adaptable to test both seal configurations.
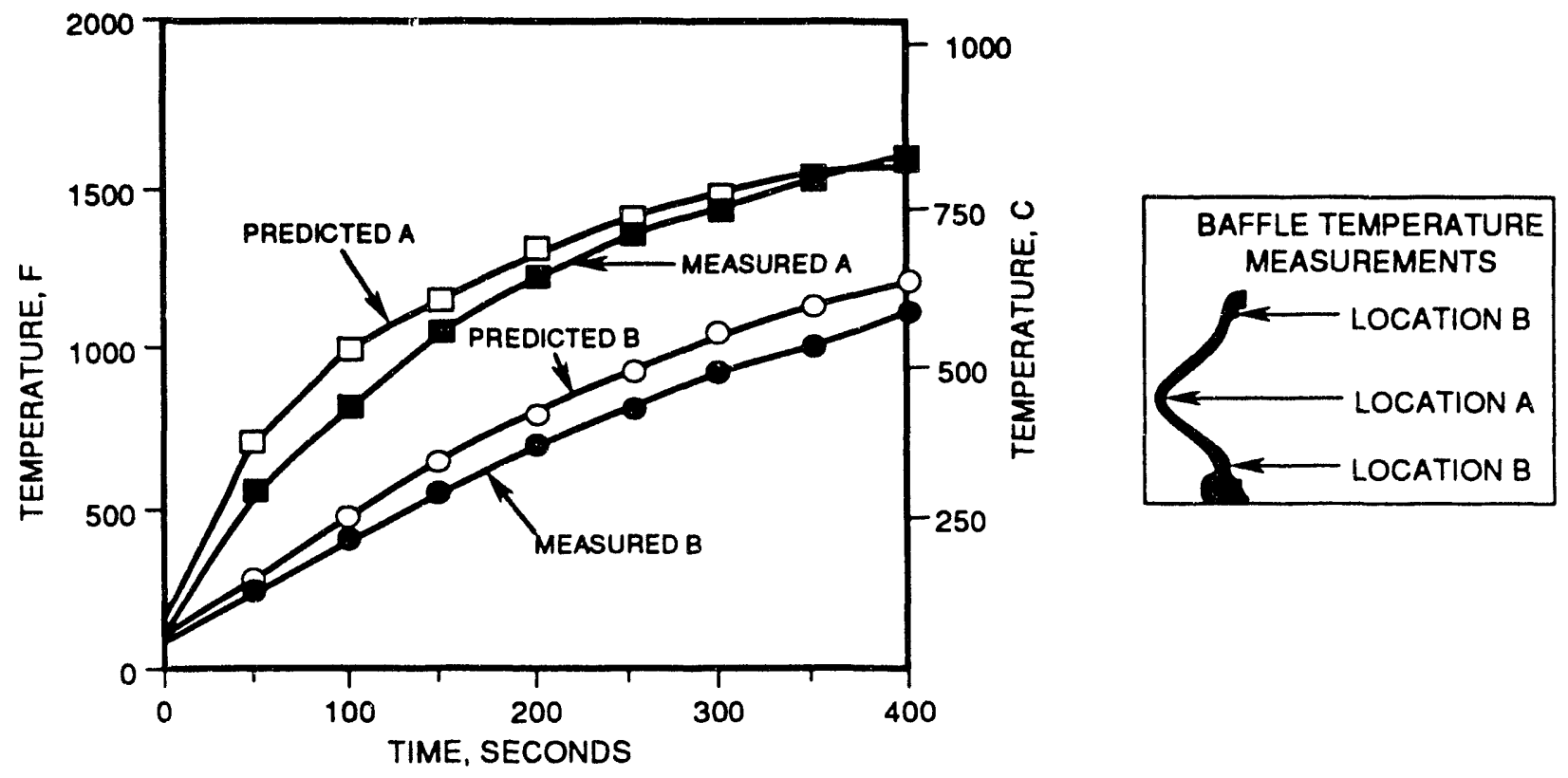

GC8071(05)-32

Figure 32. Component Thermal Proof Test Cycles Were Analytically Defined And Experimentally Verified. 


\section{(a) OUTER SEAL}

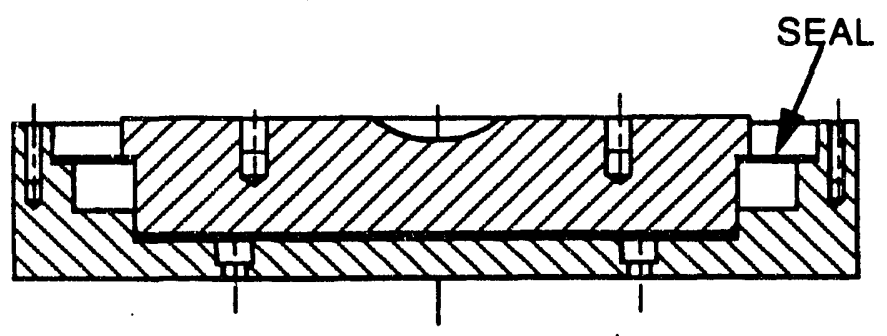

GC8071(05)-33 (b) INNER SEAL

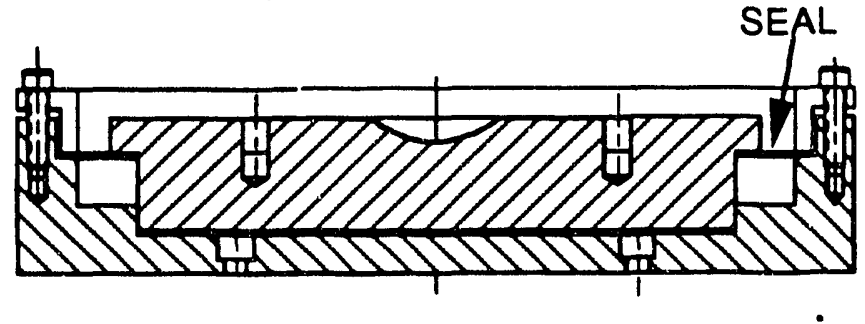

Figure 33. Spring Seal Proof Test Fixtures Simulate Deflections In The AGT101 Engine.

The proof test fixture mounts in an Instron machine which is capable of providing load versus deflection data. The actual load versus deflection data measured closely matches that predicted (Figure 34), thus verifying the stress predictions for the spring, and-the elastic modulus of the silicon nitride material.

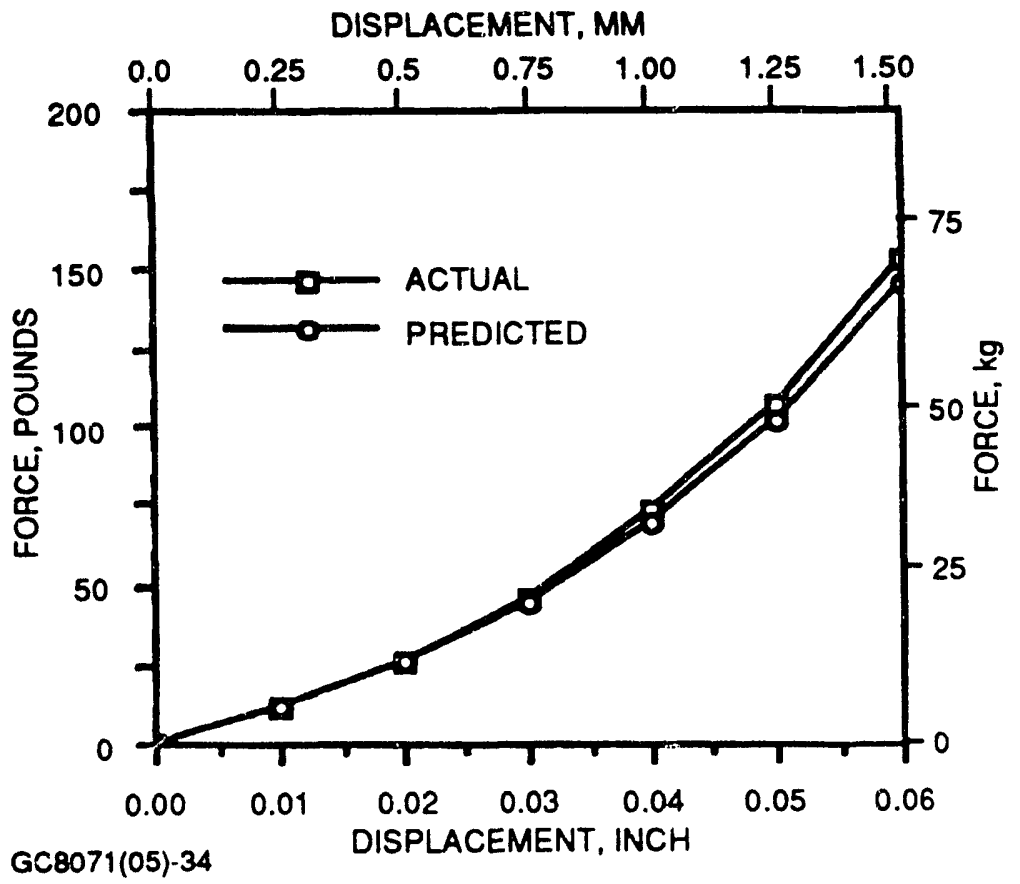

Figure 34. Proof Test Data Verified Spring Seal Stress Predictions. 


\section{$6.52500 \mathrm{~F}(1371 \mathrm{C})$ Test Rig}

The 2500F (1371C) test rig (Figure 35) subjected selected ceramic hardware to high temperatures for extended periods of time, to assess the durability of ceramic stators and other components. The testing was designed to provide information about oxidation, sticking, and interfaces between a variety of materials exposed to the combustor discharge.

The testing during 1992 exposed ceramic silicon nitride stators from two subcontractors to a stator inlet temperature of $2500 \mathrm{~F}$ (1371C) for 50 hours at an average airflow of $9.5 \mathrm{lb} / \mathrm{min}(4.3 \mathrm{~kg} / \mathrm{min})$. After exposure, the stators were then destructively evaluated. NT154 stators from Norton Advanced Ceramics exhibited no signs of deterioration. However, SN-251 stators from Kyocera did show signs of subsurface oxidation. This oxidation caused a reduction in stress rupture life. A small amount of pitting was also observed on the SN-251 stators, an additional sign of material degradation.

\subsection{Turbine Stage Aerodynamic Test Rig}

The ATTAP turbine stage aerodynamic test rig was designed to model the geometry of the AGT101 turbine in an actual engine environment. The requirement for the aerodynamic test rig grew out of the AGT101 ceramic turbine redesign effort. The new impact-resistant turbine was constrained within the existing AGT101 engine envelope and specified operating conditions, and had to provide sufficient power margin to achieve engine development goals. From an aerodynamic standpoint, the target was to verify if the impact-resistant turbine design could achieve performance equivalent to the earlier ceramic radial turbine.

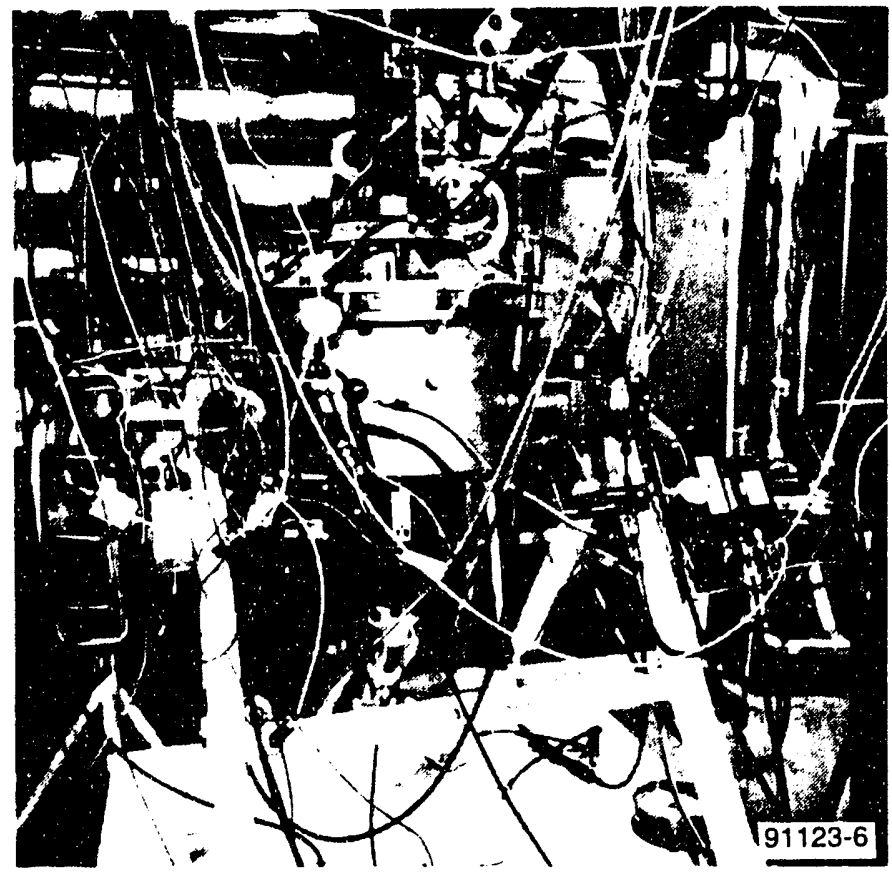

Figure 35. The 2500F (1371C) Test Rig Exposes Ceramic Hardware To High Temperature To Verify Suitability For Engine Testing. 
Several design challenges were addressed during the impact-resistant turbine design process. Limitations were imposed on airfoil thickness and contours, based on ceramic material fabrication requirements. Mechanical considerations provided similar constraints. Loss correlations, based on the earlier radial turbine experience, yielded greater uncertainty for predicted efficiency, when applied to the impact-resistant geometry. The test rig was necessary to confirm the performance of the impactresistant design.

The test rig incorporated instrumentation to monitor the operating points and provide data to obtain turbine corrected performance parameters and diagnose component flowfield behavior. Precautions were taken in the rig design to ensure safe mechanical operation over the engine cycle operating range. The rig layout is shown in Figure 36.

A performance map of the impact-resistant turbine, derived from the rig test results, is shown in Figure 37. The map reflects trends similar to other radial turbine maps. However, the design point efficiency measured 2.8 points below the AGT101 radial turbine design. Diagnostic measurements indicated sources of additional loss included a flow separation in the rotor, and strong vortices through the vane passages. Also, the nozzle throat was sized too large, which impaired performance due to higher flow through the components. The rig testing did verify that the impact-resistant turbine produced sufficient power to conduct the engine development program.

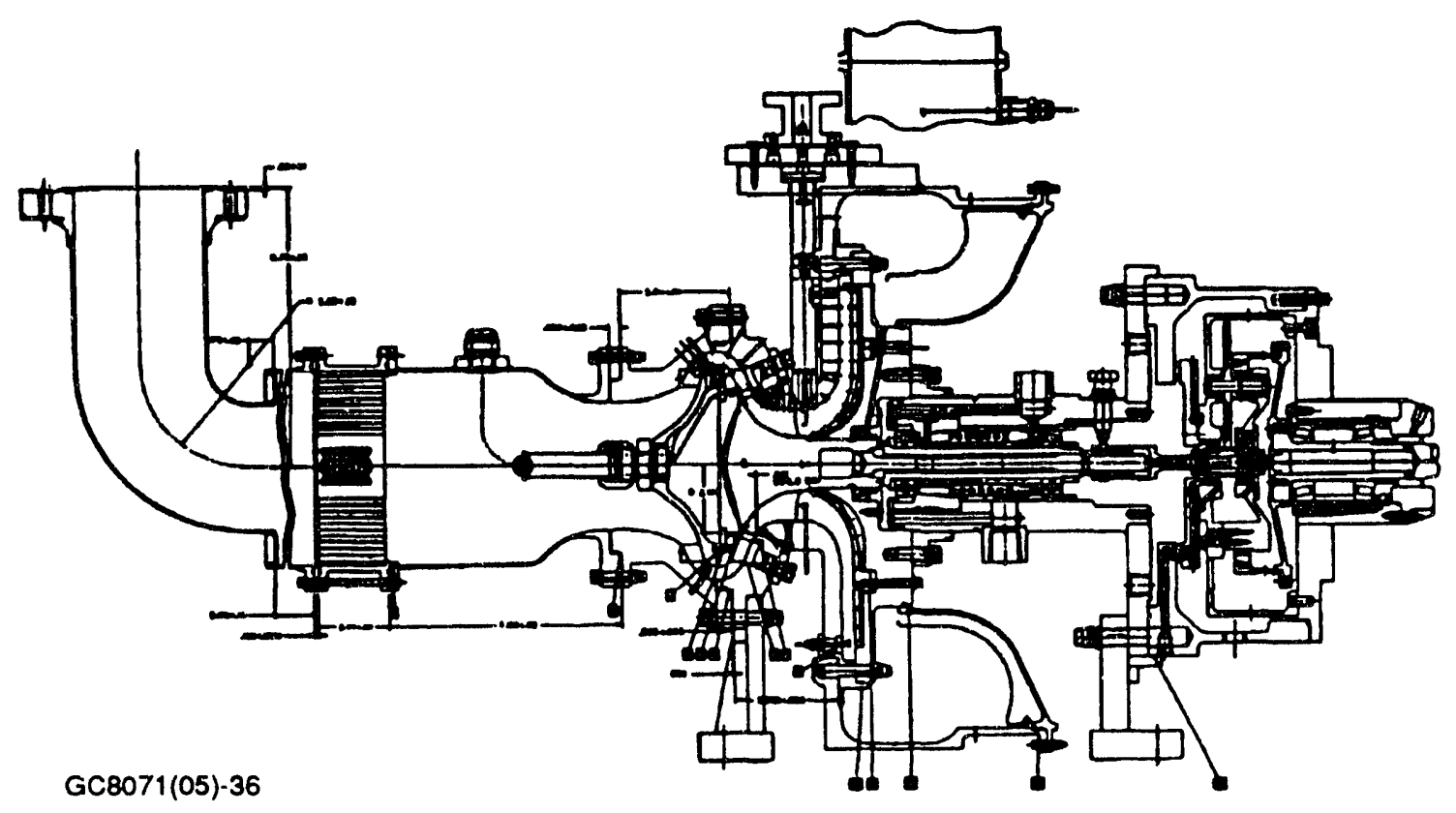

Figure 36. ATTAP Turbine Stage Aerodynamic Test Rig Layout. 


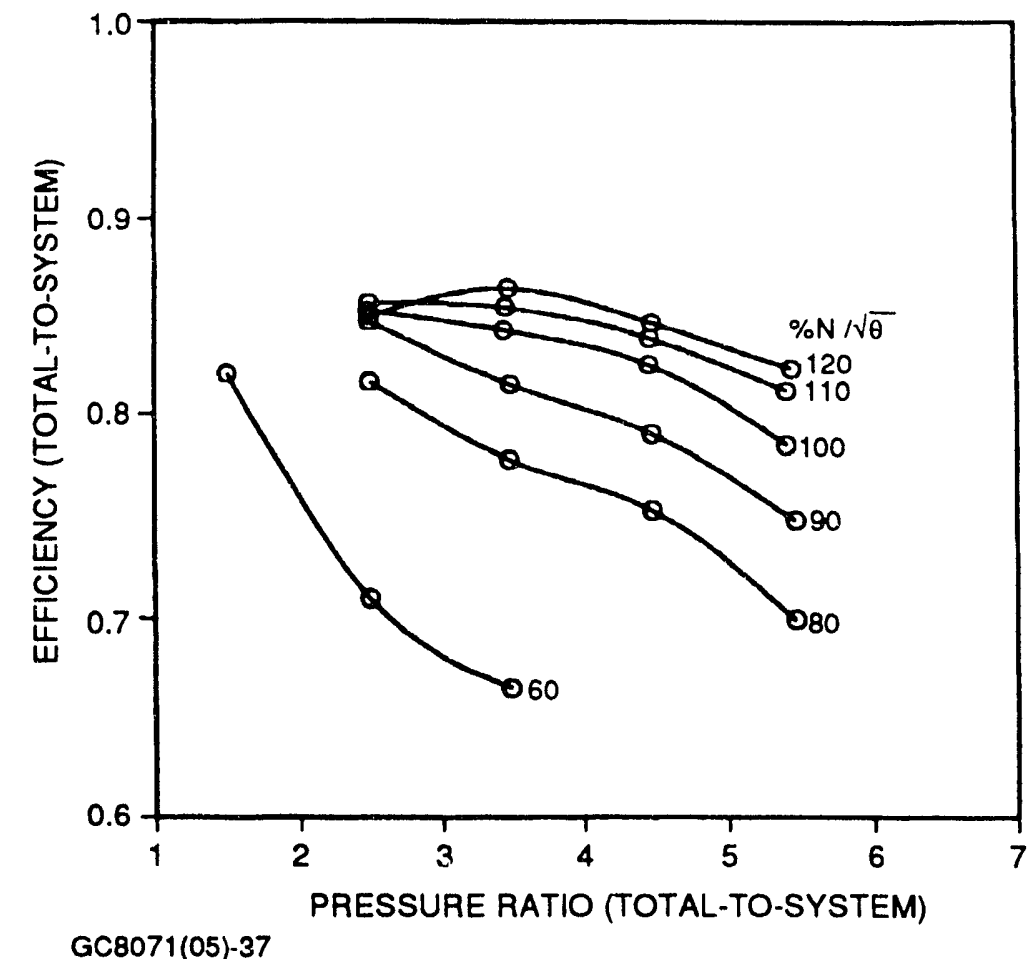

Figure 37. AGT101 Impact-Resistant Turbine Stage Performance Map Was Derived From Aerodynamic Rig Test Results.

The diagnostic rig test data agreed with the results of 3-D viscous analyses performed on the components following the detailed designs. The code used for the analysis was calibrated for the impact-resistant design features for the performance predictions with the rig test data, and the engine performance model was updated with the measured maps for the impact-resitant turbine. The rig test results will allow subsequent designs in this turbine class to benefit from the 3-D viscous analysis.

While the impact-resistant turbine efficiency measured below the design intent, the rig test program provided a basis for potential improvement, although additional test data would be required to verify the applied loss corrections to determine if the aerodynamic goals of the AGT101 radial turbine performance are achievable by the impact-resistant design. 


\subsection{ENGINE TEST BED TRIALS}

Engine test goals successfully accomplished in 1992 included proof testing/qualifying three ceramic impact-resistant turbine rotors (two NT154 and one GN-10 rotors) for use in the all-ceramic AGT101 test bed, and completion of Milestone 4: operation of the AGT101 test bed at the maximum Reference Powertrain Design (RPD) conditions of 1800F (982C) regenerator inlet temperature (RIT) and $90,000 \mathrm{rpm}$.

Milestone 5, the planned 100-hour endurance demonstration, was partially completed during 1992. Thirty-eight hours of operation at turbine inlet temperatures exceeding 2200F (1204C) were accomplished. Testing was terminated due to premature failure of the lithium aluminosilicate (LAS) ceramic flow separator housing during Tests $23 \mathrm{~A}$ and $\mathrm{B}$.

Eleven AGT101 engine builds were accomplished during 1992; the test results are listed in Table 8. Total engine test hours during the ATTAP program are summarized in Table 9.

TABLE 8. 1992 ATTAP ENGINE BUILDS AND TEST RESULTS

\begin{tabular}{|c|c|c|c|c|}
\hline $\begin{array}{c}\text { Build } \\
\text { Number }\end{array}$ & S/N & Configuration & $\begin{array}{c}\text { Operating } \\
\text { Hours }\end{array}$ & Starts \\
\hline 53 & 001 & Metal with ceramic rotor & 1.66 & 2 \\
\hline 54 & 001 & Metal with ceramic rotor & 0.75 & 3 \\
\hline 55 & 001 & Metal with ceramic rotor & 0.88 & 2 \\
\hline $21 \mathrm{~A}$ & $002 \mathrm{C}$ & All ceramic & 1.70 & 2 \\
\hline $21 \mathrm{~B}$ & $002 \mathrm{C}$ & All ceramic & 4.10 & 9 \\
\hline $21 \mathrm{C}$ & $002 \mathrm{C}$ & All ceramic & 3.70 & 1 \\
\hline 22 & $002 \mathrm{C}$ & All ceramic & 0 & 0 \\
\hline 8 & $004 \mathrm{C}$ & All ceramic & 1.38 & 2 \\
\hline 9 & $004 \mathrm{C}$ & All ceramic & 3.28 & 1 \\
\hline $23 \mathrm{~A}$ & $002 \mathrm{C}$ & All ceramic & 22 & 7 \\
\hline $23 \mathrm{~B}$ & $002 \mathrm{C}$ & All ceramic & 18.3 & 5 \\
\hline
\end{tabular}

TABLE 9. ATTAP ENGINE TEST STATUS

\begin{tabular}{|l|c|c|c|}
\hline \multicolumn{1}{|c|}{ Configuration } & Builds & Starts & Operating Hours \\
\hline Metal & 5 & 97 & 38.4 \\
\hline Metal With Ceramic Rotor & 6 & 15 & 5.1 \\
\hline All Ceramic & 9 & 107 & 67.3 \\
\hline
\end{tabular}




\subsection{Metal Engine Testing}

The purpose of the metal AGT101 engine tests was to qualify ceramic impact-resistant turbine rotors for use in the all-ceramic engine tests. The test cycle closely simulated the first transient of the ATTAP Milestone 5 endurance cycle. Running the metal engine through this cycle exposed the ceramic rotor to the thermal-mechanical loadings experienced in the all-ceramic engine testing.

The metal AGT101 test engine was assembled with metal impact-resistant flow components and a ceramic impact-resistant turbine rotor. The engine assemblies also included a ceramic regenerator core and a ceramic stepped-pilot combustor.

The metal AGT101 engine builds were operateci through a range of speeds from 60,000 to 90,000 rpm with a turbine inlet temperature (TIT) of $1650 \mathrm{~F}$ ( $899 \mathrm{C}$ ), the maximum conditions for the metal engine configurations, to ensure proper rotor dynamics. The thermal transient rotor qualification test cycle consisted of an acceleration from 60,000 to $90,000 \mathrm{rpm}$ in approximately 10 seconds, while simultaneously loading the engine to the maximum TIT.

Three successful tests were completed in 1992. The test results are summarized in Table 10. The metal AGT101 impact-resistant engine configuration ran a total of 3.29 hours with 7 starts. Total operating time on the metal engine including both the radial and impact-resistant configurations was 166.63 hours with 401 starts.

TABLE 10. METAL AGT101 ENGINE TEST SUMMARY

\begin{tabular}{|c|c|c|c|}
\hline Build No. & Time, Hours & Starts & $\begin{array}{c}\text { Ceramic Rotor } \\
\text { Material }\end{array}$ \\
\hline 53 & 1.66 & 2 & NTC NT154 \\
\hline 54 & 0.75 & 3 & NTC NT154 \\
\hline 55 & 0.88 & 2 & GCC GN-10 \\
\hline
\end{tabular}

\subsection{All-Ceramic Engine Testing}

During 1992, eight ceramic engine tests were conducted. All testing was directed toward completing Milestones 4 and 5 . The results of the testing are discussed below. 


\subsubsection{Milestone 4 Testing}

Milestone 4 was a demonstration of the ceramic materials and components reliability at the maximum Reference Powertrain Design (RPD) conditions for the impact-resistant ceramic AGT101 engine. The RPD conditions consisted of a speed of $90,000 \mathrm{rpm}$ and a regenerator inlet temperature of $1800 \mathrm{~F}(982 \mathrm{C})$.

To complete Milestone 4, the AGT101 test bed engine was required to achieve a variety of operating conditions to provide data for the evaluation of:

- Steady-state emissions

- Cycle state point conditions at idle, $60,70,80,90,95$, and 100 percent speed

- Engine torque vs. speed

- Power vs. speed

- Installed component efficiencies.

This testing was accomplished with Build 21 of the S/N 002C engine. Build 21 was actually a compilation of three builds. The accomplishments of the three builds are listed in Table 11.

TABLE 11. AGT101 ENGINE S/N 002C TEST SUMMARY

\begin{tabular}{|c|c|c|c|}
\hline Build No. & Time, Hours & Starts & $\begin{array}{c}\text { Maximum Measured } \\
\text { Power, hp }\end{array}$ \\
\hline \hline 21A & 1.7 & 2 & 25.0 \\
\hline 21B & 4.1 & 9 & 6.0 \\
\hline 21C & 3.7 & 1 & 28.9 \\
\hline
\end{tabular}

Testing of Builds $21 \mathrm{~A}$ and $21 \mathrm{~B}$ was terminated due to a damaged flow separator housing (FSH) and high regenerator core torque, respectively. The final rebuild (Build 21C) completed Milestone 4 testing. An endurance run was attempted at the conclusion of Milestone 4, but was terminated due to fuel supply difficulties. The endurance run lasted 1.5 hours at a turbine inlet temperature of $2315 \mathrm{~F}$ $(1268 C)$ and $90,000 \mathrm{rpm}$.

Test data was successfully acquired at $62,000,70,000,80,000,85,000$, and 90,000 rpm, corresponding to $70,80,90,95$, and 100 percent speed respectively. Data was not acquired at idle or 60 percent speed due to the inability to stabilize the engine at these conditions. Test data is listed in Table 12 for the cycle state point conditions shown in Figure 38. Installed component efficiencies are also listed in Table 12. 
TABLE 12. ATTAP MILESTONE 4- -AGT101 RPD ENGINE TEST DATA

\begin{tabular}{|c|c|c|c|c|c|c|}
\hline \multirow[b]{2}{*}{ Parameter } & \multirow[b]{2}{*}{ Unit } & \multicolumn{5}{|c|}{ Engine Speed, rpm } \\
\hline & & 62,217 & 70,602 & 79,765 & 85,071 & 90,005 \\
\hline T1.0 & $\begin{array}{l}\mathrm{F} \\
\text { (C) }\end{array}$ & $\begin{array}{c}115 \\
(46.1)\end{array}$ & $\begin{array}{c}125 \\
(51.7)\end{array}$ & $\begin{array}{c}121 \\
(49.4)\end{array}$ & $\begin{array}{c}122 \\
(50.0)\end{array}$ & $\begin{array}{c}98.14 \\
(36.74)\end{array}$ \\
\hline $\mathrm{T} 2.1$ & $\begin{array}{l}\mathrm{F} \\
\text { (C) }\end{array}$ & $\begin{array}{c}97 \\
(36.1)\end{array}$ & $\begin{array}{c}97 \\
(36.1)\end{array}$ & $\begin{array}{c}97 \\
(36.1)\end{array}$ & $\begin{array}{c}103 \\
(39.4)\end{array}$ & $\begin{array}{c}135 \\
(57.2)\end{array}$ \\
\hline T3.0 & $\begin{array}{c}\mathrm{F} \\
\text { (C) }\end{array}$ & $\begin{array}{c}256 \\
(124)\end{array}$ & $\begin{array}{c}303 \\
(151)\end{array}$ & $\begin{array}{c}359 \\
(182)\end{array}$ & $\begin{array}{c}396 \\
(202)\end{array}$ & $\begin{array}{c}456 \\
(236)\end{array}$ \\
\hline T3.1 & $\begin{array}{l}\mathrm{F} \\
\text { (C) }\end{array}$ & $\begin{array}{c}314 \\
(157) \\
\end{array}$ & $\begin{array}{c}336 \\
(169) \\
\end{array}$ & $\begin{array}{c}370 \\
(188) \\
\end{array}$ & $\begin{array}{c}408 \\
(209) \\
\end{array}$ & $\begin{array}{c}482 \\
(250) \\
\end{array}$ \\
\hline T3.8 & $\begin{array}{l}\mathrm{F} \\
\text { (C) }\end{array}$ & $\begin{array}{l}\text { N/A } \\
-\end{array}$ & N/A & $\begin{array}{c}\text { N/A } \\
-\end{array}$ & N/A & $\begin{array}{l}1753 \\
(956) \text {. }\end{array}$ \\
\hline T4.1 & $\begin{array}{l}F \\
\text { (C) }\end{array}$ & $\begin{array}{c}2098 \\
(1148)\end{array}$ & $\begin{array}{c}2172 \\
(1189)\end{array}$ & $\begin{array}{c}2281 \\
(1249)\end{array}$ & $\begin{array}{c}2336 \\
(1280)\end{array}$ & $\begin{array}{c}2297 \\
(1258)\end{array}$ \\
\hline T5.1 & $\begin{array}{l}F \\
\text { (C) }\end{array}$ & $\begin{array}{l}1793 \\
(978) \\
\end{array}$ & $\begin{array}{l}1808 \\
(987) \\
\end{array}$ & $\begin{array}{l}1824 \\
(996) \\
\end{array}$ & $\begin{array}{c}1835 \\
(1002) \\
\end{array}$ & $\begin{array}{l}1802 \\
(983) \\
\end{array}$ \\
\hline T6.0 & $\begin{array}{l}\mathrm{F} \\
\text { (C) }\end{array}$ & $\begin{array}{c}495 \\
(257) \\
\end{array}$ & $\begin{array}{c}531 \\
(277) \\
\end{array}$ & $\begin{array}{c}584 \\
(307)\end{array}$ & $\begin{array}{l}627 \\
(331)\end{array}$ & $\begin{array}{l}681 \\
(361)\end{array}$ \\
\hline P1.0 & $\begin{array}{r}\mathrm{psia} \\
(\mathrm{kPa})\end{array}$ & $\begin{array}{r}14.12 \\
(97.35) \\
\end{array}$ & $\begin{array}{c}14.12 \\
(97.35) \\
\end{array}$ & $\begin{array}{c}14.12 \\
(97.35) \\
\end{array}$ & $\begin{array}{c}14.12 \\
(97.35) \\
\end{array}$ & $\begin{array}{c}14.04 \\
(96.81) \\
\end{array}$ \\
\hline P2.1 & $\begin{array}{r}\mathrm{psia} \\
(\mathrm{kPa})\end{array}$ & $\begin{array}{c}14.19 \\
(97.84)\end{array}$ & $\begin{array}{r}14.21 \\
-(97.98) \\
\end{array}$ & $\begin{array}{c}14.25 \\
(98.25) \\
\end{array}$ & $\begin{array}{c}14.26 \\
(98.32) \\
\end{array}$ & $\begin{array}{c}13.90 \\
(95.84) \\
\end{array}$ \\
\hline P3.0 & $\begin{array}{r}\mathrm{psia} \\
(\mathrm{kPa})\end{array}$ & $\begin{array}{c}26.55 \\
(183.1)\end{array}$ & $\begin{array}{l}31.31 \\
(215.9)\end{array}$ & $\begin{array}{c}38.38 \\
(264.6)\end{array}$ & $\begin{array}{c}43.14 \\
(297.4)\end{array}$ & $\begin{array}{c}46.65 \\
(321.6)\end{array}$ \\
\hline P3.1 & $\begin{array}{r}\text { psia } \\
(\mathrm{kPa})\end{array}$ & $\begin{array}{c}25.93 \\
(178.8) \\
\end{array}$ & $\begin{array}{l}30.87 \\
(212.8) \\
\end{array}$ & $\begin{array}{c}37.90 \\
(261.3)\end{array}$ & $\begin{array}{c}42.53 \\
(293.2) \\
\end{array}$ & $\begin{array}{c}46.27 \\
(319.0) \\
\end{array}$ \\
\hline P3.8 & $\begin{array}{r}\text { psia } \\
(\mathrm{kPa})\end{array}$ & $\begin{array}{c}24.78 \\
(170.9)\end{array}$ & $\begin{array}{c}29.36 \\
(202.4)\end{array}$ & $\begin{array}{c}36.02 \\
(248.3)\end{array}$ & $\begin{array}{c}40.36 \\
(278.3) \\
\end{array}$ & $\begin{array}{c}43.71 \\
(301.4)\end{array}$ \\
\hline P5.1 & $\begin{array}{r}\mathrm{psia} \\
(\mathrm{kPa})\end{array}$ & $\begin{array}{c}14.79 \\
(102.0) \\
\end{array}$ & $\begin{array}{c}14.90 \\
(102.7) \\
\end{array}$ & $\begin{array}{c}15.13 \\
(104.3) \\
\end{array}$ & $\begin{array}{c}15.24 \\
(105.1) \\
\end{array}$ & $\begin{array}{c}15.25 \\
(105.1) \\
\end{array}$ \\
\hline Power & $\begin{array}{c}\mathrm{hp} \\
(\mathrm{kW})\end{array}$ & $\begin{array}{l}3.5 \\
(2.6) \\
\end{array}$ & $\begin{array}{c}8.6 \\
(6.4) \\
\end{array}$ & $\begin{array}{c}17.9 \\
(13.3)\end{array}$ & $\begin{array}{c}25.3 \\
(18.9) \\
\end{array}$ & $\begin{array}{c}28.8 \\
(21.5) \\
\end{array}$ \\
\hline Corrected Speed & $\mathrm{rpm}$ & 60,067 & 68,150 & 77,091 & 81,700 & 86,793 \\
\hline Corrected Aerodynamic Power & $\begin{array}{c}\mathrm{hp} \\
(\mathrm{kW})\end{array}$ & $\begin{array}{c}7.61 \\
(5.67) \\
\end{array}$ & $\begin{array}{c}14.32 \\
(10.68)\end{array}$ & $\begin{array}{c}25.6 \\
(19.09)\end{array}$ & $\begin{array}{c}34.4 \\
(25.65) \\
\end{array}$ & $\begin{array}{c}39.51 \\
(29.46)\end{array}$ \\
\hline Corrected Aerodynamic Torque & $\begin{array}{l}\mathrm{ft}-\mathrm{lb} \\
(\mathrm{N}-\mathrm{m})\end{array}$ & $\begin{array}{c}0.643 \\
(0.872) \\
\end{array}$ & $\begin{array}{c}1.065 \\
(1.444) \\
\end{array}$ & $\begin{array}{c}1.685 \\
(2.285) \\
\end{array}$ & $\begin{array}{c}2.124 \\
(2.880) \\
\end{array}$ & $\begin{array}{c}2.306 \\
(3.127) \\
\end{array}$ \\
\hline Specific Fuel Consumption (SFC) & $\begin{array}{c}\mathrm{lb} / \mathrm{hp}-\mathrm{hr} \\
(\mathrm{kg} / \mathrm{kW}-\mathrm{hr})\end{array}$ & $\begin{array}{c}5.626 \\
(3.422) \\
\end{array}$ & $\begin{array}{c}2.749 \\
(1.672)\end{array}$ & $\begin{array}{c}1.941 \\
(1.181)\end{array}$ & $\begin{array}{c}1.672 \\
(1.017)\end{array}$ & $\begin{array}{c}1.526 \\
(0.928)\end{array}$ \\
\hline Compressor Efficiency & Percent & 69.89 & 70.13 & 69.97 & 71.23 & 69.56 \\
\hline Turbine Efficiency & Percent & 84.66 & 83.52 & 80.66 & 81.86 & 82.92 \\
\hline Regenerator Effectiveness & - & 0.848 & 0.865 & 0.880 & 0.864 & 0.884 \\
\hline
\end{tabular}




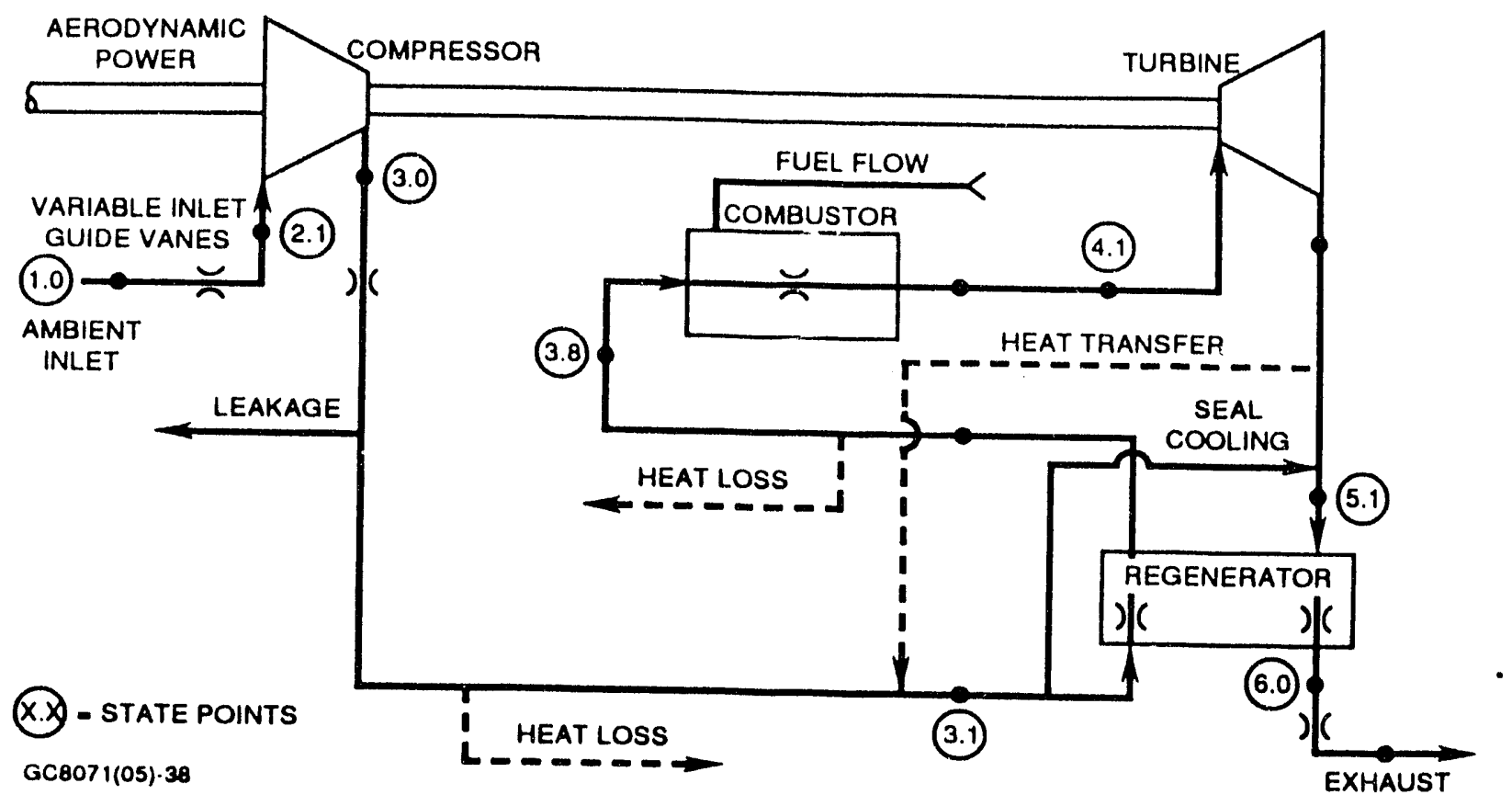

Figure 38. AGT101 Engine Cycle State Points.

Emissions sample test data from the Milestone 4 testing is shown in Figure 39, in parts per million volume (ppm-vol) versus engine speed for nitrous oxide (NOx), carbon monoxide (CO), and unburned hydrocarbons (UHC). In Figure 40, NOx, CO, and UHC emissions are plotted against the emissions index (EI), defined as pounds of specific pollutant per 1000 pounds of fuel burned. In this test, the fuel was commercial ethanol (90 percent ethanol with 10 percent impurities.) A comparison of the lower heating values (LHVs) for ethanol, 11,522 Btu/lb $(26.8 \mathrm{~kJ} / \mathrm{kg})$, versus $18,272 \mathrm{Btu} / \mathrm{lb}(42.5$ $\mathrm{kJ} / \mathrm{kg}$ ) for Diese! Fuel No. 2 (DF-2) indicates there will be a difference in emissions and fuel economy for these two automotive fuels. Further work would be required to optimize AGT101 engine performance for DF-2 fuel.

General operating trends for the AGT101 test bed engine indicate combustor inlet temperature and pressure increase as speed increases. This results in an increase in NOx emissions, while CO and UHC decrease with increased engine speed. The plots shown in Figures 39 and 40 are for fairly low engine load levels, with a fair degree of engine load leakage. Both conditions cause variations in fuel flow, affecting emissions and resulting in some scatter in the data. Regarding air leakage, regenerator seal leakage varies from 20 to 35 percent of compressor flcw, depending upon engine speed.

Specific fuel consumption (SFC) reached a maximum of $5.6 \mathrm{lb} / \mathrm{hp}-\mathrm{hr}(3.4 \mathrm{~kg} / \mathrm{kW}-\mathrm{hr})$ at the lowest state point condition. Minimum SFC was $1.5 \mathrm{lb} / \mathrm{hp}-\mathrm{hr}(0.91 \mathrm{~kg} / \mathrm{kW}-\mathrm{hr})$ at $90,000 \mathrm{rpm}$. As plotted in Figure 41, SFC initially drops sharply and then begins to level at higher speeds. 


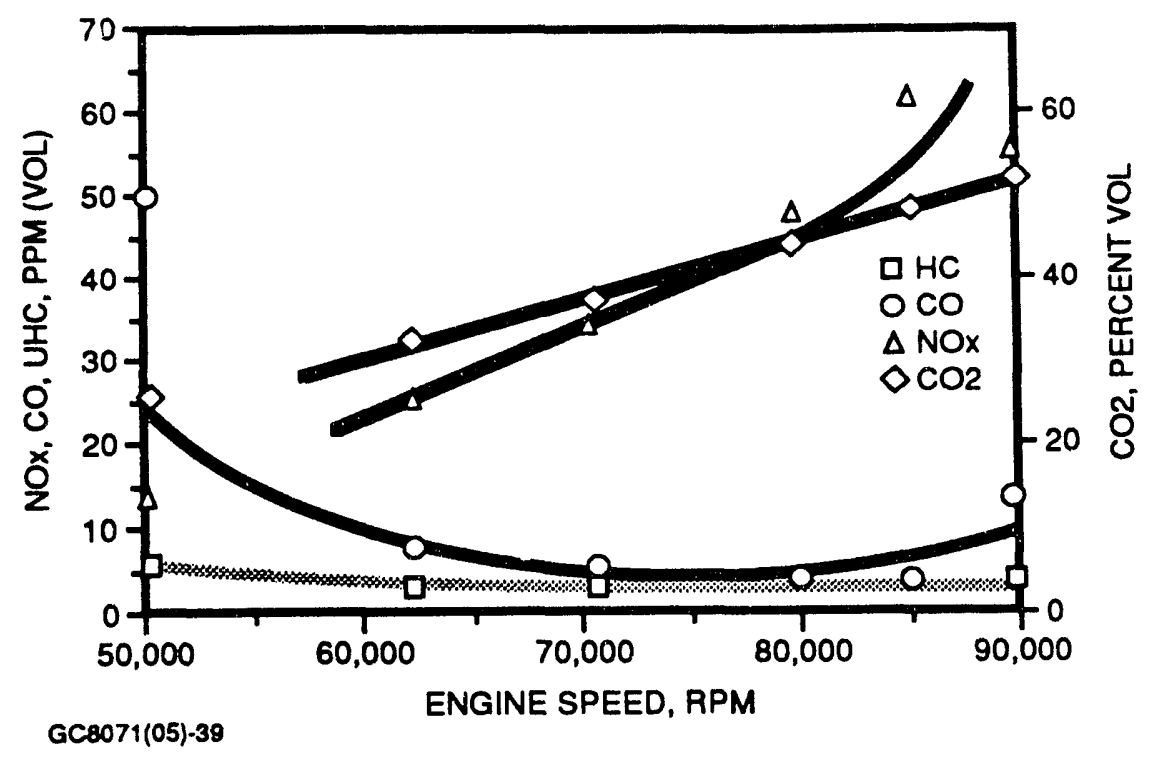

Figure 39. Milestone 4 Emissions Volume Versus Engine Speed (Commercial Ethanol Fuel).

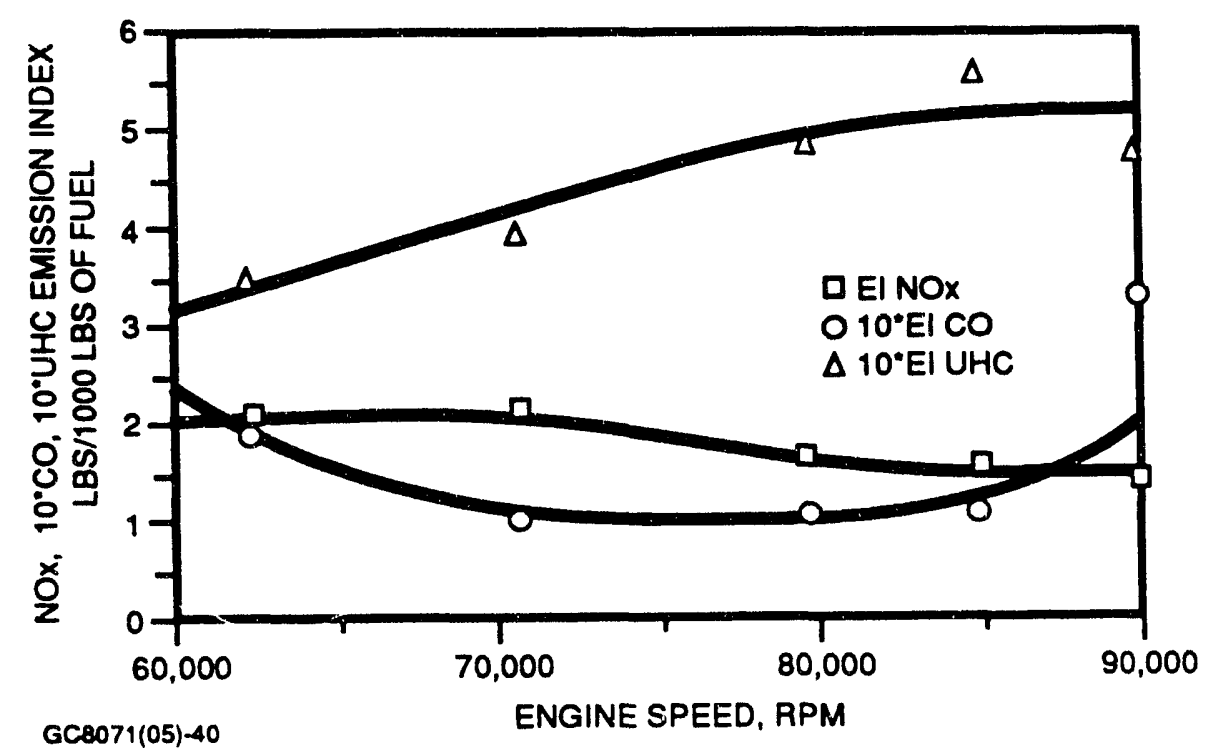

Figure 40. Milestone 4 En issions Index (EI) Versus Engine Speed (Commercial Ethanol Fuel).

Power vs. speed plots were also generated for Build 21. The data is plotted in Figures 42 and 43 , in terms of corrected aerodynamic horsepower and corrected aerodynamic torque, respectively. Corrected aerodynamic horsepower and torque account for mechanical losses such as gearbox and bearings while corrected engine sfeed normalizes speed to standard day conditions. 


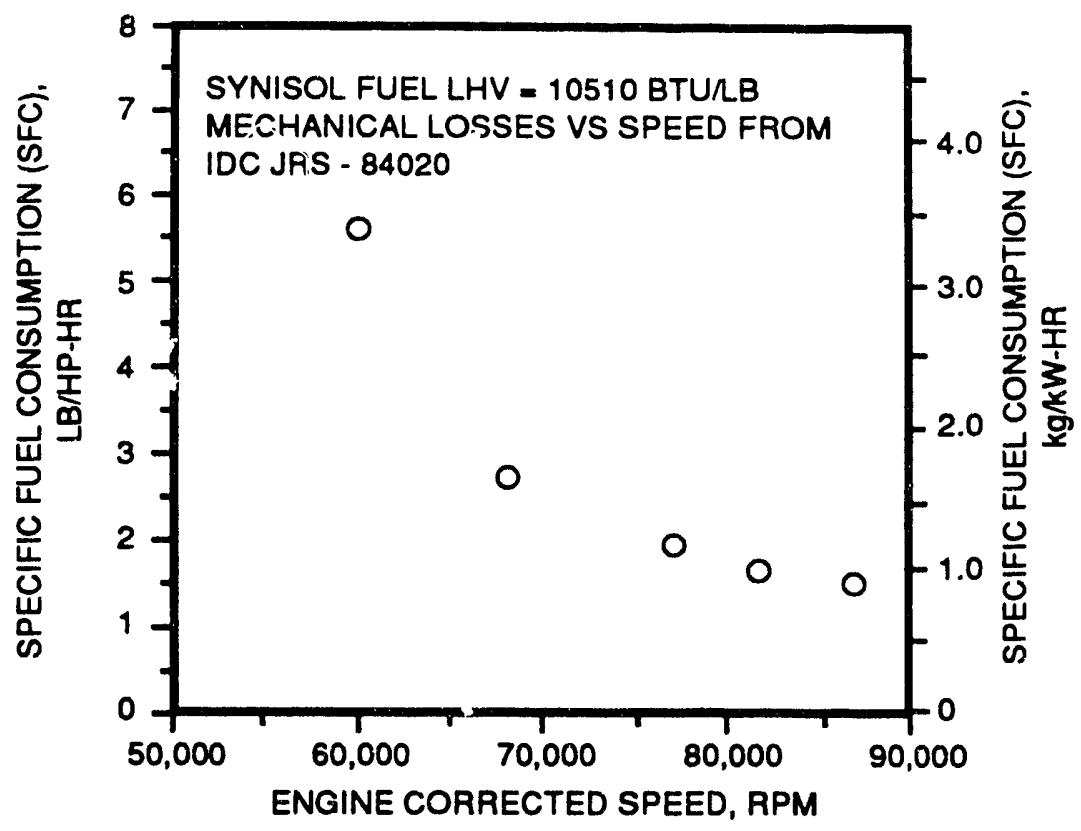

GC8071(05)-41

Figure 41. Milestone 4 Specific Fuel Consumption.

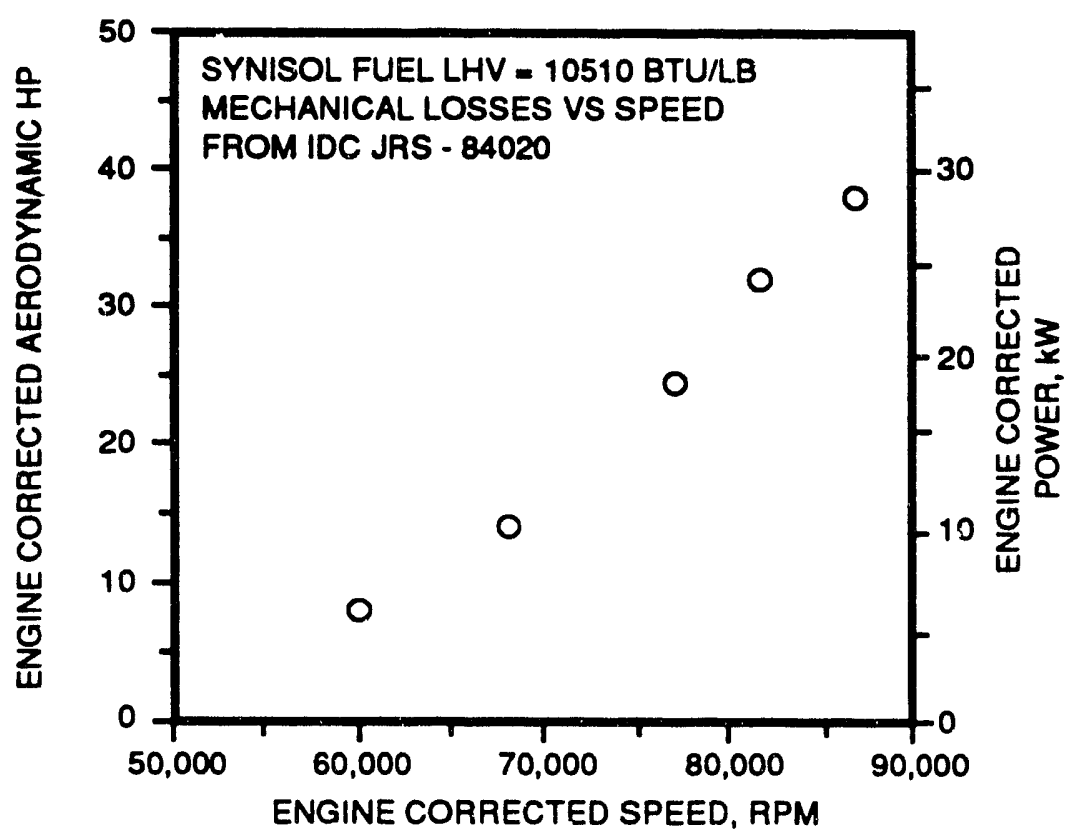

GC8071(05)-42

Figure 42. Milestone 4 Corrected Aerodynamic Horsepower. 


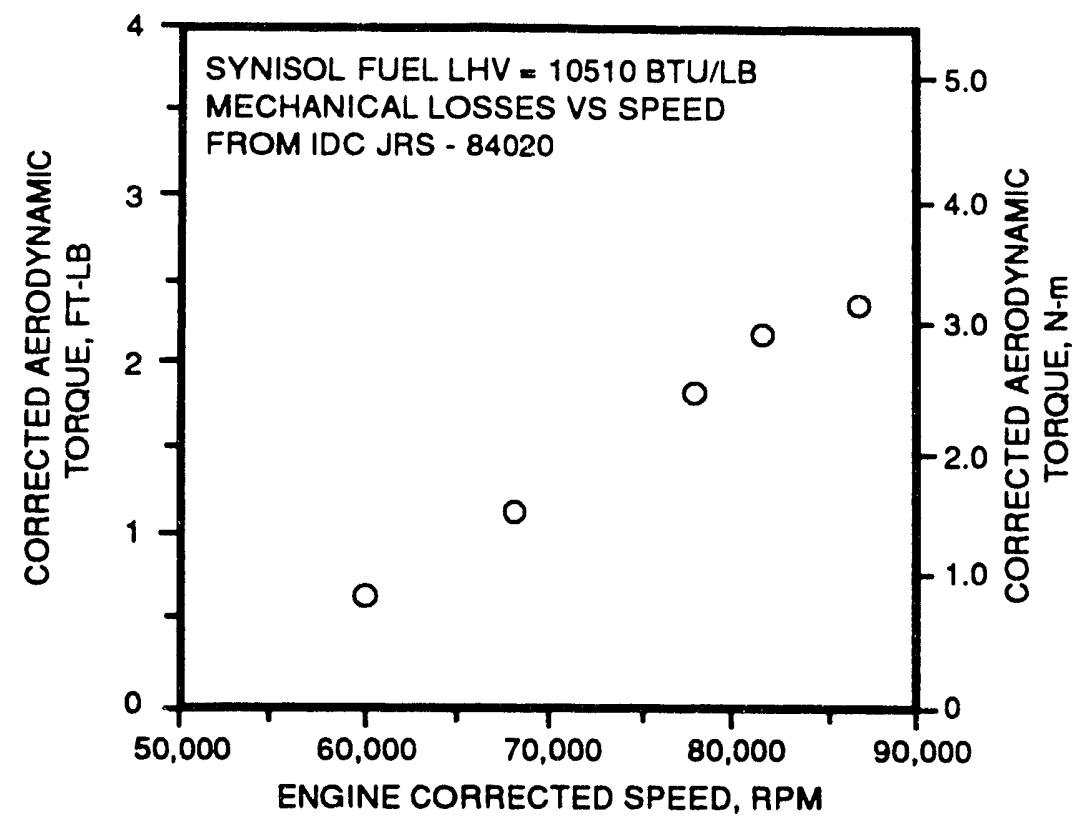

GC8071(05)-43

Figure 43. Milestone 4 Corrected Aerodynamic Torque.

\subsubsection{Milestone 5 Testing}

After the completion of Milestone 4, all efforts were focused on the Milestone 5 endurance test. Two engines were used in this endeavor; $S / N s 002 \mathrm{C}$ and $004 \mathrm{C}$. The Milestone 5 objective was to run the engine for a total of 100 hours; 50 hours to be run at approximately $80,000 \mathrm{rpm}$ with a turbine inlet temperature of $2200 \mathrm{~F}$ (1204C), and an additional 50 hours run at the maximum operating conditions of $90,000 \mathrm{rpm}$ and a regenerator inlet temperature of $1800 \mathrm{~F}(982 \mathrm{C})$.

Build 8 of the S/N 004C engine was the first to attempt this goal. The engine was started and slowly brought up to $90,000 \mathrm{rpm}$ to check rotor dynamics. Afterwards, the engine was brought back to $80,000 \mathrm{rpm}$ and loaded with the water dynomometer to increase the turbine inlet temperature. However, this test condition could not be reached, due to fuel limitations. After shutting down the engine, the problem was determined to be a faulty fuel supply system. After repairs to the fuel system, the engine lighted off and a normal start cycle was initiated, to slowly bring the engine speed up to $70,000 \mathrm{rpm}$. At $58,000 \mathrm{rpm}$, the engine flamed out.

A borescope inspection revealed an engine failure involving all the major ceramic components. Following teardown and inspection, fractography was performed on the failed ceramic components in an attempt to determine the failure origins. Two possible major failure origins were identified: the turbine rotor and the turbine shroud. Evidence suggests the the shroud was intact when the rotor burst. 
Build 22 of the S/N $002 \mathrm{C}$ engine was next in line for testing. However, rotor dynamics instrumentation problems required that the engine be removed from the test cell before any significant results could be achieved.

By this time, Build 9 of the S/N 004C engine was ready for testing. This engine build had one deviation from all the other ceramic engine builds. For the first time, an all-ceramic engine was built with a GCC GN-10 rotor instead of an NAC NT154 rotor. This engine began testing and operated for a total of 1.9 hours on a single start. The engine reached a maximum speed of $82,500 \mathrm{rpm}$ with turbine inlet temperatures reaching 2200F (1204C). After running for 1.22 hours at the desired test point, an incident occurred without warning. Following shutdown, borescope inspection revealed a catastrophic failure of all the major ceramic components. During this test, up to the point of the failure, the engine ran smoothly.

Fractography results determined that all the flowpath components had secondary failures. Data analysis from the disaster monitor showed that the rotor sustained an instantaneous imbalance, which supports the fractography results. This leads to the conclusion that the GN-10 rotor was the primary failure.

Insufficient material from the rotor was recovered to permit reconstruction, and it was not possible to identify the failure origination site. Since several rotor fracture segments show the direction of primary crack propagation to be towards the backface, the failure origin was not likely to be from the backface. Evidence suggests the origin to be either inside the hub or on the rotor surfaces farther aft.

The last test of the AGT101 engine conducted was Build 23 of the S/N $002 \mathrm{C}$ engine. This test was actually a compilation of two builds. Tests of Builds $23 \mathrm{~A}$ and $23 \mathrm{~B}$ were both terminated due to flange failures on the respective ceramic flow separator housings. Accomplishments of Build 23 are listed in Table 13.

TABLE 13. AGT101 ENGINE S/N $002 C$ BUILD 23 TEST SUMMARY.

\begin{tabular}{|c|c|c|c|}
\hline \multirow{2}{*}{ Build No. } & \multirow{2}{*}{ Starts } & \multicolumn{2}{|c|}{ Operating Time, Hours } \\
\cline { 3 - 4 } & 7 & Total & At 2200F (1204C) \\
\hline $23 \mathrm{~A}$ & 7 & 22 & 20.7 \\
\hline $23 B$ & 5 & 18.3 & 16.7 \\
\hline
\end{tabular}


During testing of Build 23A, the engine reached a maximum speed of 78,000 rpm. The longest segment of time at 2200F (1204C) was 11.6 hours. During the last shutdown of Build 23A, anomalies were noted on the strip charts during the turbine roll down. The event was not smooth like the six previous shutdowns. As a precaution, the engine was removed from the test cell for inspection. Teardown revealed that the engine had sustained a failure originating in the flange area of the ceramic flow separator housing.

During testing of Build 23B, the engine reached a maximum speed of $82,000 \mathrm{rpm}$. The longest segment of time at $2200 \mathrm{~F}(1204 \mathrm{C})$ was 14.9 hours. The engine achieved 15.6 hours of total run time on the first lightoff, which included the longest segment at 2200F (1204C).

The last lightoff of Build 23B was stabilized at $82,000 \mathrm{rpm}$ while at 2200F (1204C). Thirteen minutes later, the engine ceased operation. The strip charts indicated a problem in the engine, so the engine was again removed from the test cell for inspection. Teardown revealed another failure in the flange area of the flow separator housing (FSH).

After the FSH failure in Build 23A, the only piece of ceramic hardware replaced in the subsequent rebuild (Build 23B) was the FSH. All other ceramic hardware was reused. Furthermore, in a deviation from normal engine build procedures, the hardware was not cleaned except in the critical interface locations.

Precautions had been taken to help prevent a second failure in a rocker support location during Build $23 \mathrm{~B}$ of the engine. First, the flat washer associated with the previous failure was replaced. Special care was then taken to make sure the rocker supports were level within the prescribed tolerance range. Also, the FSH was placed in the engine, loaded, and then removed from the engine to check the witness marks left by the support system. The witness marks revealed good contact with each of the support locations. The engine was then fully assembled.

After the failure of the second FSH (Build 23B), measurements were made to determine whether or not the supports were coplanar. The results indicated the supports were still within the designated tolerance range. No corrective action was determined, since this was the last test of the AGT101 test bed engine.

Both failures of the FSH originated at a rocker support location. However, the location of the failures were not at the same support. The locations of the failure origins and the rocker support witness marks are shown in Figure 44. Origin 1, from Build 23A, came from an internal corner of a 


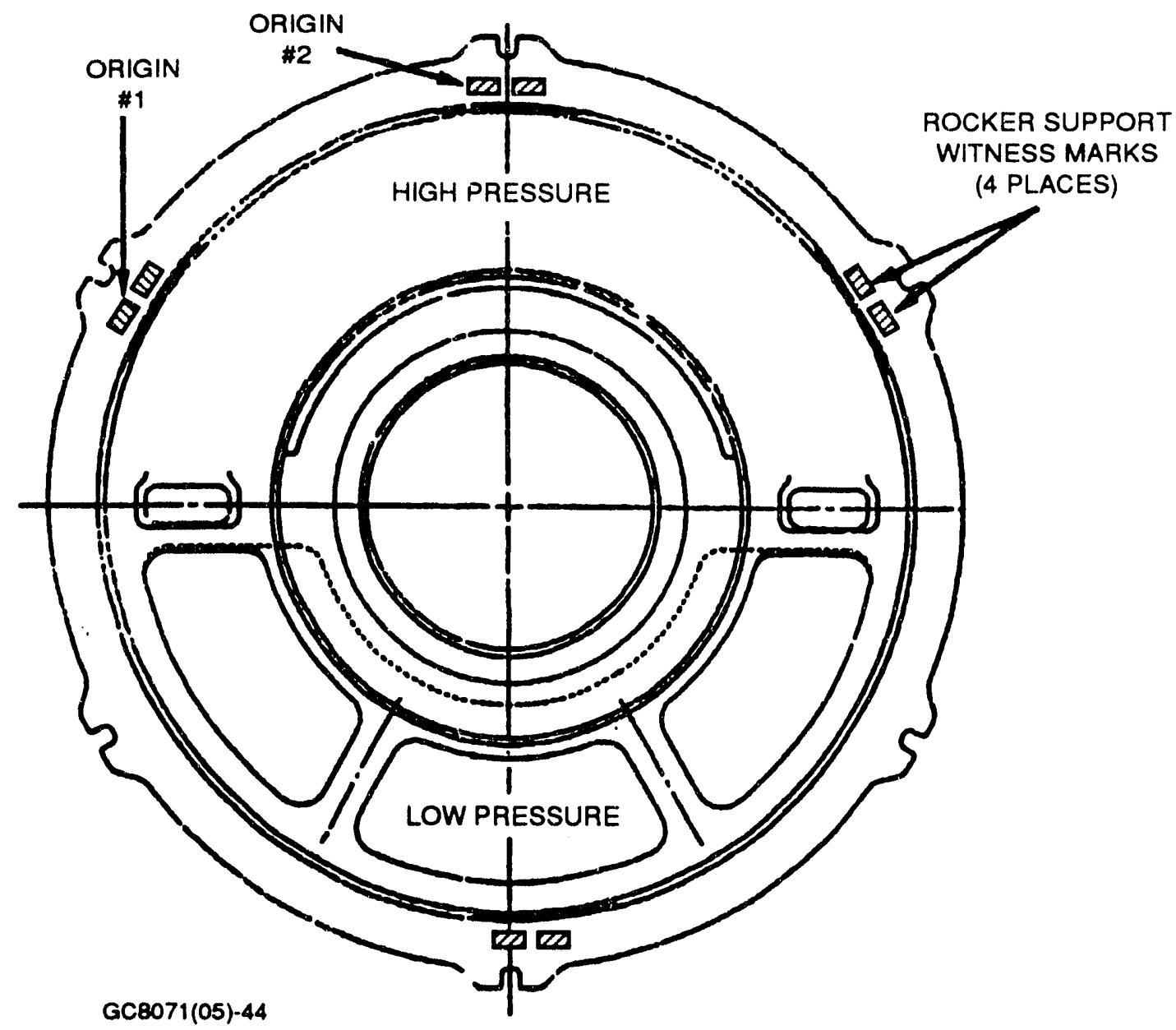

Figure 44. Milestone 5 Flow Separator Housing Failure Origins.

flat washer used in the rocker support system. This was on one of the outside supports on the highpressure side of the FSH. Origin 2, from Build 23B, started at an outside corner of the middle support flat washer on the high-pressure side of the housing.

Milestone 5 testing was terminated after $\mathbf{4 0 . 2}$ hours of operation, which included 37.4 hours at the designated endurance temperature. Some of the planned test objectives were not completed. However, none of the ceramic hardware displayed noticeable signs of degradation at the conclusion of testing, with the exception of the two failed flow separator housings.

\subsection{Engine Test Summary}

During 1992, three successful metal AGT101 engine tests were accomplished, using ceramic rotors. The 3 metal engine builds accomplished 3.3 hours of testing with 7 engine starts. Two of the engines used NAC NT154 rotors and one of the engines used a GCC GN-10 rotor. 
Eight tests of the all-ceramic engine were attempted during 1992, with varying degrees of success. The highlight of the year was the completion of Milestone 4 testing. Only partial goals were accomplished for Milestone 5, as testing was terminated before all the test objectives could be completed. Summarizing the all-ceramic AGT101 engine testing, 8 builds were used to accomplish 67.3 hours of testing. 


\subsection{PROJECT MANAGEMENT AND REPORTING}

The ATTAP Milestone Schedule is shown in Figure 2. Engine testing Milestone 4 was completed in 1992. GAPD issued seven Bimonthly Technical Progress Reports during 1992 and conducted five Bimonthly Review Meetings with NASA/DOE.

GAPD personnel attended the Thirtieth Automotive Technology Development Contractors' Coordination Meeting in Dearborn, Michigan, November 3-5, 1992 and made a presentation entitled "ATTAP Ceramic Turbine Engine Technology Development" (GAPD Report 31-10824), reporting on ATTAP accomplishments over the past year. At the Dearborn meeting, an additional presentation was made by GAPD personnel entitled "Progress In Ceramic Design Methods During the Advanced Turbine Technology Applications Project" (GAPD Report 31-10826), on the ATTAP impact design methods support program. An additional presentation by GAPD personnel, entitled "Life Prediction Methodology For Ceramic Components of Advanced Heat Engines" (GAPD Report 3110825) was made at the Dearborn meeting, describing the ceramic life prediction work under a separate DOE - Oak Ridge National Laboratory contract in conjunction with ATTAP. These presentations will be published by the Society of Automotive Engineers (SAE) in the Proceedings of the Dearborn meeting.

GAPD personnel made an additional presentation on the ATTAP effort in June 1992 at the 37th International Gas Turbine and Aeroengine Congress and Exposition, in Cologne, Germany, sponsored by the American Society of Mechanical Engineers (ASME), published as ASME Report No. 92 GT-381 (GAPD Reports 31-10258 and 31-10678).

A paper entitled "Ceramic Technology For Small Gas Turbine Engines" (GAPD Reports 3110393 and 31-10438) was presented by Dr. J.R. Smyth of GAPD at the International Forum on Fine Ceramics '92, held in Nagoya, Japan, March 9 - 11, 1992, in part summarizing the U.S. ATTAP ceramic turbine development efforts. 


\section{REFERENCES}

1) A.M. Comfort and J.S. Cuccio, "Life Prediction Methodology for Ceramic Components of Advanced Heat Engines," Society of Automotive Engineers (SAE) Publication P-230, Proceedings of the Automotive Technology Development Contractors' Coordination Meeting, Dearborn, Michigan, October 1989 (GAPD Report 31-8576).

2) J.R. Smyth and R.E. Morey, "ATTAP Ceramic Gas Turbine Technology Development," American Society of Mechanical Engineers (ASME) Paper 92-GT-381 (GAPD Report 31-10258), presented at the International Gas Turbine and Aeroengine Congress and Exposition, Cologne, Germany, June 1-4, 1992. 
APPENDIX I

ANNUAL TECHNICAL PROGRESS REPORT GARRETT CERAMIC COMPONENTS 
ADVANCED TURBINE TECHNOLOGY APPLICATIONS PROJECT

\author{
GARRETT CERAMIC COMPONENTS \\ 1992 ANNUAL TECHNICAL PROGRESS REPORT \\ FOR GARRETT AUXILIARY POWER DIVISION
}

\title{
I. INTRODUCTION
}

The objective of this 54-month technical effort was to develep a fabrication process with the potential for low-cost, mass production of AGT101 turbine rotors using GN-10 silicon nitride. Pressure slip casting was the primary fabrication approach. Materials and components were extensively characterized and NDE methods were developed and evaluated for improved process control and material/component qualifica- . tion. In Task A, fabrication of the AGT101 rotor using GN-10 silicon nitride and pressure slip casting was developed. In Task C, GN-10 test specimens and NDE seeded defect standards were fabricated by pressure silip casting.

\section{SUMMARY OF PROGRAM EFFORTS PRIOR TO 1992}

\section{TASK A. FABRICATION OF AGT101 ROTORS BY PRESSURE} SLIP CASTING

\section{SUBTASK A.A FABRICATION OF ROTORS AND PLATES USING BASELINE SLIP AND FORMING PROCESS}

The goal of Subtask A.A was to evaluate the capability of the GN-10 slip preparation, rotor and plate-forming, and densification processes on resultant component shape forming capability and mechanical properties. Subtask A.A was begun at the beginning of the program (July 1988) and completed in 1989. Evaluation of the basel ine forming and densification processes resulted in the identification of areas in need of improvement.

\section{SUBTASK A.B SLIP CAST ROTOR PROCESS DEVELOPMENT 1}

The goal of Subtask A.B was to take the problems identified in Subtask A.A and investigate their elimination using iterative process development, and designed experiments, where appropriate. Subtask A.B was begun in early 1989. GN-10 silip properties were improved, specifically degree of dispersion and stability time, resulting in slip revision \#15, which allowed slip casting of defect-free AGT101 rotors. Subtask A.B ended in early 1990 with the delivery of four as-HIPed AGT101 radial rotors to Garrett Auxiliary Power Division. The rotors were fabricated using revision \#15 slip and the revision \#1 HIP process (HIPed at ASEA). 
SUBTASK A.C SLIP CAST ROTOR DEVELOPMENT 2

Subtask A.C addressed further reproducibility and improvement of the fabrication of the radial AGT10l rotor focusing on both netshape development and material property improvements and was initiated in January 1990. In April 1990, densification of GN-10 $\mathrm{Si}_{3} \mathrm{~N}_{4}$ material using the ASEA glass-encapsulation HIP process was initiated in-house. Refinement of the in-house HIP process resulted in HIP revision \#8 and the resulting $\mathrm{GN}-10 \mathrm{Si}_{3} \mathrm{~N}_{4}$ mechanical properties were equivalent or better than any previous slipcast GN10 material HIPed at ASEA. Subtask A.C was completed in October 1990 with the delivery to Garrett Auxiliary Power Division of two radial-design AGT101 rotors. The rotors were utilized for spin balancing and spin-to-burst evaluation (with just the shaft outside diameter machined). Due to a small shaft-hub misalignment in the original mold fabrication tool, the radial-design rotors required extensive stock removal for spin balancing. The first rotor burst at approximately $80,000 \mathrm{rpm}$, suspected to be due to the size of the balancing groove that needed to be machined into the part. The second rotor burst at $114,000 \mathrm{rpm}$, within $1 \%$ of the required proof test spin speed for deliverable rotors.

\section{SUBTASK A.D IMPACT-RESISTANT DESIGN ROTOR DEVELOPMENT}

This subtask was initiated in January 1990 to develop the fabrication of the impact-resistant design (IRT) AGT101 rotor, building on the GN-10 silicon nitride pressure slip casting process developed for the radial-design radial shaped AGTIOl rotor. Due to rotor and mold design changes, the impact-resistant design rotor mold hard tool delivery was delayed until late November 1990.

In order to evaluate the castability of the impact-resistant design rotor shape before the hard tool was delivered, a stereolithographically generated plastic pattern impact-resistant design rotor was provided to Garrett Ceramic Components by Garrett Auxiliary Power Division to fabricate slip casting molds for rotor casting evaluations. The only significant difference between the mold developed from the stereolithographic pattern and the hard tool being built was that the stereo pattern has approximately 0.003 " ridges on its surface due to the limited surface detail resolution of the stereolithographic process. Casting of the prototype impactresistant design rotors was very successfui. Two prototype impactresistant-design AGT101 rotors were provided to Garrett Auxiliary Power Division for evaluation in January 1991.

The hard tooling for the impact-resistant design rotors was received in late November 1990. Pressure slip casting of hardtool derived rotors was begun in mid-December 1990.

Development efforts in 1991 focussed on fabrication development of the modified design AGT101 rotor - the impact resistant turbine. Initial fabricated rotors indicated defects in the tooling and 
casting process that needed to be eliminated. The hard tooling and mold assemblies were modified, and the casting and drying procedures slightly modified to eliminate all defects. Defect-free rotors using GN-10 slip process revision \#15 and HIP process revision \#8 were slip cast starting in May 1991. All densified engine candidate rotors were submitted for final machining in early August 1991.

Six IRT design rotors were spun-to-burst to evaluate rotor material and property performance and capability of meeting proofspin testing requirements. Two rotors were stereolithographic derived, while four were fabricated from hard tooling. The hard tooling derived rotors had backfaces and shaft outside diameters fully machined (three rotors had solid shafts while one had a simple bisque-machined pilot hole) while the two stereolithographic derived rotors had solid shafts with only the shaft outside diameters machined. Both stereolithographic rotors and the three solid shaft hard tool derived rotors burst at speeds between $111,250 \mathrm{rpm}$ and $119,800 \mathrm{rpm}$, above the required proof speed of $105,000 \mathrm{rpm}$. An analys is of predicted rotor room temperature spin performance was conducted by Garrett Auxiliary Power Division using GN-10 asprocessed surface and machined flexure test bars. The analysis results correlate well with as-processed surface strengths, which would indicate that the rotors fail at the as-processed surfaces, which exist only on the blade surfaces and on the hub surfaces in between the blades. Finite element analysis of rotor stress distributions indicates that the maximum as-processed surface stress is on the hub surface near blade roots.

Machining of the deliverable rotors was completed in November 1991. Garrett Auxiliary Power Division decided to balance and proof spin the rotors in-house, because of discrepancies in balancing results previously obtained (on both ceramic and metal rotors) at the rotor balancing and spin testing company being used. The five engine candidate rotors were delivered to Garrett Auxiliary Power Division in December 1991. The rotors were balanced and heat treated. One rotor was selected for proof testing in the metal structure AGT101 test bed engine. The rotor successfully passed test conditions that consisted of maximum operating conditions of $90,000 \mathrm{rpm}$ and $1650^{\circ} \mathrm{F}$, with thermal and speed cycling. The rotor was then accepted as engine qualified hardware.

Two rotors, from the same raw material lot and processing time frame as the delivered rotors, were cut up into test bars for mechanical property evaluation. The bars were not tested until April, when the mechanical testing facilities for Garrett Ceramic Components were completed. The results are presented in Table 14. 
Table 14. Mechanical Properties of AGT101 Rotors (Same Vintage as First IRT Rotor Delivery in 1991)

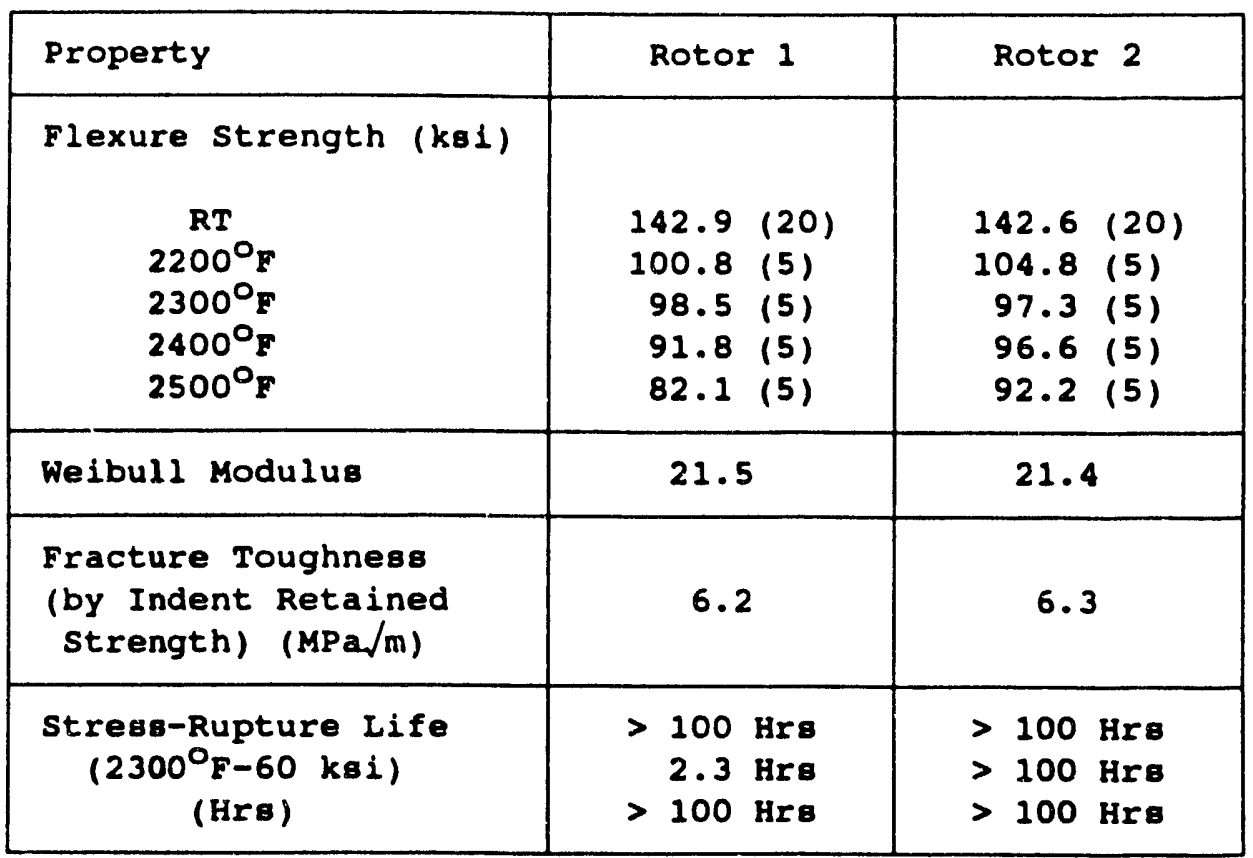

The properties are obviously very good, and meet the stress-rupture life and Weibull modulus targets for the GAPD ATTAP program. Fractography of specimens tested at room temperature shows that the majority of failure origins are due to inclusions (see Figure 45). SEM quantitative analysis shows the inclusions to be either carbon (suspected to be from ball mill liner material) or sintering aid agglomerates (from incomplete mixing and milling during slip preparation).

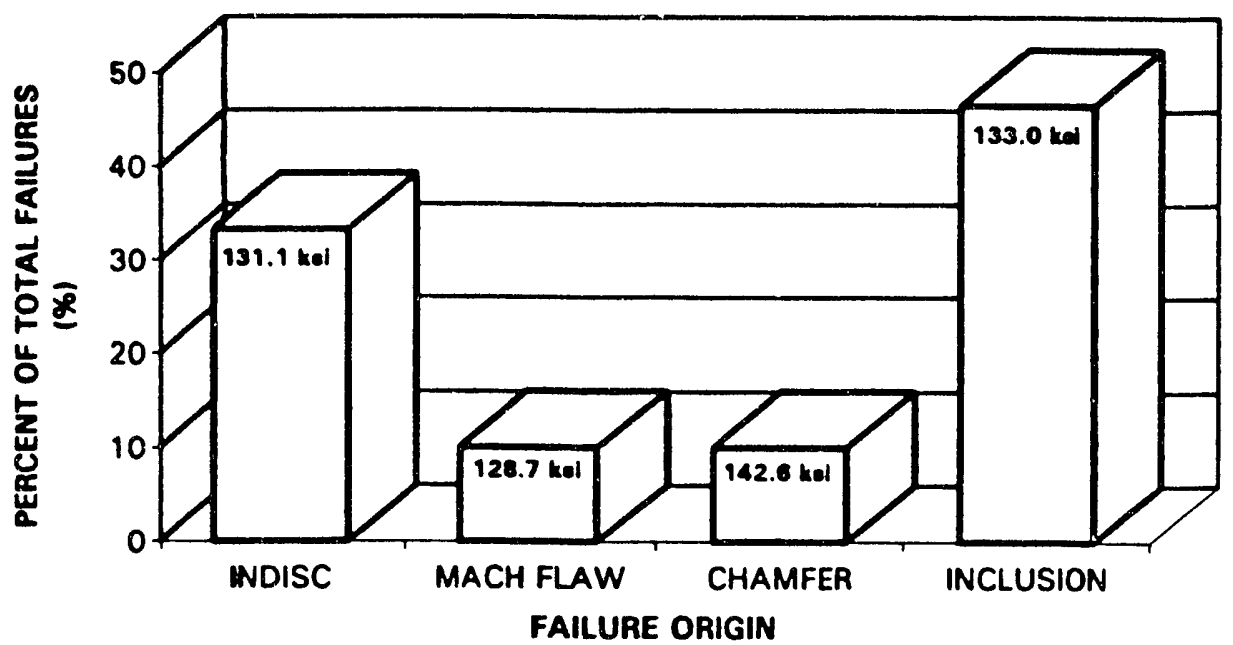

Figure 45. Fractography Results of First IRT Rotor Delivery Cut-up Test Specimens. 


\section{SUBTASK C.C FABRICATION OF SLIP CAST DEFECT SEEDED BILLETS FOR NDE DEVELOPMENT}

Garrett Ceramic Components fabricated GN-10 seeded defect specimens (containing both controlled size iron inclusions and voids) for evaluation of $X$-Ray radiographic and $u 1$ trasonic NDE detection capabilities. Seeded defect sizes ranged from $25 \mu \mathrm{m}$ to $500 \mu \mathrm{m}$ in diameter. The specimens were inspected at each intermediate processing step nondestructively and then the results quantified using destructive cut-up and characterization. The three processing steps evaluated were green (dried after slip casting, calcined (presintered), and HIPed (fully densified). Destructive characterization of the calcined specimens revealed smallest detectable voids as 0.002 " diameter and 0.002 " diameter for iron inclusions. Using nondestructive techniques, the smallest detectable voids $0.003^{\prime \prime}$ diameter using realtime fluoroscopy at $10 \mathrm{X}$ magnification and $0.002 "$ diameter using film radiography at $1 X$ magnification. The smallest detectable iron inclusion using either realtime or film radiographic techniques was $0.00 \%$ ". The remaining calcined specimens were then HIPed at Garrett Ceramic Components and characterized by realtime and film microfocus $X$-ray, then delivered to Garrett Auxiliary Power Division for evaluation.

\section{PROGRAM EFFORTS}

\section{SUBTASK A.E IMPACT RESISTANT ROTOR DEVELOPMENT 2}

1992 program plans developed by Garrett Auxiliary Power

Division and Garrett Ceramic Components consisted of development, fabrication, and delivery of a second set of three AGT10l impact resistant design rotors, in July 1992. The rotors were to have improved properties which would result in increased performance margins. Property improvement efforts focussed on as-processed surface strength, tensile strength, and high temperature stressrupture resistance. The goals for improved $\mathrm{GN}-10 \mathrm{Si}_{3} \mathrm{~N}_{4}$ were:

1) As-processed surface strength of $100 \mathrm{ksi}$ at RT and $85 \mathrm{ksi}$ at $2200^{\circ} \mathrm{F}$

2) Tensile strength of $110 \mathrm{ksi}$ at RT and $60 \mathrm{ksi}$ at $2500^{\circ} \mathrm{F}$

3) Stress-Rupture life of $>100$ hours at $2200^{\circ} \mathrm{F}$ and $70 \mathrm{ksi}$ load

4) Weibull Modulus at RT of 20

Three routes were selected for property inprovement development. The first route examined as-processed surface property improvement by flow machining removal of small amounts (<.005") of material, and improved HIP and post-HIP heat treatments by manipulation of microstructure and grain boundary phases. The second route examined was the implementation of improved slip process $\mathrm{GN}-10$, where the slip preparation process has been modified 
to eliminate the yttria agglomerates and carbon inclusions that were the majority of failure origins in tensile specimens of the rev.

\#15 process GN-10. The third route examined the development of slip casting of $\mathrm{GN}-10$ with an alternate $\mathrm{Si}_{3} \mathrm{~N}_{4}$ powder with improved purity. The route that resulted in the best combination of property improvements while maintaining rotor dimensional requirements would then be selected for fabricating the deliverable engine candidates.

\section{ROUTE 1 - IMPROVEMENT OF CURRENT PROCESS ROTOR PROPERTIES}

Experiments on as-processed surface flow machining did not result in strength improvements. A maximum of .001" of material was able to be removed from as-processed surfaces by flow machining. The resulting strengths for either $.0005^{\prime \prime}$ or .001" of material removal were similar to unmachined as-processed surfaces ( 70 to $77 \mathrm{ksi}$ ) even though they had much smoother surfaces. The defects that cause failure at room temperature (small pits and rough surface topography) are still present, although much shallower and are still the failure origins.

HIP process modifications and post-HIP inert and oxidative heat treatments did not result in any property improvements for either machined or as-processed surfaces test specimens, indicating that current heat treatment conditions have been optimized.

\section{ROUTE 2 - IMPROVEMENTS OF CURRENT SLIP PROCESS}

A slip preparation process was developed that minimizes sintering aid agglomerates and eliminates carbon inclusions.

linings were changed to eliminate carbon inclusions and milling procedures were modified to maximize deagglomeration of sintering aid powder. The slip process demonstrated successful fabrication of AGT101 rotors and was designated slip revision 17 . The slip process combined with HIP revision 10 and a lower temperature calcine cycle was successfully implemented to result in fully dense defect-free rotors meeting dimensional reproducibility. Mechanical properties of cut-up rotors indicated a substantial improvement in room temperature properties and similar high temperature strength compared to the first set of delivered impact resistant turbine design rotor properties.

\section{ROUTE 3 - EVALUATION OF ALTERNATE SILICON NITRIDE POWDER} MATERIAL EVALUATION

The alternate $\mathrm{Si}_{3} \mathrm{~N}_{4} \mathrm{GN}-10$ slip was investigated. The first set of rotors cracked during drying. Further slip process refinement higher solids content) corrected the drying problem and rotors have been slip cast, and dried without defect formation. The rotors still exhibited cracking during calcining and the deadline to select a deliverable rotor fabrication process was reacher before the calcining cracking could be eliminated. 
ENGINE CANDIDATE ROTOR FABRICATION

Based on the results of the three different process routes at the process selection deadline, the second route (slip preparation process improvement) was selected for use in fabricating the second and final set of deliverable rotors.

Six rotors were cast as candidates for the second rotor delivery set to Garrett Auxiliary Power Division. Two rotors were slightly damaged during bisque machining due to the fact that a modified bisque firing cycle was implemented and the machining properties of the bisque material were slightly different. The following four rotors were successfully machined. All six wheels were successfully densified. Three rotors (and one rotor for machining set-up) were machined as deliverables and were received back from the machining vendor in late October 1992. Because of program monetary constraints at Garrett Auxiliary Power Division, and the fact that they already have enough engine qualified rotors to meet 1992 test plans, they requested that the rotors be held at Garrett Ceramic Components. One rotor was dimensionally inspected to confirm machining corformance to required dimensions. The engine candidate rotors are shown in Figure 46.

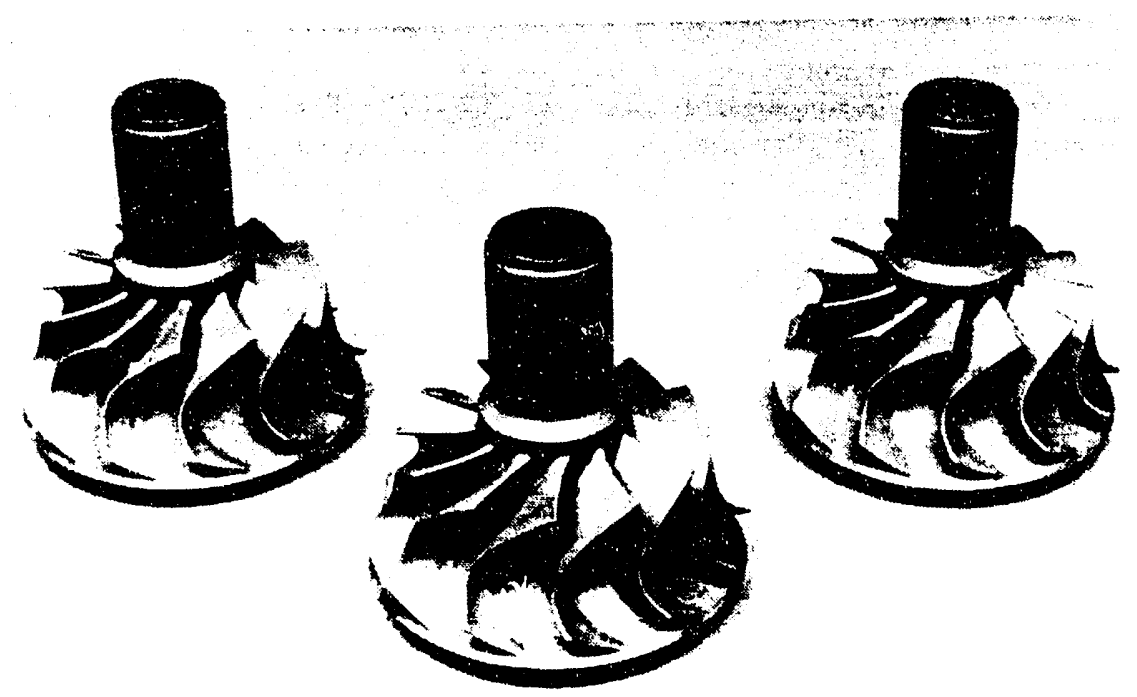

124243

Figure 46. Engine Candidate AGT101 IRT Rotors For Second and Final Scheduled Delivery (Rev. \#17 Slip, Rev. \#10 HIP Processes). 
Two rotors made by the same slip and HIP process were cut up into test bars and tested to verify rotor mechanical properties. The fast fracture flexure properties are shown in Table 15.

Table 15. Mechanical Properties of 1992 AGT101 Rotors (Second and Final Del ivery Candidates)

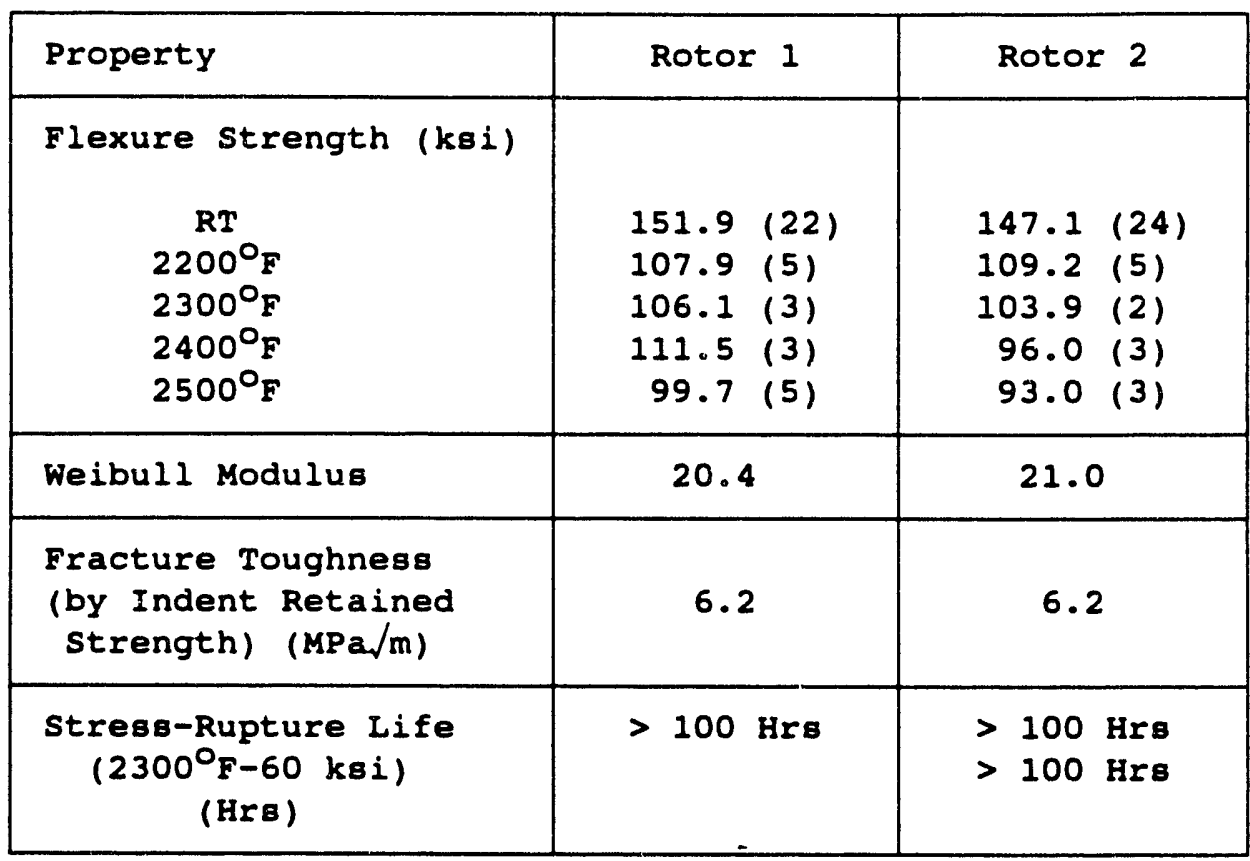

Average strengths were very similar between the two rotors. The rev. 17 slip process results in strength improvements across the range of temperatures compared to the earlier set of deliverable rotors made from rev. 15 slip (Task A.D) and shown in Table 14. Fractography of rev. 17 slip room temperature test specimens showed that the majority of failure origins were 10 to $15 \mu \mathrm{m}$ size $\mathrm{Fe}-\mathrm{Si}-\mathrm{C}$ containing inclusions. These inclusions are inherent in the silicon nitride powder used. The inclusions seen as the major source of failure origins in the rev. 15 slip rotors (15-25 $\mathrm{mm}$ size sintering aid agglomerates and carbon inclusions) were not detectable and it is surmised that the rev. 17 slip process minimizes them. The slightly smaller average size of the rev. 17 inclusions correlates well with the slight increase in strength of the rev. 17 slip material compared to rev. 15 material. The weibull modulus of the rev. 17 rotors was 20.5, which is similar to the previously measured rev. 15 rotors $(22.3)$.

Three rev. 17 rotor test bars were evaluated in a flexure stress-rupture test at $2300^{\circ} \mathrm{F}$ and $60 \mathrm{ksi}$ load. All three survived 100 hours before the test was stopped. In addition, interrupted 
static fatigue ( 4 hour hold at temperature) was performed on rev. 17 rotor test bars at $2200^{\circ} \mathrm{F}$ and $2500^{\circ} \mathrm{F}$. The slow crack growth

threshold was $40 \%$ of the fast fracture strength at $2500 \% \mathrm{~F}$ and $70 \%$ at $2200^{\circ} \mathrm{F}$. These results are the same as was measured with the rev. 15 slip GN-10 rotors, confirming that the rev. 17 slip process affected fast fracture failure origins but did not influence grain boundary phase properties, and thus, long term high temperature properties. The actual stress at which the slow crack growth threshold was reached, was higher compared to the earlier rotor delivery (revision \#15 slip) due to consistently higher flexure strengths for the revision slip prepared rotors (Figure 47 ).

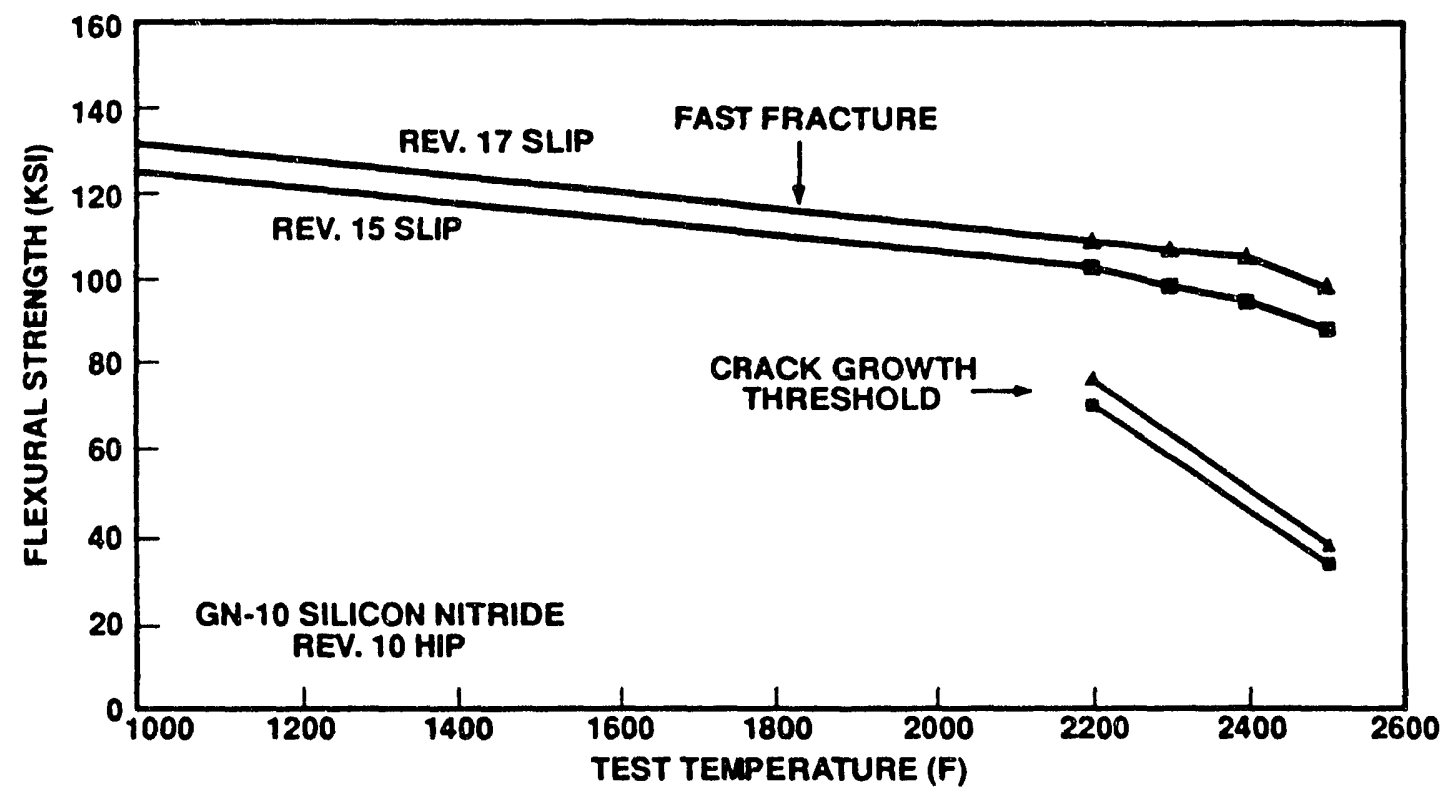

Figure 47. Comparison of Fast Fracture Strength and Slow Crack Growth Threshold for Rev. 15 and Rev. 17 GN-10 Slip.

In summary, 1992 program efforts resulted in the development and implementation of an improved slip preparation process (revision \#17) and fabrication of a second set of three engine candidate AGT101 IRT design GN-10 silicon nitride rotors. Rotors were cut-up for mechanical properties and demonstrated that machined surface properties met the ATTAP program requirements. As-processed surfaces were not able to be improved.

The 1992 effort completes Garrett Ceramic Components' efforts for Garrett Auxiliary Power Division on the ATTAP program. The ATTAP program efforts supported by DOE, managed by NASA, and directed by Garrett Auxiliary Power Division have allowed Garrett 
Ceramic Components to make significant advances in the fabrication of silicon nitride turbine wheels. Over the 54 months of the program, significant improvements in both strength and weibull modulus have been achieved in the AGT101 turbine wheels (as shown in Figure 48). The slip casting and HIP forming process developed is capable of fabrication of engine quality silicon nitride turbine wheels in prototype and limited production quantities.

The above described work completes Garrett Ceramic Component's efforts for Garrett Auxiliary Power under the ATTAP program and this will be the last report.

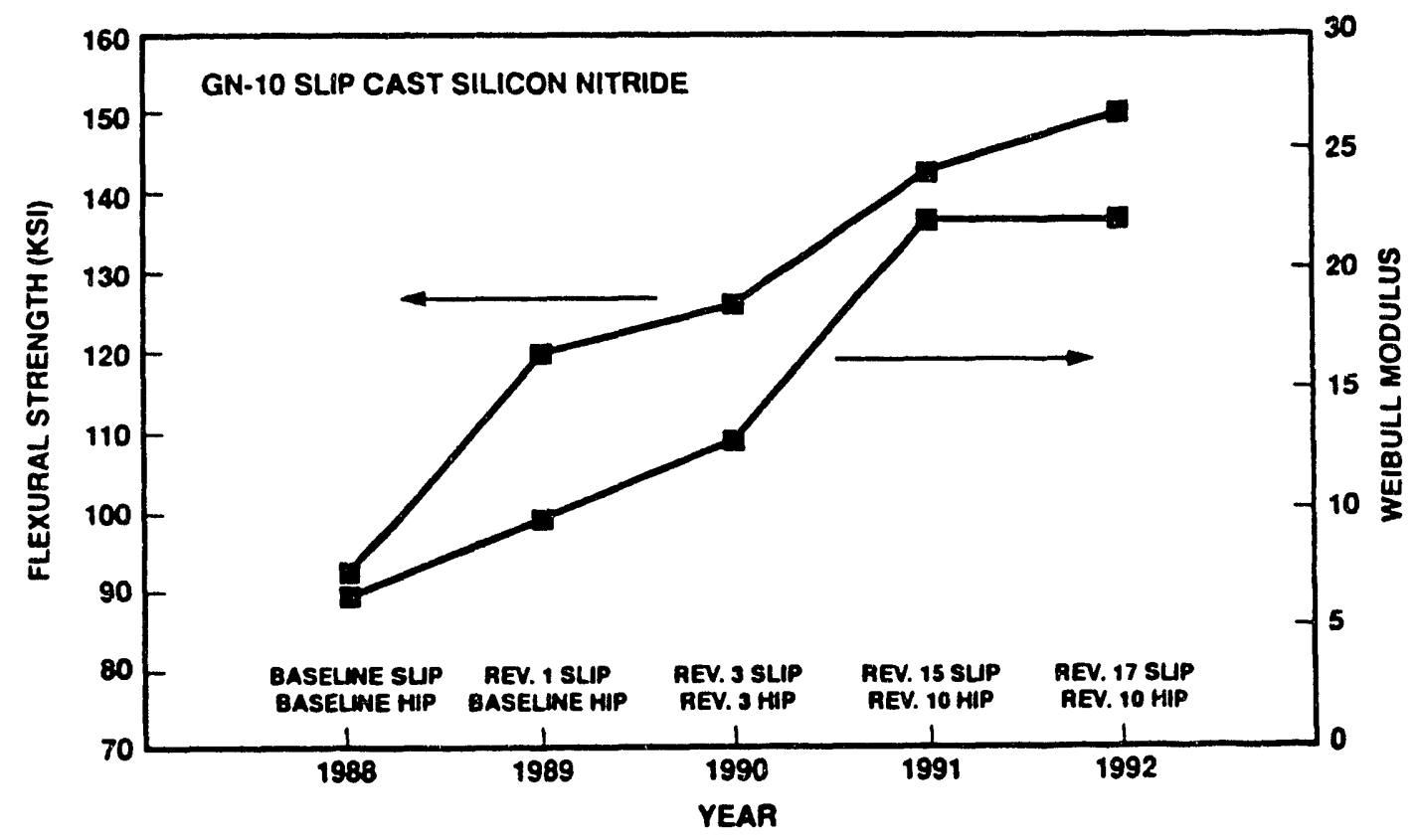

Figure 48. Significant Improvements in GN-10 Rotor Properties Achieved During the ATTAP Program. 
APPENDIX II

ANNUAL TECHNICAL PROGRESS REPORT NORTON ADVANCED CERAMICS COMPANY 


\section{ADVANCED TURBINE TECHNOLOGY APPLICATIONS PROJECT COMPONENT DEVELOPMENT PROGRAM}

\section{ANNUAL TECHNICAL PROGRESS REPORT}

For The Period

January 1, 1992 through December 31, 1992

Work Performed Under GAPD Purchase Order Nos. P11776307, P1772578, P1772588, P1772598, and P1772606.

Submitted By:

NORTON ADVANCED CERAMICS

Northboro, MA 01532-1545

Tony Taglialavore

Principal Project Engineer

Report Date: March 26, 1993

Prepared For:

NASA-LEWIS RESEARCH CENTER

Cleveland, $\mathrm{OH} 44135$

Submitted to:

Garrett Auxiliary Power Division

AlliedSignal Aerospace Company

Phoenix, AZ 85034 
$\begin{array}{ll}\text { 3.0 TECHNICAL PROGRESS SUMMARY } & 87\end{array}$

$\begin{array}{llr}3.1 & \text { Design And Cost Analysis } & 87\end{array}$

$\begin{array}{lll}\text { 3.1.1 Design Assistance } & 87\end{array}$

3.1.2 Component Cost Analysis $\quad 92$

3.2 Forming Methods $\quad 92$

3.2.1 Casting System Development $\quad 92$

3.2.2 AGT101 Rotor Fabrication Development 100

3.2.3 AGT101 Stator Fabrication Development 102

$\begin{array}{ll}\text { 3.2.4 HIP Development } & 104\end{array}$

3.3 Process Engineering $\quad 106$

$\begin{array}{ll}3.4 & \text { Nondestructive Evaluation (NDE) } \\ \end{array}$

- 3.4.1 Microfocus X-Radiography (MFXR) Development 107

$\begin{array}{ll}\text { 3.4.2 Fluorescent Dye Penetrant Development } & 107\end{array}$

$\begin{array}{llr}3.5 & \text { Quality Assurance } & 108\end{array}$

3.5.1 Documentation Of The NAC Quality System 108

3.5.2 Measurement Techniques/Standards Development 108

$\begin{array}{ll}\text { 3.5.3 Process Documentation } & 109\end{array}$

3.5.4 SPC Development And Implementation $\quad 109$

3.5.5 Component Manufacturing And Inspection Plans 109

$\begin{array}{llr}3.6 & \text { Deliverables } & 109\end{array}$

$\begin{array}{lll}\text { 3.6.1 NT164 Test Specimens } & 110\end{array}$

3.6.2 Engine-Quality AGT101 Rotors $\quad 110$

$\begin{array}{ll}\text { 3.6.3 Engine-Quality AGT101 Stators } & 113\end{array}$

$\begin{array}{lll}3.7 & \text { Project Management And Planning } \quad 130\end{array}$

$\begin{array}{ll}\text { 4.0 SUMMARY AND CONCLUSIONS } & 131\end{array}$

$\begin{array}{ll}5.0 & \text { ACKNOWLEDGMENTS } \\ \end{array}$

$\begin{array}{ll}\text { 6.0 NOMENCLATURE } & 136\end{array}$

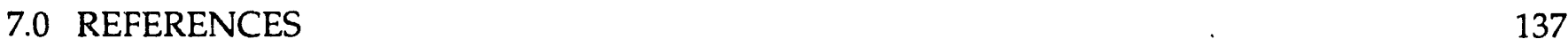




\section{LIST OF FIGURES}

Figure

49

50

51

52

53

54

55

56

57

58

59

60

61

62

63

64

65

66

67

68
Title

Page

1992 NAC ATTAP Work Plan Schedule

86

NT154 Process Flow Chart

88

Creep Behavior Of NT154 And NT164 $\mathrm{Si}_{3} \mathrm{~N}_{4}$ At 1370C

89

Fatigue Life Improvements Of $\mathrm{Si}_{3} \mathrm{~N}_{4}$ (ORNL Data)

90

NT230 Process Flow Chart

91

NT154 Process Flow Diagram

94

Inclusion Frequency Of Alcohol- Versus Aqueous-Milled NT154

95

Aqueous-Milled, Agglomerated NT154 Weibull Distribution For Room Temperature And 1370C MOR

96

1370C MOR Statistical Process Control Chart For Aqueous-Milled, Agglomerated NT154 Slip Batches 30 Through 58

97

Aqueous-Milled NT154 And NT164 Stress Rupture Char.dcteristics

97

Aqueous-Milled, Agglomerated NT164 Weibull Distribution For Room Temperature And $1370 \mathrm{C}$ MOR

99

1370C MOR Statistical Process Control Chart For Aqueous-Milled,

Agglomerated NT164 Slip Batches 1 Through 25

99

Second-Generation AGT101 Stator Casting Pattern Design

103

Engine-Quality AGT101 Rotors

111

AGT101 Rotor Deliverable Set No. 1 Process Yields

113

AGT101 Rotor Deliverable Set No. 2 Process Yields

114

AGT101 Rotor Deliverable Set No. 3 Process Yields

114

AGT101 Rotor Process Losses By Defect Type

115

Engine-Quality AGT101 Stators

115

AGT101 Stator Deliverable Set No. 1 Process Yields 


\section{LIST OF FIGURES (Contd)}

Figure

Title

Page

AGT101 Stator Deliverable Set No. 2 Process Yields

AGT101 Stator Deliverable Set No. 3 Process Yields

AGT101 Stator Deliverable Set No. 4 Process Yields

AGT101 Stator Deliverable Set No. 4 - Histogram Of Z-Section CMM Data

121

AGT101 Stator Deliverable Set No. 3 - Histogram Of L-Section CMM Data

122

AGT101 Stator Set 1 Versus Set 3 Quality Comparison Green Casting Visual Inspection

123

AGT101 Stator Set 1 Versus Set 3 Quality Comparison Green Casting MFXR Inspection

AGT101 Stator Set 1 Versus Set 3 Quality Comparison Dense Casting Visual Inspection

AGT101 Stator Set 1 Versus Set 3 Quality Comparison Sense Casting FPI Inspection

AGT101 Stator Set 1 Versus Set 3 Quality Comparison Dense Machined Visual Inspection

AGT101 Stator Set 1 Versus Set 3 Quality Comparison Dense Machined FPI Inspection

AGT101 Stator Set 1 Versus Set 3 Quality Comparison Dense Machined MFXR Inspection 


\section{LIST OF TABLES}

Table

16

17

18

19

20

21

22

23

24

25

26

27

Title

Page

PROPERTIES OF NT154 AND NT164 $\mathrm{Si}_{3} \mathrm{~N}_{4}$

PHYSICAL, THERMAL, AND MECHANICAL PROPERTIES OF NT230 Si-SiC

AQUEOUS-MILLED, PRESSURE-CAST NT154 TENSILE FAST

FRACTURE AND STRESS RUPTURE QUALIFICATION RESULTS

DIMENSIONAL EVALUATION OF AGT101 ROTORS

$10 \dot{2}$

AS-FIRED SURFACE IMPROVEMENT TRIAL RESULTS

$10 \dot{5}$

COMBINED CO-PROCESS MECHANICAL PROPERTY RESULTS FOR ALL ENGINE-QUALITY AGT101 ROTOR, ENGINE-QUALITY STATOR, AND NT164 SPECIMEN DELIVERABLES

AGT101 ROTOR SPIN TEST RESULTS

CO-PROCESS MECHANICAL PROPERTIES FOR DELIVERABLE ROTOR SET NO. 2

MECHANICAL PROPERTIES FOR ROTOR CUT-UP FROM SET NO. 2

CO-PROCESSED MECHANICAL PROPERTIES FOR DELIVERABLE STATOR SET NO. 1

CO-PROCESSED MECHANICAL PROPERTIES FOR DELIVERABLE STATOR SET NO. 2

CO-PROCESSED MECHANICAL PROPERTIES FOR DELIVERABLE STATCR SET NO. 3 


\subsection{EXECUTIVE SUMMARY}

Norton Advanced Ceramics (NAC) completed its fifth-year effort of the ATTAP. Process and component development work was completed for both the AGT101 rotor and stator. Development of component specific fabrication operations for engine-quality hardware was completed early in the year. The major focus for 1992 was the fabrication of engine-quality rotor and stator deliverables. NAC successfully produced, proof tested and delivered five engine-quality rotors during 1992 - ten total throughout the entire ATTAP effort. A total of 163 engine-quality stators were also successfully produced and delivered to AlliedSignal Garrett Auxiliary Power Division (GAPD) during 1992 - 189 total throughout the entire ATTAP effort. In addition, numerous NT154 and NT164 specimens were fabricated and delivered to GAPD for evaluation. A summary of significant accomplishments for the year is given below.

- $\quad$ NT154 Silicon Nitride $\left(\mathbf{S i}_{3} \mathbf{N}_{4}\right)$ - Characterization of NT154 continued during the year. A significant data base of critical mechanical properties for this material continues to be built at NAC, GAPD, other engine builders, and a number of independent laboratories. Flexural strength, fracture toughness, static and dynamic fatigue, creep, and therinal property information are available for engine design and analyses. Overall, properties for this material continue to meet program specifications. Under the 1992 GAPD ATTAP effort, NT154 was utilized to produce engine-quality AGT101 rotors and stators. An aqueous-milled version of NT154 with improved high-temperature fast fracture and stress rupture properties was developed and implemented on Rotor Deliverable Set No. 3.

- NT164 Silicon Nitride $\left(\mathbf{S i}_{3} \mathbf{N}_{4}\right)$ - Through its experience with NT154, NAC has been able to develop a highly creep resistant $\mathrm{Si}_{3} \mathrm{~N}_{4}$. Designated NT164, this material has approximately four times the creep life of NT154 at $1370 \mathrm{C}$. This evolutionary achievement was realized by a slight change in overall composition, and by selective post-HIP heat-treatments. The NT164 microstructure has no amorphous grain boundary phases. Because of this, NT164 has higher hot strength $(\approx 690 \mathrm{MPa}$ at $1370 \mathrm{C})$ with equivalent fracture toughness and room temperature strength when compared with NT154. During 1992, NT164 was incorporated into the GAPD ATTAP program. Under the 1992 GAPD ATTAP effort, NAC optimized a pressure-cast version of NT164 and fabricated numerous test specimens for GAPD evaluation.

- NT230 Siliconized Silicon Carbide (Si-SiC) - A new generation siliconized silicon carbide (Si$\mathrm{SiC}$ ) was developed and introduced. Designated NT230, NAC is used this material to produce transition ducts for GAPD under a parts-supply contract. This material has approximately 
double the strength of existing $\mathrm{Si}-\mathrm{SiC}$ compositions. At elevated temperatures (up to $1370 \mathrm{C}$ ), its strength is nearly equivalent to NT154.

- Casting System Development - In an effort to simplify the NT154 process, and as a prerequisite to aqueous-based component casting, development of an aqueous-milled NT154 system was completed. Substitution of water for alcohol in the current process was seen as necessary to improve product quality and reduce cost. An experimental matrix was completed using standard pilot level equipment during the 1991 effort. From water-milled powders, casting trials were conducted for rotors, stators, tensile rods, and test tiles. Flexural and tensile mechanical properties were generated. Casting techniques and properties were found to be equivalent with or superior to the current alcohol-based process. Based on the successful development of the aqueous-milled system, NAC implemented its use on Rotor Deliverable Set No. 3. Additionally, by the middle of 1992, NAC replaced alcohol-milled NT154 with the aqueous-milled system.

- AGT101 Rotor Production - NAC performed a comprehensive review of the entire rotor fabrication process used to successfully deliver engine-quality Rotor Set No. 1 during 1991. Based on experience gained from Set No. 1, NAC performed a limited amount of component specific casting development to improve dimensional control and yields. Using fixed and documented processes, NAC successfully cast, densified, machined, characterized, spintested, and delivered to GAPD five AGT101 rotors from Set No. 2. Mechanical properties for these components met program requirements, ana were comparable to data acquired from coprocessed test tiles. Based on the successful development of the aqueous-milled NT154 system, NAC implemented its use on Rotor Deliverable Set No. 3. Using fixed and documented processes, NAC successfully cast, densified, and characterized five AGT101 rotors. These rotors were placed on hold prior to machining by GAPD due to budgetary constraints. Under the 1991 and 1992 efforts, NAC successfully spin tested all eleven AGT101 rotors to the proof speed of $105 \mathrm{krpm}$. Nine components were delivered to GAPD. Engine testing of this hardware by GAPD was conducted during 1992. The remaining two rotors were purposefully spun to failure. They failed at speeds of 126.6 and $118.9 \mathrm{krpm}$, or 141 and 132 percent of maximum engine design speed, (i.e., $\approx 90 \mathrm{krpm}$ ).

- AGT101 Stator Production - At the close of 1991, NAC performed a comprehensive review of the entire stator fabrication process. Corrective action was identified and became part of NAC's 1992 Technical Work Plan. In accordance with this plan, NAC fabricated a secondgeneration casting pattern to improve dimensional control, and improved mold design and casting procedures to increase process yields. While performing these corrective action tasks, 
NAC completed deliveries on Stator Deliverable Set No. 1. A total of 33 additional stators were delivered, bringing the total for Set No. 1 to 57. Mechanical properties for this hardware were evaluated and found to meet ATTAP specifications. Using the identical tooling and methods as Set No. 1, NAC fabricated and delivered 50 engine-quality stators for Set No. 2. Mechanical properties for this hardware were evaluated and found to meet ATTAP specifications. Both Set No. 1 and No. 2 met print requirements for machined surfaces, but were out of specification for as-processed dimensions. Although these sets were deemed adequate for engine testing by GAPD, NAC completed its corrective action tasks and implemented a second-generation casting pattern and improved mold design to improve dimensional control and process yields. NAC fabricated and delivered a total of 80 enginequality stators for Set No. 3. Mechanical properties for this hardware were evaluated and found to adequately meet ATTAP specifications. High-temperature properties, however, were abnormally low for NT154. The degradation in properties was attributed to contamination from the agglomeration process and alcohol milling. Both problem sources have been corrected by NAC. Dimensional control for Set No. 3 was improved over Set No. 1 and No. 2 with airfoil c.lord length specifications being met. Due to bi-directional shrinkage, however, inne: platform distance was still out of specification although better than for the first two sets. Although NAC's iniproved mold design dramatically improved process yields, surface quality in critical component areas degraded from Sets No. 1 and No. 2 to Set No. 3. NAC has investigated this quality issue and as a result has developed a comprehensive program for 1993 to improve as-processed surface quality. Using the identical tooling and methods as Set No. 3, NAC fabricated and machined a total of 79 engine-quality stators for Set No. 4. Due to budgetary constraints, however, GAPD placed these components on hold after machining. NAC has gained valuable experience in the development of processes and fabrication of engine-quality AGT101 stators for GAPD. Using this experience, NAC has developed and implemented comprehensive plans to improve quality and yields for all NT154 component products.

- HIP Development - NAC performed a limited amount of long-term stress rupture testing for the As-Fired Surface Optimization L16 experiment which was initiated in 1991. Completion of this effort was suspended due to time and budgetary constraints. NAC also performed a limited amount of development work on the improvement of as-processed surface strengths. None of the experimental work performed yielded significant improvements in as-processed properties. NAC recognizes that as-processed surface quality and strength of NT154 must be improved in the future to be commercially viable. 
- Process Engineering, NDE Development And Quality Assurance - Documentation of the NT154 process and component specific operations was completed in 1991. Revisions of these documents, as necessary, were conducted during 1992. Microfocus X-Ray Radiography (MFXR) and Fluorescent Dye Penetrant Inspection (FPI) are routinely conducted on all components. NAC's Quality System was audited by GAPD and found to be in conformance with their internal requirements.

- Deliverables - In addition to delivering 5 engine-quality rotors and 163 engine-quality stators, NAC also supplied numerous NT164 specimens for GAPD evaluation.

NAC's effort under the GAPD ATTAP was completed during 1992. NAC is now using its experience gained under the ATTAP to focus on process simplification and scale-up to commercialization. The ATTAP program has been a vital stepping stone for NAC along the path to high volume production of ceramic engine components. 


\subsection{INTRODUCTION}

Commercialization of advanced structural ceramics requires development of reliable comf onent manufacturing processes. The Advanced Turbine Technology Applications Project (ATTAP) addresses this requirement. The ATTAP is a Department of Energy (DOE)-sponsored, five-year ceramic component development program which utilizes the AGT101 gas turbine engine as a functional test bed. The goals of this program include: (1) The development and demonstration of reliable ceramic fabrication processes; (2) Production of the required ceramic components; and (3) Evaluation of these components in actual engine tests.

As a participant in ATTAP, and subcontractor to Garrett Auxiliary Power Division (GAPD) ${ }^{\circ}$ of AlliedSignal Aerospace Company, Norton Advanced Ceramics (NAC) developed ceramic fabrication processes for the AGT101 rotor and stator. NAC's effort centered on the development of controlled manufacturing processes for each component. NAC has performed work in accordance with GAPD's overall ATTAP program schedule. Based on GAPD's requirements, NAC has been responsive in the development of an annual detailed Technical Work Plan. During 1992, a Work Plan was prepared, and later revised due to budgetary restrictions. The 1992 ATTAP Work Plan Schedule is shown in Figure 49. This plan describes NAC's 1992 efforts for all major tasks and sub-tasks. Work performed during the year and summarized in this report fall within the following tasks:

(1) Design and Cost Analysis

(2) Forming Methods

(3) Process Engineering

(4) NDE

(5) Quality Assurance

(6) Deliverables

(7) Project Management.

The report comprises a summary of NAC's activities for the fifth and final year of the ATTAP. 


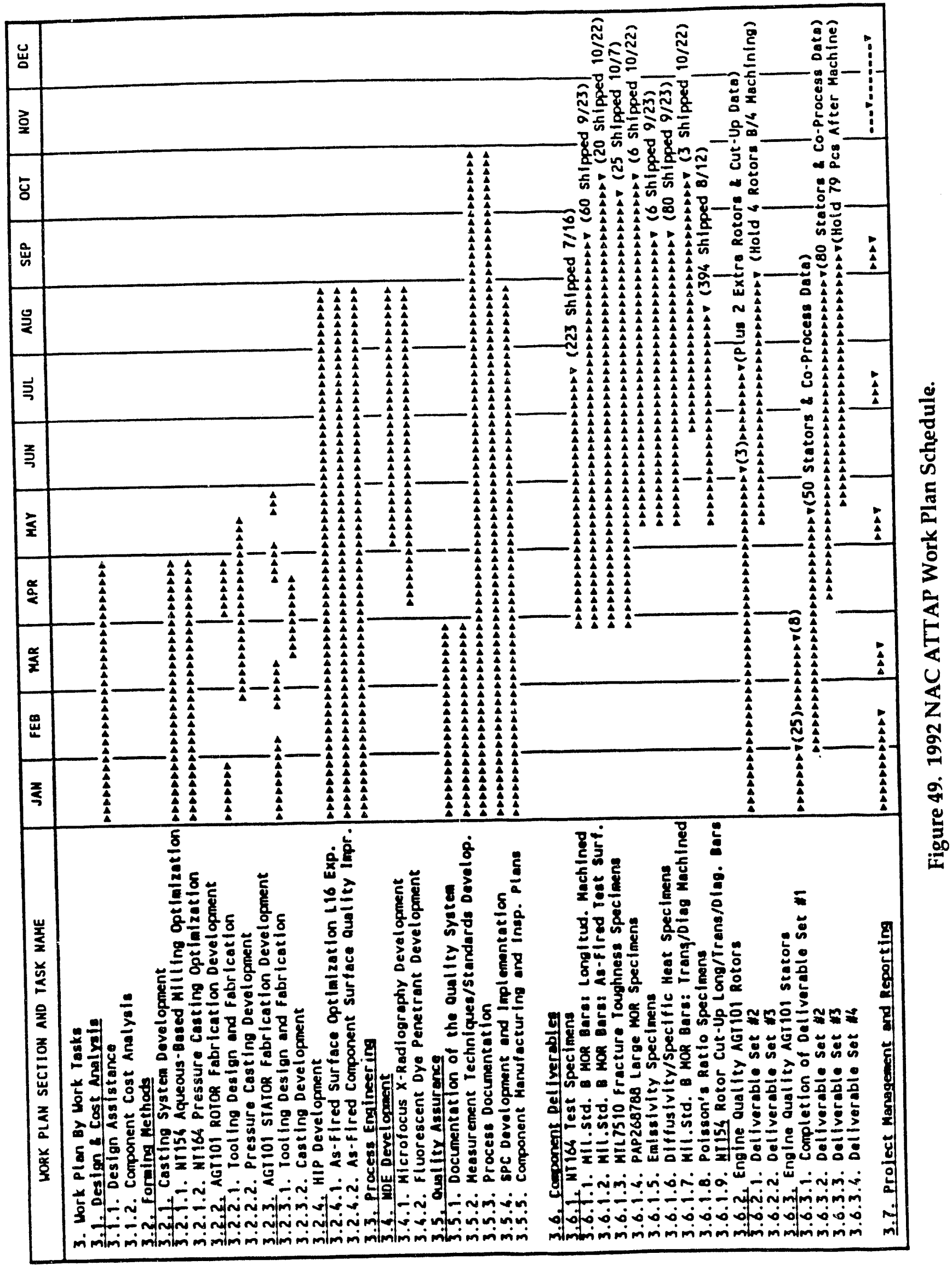




\subsection{TECHNICAL PROGRESS SUMMARY}

\subsection{Design And Cost Analysis}

\subsubsection{Design Assistance}

NAC supported GAPD during 1992 in design analysis and review activities for rotors, stators and test specimens. NAC supported GAPD in the modification of slash angle specifications for the AGT101 stator. After prints were finalized by GAPD, the slash angle change was implemented on AGT101 Stator Deliverable Set 2. No further design assistance was required during 1992.

During 1992, NAC continued to develop its principal high temperature materials for gas turbine applications including $\mathrm{NT} 154 \mathrm{Si}_{3} \mathrm{~N}_{4}, \mathrm{NT} 164 \mathrm{Si}_{3} \mathrm{~N}_{4}$, and NT230 Si-SiC. This activity is briefly described below.

- $\underline{N} 154 \mathrm{Si}_{3} \underline{N}_{4}-\mathrm{NT} 154$ is a 4 percent $\mathrm{Y}_{2} \mathrm{O}_{3}$-doped composition densified by hot-isostatic pressing (HIP). HIPing is accomplished using glass encapsulation techniques. Assessment and characterization of this material has been conducted at NAC, GAPD, other engine builders, and independent laboratories.(1-4)* NT154 continues to be one of the favorite materials of choice for a number of DOE-sponsored heat engine programs including the two major ATTAP contracts with Allison and AlliedSignal Aerospace Company (GAPD). The material is also utilized in the Oak Ridge National Laboratories (ORNL)/GAPD Life Prediction Methodology Program.** Updated typical physical, thermal and mechanical properties for NTi54 are given in Table 16. A process flow chart for both NT154 and NT164 is shown in Figure 50. NT154 possesses excellent flexural fast-fracture behavior up to $1370 \mathrm{C}$, accompanied by an acceptable Weibull Modulus. Failure origins have been associated with surface related machining flaws or internal impurities. Reported tensile strengths under fast-loading conditions parallel flexural tests. For tensile tests, principal failure origins were volume inclusions-generally identified as iron impurities. Under slow-loading conditions at elevated temperatures, creep and slow crack growth behavior have been characterized.(1,2,5). NT154 exhibits creep through a cavity nucleation and growth mechanism. Failure occurs via cavity link-up. In comparison with other advanced materials, excellent durability has been noted. NT154 remains as one of the foremost high-temperature ceramic materials available today. Under the 1992 GAPD ATTAP effort, NAC utilized NT154 to fabricate engine-quality AGT101 rotors and stators.

\footnotetext{
*Numbered references in parentheses are listed in Section 7.0.

* Life Prediction Methodology For Ceramic Components Of Advanced Heat Engines, DOE/ORNL Contract No. 86X-SC674C.
} 
TABLE 16. PROPERTIES OF NT154 AND NT164 Si ${ }_{3} \mathbf{N}_{4}$

\begin{tabular}{|c|c|c|}
\hline Properties & NT154 & NT164 \\
\hline Density, $g / c c$ & 3.23 & 3.19 \\
\hline Elastic modulus, GPa & $310-320$ & * \\
\hline Shear modulus, GPa & 126 & * \\
\hline Poisson's ratio & 0.273 & * \\
\hline Hardness, $\mathrm{kg} / \mathrm{mm}^{2}$ & 1620 & * \\
\hline Expansion coefficient, $\times 10^{-6} / \mathrm{C}$ & 3.93 & * \\
\hline $\begin{array}{l}\text { Thermal conductivity, } \mathrm{W} / \mathrm{m}^{\circ} \mathrm{K} \\
25 \mathrm{C} \\
900 \mathrm{C} \\
1400 \mathrm{C}\end{array}$ & $\begin{array}{l}37.6 \\
20.7 \\
15.8\end{array}$ & * \\
\hline $\begin{array}{l}\text { 22C mechanical properties } \\
\text { Flexural strength, } \mathrm{MPa} \\
\text { Characteristic strength, } \mathrm{MPa} \\
\text { Weibuli modulus } \\
\text { Fracture toughness, } \mathrm{MPa} \bullet \mathrm{m}^{1 / 2} \\
\text { Tensile Strength, } \mathrm{MPa} \\
\end{array}$ & $\begin{array}{c}896 \pm 55 \\
917 \\
19 \\
4.7-5.5 \\
900-920 \\
\end{array}$ & $\begin{array}{c}910 \pm 90 \\
944 \\
12 \\
5.4-6.5 \\
-\end{array}$ \\
\hline $\begin{array}{l}\text { 1370C Mechanical Properties } \\
\text { Flexural strength, } \mathrm{MPa} \\
\text { Characteristic strength, } \mathrm{MPa} \\
\text { Weibull modulus } \\
\text { Fracture toughness, } \mathrm{MPa} \bullet \mathrm{m}^{1 / 2} \\
\text { Tensile Strength, } \mathrm{MPa} \\
\end{array}$ & $\begin{array}{c}579 \pm 48 \\
600 \\
11.4 \\
4.1 \\
240-520 \\
\end{array}$ & $\begin{array}{c}648 \pm 41 \\
670 \\
* \\
* \\
-\end{array}$ \\
\hline $\begin{array}{l}\text { Creep properties } \\
1260 \mathrm{C} \text { tensile creep rate, } 300 \mathrm{MPa} \\
1370 \mathrm{C} \text { tensile creep rate, } 200 \mathrm{MPa}\end{array}$ & $\begin{array}{l}1.9 \times 10^{-8} \\
8.7 \times 10^{-7}\end{array}$ & $\begin{array}{l}2.2 \times 10^{-9} \\
1.0 \times 10^{-8}\end{array}$ \\
\hline
\end{tabular}

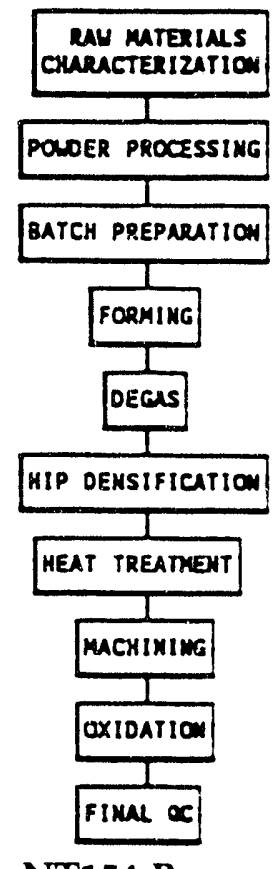

Figure 50. NT154 Process Flow Chart. 
- NT164 $\mathbf{S i}_{3} \mathbf{N}_{1}$ - NAC has utilized the experience in processing NT154 to make several alterations within the material itself in an effort to improve its properties. Recent research has focused on slight changes to the glass phase composition, along with adjustments of selected heat-treatment schedules. These modifications have resulted in an improved version of NT154, which NAC has designated NT164. NT164 has equivalent room-temperature strength and fracture toughness to NT154. However, significant improvements are noted in hightemperature strength and creep resistance. Typical NT164 properties are also presented in Table 16 for comparison with NT154. NT164 is processed identically to NT154 as shown in Figure 50. NT164 data has been generated at NAC, ORNL, and a variety of engine builders. A comparison of the creep behavior of both NT154 and NT164 are shown in Figure 51. NT164 has four times the expected creep life of NT154 at 1370C. NT164 derives its enhanced hightemperature strength and creep resistance from the fact that it has no intergranular phase at two grain junctions. Two grain junctions in NT154 possess a glassy phase which allows creep, cavity nucleation, and growth to occur. In NT164, the absence of any discernible intergranular phase greatly enhances creep resistance. ORNL performed long-term fatigue tests on pressure-cast NT164 tensile rods. As shown in Figure 52 (courtesy ORNL), NT164 is superior to NT154 in terms of long-term, high-temperature durability. NAC plans to continue the mechanical property optimization of NT164 to increase fracture toughness and Weibull modulus. Under the 1992 GAPD ATTAP effort, NAC fabricated NT164 test specimens for evaluation. NT164 was not utilized for any component fabrication.

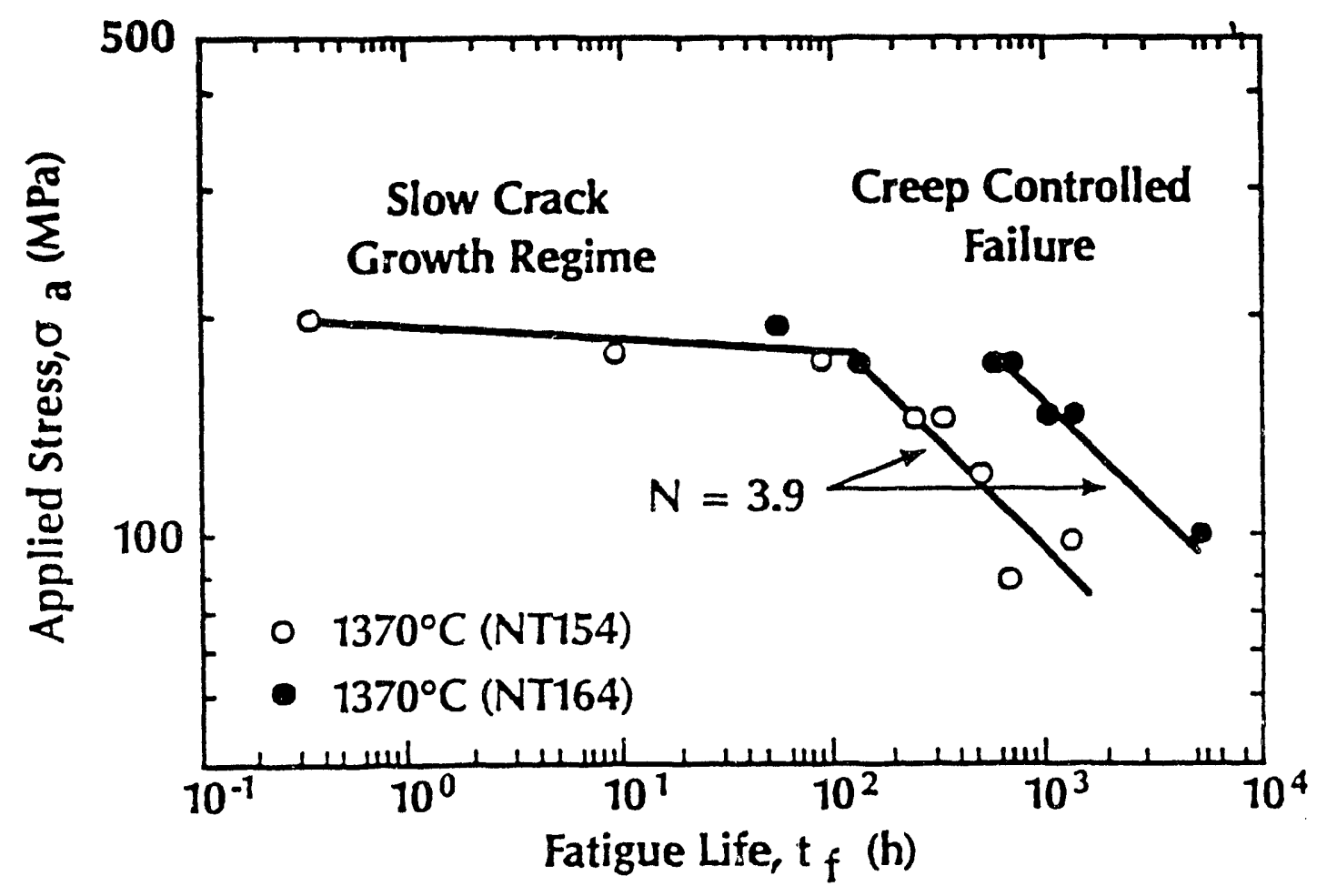

Figure 51. Creep Behavior Of NT154 And NT164 $\mathrm{Si}_{3} \mathrm{~N}_{4}$ At 1370C. 


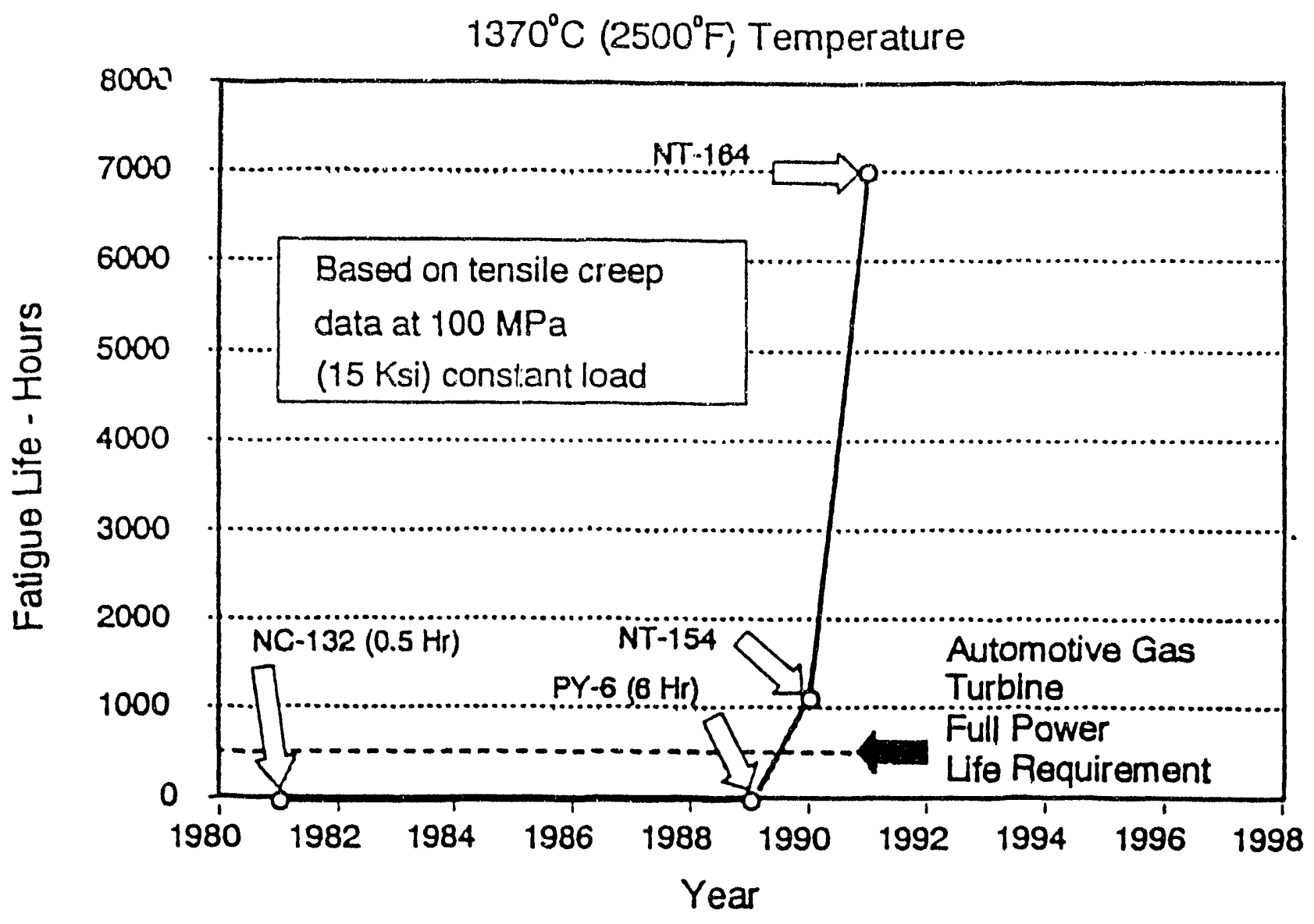

Figure 52. Fatigue Life Improvements $\mathrm{Of} \mathrm{Si}_{3} \mathrm{~N}_{4}$ (ORNL Data).

- NT230 Si-SiC - During 1990-91, NAC completed an IR\&D development program on improving Norton's siliconized silicon carbide ( $\mathrm{Si}-\mathrm{SiC}$ ). NAC investigated $\mathrm{Si}-\mathrm{SiC}$ because of its potential as a static-structural material within advanced gas turbine engines. Initial studies utilized an existing Si-SiC, designated NT235. This material has been previously examined for heat-engine applications (6,7), and is commonly known under a Norton designation as NC430, or Erystar.$(8,9)$ These products are densified, reaction-sintered silicon carbides featuring a bimodal distribution of silicon carbide grains and metallic silicon. Compositionally, they contain between 5 and 15 percent silicon, along with extremely low levels of trace impurities. NAC's efforts were directed at improving the mechanical behavior of these Si-SiC composites. By modification of the grain size distribution, and through selective changes to the fabrication process, NAC was able to approximately double the strength of the existing NT235 Si-SiC. A new material, designated NT230, resulted from this effort. Typical material properties of NT230 are shown in Table 17. A process flow chart is shown in Figure 53. This material is an ideal candidate for static structural components within the engine at temperatures below 
TABLE 17. PHYSICAL, THERMAL, AND MECHANICAL PROPERTIES OF NT230 Si-SiC

\begin{tabular}{|c|c|}
\hline Properties & NT230 Values \\
\hline 1. Density, g/cc & 305 \\
\hline 2. Elastic modulus, GPa & 395 \\
\hline 3. Shear modulus, GPa & 165 \\
\hline 4. Poisson's ratio & 0.17 \\
\hline 5. Hardness, $\mathrm{kg} / \mathrm{mm}^{2}$ & $\approx 1620$ \\
\hline 6. Thermal expansion coefficient & $4.7 \times 10^{-6} / \mathrm{C}$ \\
\hline $\begin{array}{l}\text { 7. Thermal conductivity, } \mathrm{W} / \mathrm{m}^{\circ} \mathrm{K} \\
25 \mathrm{C} \\
1000 \mathrm{C}\end{array}$ & $\begin{array}{c}\approx 135 \\
36\end{array}$ \\
\hline $\begin{array}{l}\text { 8. Flexural strength } \\
25 \mathrm{C} \\
1260 \mathrm{C} \\
1370 \mathrm{C} \\
\text { Weibull modulus } \\
\end{array}$ & $\begin{array}{r}410 \\
540 \\
500 \\
8-10 \\
\end{array}$ \\
\hline $\begin{array}{l}\text { 9. Fracture toughness, } \mathrm{MPa} \bullet \mathrm{m}^{1 / 2} \\
25 \mathrm{C} \\
25 \mathrm{C} \\
1370 \mathrm{C} \\
1370 \mathrm{C} \\
\end{array}$ & $\begin{array}{l}3.2^{*} \\
3.2^{* *} \\
8.1^{*} \\
5.5^{* *}\end{array}$ \\
\hline \multicolumn{2}{|c|}{$\begin{array}{l}\text { * Controlled flaw method at } 25 \mathrm{C} \text { and } 1370 \mathrm{C} \text {, respectively. } \\
\text { Single edge pre-cracked beam method at } 25 \mathrm{C} \text { and } 1370 \mathrm{C} \text {, respectively, } \\
\text { ORNL data. }\end{array}$} \\
\hline
\end{tabular}

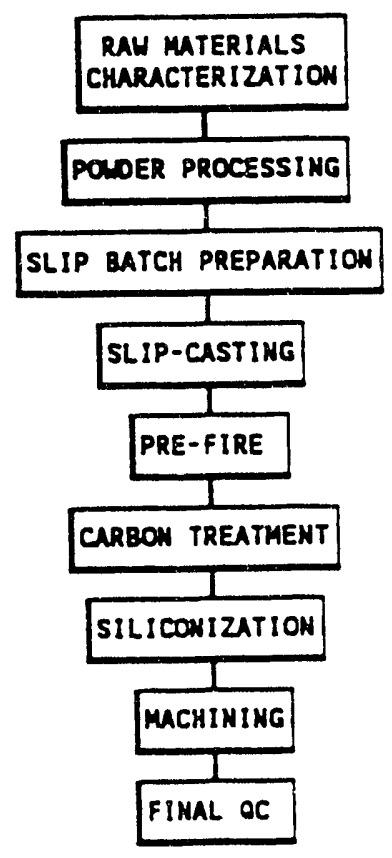

Figure 53. NT230 Process Flow Chart. 
about $1400 \mathrm{C}$. Due to the fact that the material exhibits little or no shrinkage upon densification, complex large components such as scrolls, combustors, shrouds and transition ducts can be readily produced to near final size. Also, because NT230 utilizes low-cost raw materials and excludes HIP as the densification step, total material and processing costs remain relatively low in comparison with NT154 or NT164 $\mathrm{Si}_{3} \mathrm{~N}_{4}$. During 1992, NAC utilized NT230 to fabricate engine-quality AGT101 Transition Ducts under a fixed price, parts-buy type contract.

\subsubsection{Component Cost Analysis}

NAC performed no formal cost analyses work during the year. Due to budgetary constraints, this task was eliminated from the 1992 Work Plan under the direction of GAPD.

\subsection{Forming Methods}

During 1992, NAC continued to focus all forming efforts on pressure slip-casting for the stator and rotor. NAC continued to utilize an integrated approach in the performance of this work. As such, developmenial activities were conducted in the following areas:

(1) Casting System Development

(2) AGT101 Rotor Fabrication Development

(3) AGT101 Stator Fabrication Development

(4) HIP Development.

\subsubsection{Casting System Development}

During 1992, NAC focused casting system development efforts in two areas including: (1) NT154 Aqueous-Based Milling Optimization, and (2) NT164 Pressure Casting Optimization. The first task was initiated during 1991 and completed auring 1992. Based on the successful completion of this task, NAC has replaced alcohol-milled NT154 with the optimized aqueous-milled system. The second task was a limited effort to develop near-net-shape pressure casting methods for NAC's NT164 $\mathrm{Si}_{3} \mathrm{~N}_{4}$. This task was successfully completed and pressure-cast NT164 test specimens were delivered to GAPD for evaluation. Based on the successful completion of this second task, NAC was able to implement its use on complex component fabrication for other customers. 


\subsubsection{NT154 Aqueous-Based Milling Optimization}

During 1990, NTC completed experimental efforts on two concepts in casting development: (1) PEEP Casting (Pressure-assisted Endothermic Extraction Process); and (2) WEEP Casting (Water Endothermic Extraction Process). Upon completion of the experimental plan, the PEEP process was chosen for further development work during 1991. Within the PEEP process itself, two conceptual variations were identified for optimization. As shown in Figure 54, PEEP methods can involve either: (1) agglomeration and calcination of alcohol-milled raw materials, or (2) aqueous milling and controlled flocculation of the same materials.

Following these batching operations, components are formed by pressure-casting, freezing, drying, firing, densification, crystallization, machining, and oxidation. During the early part of 1991, PEEP Method 1 was selected for the production of 1991's engine-quality deliverable hard ware.

The agglomeration step within the process was shown to be necessary for the production of crack free rotors; although stators were produced exclusive of agglomerated powders. (Cross-sectional thickness appears to account for the need to use agglomeration methods for rotors). During 1991, engine-quality AGT101 rotors and stators with adequate physical and mechanical properties were produced and delivered using the PEEP Method 1 process.

Despite the success of PEEP Method 1 to produce engine-quality hardware, the agglomeration equipment was identified during development work as a source of impurities which adversely affected mechanical properties. In order to use the agglomeration process reliably for engine-quality hardware, NAC implemented both equipment and procedural improvements. The agglomeration equipment was modified by incorporating highly wear-resistant NT154 components which resolved most impurity issues. In addition, standard procedures were written for this process and SPC methods implemented.

Because of impurity concerns associated with PEEP Method 1, NAC initiated development work during 1991 on PEEP Method 2 which involves controlled flocculation as an alternative to agglomeration. This work initially focused on development of an aqueous-based milling process which is a prerequisite to the subsequent development of controlled flocullation methods. During 1991, NAC completed the development of an aqueous-based milled, agglomeration process for NT154. Flexural test specimens were prepared and mechanical property improvements were successfully verified. As will be discussed below, tensile mechanical property testing was completed under NAC's 1992 work plan and the aqueous-milled, agglomerated NT154 system was qualified for use in making engine-quality components for all of NAC's customers. Due to budgetary restraints, 


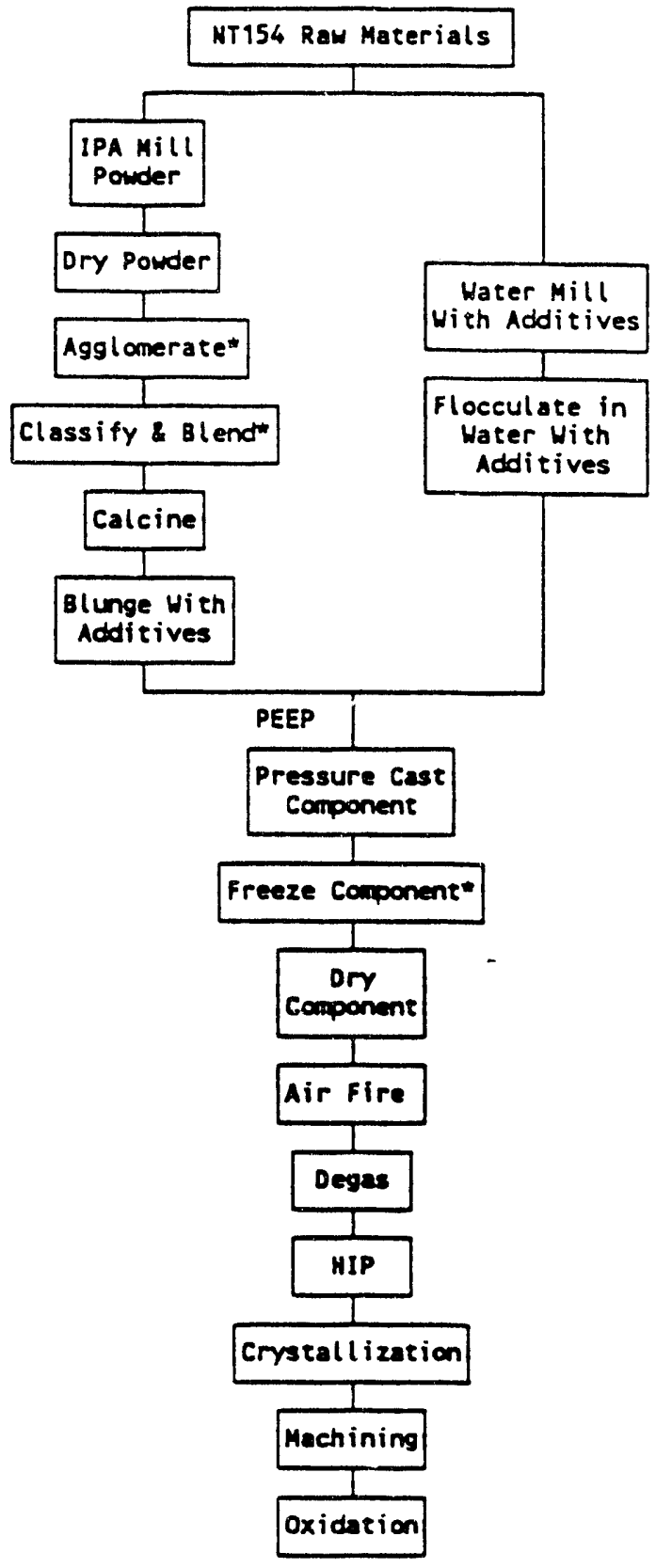

- Optional Process Operations thich Moy Mot Be Essential for Every Component.

Figure 54. NT154 Process Flow Diagram. 
however, NAC's 1992 work plan did not include further development of flocullation methoas and the complete development of PEEP Method 2. Instead. the aqueous-based milling process was qualified and then implemented as a substitute for alcohol-based milling with PEEP Method 1. As shown in Figure 55, this substitution has reduced NT154 material impurities but the agglomeration process step (and its associated impurity risks) continues to be utilized as a necessary powder preparation step to provide the excellent castability associated with PEEP Method 1.

Based on the positive flexural testing results obtained during 1991 for the aqueous milled, agglomerated NT154 system, NAC fabricated and tested a total of twelve tensile rods. The results of these tensile tests are presented in Table 18. These tensile testing results for aqueous-milled, pressurecast NT154 are equivalent to those obtained for typical, alcohol-milled, pressure-cast NT154.

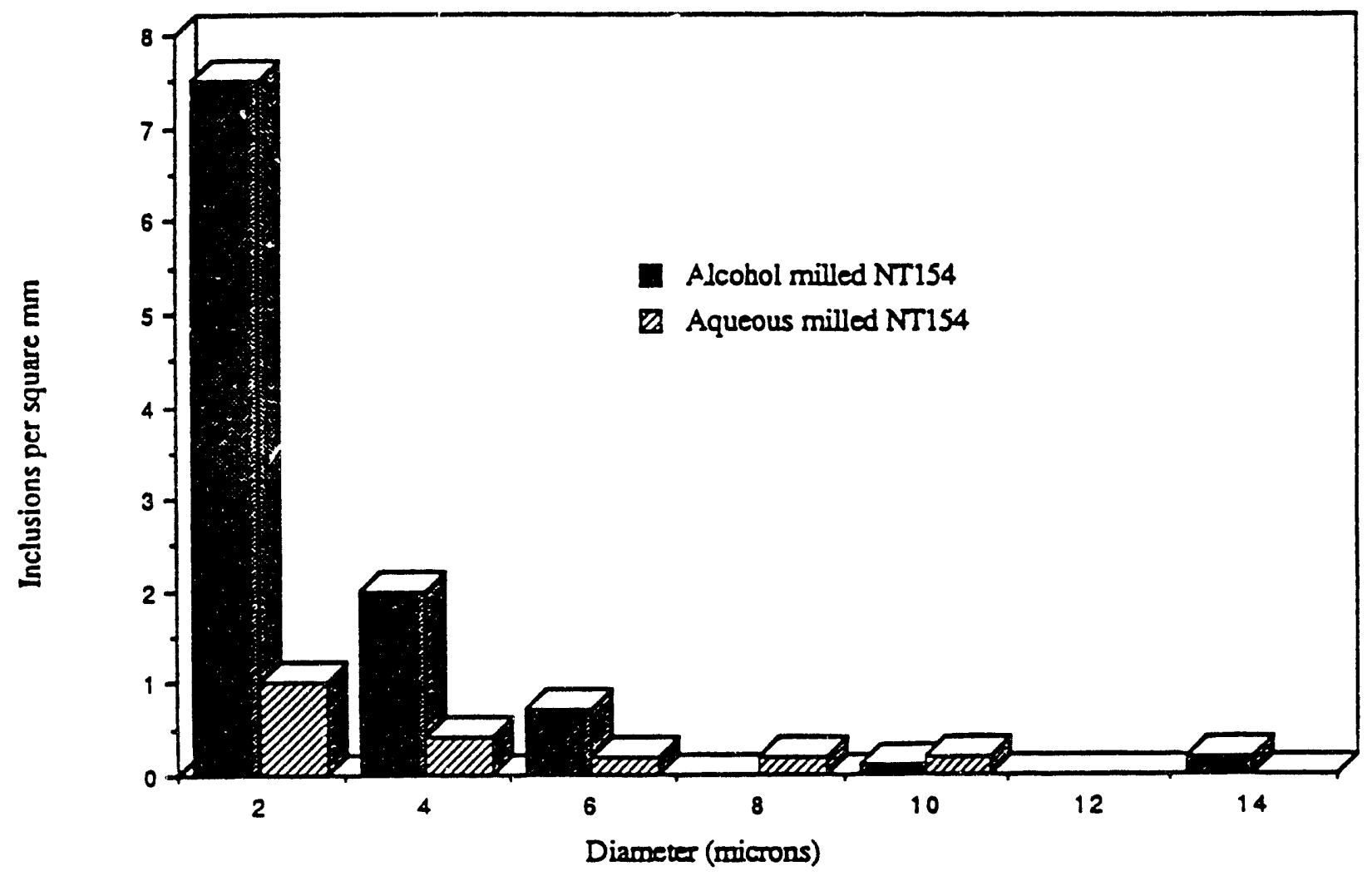

Figure 55. Inclusion Frequency Of Alcohol- Versus Aqueous-Milled NT154.

TABLE 18. AQUEOUS-MILLED, PRESSÜRE-CAST NT154 TENSILE FAST FRACTURE AND STRESS RUPTURE QUALIFICATION RESULTS

\begin{tabular}{|l|c|}
\hline Temperature And Stress Conditions & Result, ksi (MPa) \\
\hline \hline Rrom temperature fast fracture, $n=6$ & $93(639) \pm 10(70)$ \\
\hline $1370 \mathrm{C}$ fast fracture, $\mathrm{n}=4$ & $56(387) \pm 7(49)$ \\
\hline $1370 \mathrm{C} / 150 \mathrm{MPa}$ stress rupture & {$[2 \text { of } 2]^{*}$} \\
\hline${ }^{*}$ Number to survive $>300$ hours without failure \\
\hline
\end{tabular}


Based on the successful flexural and tensile testing results, the aqueous-milled, agglomerated, pressure-cast NT154 process was considered for use in fabricating deliverable AGT101 rotor and stator components. Under Task 3.2.2.2 for the rotor and Task 3.2.3.2 for the stator, components were cast, densified, and evaluated. Based on these evaluations, NAC implemented the aqueous milling process for AGT101 Rotor Deliverable Set No. 3. The aqueous-milled system was not implemented on AGT101 stator deliverables, due to shrinkage issues related to the second-generation pattern, not castability. Based on the successful fabrication of demonstration AGT101 rotors and stators, NAC implemented the aqueous-milled, agglomerated NT154 system for all its products. During the second half of 1992, numerous engine-quality components were fabricated and delivered to other NAC customers. From this work, a large data base for the aqueous-milled system has been generated. Figures 56, 57, and 58 show portions of this data base. Figure 56 shows a Weibull distribution for 596 room-temperature flexural data points and $1201370 \mathrm{C}$ flexural points. The Weibull modulus is $\mathbf{1 0 . 5}$ and $\mathbf{1 5 . 7}$ for room and high temperature, respectively. These Weibull moduli are similar to the alcohol-milled NT154 system, but the mean strengths of $142 \mathrm{ksi}$ and $96 \mathrm{ksi}$ for room and high temperature, respectively, have been substantially increased. Figure 57 shows NAC's actual statistical process control chart for aqueous-milled batches 30 through 58 . This chart demonstrates that batch-to-batch consistency has been excellent. Finally, Figure 58 shows stress rupture characteristics for aqueous-milled NT154 and NT164. Aqueous-milled NT154 has been demonstrated to have very consistent durability at a stress of $300 \mathrm{MPa}$ at $1370 \mathrm{C}$. In summary, the aqueous-milled, agglomerated system has made a very positive improvement to the mechanical properties of NT154. NAC expects that the Weibull modulus of NT154 can be further improved by the elimination of agglomeration in the future.

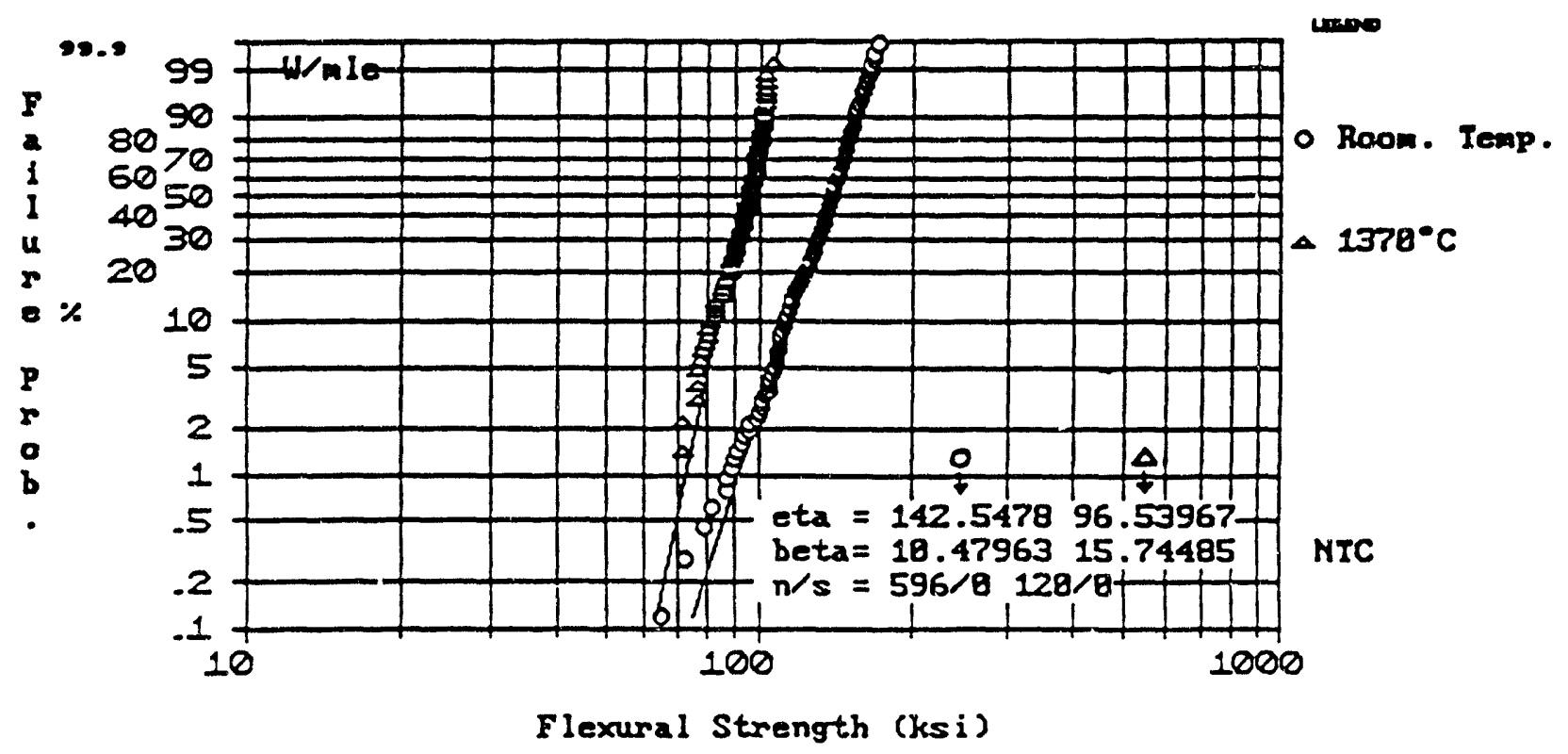

Figure 56. Aqueous-Milled, Agglomerated NT154 Weibull Distribution For Room Temperature And $1370 \mathrm{C}$ MOR. 
NT154 $1370^{\circ} \mathrm{C}$ Flexural Strength

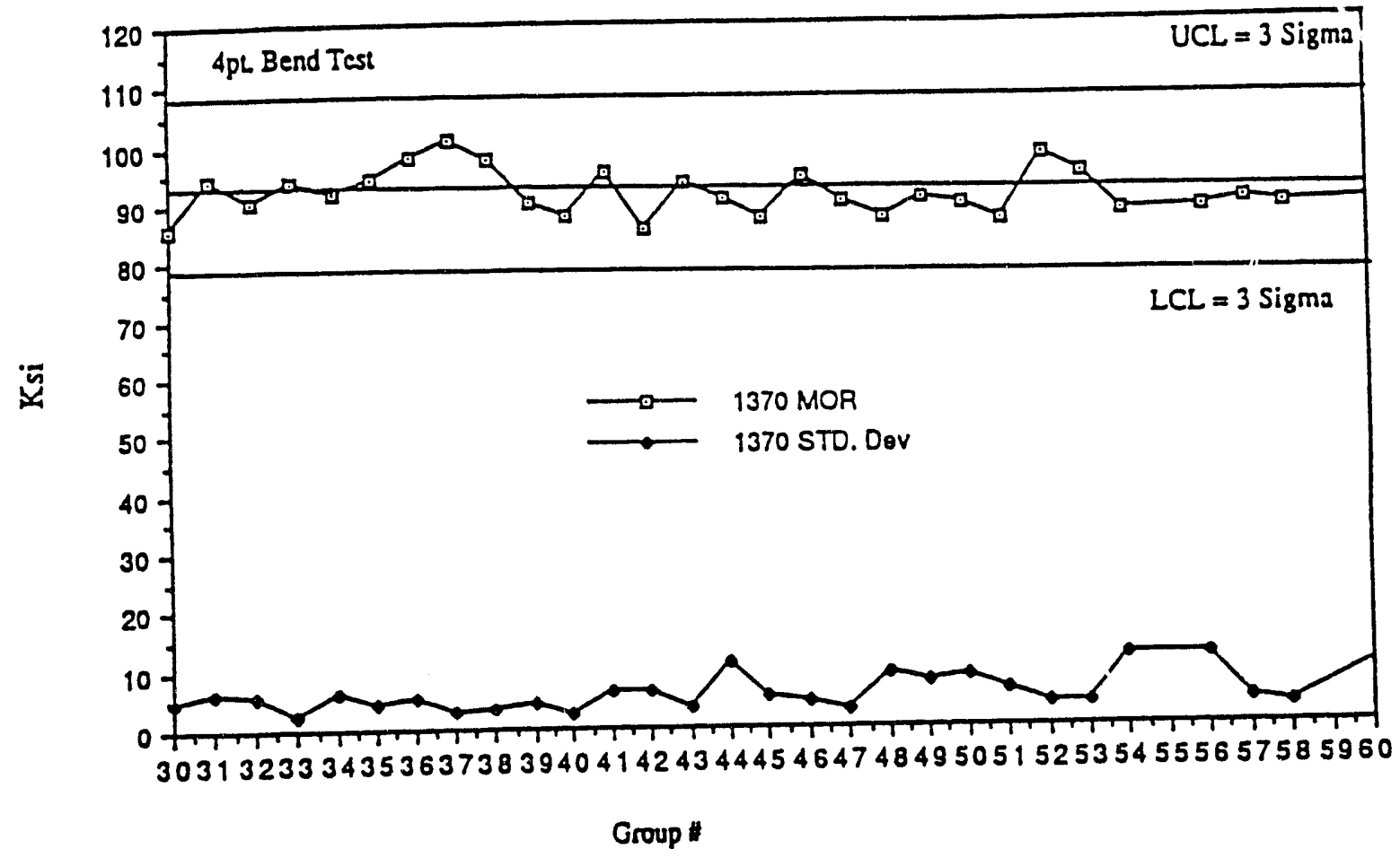

Figure 57. 1370C MOR Statistical Process Control Chart For Aqueous-Milled, Agglomerated NT154 Slip Batches 30 Through 58.

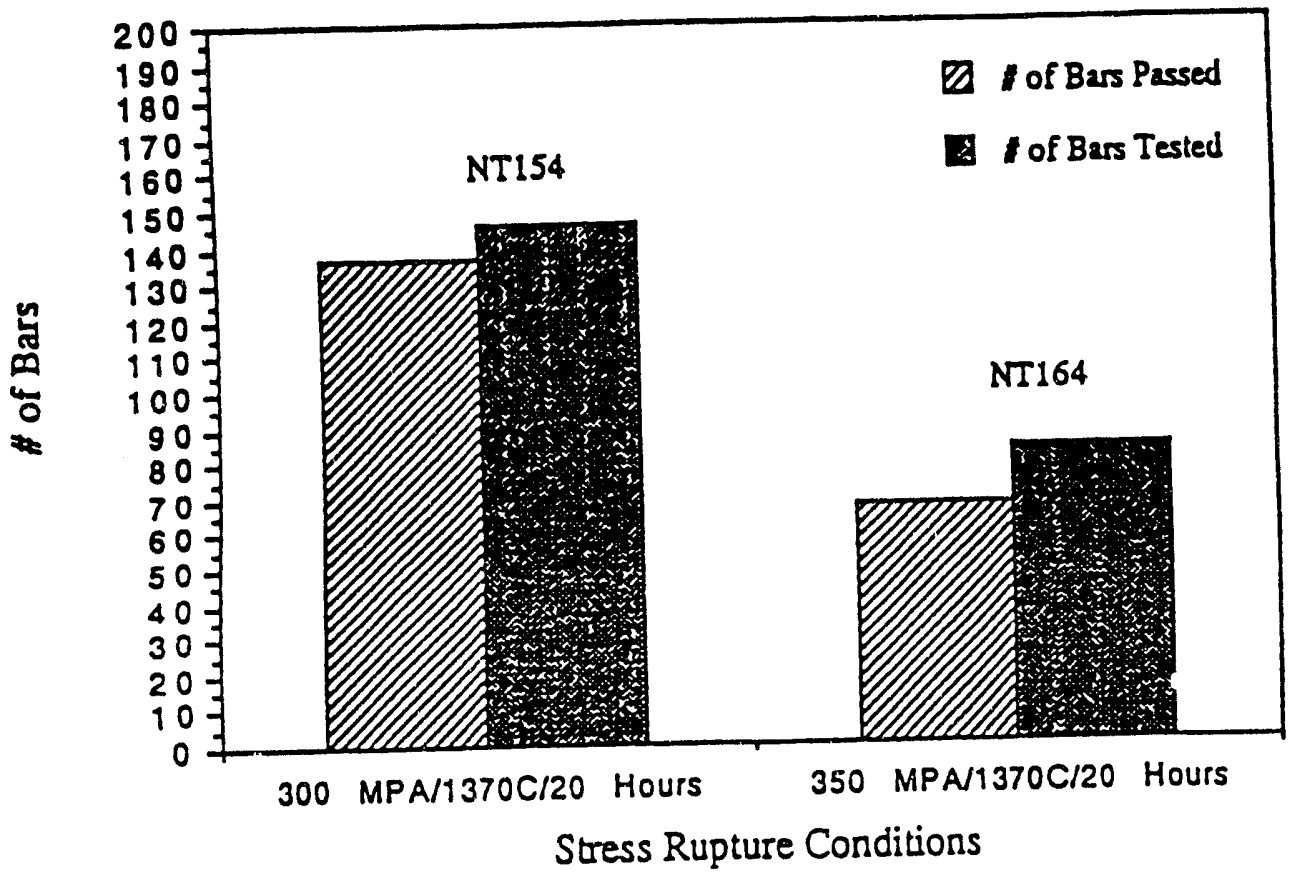

Figure 58. Aqueous-Milled NT154 And NT164 Stress Rupture Characteristics. 


\subsubsection{NT164 Pressure Casting Optimization}

During 1991, NAC completed internal materials development of NT164 $\mathrm{Si}_{3} \mathrm{~N}_{4}$. This material is compositionally very similar to NT154 and utilizes the same basic steps for processing. NAC's internal materials development was accomplished using dry pressing as the forming method to fabricate simple test billets. Under its 1992 work plan, NAC optimized a pressure-cast version of NT164 while preserving its superior high-temperature durability properties and providing near-netshape forming capability. NAC first processed NT164 powder through the PEEP Method 1 agglomeration and calcination steps. Using the agglomerated, calcined NT164 powder, NAC optimized a slip formulation based on NT154 processing technology. The optimized NT164 slip was developed to maximize green density and casting rate. Using an optimized slip, AGT101 rotors and stators were pressure cast to demonstrate complex shape castability. After castability was demonstrated, NAC utilized the optimized NT164 slip to produce deliverable test specimens required under Task 3.6.1. for GAPD evaluation. Under GAPD guidance, NAC did not plan to implement NT16.4 for engine-quality AGT101 hardware during 1992.

Based on the successful fabrication of demonstration AGT101 rotors and stators, however, NAC implemented the aqueous-milled, agglomerated NT164 system for production of complex components for other customers. During the second half of 1992, numerous engine-quality components were fabricated and delivered to other NAC customers. From this work, a large data base for the aqueous-milled NT164 system was generated. Figures 58, 59, and 60 show portions of this data base. Figure 59 shows a Weibull distribution for 564 room temperature flexural data points and $1201370 \mathrm{C}$ flexural points. The Weibull modulus is 8.9 and 12.6 for room and high temperature, respectively. These Weibull moduli and mean strengths of $134 \mathrm{ksi}$ and $96 \mathrm{ksi}$ for room and high temperature, respectively, are similar to the dry-pressed NT164 system, demonstrating that the mechanical properties were preserved during the pressure casting optimization effort. Figure 60 shows NAC's actual statistical prscess control chart for aqueous-milled NT164 batches 1 through 25. This chart demonstrates that batch-ło-balich consistency has been excellent. Finally, Figure 58 shows stress rupture characteristics for aqueo'us-milled NT154 and NT164. Aqueous-milled NT164 has been demonstrated to have very consistent durability at a stress of $350 \mathrm{MPa}$ at $1370 \mathrm{C}$. In summary, the aqueous-milled, agglomerated NT164 system was successfully developed. NAC expects that the Weibull modulus of NT164 can be further improved by the elimination of agglomeration in the future. 


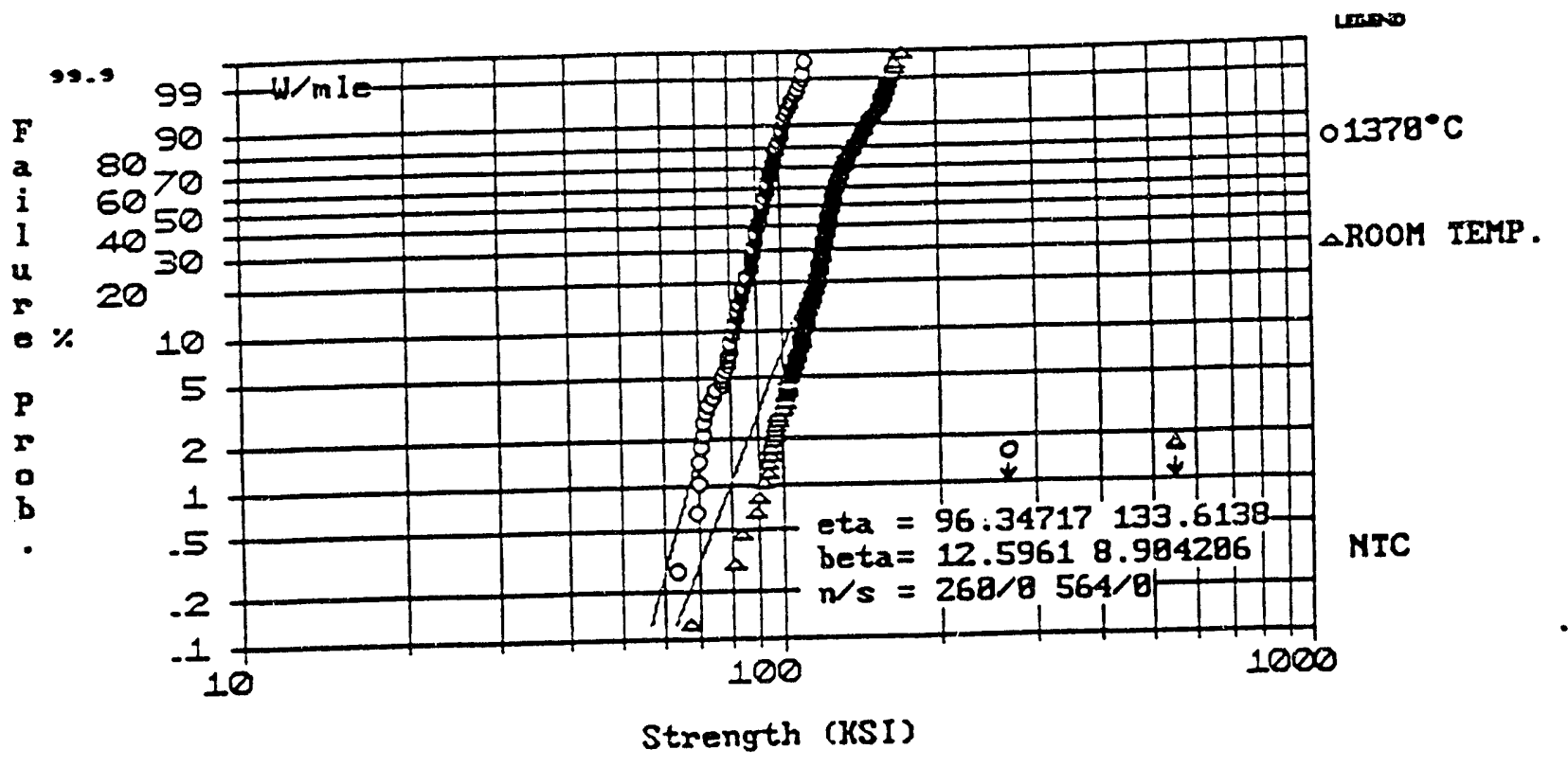

Figure 59. Aqueous-Milled, Agglomerated NT164 Weibull Distribution For Room Temperature And 1370C MOR.

NT164 $1370^{\circ} \mathrm{C}$ Flexural Strength

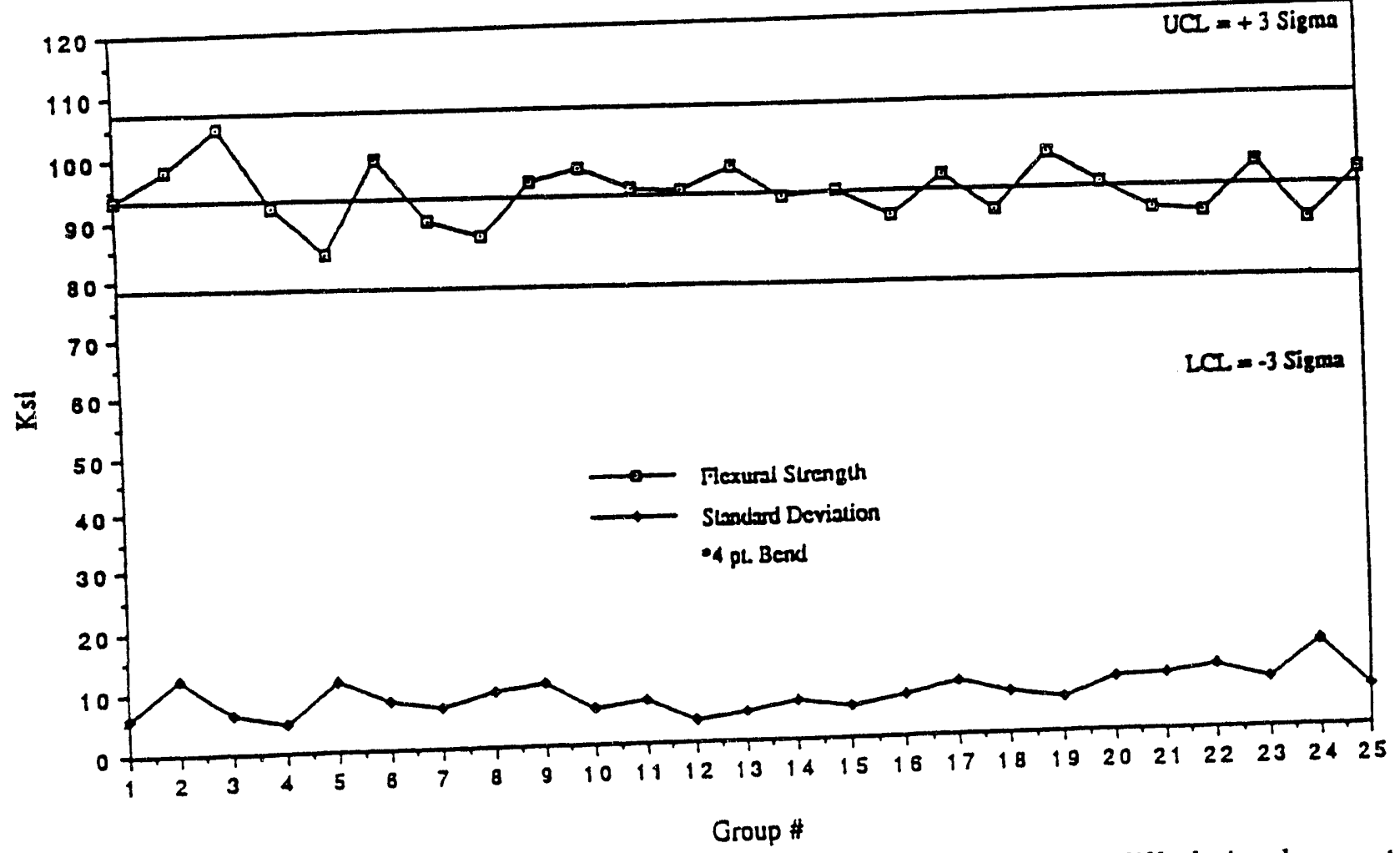

Figure 60. 1370C MOR Statistical Process Control Chart For Aqueous-Milled, Agglomerated NT164 Slip Batches 1 Through 25. 


\subsubsection{AGT101 Rotor Fabrication Development}

For 1992, each set of deliverable rotors was produced from a defined and qualified process. Component specific tabrication development, as necessary, was performed prior to component production, and mainly involved the following sub-tasks: (1) Tooling Design and Fabrication; and (2) Casting Development. These tasks were directed at defining features and achieving dimensional tolerance. Deliverable Set No. 2 was produced from an identical process as that used for Set No. 1 which was delivered during 1991. However, before component production was initiated for Deliverable Set No. 3, NAC elected to revise process operations to incorporate newly-developed aqueous-milled NT154 technology. Each rotor within a delivery set of four components (three engine-quality rotors plus one cut-up) was produced under an identical fixed process.

\subsubsection{Tooling Design And Fabrication}

Prior to initiation of Rotor Deliverable Set No. 2, NAC performed a comprehensive review of the fixed process utilized in the production of the 1991 Set No. 1 deliverables. Issues requiring improvement were identified and a corrective action plan was formulated. Under Rotor Set No. 1, NAC experienced a variety of dimensional non-conformances including:

(1) An undersized backface diameter

(2) Leading and trailing edge profiles out of tolerance

(3) Hub profile out of tolerance

(4) Blade $\mathrm{L}$ and $\mathrm{Z}$ section profiles out of tolerance.

Mostly, these issues could only be resolved through a change in the shrinkage of the component. Shrinkage issues are addressed under Task 3.2.2.2. Slight modifications to casting tools were, however, made prior to fabrication of casting molds for Deliverable Set No. 2. NAC modified the backface of the stainless steel AGT101 rotor casting pattern by adding $\approx 0.070$ inch machining stock onto the entire surface except for datum D. Based on Deliverable Set No. 1, NAC experienced slightly higher shrinkage than planned along the axis of the AGT101 rotor, thus reducing the amount of machining stock on the backface from the planned $=0.020$ inch to $\leq 0.005$ inch. In order to assure that the backface could be reliably cleaned up to the required machined geometry, NAC elected to add a plentiful amount of excess stock which was easily and quickly machined away by creep feed grinding methods using large depths of cut.

Using the modified casting pattern, casting molds were fabricated prior to production of both Set No. 2 and Set No. 3 using the identical design as was used for Set No. 1. These molds were prepared 
from plaster and plastic materials with various porous and non-porous surfaces. A total of three molds were fabricated prior to each set of deliverables. NAC utilized the identical component specific tooling and $f_{1} x t u r e s$ for green and dense machining of AGT101 rotors as previously optimized under the Set No. 1 deliverable effort during 1991. Only minor modifications and improvements were implemented to this tooling to improve dimensional control and yields.

\subsubsection{Casting Development}

During 1992, AGT101 rotor casting development was limited in scope and focused specifically on improvements ' $)$ the dimensional correctness of the densified components. Based on the results of Rotor Set No. 1 fabricated during 1991, NAC experienc. d a variety of dimensional non-conformances, including:

(1) An undersized backface diameter

(2) Leading and trailing edge profiles out of tolerance

(3) Hub profile out of tolerance

(4) Blade $\mathrm{L}$ and $\mathrm{Z}$ section profiles out of tolerance.

Prior to initiation of Deliverable Set No. 3, NAC performed various screening trials in an attempt to demonstrate correction to each of these dimensional issues. These casting trials focused on increasing green density, reducing warpage, and minimizing green density gradients.

As discussed under Task 3.2.1.1, the aqueous-milled, agglomerated, pressure-cast NT154 process was utilized in these casting trials due to its inherently higher green density. Using this process, NAC treated the porous surfaces of the casting mold in various ways to modify casting behavior to minimize green density gradients. A total of four rotors were cast. Two of the four rotors were cast with the porous base surface treated to modify casting behavior and minimize green density gradients. The other two rotors were cast with non-treated porous bases. The four rotors were densified and critical dimensions measured to evaluate improvements compared to Delivery Set No. 1 and No. 2 rotors cast using alcohol-milled NT154 powder. Results of this dimensional evaluation are shown in Table 19. Whereas the alcohol-milled NT154 powder system yielded dimensions which were below specification, the aqueous-based system yielded dimensions above specification. This result was expected due to the increased green density for this system. NAC considered the dimensions for aqueous-milled NT154 powder with treated porous base to be the best because the datum E dimension was closest to the print specification. The base diameter was over the specification but can easily be machined to the print requirements. NAC also made a blade profile comparison between the three processes and found that the aqueous-milled NT154 powder with 
TABLE 19. DIMENSIONAL EVALUATION OF AGT101 ROTORS

\begin{tabular}{|l|c|c|}
\hline \multicolumn{1}{|c|}{ Process Description } & Base Diameter, in & Datum E Diameter, in \\
\hline \hline $\begin{array}{l}\text { Alcohol-milled NT154 puwder } \\
\text { with nontreated porous base }\end{array}$ & 4.194 & 1.655 \\
\hline $\begin{array}{l}\text { Aqueous-milled NT154 powder } \\
\text { with nontreated porous base }\end{array}$ & 4.288 & 1.694 \\
\hline $\begin{array}{l}\text { Aqueous-milled NT154 powder } \\
\text { with treated porous base }\end{array}$ & 4.290 & 1.687 \\
\hline Print specification & 4.2634 & 1.6736 \\
\hline All dimensions are the mean of three measurements. & \\
\hline
\end{tabular}

treated porous base yielded leading and trailing edges closest to print requirements. Based on these dimensional results and the mechanical property results for the aqueous-milled NT154 powder discussed under Task 3.2.1.1, NAC selected and implemented this system for use on Rotor Deliverable Set No. 3. Set No. 3 was processed through HIP densification and was then placed on hold by GAPD due to budgetary constraints, as shown in Figure 49. No further dimensional evaluation was performed on Rotor Set No. 3 to verify improved dimensional conformance to print.

\subsubsection{AGT101 Stator Fabrication Development}

In a similar fashion to the rotor, each set of deliverable stators during 1992 was produced from a defined and qualified process. Component specific process development, as necessary, was performed prior to component production, and mainly involved the following sub-tasks: (1)Tooling Design and Fabrication, and (2) Casting Development.

These tasks were directed at defining features and achieving dimensional tolerance. Deliverable Set No. 2 was produced from an identical process as that used for Set No. 1 which was delivered during 1991. However, before component production was initiated for Deliverable Sets No. 3 and No. 4, NAC elected to revise process operations to incorporate the use of a second-generation casting pattern and mold design. Each stator within a delivery set was produced under an identical fixed process.

\subsubsection{Tooling Design And Fabrication}

In the production of Deliverable Set No. 1, NAC experienced poor yields and a variety of dimensional non-conformances. Prior to the initiation of Deliverable Set No. 2, NAC performed a 
comprehensive review of the fixed process utilized in the production of the 1991 Set No. 1 deliverables. Issues requiring improvement were identified and a corrective action plan was formulated. To improve dimensional conformance, NAC decided to design and procure a second-generation casting pattern for implementation on Set No. 3. To improve yields, NAC decided to improve the mold design itself to minimize the occurrence of trailing edge and cleat cracks which were the main cause for rejection in the production of Set No. 1. The design of the new pattern incorporated the necessary overstock and features to maximize castability and machinability of the component.

As shown in Figure 61, the second-generation pattern was designed with large radii between surfaces to decrease the difficulty in removing the component from the casting mold. In addition, this new pattern was designed with a bi-directional shrink factor based on experience from Set No. 1 . In the production of Set No. 1, NAC learned that platform-to-platform shrinkage was greater than the airfoil chord length shrinkage. Because the first-generation pattern was based on chord length shrinkage, the distance between platforms was $\approx 0.020$ inch shorter than required. Because of schedule requirements, NAC was unable to implement the second-generation pattern for Set No. 2 deliverables. The new pattern was implemented starting with Set No. 3 deliverables.

Prior to the initiation of Deliverable Set No. 2, NAC modified its first-generation casting pattern to add stock to surfaces requiring finish machining. This stock was added not only to assure that these surfaces clean up properly but also to improve castability by decreasing the difficulty in removing the component from the casting mold. In addition, an improved mold design was implemented that was expected to eliminate the occurrence of trailing edge and cleat cracks which were the main cause for rejection in the production of Set No. 1. A total of four new casting molds were fabricated and implemented for production of Stator Deliverable Set No. 2.

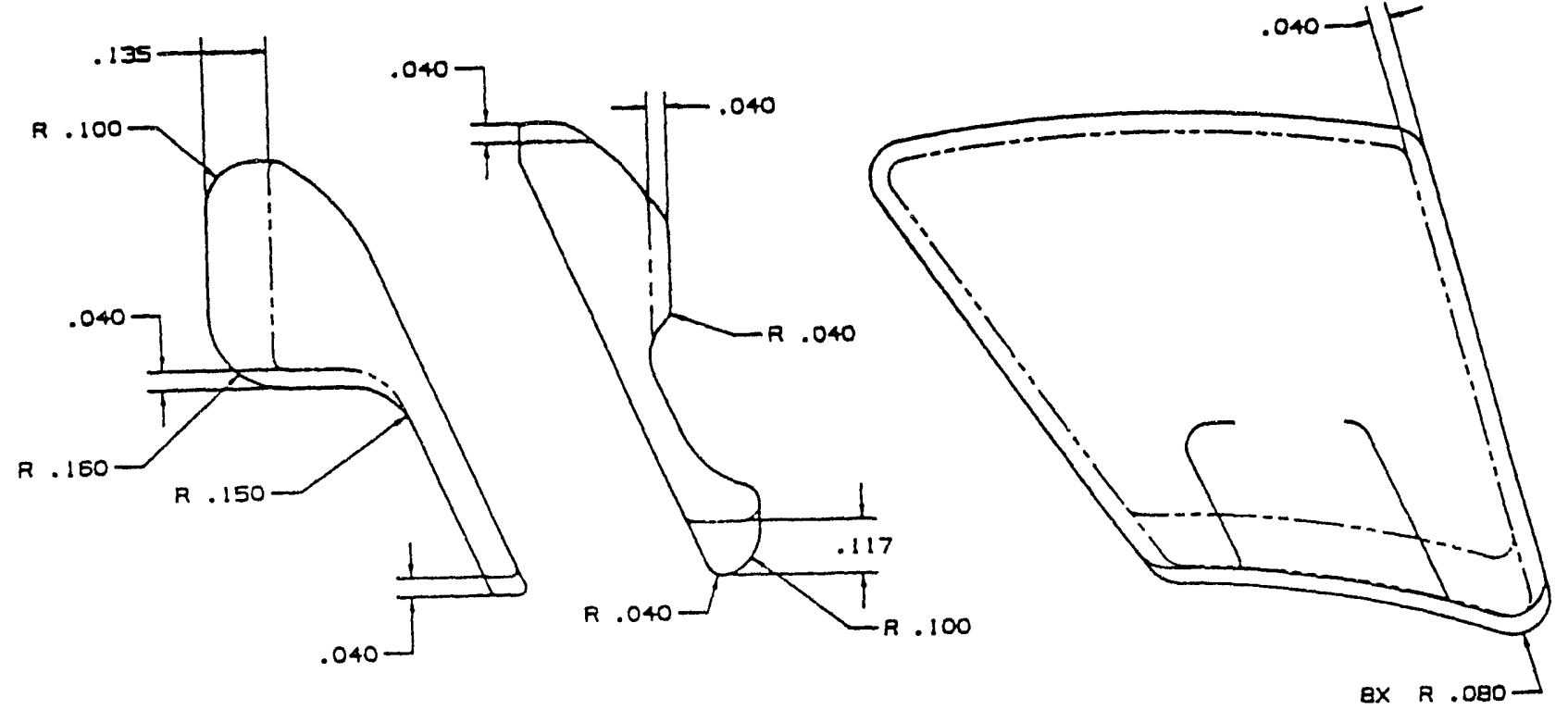

Figure 61. Second-Generation AGT101 Stator Casting Pattern Design. 
Using the second-generation pattern in preparation for Set No. 3 production, NAC fabricated a development casting mold using the same mold design as implemented for Set No. 2. Iterative casting trials were successfully performed to evaluate castability and to optimize the casting mold design specifically for the second-generation casting pattern. Using the optimized mold design, four production molds were fabricated and implemented prior to the initiation of both Set No. 3 and No. 4 .

\subsubsection{Casting Development}

During 1992, AGT101 stator casting development was limited in scope and focused specifically on improvements to the dimensional correctness of the densified components. Prior to the initiation of Deliverable Set No. 3, NAC used the second-generation casting pattern and the Deliverable Set No. 2 mold design to fabricate a single casting mold. Preliminary screening trials were performed to verify the viability of the original mold design as applied to the new casting pattern. Only minor adjustments to the mold were required to optimize the design for use in performing casting optimization trials in preparation for the production of Deliverable Set No. 3. Using the optimized mold, a limited number of stators were cast at systematically varied casting parameters using both the alcohol- and aqueous-milled NT154 casting systems to manipulate green density and thus final dimensions. These stators were densified and a dimensional evaluation was completed. Based on these results, the alcohol-milled NT154 system was selected due to its conformance to print as compared to the aqueous-milled system. Due to its inherent higher green density and lower shrink factor, the aqueous-milled system casting parameters could not be manipulated to conform to the shrink factor designed into the second-generation pattern for the alcohol-milled system. Although improved mechanical properties could have been achieved through the use of the aqueous-milled system, NAC finalized casting parameters and mold design for use of the alcohol-milled system for the production of both Stator Sets No. 3 and No. 4.

\subsubsection{HIP Development}

Two sub-tasks were conducted within HIP development: (1) As-Fired Surface Optimization L16 Experiment; and (2) As-Fired Component Surface Improvement Screening Trials.

\subsubsection{As-Fired Surface Optimization L16 Experiment}

The As-Fired Surface Optimization L16 experiment was carried over from 1991 for completion in 1992. Only a limited amount of long-term flexural stress rupture testing remained to finish this experiment. The experiment was originally initiated in 1991 in an attempt to identify materials and procedures which allowed control over the HIP reaction layer. Dry-pressed NT154 tiles were utilized 
to fabricate the as-processed and bulk test specimens in this experiment. The intent of the experiment was to identify powder processing, presintering, HIPping, crystallization, and sandblasting conditions which would maximize both bulk and as-fired mechanical properties. Previously reported fast fracture and stress rupture results were able to identify thuse processing conditions for this drypressed material. Due to budgetary and time constraints and the fact that the dry-pressed material was not truly representative of the strength-limiting defects on pressure-cast surfaces, the remaining long-term stress rupture testing was not completed during 1992. NAC elected to cease further data collection on this experiment and focus instead on improvement of as-processed surface strengths of pressure-cast material performed under Task 3.2.4.1.

\subsubsection{As-Fired Component Surface Improvement Trials}

The second sub-task was aimed at improving the as-fired surface quality of pressure-cast components. Screening trials were performed to investigate various methods for improving the as-fired strength and finish of as-cast component surfaces. A total of four different methods involving postcasting, post-presintering, and post-densification treatments were investigated. Surfaces were characterized via finish, SEM, and mechanical properties. A summary of mechanical property results is shown in Table 20 below. As shown in the table, none of the surface treatments significantly improved as-fired surface mechanical properties. Treatment No. 5 gave the best results. This treatment involved post-HIP sirface modification via chemical etching. In all cases, the surface treatments were not capable of eliminating strength-limiting flaws. NT154 as-fired surfaces possess $<0.005$ inch pits which are inherent to the forming and HIP densification processes. None of the postpresinter surface treatments were able to fill in these pits. Treatment No. 5 was not able to blunt these flaws either by chemically polishing.

TABLE 20. AS-FIRED SURFACE IMPROVEMENT TRIAL RESULTS

\begin{tabular}{|c|c|c|c|c|}
\hline $\begin{array}{c}\text { Trial } \\
\#\end{array}$ & $\begin{array}{c}\text { Surface } \\
\text { Treatment }\end{array}$ & 25C MOR, ksi & 1370C MOR, ksi & $\begin{array}{c}\text { Stress Rupture, } \\
1370 \mathrm{C} / 43 \mathrm{ksi}\end{array}$ \\
\hline 1 & Bulk control & $\begin{array}{c}128 \pm 16 \\
{[32]}\end{array}$ & $\begin{array}{c}85 \pm 6 \\
{[10]}\end{array}$ & 0 of $4>100$ hours \\
\hline 2 & Post presinter & $\begin{array}{c}65 \pm 15 \\
{[6]}\end{array}$ & $\begin{array}{c}52 \pm 7 \\
{[3]}\end{array}$ & Not Tested \\
\hline 3 & Post presinter & $\begin{array}{c}74 \pm 16 \\
{[18]}\end{array}$ & $\begin{array}{c}56 \pm 13 \\
{[5]}\end{array}$ & Not Tested \\
\hline 4 & Post presinter & $\begin{array}{c}4 \pm 9 \\
{[34]}\end{array}$ & $\begin{array}{c}61 \pm 5 \\
{[8]} \\
\end{array}$ & Not Tested \\
\hline 5 & Post HIP & $\begin{array}{c}86 \pm 8 \\
{[5]}\end{array}$ & Not Tested & Not Tested \\
\hline 6 & As-fired control & $\begin{array}{c}74 \pm 12 \\
{[34]}\end{array}$ & $\begin{array}{c}57 \pm 3 \\
{[8]} \\
\end{array}$ & Not Tested \\
\hline
\end{tabular}


Under the ATTAP program, NAC has attempted to improve as-fired surface strengths by a variety of processing techniques. None of these techniques proved to be successful in reaching the goal of equivalent strength between as-fired and bulk-ground surfaces. The majority of NAC's work focused on firing optimization. These methods can be considered repair techniques. Based on the body of work performed by NAC throughout ATTAP, NAC believes that much more work is required on prevention and removal techniques. Prevention measures are preferred and can only be accomplished during the slip preparation and casting processes. Removal measures are less preferred, due to the inherent difficulties in the uniform removal of $a \approx 0.005$ inch surface layer of material from the complex surfaces.

\subsection{Process Engineering}

Consistent with the submission of bimonthly technical progress reports, NAC revised and updated its Work Plan as needed to address new problems or take advantage of new technology as it developed within the program. NAC completed and delivered its 1992 Technical Work Plan during February. A number of changes were made to this original Work Plan by GAPD during the year. Additional NT154 and NT164 specimen fabrication deliverables were made part of the Work Plan, including sub-tasks 3.6.1.5 through 3.6.1.9 as shown in Figure 49. At mid-year, GAPD implemented a program completion strategy for NAC due to budgetary constraints. Under GAPD's plan, all nonessential activities were put on hold at the end of August. The last sets of engine-quality rotors and stators were not completed per GAPD's plan. The last set of rotors were processed through premachining inspection and then held prior to finish machining. The last set of stators were processed through finish machining and then held prior to final inspection. NAC completed its activities on the 1992 effort in accordance with the work plan schedule shown in Figure 49.

\subsection{Nondestructive Evaluation (NDE)}

NAC's efforts in NDE development using microfocus x-ray radiography (MFXR) were completed during the first two program years. An assessment of seeded defects was conducted, and specific inspection protocols were developed and documented. NAC determined that MFXR was an effective tool for the characterization of process and forming development for relatively large defects $(>25 \mathrm{~mm})$; but was ineffective in assuring ultimate component quality. From this prior work, NAC utilized MFXR during 1992 to support component forming development activities and as a standard pre-HIP inspection tool. 


\subsubsection{Microfocus X-Radiography (MFXR) Development}

Component specific inspection protocols for MFXR characterization of AGT101 rotors and stators that were previously developed, documented, and provided to GAPD were modified during 1992. The modified inspection procedures, defining protocols for both green state and dense state MrXR characterization, incorporated: (1) Recent component design changes, (2) Pass/fail criteria, and (3) Additional exposures to improve inspection coverage.

\subsubsection{Fluorescent Dye Penetrant Development}

\subsubsection{Fluorescent Dye Penetrant System Optimization}

As part of the original 1992 Work Plan, NAC proposed an experiment to optimize an appropriate fluorescent dye penetrant inspection system (or systems) in terms of defect detectability and reliability of inspection from inspector to inspector over a range of different ceramic materials, surface types, component shapes, and defect types. Experimental factors to be investigated included penetrant type, cleaning treatment, developer form, inspection location, penetrant dwell time, and developer dwell time. The experiment design was finalized with inputs from GAPD. Due to budgetary constraints discussed under Task 3.3, however, the experiment was not initiated.

\subsubsection{Fluorescent Dye Penetrant Inspection Procedures}

Based on the expected results of the flucrescent dye penetrant system optimization experiment originally planned in section 3.4.2.1, inspection procedures that were previously developed, documented, and reported to GAPD were planned to be modified to incorporate changes in:

(1) Cleaning procedure

(2) Penetrant type

(3) Penetrant dwell time (currently not formally specified)

(4) Developer form, and Developer dwell time (currently not formally specified).

Because the experiment was not performed under Task 3.4.2.1., NAC did not modify its standard operating procedures for fluorescent penetrant inspection. 


\subsection{Quality Assurance}

During 1992, NAC continued to implement its Quality Assurance Plan. This effort was subdivided into five tasks:

(1) Documentation of the Quality System

(2) Measurements and Standards Development

(3) Process Documentation

(4) Statistical Process Control (SPC) Development and Implementation

(5) Component Manufacturing and Inspection Plans.

\subsubsection{Documentation Of The NAC Quality System}

During 1990, NAC completed incorporation of GAPD's commentary into its Quality Manual. This document was been approved internally and formally implemented throughout the organization. No significant modifications to this manuscript were nıade in 1992.

\subsubsection{Measurement Techniques/Standards Development}

In previous years of the ATTAP program, NAC standardized and documented various test, measurement, and inspection procedures including:

(1) MFXR characterization

(2) Fluorescent dye penetrant inspection

(3) Density measurement

(4) Mechanical properties testing.

During 1990, NAC completed documentation of all of its in-house mechanical properties testing procedures, including room temperature flexural strength, high temperature flexural strength, flexural stress rupture testing, and flexural dynamic fatigue testing. In 1992, NAC:

(1) Modified the AGT101 rotor and stator MFXR characterization procedures (See Section 3.4.1), and

(2) Modified and expand its existing measurement standards and calibration system to be in accordance with GAPD and MIL-STD-45662 requirements. 


\subsubsection{Process Documentation}

Work in this area was a continuation of efforts initiated in previous years of the program. In 1990 and 1991, procedures were formally documented for the following process steps:

(1) Powder processing (batch qualification siteria only)

(2) Powder agglomeration

(3) Powder rotary calcining

(4) Slip Preparation

(5) Presintering

(6) HIP operation (run qualification criteria only)

(7) Post-HIP crystallization

(8) Post-machining oxidation.

As experiments were completed and specific processing operations selected throughout 1992, written procedures were prepared and implemented.

\subsubsection{SPC Development And Implementation}

Implementation and maintenance of SPC on defined (fixed) processes was a continuation of efforts initiated in previous years of the program. In 1990, SPC implementation was completed for all non-component specific uperations. Activity in 1992 continued to focus on developing and implementing SPC for AGT 101 rotor and stator forming operations.

\subsubsection{Component Manurasturing And Inspection Plans}

Consistent with the production and delivery of components, NAC implemented manufacturing routing work instructions (operations sheets) and inspection plans for AG T101 rotors, stators and test specimen deliverables. During 1992, these documents were modified to include changes in operations sequence, detailed component-specific work instructions, in-process inspection requirements, and pass/fail criteria at each process step.

\subsection{Deliverables}

In accordance with the work plan schedule shown in Figure 49, NAC delivered numerous NT164 and NT154 specimens, engine-quality AGT101 rotors, and engine-quality AGT101 stators. The details of these deliverables are summarized in this section. 


\subsubsection{NT164 Test Specimens}

Using the optimized pressure casting process developed under Task 3.2.1.2, NAC fabricated and delivered numerous NT164 specimens for GAPD evaluation. The types, quantities, and delivery dates are shown in Figure 49. Co-processed mechanical property data generated for these deliverable specimens was combined and is shown in Table 21. For comparison purposes, all data generated for AGT101 Rotor Sets No. 1 and No. 2 and for AGT101 Stator Sets No. 1, No. 2, and No. 3 were combined and also included in Table 21. Overall, co-processed mechanical properties for both NT154 and NT164 adequately met ATTAP material specifications.

\subsubsection{Engine-Quality AGT101 Rotors}

In accordance with the work plan schedule shown in Figure 49, NAC fabricated and delivered a total of five engine-quality, proof-tested AGT101 Rotors under deliverable Set No. 2. Figure 62 shows two of these proof-tested rotors. Combined with the results of Rotor Deliverable Set No. 1, NAC successfully spin tested all eleven rotors attempted. Spin test results are presented in Table 22. Both rotor sets No. 1 and No. 2 were fabricated using the alcohol-milled, agglomerated NT154 system. Coprocess mechanical properties were generated from test billets and a cut-up rotor. Co-processed

\section{TABLE 21. COMBINED CO-PROCESS MECHANICAL PROPERTY RESULTS FOR ALL ENGINE-QUALITY AGT101 ROTOR, ENGINE-QUALITY STATOR, AND NT154 SPECIMEN DELIVERABLES}

\begin{tabular}{|l|c|c|c|}
\cline { 2 - 4 } \multicolumn{1}{c|}{} & $\begin{array}{c}\text { NT154 AGT101 } \\
\text { Rotors }\end{array}$ & $\begin{array}{c}\text { N154 AGT101 } \\
\text { Stators }\end{array}$ & $\begin{array}{c}\text { NT164 } \\
\text { Specimens }\end{array}$ \\
\hline 22C bulk MOR, MPa & $895.6 \pm 122.0$ & $863.9 \pm 105.5$ & $917 \pm 76.5$ \\
Number of Samples & 200 & 146 & 70 \\
$22 \mathrm{C}$ bulk Weibull modulus & 9.6 & 9.4 & 9.8 \\
\hline $1370 \mathrm{C}$ bulk MOR, MPa & $651.6 \pm 54.5$ & $561.9 \pm 43.4$ & $641.2 \pm 44.1$ \\
Number of samples & 76 & 63 & 50 \\
$1370 \mathrm{C}$ bulk Weibull Modulus & 14.1 & 16 & 15.2 \\
\hline $22 \mathrm{C}$ as-processed MOR, MPa & $\mathrm{N} / \mathrm{A}$ & $522.6 \pm 116.5$ & $545.6 \pm 72.4$ \\
Number of samples & - & 57 & 23 \\
$22 \mathrm{C}$ as-processed Weibull modulus & - & 6.5 & 8.1 \\
\hline $1370 \mathrm{C}$ as-processed MOR, MPa & $\mathrm{N} / \mathrm{A}$ & $472 \pm 106.2$ & $510.1 \pm 102.7$ \\
Number of samples & - & 58 & 15 \\
$1370 \mathrm{C}$ as-prncessed Weibull modulus & - & 9.6 & 5.7 \\
\hline Fracture toughness, MPa $\bullet \mathrm{m}^{1 / 2}$ & $5.29 \pm 0.17$ & $5.44 \pm 0.25$ & $5.39 \pm 0.22$ \\
Number of samples & 30 & 15 & 20 \\
\hline Stress rupture, number passed of number tested & 11 of 32 & 28 of 58 & 16 of 16 \\
Temperature, C & 1370 & 1370 & 1370 \\
Time, hours & $>20$ & $>20$ & $>20$ \\
Stress, MPa & 300 & 300 & $350 \mathrm{MPa}$ \\
\hline
\end{tabular}



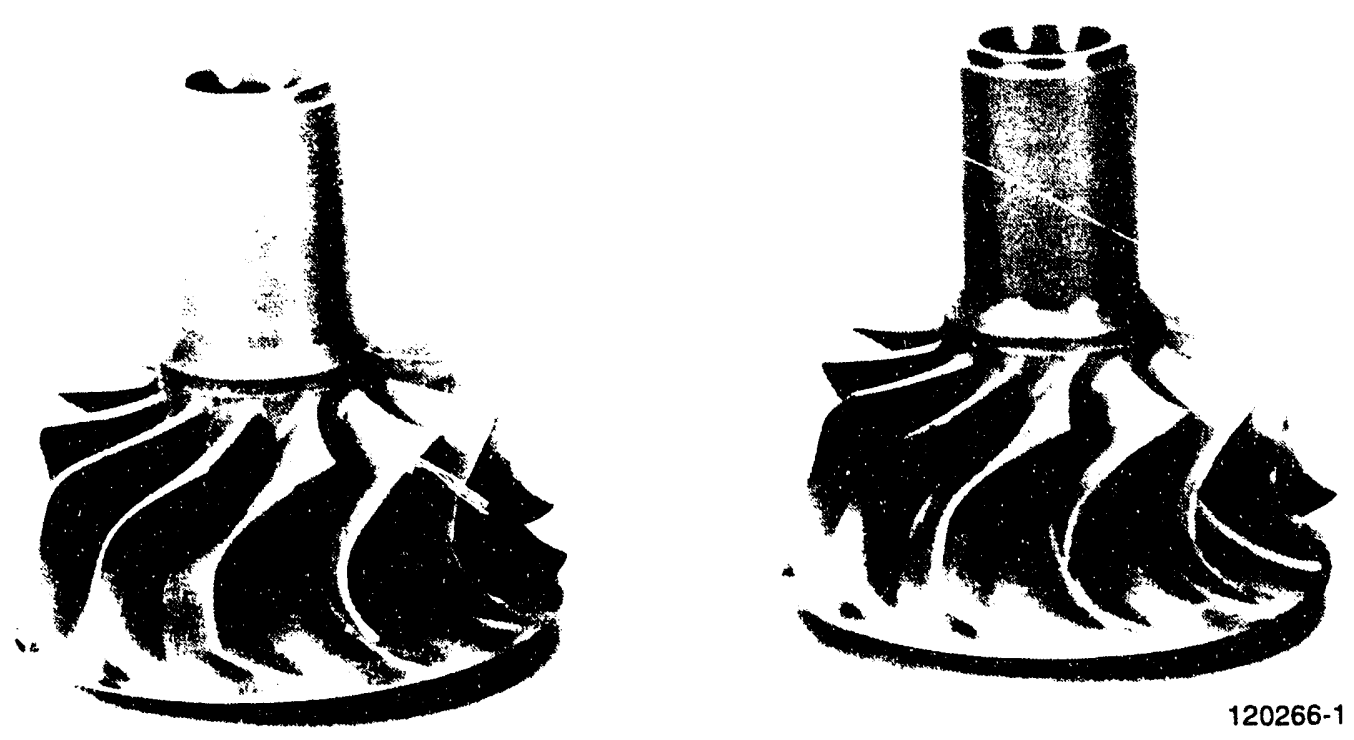

Figure 62. Engine-Quality AGT101 Rotors.

TABLE 22. AGT101 ROTOR SPIN TEST RESULTS

\begin{tabular}{|c|c|c|c|}
\hline Set No. & Rotor ID & $\begin{array}{c}\text { Spin-Test } \\
\text { Speed, krpm* }\end{array}$ & Rotor Status** \\
\hline 1 & $632-950$ & 105 & Passed - delivered \\
\hline 1 & $646-953$ & 105 & Passed - delivered \\
\hline 1 & $650-953$ & 105 & Passed - delivered \\
\hline 1 & $654-953$ & 105 & Passed - delivered \\
\hline 1 & $653-950$ & 127 & Passed - burst test \\
\hline 1 & $657-953$ & 119 & Passed - burst test \\
\hline 2 & $7389-1032$ & 105 & Passed - delivered \\
\hline 2 & $742-1005$ & 105 & Passed - delivered \\
\hline 2 & $751-1005$ & 105 & Passed - delivered \\
\hline 2 & $734-1005$ & 105 & Passed - delivered \\
\hline \multirow{2}{*}{$\begin{array}{l}\text { Proof test speed }=105 \text { krpm. } \\
\text { 11 of } 11 \text { rotors passed proof test. }\end{array}$} & Passed - delivered \\
\hline
\end{tabular}


mechanical properties generated from test tile are presented in Table 23 while data for a cut-up rotor from Set No. 2 is given in Table 24. Mechanical properties for Rotor Set No. 2 adequately met ATTAP specifications. NAC initiated fabrication of Rotor Set No. 3 using the aqueous milled, agglomerated NT154 system in accordance with the work plan schedule shown in Figure 49 . Processing of this rotor set, however, was placed on hold after pre-machining inspection due to budgetary constraints. NAC was not able to perform dimensional or co-process mechanical property evaluations to document the expected benefits of the aqueous-milled NT154 system.

TABLE 23. CO-PROCESS MECHANICAL PROPERTIES FOR DELIVERABLE ROTOR SET NO. 2

\begin{tabular}{|c|c|c|c|c|c|}
\hline Process Path $\rightarrow$ & 1 & 2 & 3 & 4 & 5 \\
\hline Component Number $\rightarrow$ & $738,9-1032$ & $742-1005$ & $751 \cdot 1005$ & $734-1005$ & $745-1032$ \\
\hline $\begin{array}{l}\text { Flexural strengths: } \\
22 \mathrm{C} \text { as processed } \\
1370 \mathrm{C} \text { as processed } \\
22 \mathrm{C} \text { bulk } \\
1370 \mathrm{C} \text { bulk }\end{array}$ & $\begin{array}{l}\text { Average/individual } \\
\text { Average/individual } \\
\text { Average/individual } \\
903 \mathrm{MPa} / 731 \mathrm{MPa} \\
669 \mathrm{MPa} / 461 \mathrm{MPa}\end{array}$ & $\begin{array}{l}\text { Average/individual } \\
\text { Average/individual } \\
\text { Average/individual } \\
910 \mathrm{MPa} / 593 \mathrm{MPa} \\
600 \mathrm{MPa} / 476 \mathrm{MPa}\end{array}$ & $\begin{array}{l}\text { Average/individual } \\
\text { Average/individual } \\
\text { Average/individual } \\
958 \mathrm{MPa} / 703 \mathrm{MPa} \\
669 \mathrm{MPa} / 552 \mathrm{MPa} \\
\end{array}$ & $\begin{array}{l}\text { Average/individual } \\
\text { Average/individual } \\
\text { Average/individual } \\
896 \mathrm{MPa} / 662 \mathrm{MPa} \\
676 \mathrm{MPa} / 648 \mathrm{MPa} \\
\end{array}$ & $\begin{array}{l}\text { Average/individual } \\
\text { Average/individual } \\
\text { Average/individual } \\
862 \mathrm{MPa} / 717 \mathrm{MPa} \\
621 \mathrm{MPa} / 558 \mathrm{MPa}\end{array}$ \\
\hline Fracture toughness & $5.4 \mathrm{klc} / 5.3 \mathrm{~K} 1 \mathrm{c}$ & $5.3 \mathrm{~K} 1 \mathrm{c} / 5.0 \mathrm{~K} 1 \mathrm{c}$ & $5.3 \mathrm{~K} 1 \mathrm{c} / 5.1 \mathrm{~K} 1 \mathrm{c}$ & $5.3 \mathrm{~K} 1 \mathrm{c} / 5.2 \mathrm{~K} 1 \mathrm{c}$ & $5.3 \mathrm{~K} 1 \mathrm{c} / 5.3 \mathrm{~K} 1 \mathrm{c}$ \\
\hline $\begin{array}{l}\text { Stress rupture: } \\
\qquad 1370 \mathrm{C} / 300 \mathrm{MPa} / 150 \mathrm{hr}\end{array}$ & $\begin{array}{c}\text { No pass/no test } \\
0 / 4 \\
\end{array}$ & $\begin{array}{c}\text { No pass / no test } \\
1 / 4 \\
\end{array}$ & $\begin{array}{c}\text { No pass / no test } \\
1 / 4 \\
\end{array}$ & $\begin{array}{c}\text { No pass / no test } \\
1 / 4 \\
\end{array}$ & $\begin{array}{c}\text { No pass/no test } \\
1 / 4 \\
\end{array}$ \\
\hline \multicolumn{6}{|c|}{$\begin{array}{l}\text { Notes: } \\
\text { As procsssed material was not tested for these components. } \\
\text { 1. Fracture toughness by controlled flaw technique. }\end{array}$} \\
\hline
\end{tabular}

TABLE 24. MECHANICAL PROPERTIES FOR ROTOR CUT-UP FROM SET NO. 2

\begin{tabular}{|c|c|c|}
\hline & $\begin{array}{l}\text { Test Specimens From Rotor } \\
\text { Average/Minimum Individual } \\
\text { Bar }\end{array}$ & $\begin{array}{c}\text { Test Specimens From Tile } \\
\text { Average/Minimum Individual } \\
\text { Bar }\end{array}$ \\
\hline $\begin{array}{l}\text { Flexural strength data: } \\
22 \mathrm{C} / 72 \mathrm{~F} \text { bulk ground } \\
1204 \mathrm{C} / 2200 \mathrm{~F} \text { bulk ground } \\
1260 \mathrm{C} / 2300 \mathrm{~F} \text { bulk ground } \\
1316 \mathrm{C} / 2400 \mathrm{~F} \text { bulk ground } \\
1371 \mathrm{C} / 2500 \mathrm{~F} \text { bulk ground }\end{array}$ & $\begin{array}{l}889 \mathrm{MPa} / 552 \mathrm{MPa} \\
579 \mathrm{MPa} / 489 \mathrm{MPa} \\
579 \mathrm{MPa} / 496 \mathrm{MPa} \\
565 \mathrm{MPa} / 490 \mathrm{MPa} \\
531 \mathrm{MPa} / 469 \mathrm{MPa}\end{array}$ & $\begin{array}{c}862 \mathrm{MPa} / 655 \mathrm{MPa} \\
* \\
634 \mathrm{MPa} / 586 \mathrm{MPa} \\
* \\
620 \mathrm{MPa} / 600 \mathrm{MPa}\end{array}$ \\
\hline Fracture toughness & $5.3 \mathrm{~K} 1 \mathrm{c} / 5.1 \mathrm{~K} 1 \mathrm{c}$ & $5.2 \mathrm{~K} 1 \mathrm{c} / 5.1 \mathrm{~K} 1 \mathrm{c}$ \\
\hline $\begin{array}{l}\text { Stress rupture data: } \\
2300 \mathrm{~F} / 60 \mathrm{ksi} / 150 \text { hours } \\
2300 \mathrm{~F} / 65 \mathrm{ksi} / 150 \text { hours } \\
2500 \mathrm{~F} / 43 \mathrm{ksi} / 150 \text { hours }\end{array}$ & $\begin{array}{c}\text { Number pass/number tested } \\
0 / 4 \\
1 / 4 \\
*\end{array}$ & $\begin{array}{c}\text { Number pass/number tested } \\
* \\
* \\
0 / 4\end{array}$ \\
\hline \multicolumn{3}{|c|}{$\begin{array}{l}\text { Notes: } \\
\text { 1. }{ }^{*}=\text { Not tested. } \\
\text { 2. Fracture toughness by controlled flaw technique. } \\
\text { 3. Rotor used for cut up data acquisition is S/N } 735-1003 \text {. }\end{array}$} \\
\hline
\end{tabular}


Throughout the 1991 and 1992 engine-quality rotor fabrication effort, NAC endeavored to continuously improve its prototyping process in terms of both process yields and component quality. As evidenced by the 100 percent proof test yield presented in Table 22, NAC was successful in identifying and maintaining the quality of the deliverable hardware. But as shown in Figures 63, 64, and 65 for Rotor Sets No. 1, No. 2, and No. 3, respectively, cumulative process yield remained at 15-25 percent for all three sets. For Rotor Sets No. 1 and No. 2, individual process step yields were all $>65$ percent. For Rotor Set No. 3, all individual process step yields were $>60$ percent with the exception of pre-HIP MFXR inspection which was $\approx 40$ percent. As shown in Figure 66 , numerous minor defects caused rejection of rotors from all three sets. NAC believes that the process yields experienced during the production of engine-quality AGT101 rotors were to be expected for a prototyping process with numerous, complex steps. From this experience, NAC believes that the robustness of the NT154 process can only be improved through simplification and scaleup.

\subsubsection{Engine-Quality AGT101 Stators}

In accordance with the work plan schedule shown in Figure 49, NAC fabricated and delivered a total of 187 engine-quality AGT101 Stators under deliverable Sets No. 1, No. 2, and No. 3. Figure 67 shows a ring of these stators. All three stator sets were fabricated using the alcohol-milled, agglomerated NT154 system. Co-process mechanical properties were generated from test billets and

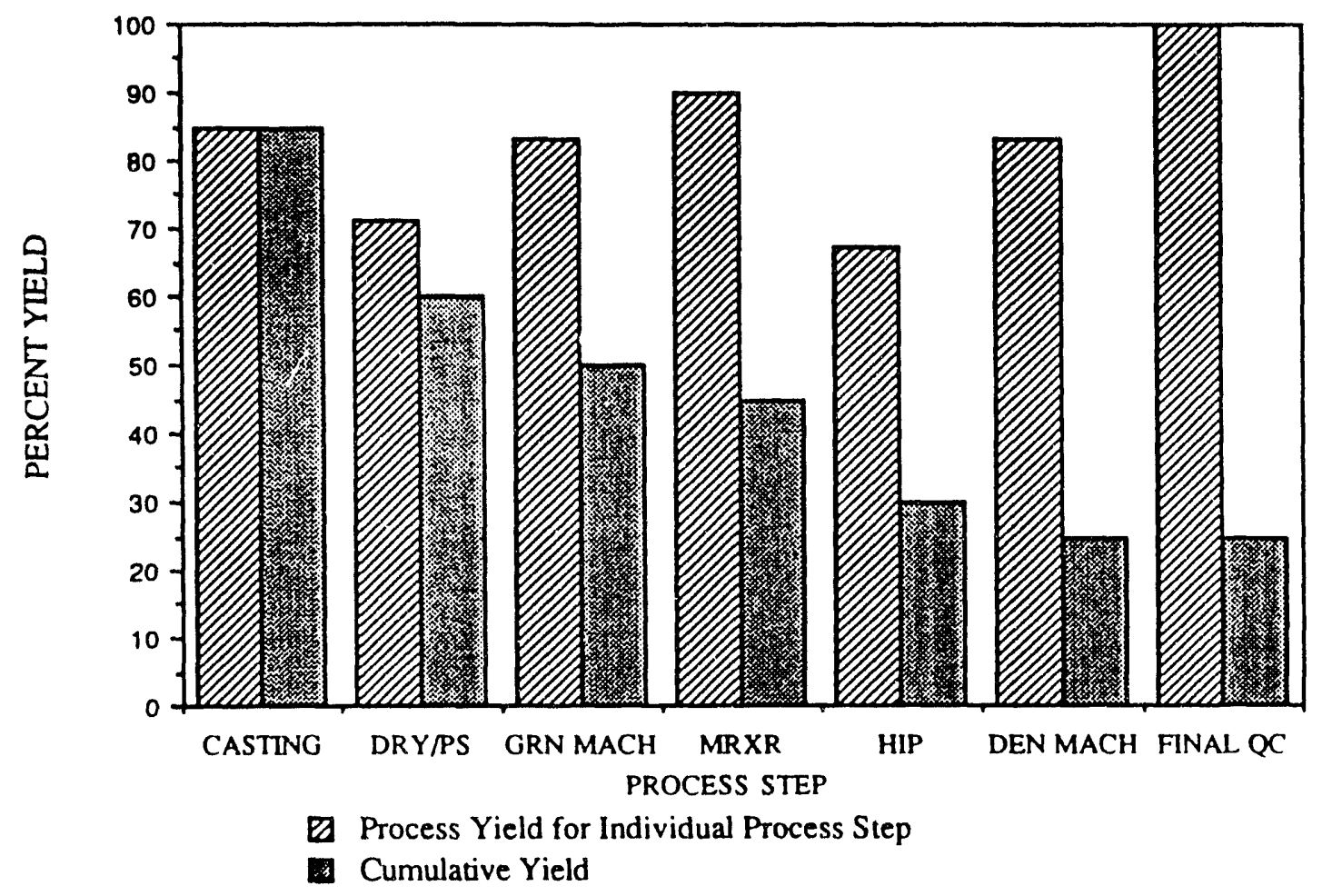

Figure 63. AGT101 Rotor Deliverable Set No. 1 Process Yields. 


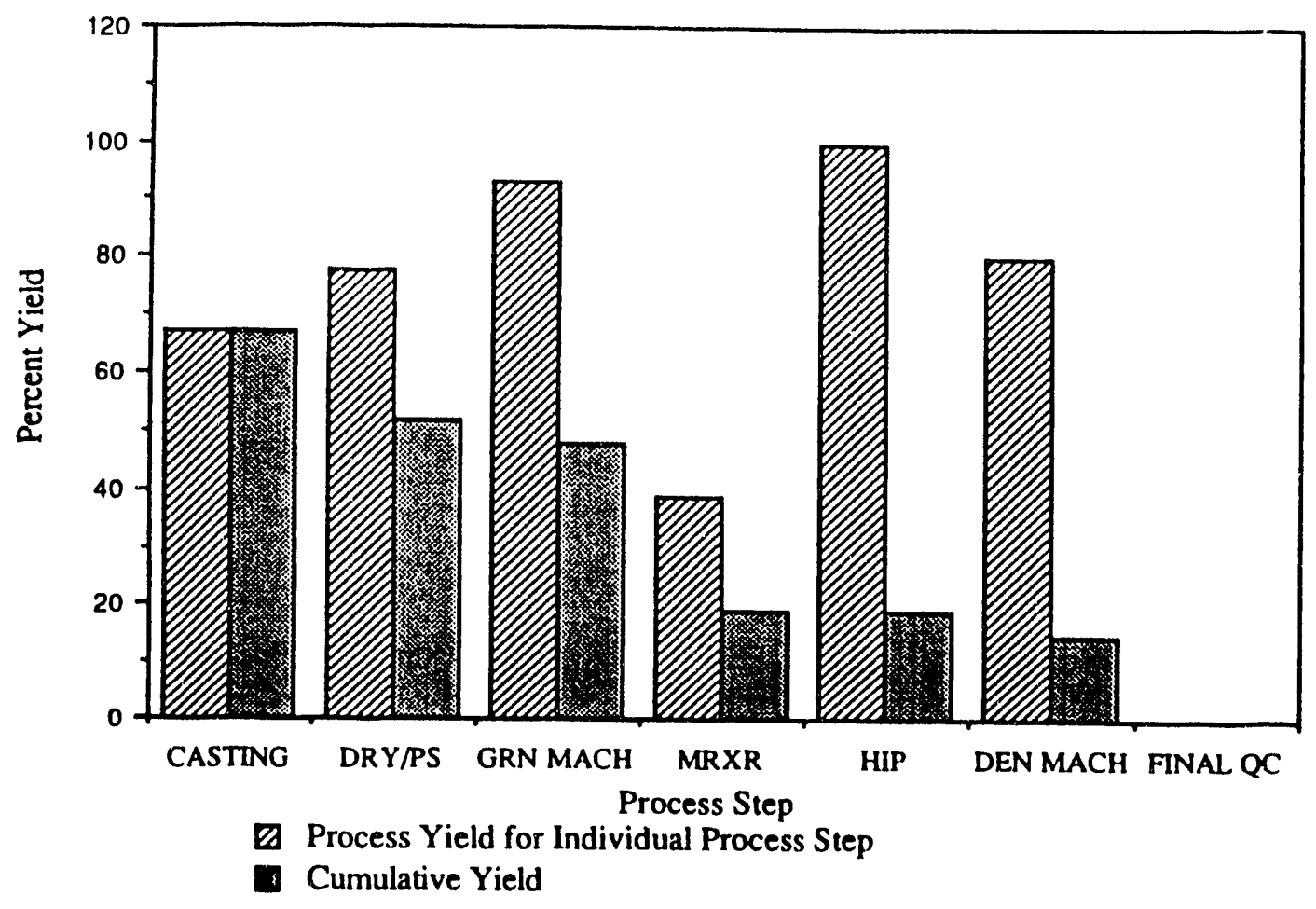

Figure 64. AGT101 Rotor Deliverable Set No. 2 Process Yields.

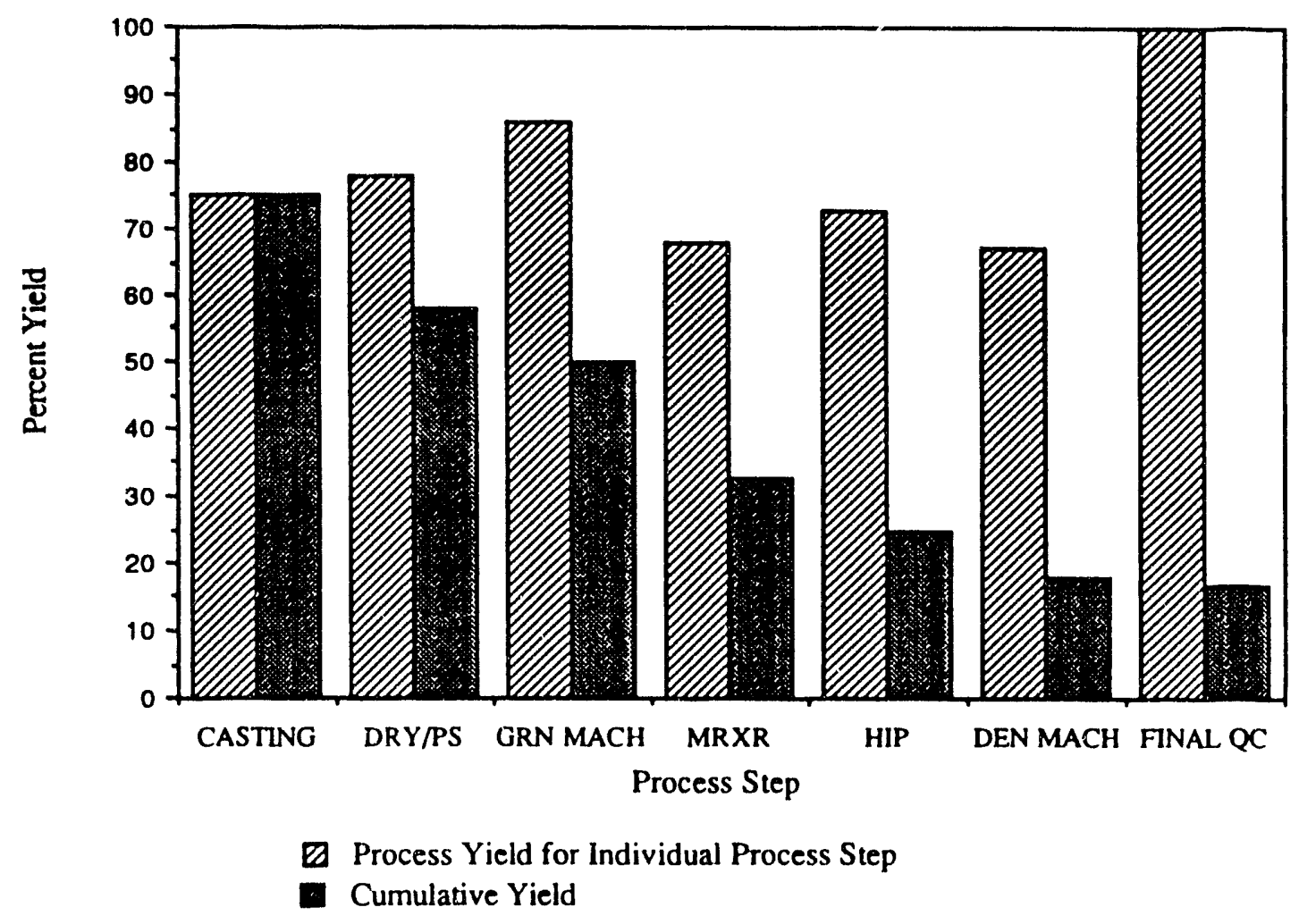

Figure 65. AGT101 Rotor Deliverable Set No. 3 Process Yields. 


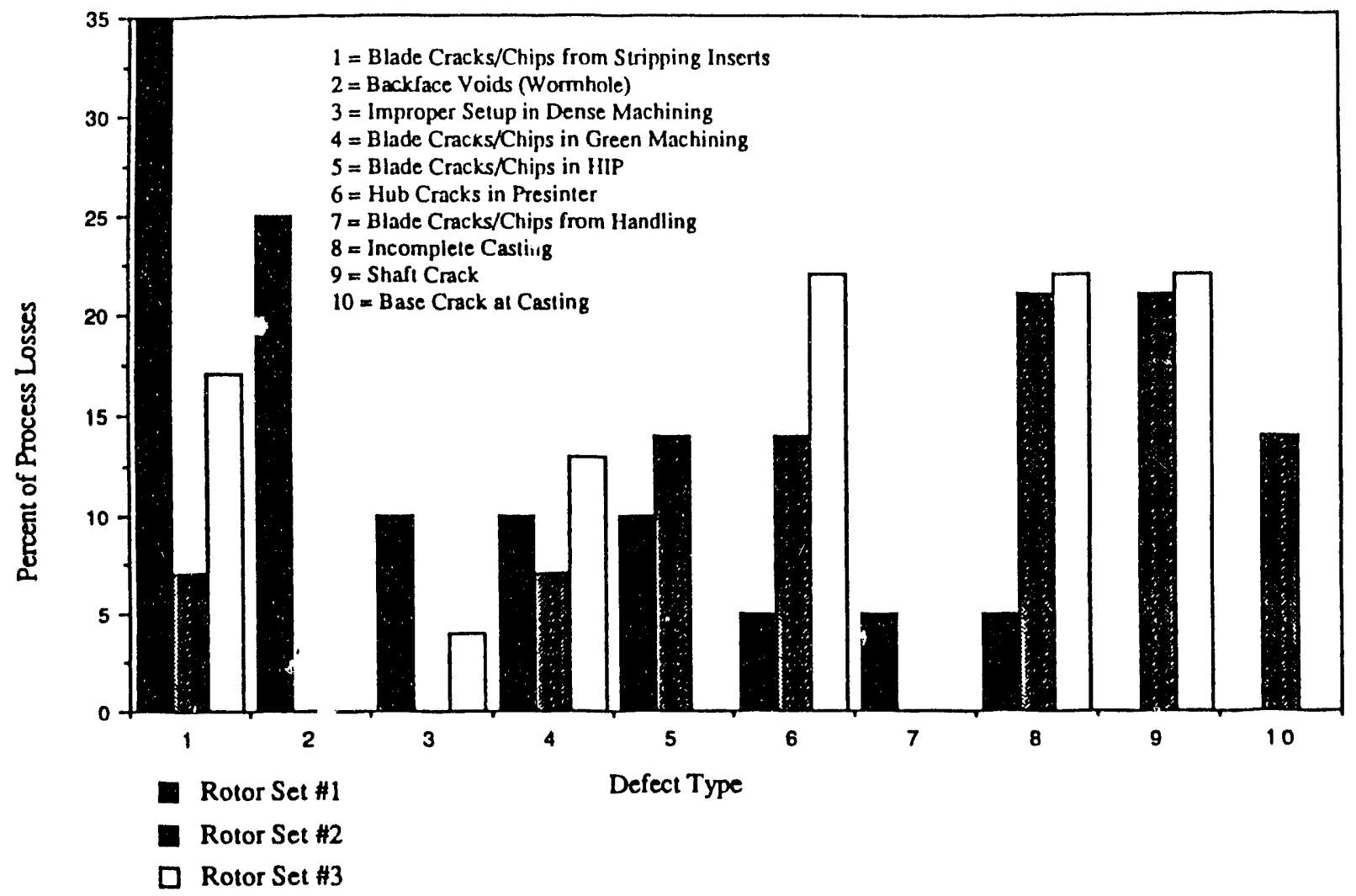

Figure 66. AGT101 '.otor Process Losses By Defect Type.

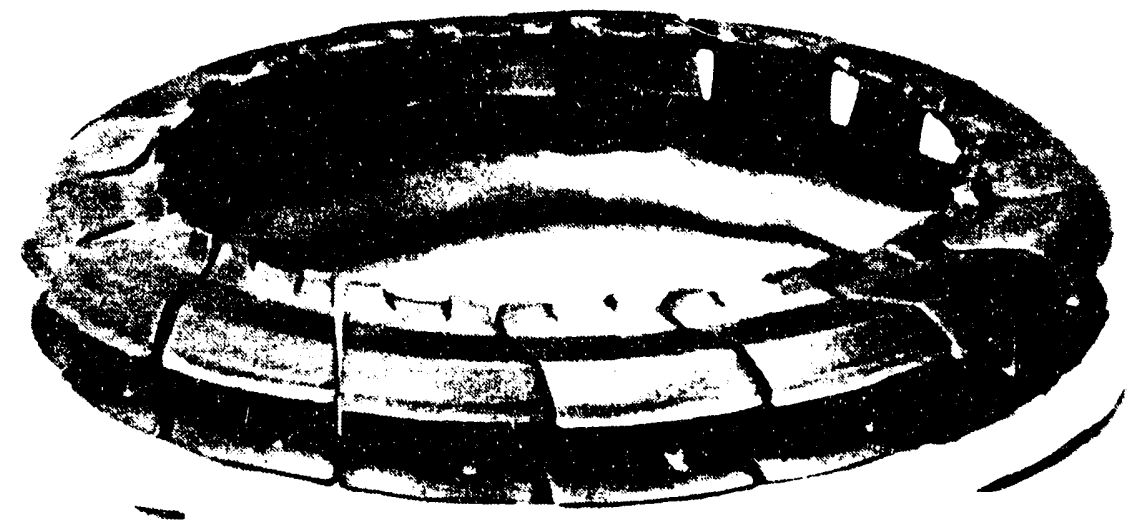

120266-2

Figure 67. Engine-Quality AGT101 Stators. 
are presented in Tables 25, 26, and 27, respectively. Mechanical properties for all three stator sets adequately met ATTAP specifications, but high-temperature properties, especially stress rupture, were abnormally low for Sets No. 2 and No. 3 as compared to typical NT154. The degradation in properties was attributed to contamination from the agglomeration process and alcohol milling. Both problem sources have since been corrected by NAC. As discussed under Task 3.2.1.1, NAC has replaced alcohol milling with aqueous milling which has greatly reduced the frequency of strengthlimiting inclusions in the material as previously presented in Figure 55. As demonstrated by the Weibull distributions shown in Figure 56, the 1370C MOR control chart shown in Figure 57, and the stress rupture results presented in Figure 58, NAC believes that implementation of the aqueousmilled system has solved the degradation of high-temperature properties experienced for Stator Sets No. 2 and No. 3. NAC recognizes, however, that Weibull modulus must be further improved and intends to do so by eliminating the agglomeration process during 1993.

TABLE 25. CO-PROCESSED MECHANICAL PROPERTIES FOR DELIVERABLE; STATOR SET NO. 1

\begin{tabular}{|c|c|c|c|c|c|c|c|c|c|}
\hline Stator Batch No. $\rightarrow$ & 674 & 675 & 677 & 678 & 679 & 681 & 682 & 684 & 688 \\
\hline Location Of Material In HIP $\rightarrow$ & Bottom & Middle & Middle & Bottom & Top & Top & Top & Middle & Middle \\
\hline $\begin{array}{l}\text { Bulk-ground surface flexural strength } 1 \\
\text { at } 21 C(n=5, n=20 \text { for } 674 \text { and } 681) \\
\text { at } 1204 C(n=5) \\
\text { at } 1260 C(n=5) \\
\text { at } 1316 C(n=5) \\
\text { at } 1370 C(n=5)\end{array}$ & $\begin{array}{l}128 \pm 17 \\
98 \pm 2 \\
97 \pm 3 \\
86 \pm 3 \\
82 \pm 4\end{array}$ & $\begin{array}{l}131 \pm 12 \\
N / A \\
N / A \\
N / A \\
78 \pm 4\end{array}$ & $\begin{array}{l}118 \pm 9 \\
\text { N/A } \\
\text { N/A } \\
\text { N/A } \\
89 \pm 2\end{array}$ & $\begin{array}{c}120 \pm 10 \\
\text { N/A } \\
\text { N/A } \\
\text { N/A } \\
86 \pm 3\end{array}$ & $\begin{array}{l}102 \pm 13 \\
\text { N/A } \\
\text { N/A } \\
\text { N/A } \\
73 \pm 4\end{array}$ & $\begin{array}{c}123 \pm 14 \\
83 \pm 8 \\
80 \pm 6 \\
79 \pm 4 \\
74 \pm 6\end{array}$ & $\begin{array}{l}113 \pm 15 \\
\text { N/A } \\
\text { N/A } \\
\text { N/A } \\
74 \pm 3\end{array}$ & $\begin{array}{l}122 \pm 7 \\
\text { N/A } \\
\text { N/A } \\
\text { N/A } \\
78 \pm 2\end{array}$ & $\begin{array}{l}117 \pm 15 \\
\text { N/A } \\
\text { N/A } \\
\text { N/A } \\
82 \pm 4\end{array}$ \\
\hline $\begin{array}{l}\text { As-processed surface flexural strength } \\
\text { at } 21 C(n=6) \\
\text { at } 1370 C(n-6)\end{array}$ & $\begin{array}{l}\mathrm{N} / \mathrm{A} \\
\mathrm{N} / \mathrm{A}\end{array}$ & $\begin{array}{l}72 \pm 2 \\
58 \pm 2\end{array}$ & $\begin{array}{l}66 \pm 4 \\
65 \pm 4\end{array}$ & $\begin{array}{l}77 \pm 7 \\
63 \pm 6\end{array}$ & $\begin{array}{l}71 \pm 8 \\
64 \pm 5\end{array}$ & $\begin{array}{l}\text { N/A } \\
\text { N/A }\end{array}$ & $\begin{array}{c}74 \pm 13 \\
64 \pm 9\end{array}$ & $\begin{array}{c}78 \pm 10 \\
65 \pm 4\end{array}$ & $\begin{array}{l}78 \pm 4 \\
69 \pm 6\end{array}$ \\
\hline $\begin{array}{l}\text { Fracture toughness }{ }^{2}, \mathrm{MPa} \cdot \mathrm{m}^{1 / 2} \\
\text { at } 21 \mathrm{C}(\mathrm{n}=3) \\
\text { at } 1370 \mathrm{C}\end{array}$ & $\begin{array}{c}5.82 \pm 0.15 \\
\mathrm{~N} / \mathrm{A}\end{array}$ & $\begin{array}{l}\text { N/A } \\
\text { N/A }\end{array}$ & $\begin{array}{l}\text { N/A } \\
\text { N/A }\end{array}$ & $\begin{array}{l}\text { N/A } \\
\text { N/A }\end{array}$ & $\begin{array}{l}\text { N/A } \\
\text { N/A }\end{array}$ & $\begin{array}{c}5.57 \pm 0.07 \\
\mathrm{~N} / \mathrm{A}\end{array}$ & $\begin{array}{l}\text { N/A } \\
\text { N/A }\end{array}$ & $\begin{array}{l}\text { N/A } \\
\text { N/A }\end{array}$ & $\begin{array}{l}\text { N/A } \\
\text { N/A }\end{array}$ \\
\hline $\begin{array}{l}\text { Flexural stress rupture } \\
1260 \mathrm{C} / 414 \mathrm{MPa} / 10 \text { hours } \\
1370 \mathrm{C} / 276 \mathrm{MPa} / 10 \text { hours } \\
1370 \mathrm{C} / 310 \mathrm{MPa} / 10 \text { hours }\end{array}$ & $\begin{array}{l}N / A \\
2 / 3 \\
3 / 3\end{array}$ & $\begin{array}{l}3 / 4 \\
0 / 4 \\
\text { N/A }\end{array}$ & $\begin{array}{l}2 / 4 \\
1 / 4 \\
\mathrm{~N} / \mathrm{A}\end{array}$ & $\begin{array}{l}4 / 4 \\
2 / 4 \\
N / A\end{array}$ & $\begin{array}{r}1 / 4 \\
2 / 4 \\
\mathrm{~N} / \mathrm{A}\end{array}$ & $\begin{array}{c}N / A \\
1 / 3 \\
2 / 3\end{array}$ & $\begin{array}{r}2 / 4 \\
2 / 4 \\
N / A\end{array}$ & $\begin{array}{r}0 / 4 \\
2 / 4 \\
\mathrm{~N} / \mathrm{A}\end{array}$ & $\begin{array}{c}4 / 4 \\
3 / 4 \\
\mathrm{~N} / \mathrm{A}\end{array}$ \\
\hline \multicolumn{10}{|c|}{$\begin{array}{l}\text { Notes: } \\
\text { 1. All flexural strength data is shown as the average } \pm 1 \text { standard deviation in ksi. } \\
\text { 2. Fracture toughness measured by controlled flaw method (hardness }=15.4 \mathrm{GPa} \text {, modulus }=310 \mathrm{GPa} \text {, indent load }=10 \mathrm{~kg} \text { ). } \\
\text { 3. Flexural stress rupture results are shown as the following ratio: number of specimens that survive } / \text { number of specimens tested. } \\
\text { 4. All test bars were } 3 \mathrm{~mm} \times 4 \mathrm{~mm} \times 50 \mathrm{~mm} \text {; crosshead speed of } 0.5 \mathrm{~mm} / \mathrm{min} \text {; outer span }=40 \mathrm{~mm} \text {; inner span }=20 \mathrm{~mm} \text {. } \\
\text { 5. All test bars possessed densities greater than } 3.225 \mathrm{~g} / \mathrm{cc} \text { and Ra surface finish less than } 0.5 \text { micrometer }(20 \text { microinches). } \\
6 \text {. Most room temperature fracture origins were machining induced flaws. Some high temperature fracture origins were minor } \\
\text { impurities or defects, typically less than } 10 \text { microns in size. }\end{array}$} \\
\hline
\end{tabular}

TABLE 26. CO-PROCESSED MECHANICAL PROPERTIES FOR DELIVERABLE STATOR SET NO. 2

\begin{tabular}{|l|c|c|c|}
\hline Process Path $\rightarrow$ & 1 & 2 & 3 \\
\hline Component Batch $\rightarrow$ & $\mathbf{7 2 5}-\mathbf{7 2 9}$ & $\mathbf{7 3 0 - 7 3 2}$ & 733 \\
\hline Flexural strengths: & Average/Individual & Average/Individual & Average/Individual \\
$22 \mathrm{C}$ as processed & $566 \mathrm{MPa} / 438 \mathrm{MPa}$ & $628 \mathrm{MPa} / 503 \mathrm{MPa}$ & $613 \mathrm{MPa} / 515 \mathrm{MPa}$ \\
$1370 \mathrm{C}$ as processed & $511 \mathrm{MPa} / 472 \mathrm{MPa}$ & $563 \mathrm{MPa} / 426 \mathrm{MPa}$ & $632 \mathrm{MPa} / 467 \mathrm{MPa}$ \\
$22 \mathrm{C}$ bulk & $871 \mathrm{MPa} / 733 \mathrm{MPa}$ & $935 \mathrm{MPa} / 730 \mathrm{MPa}$ & $842 \mathrm{MPa} / 650 \mathrm{MPa}$ \\
$1370 \mathrm{C}$ bulk & $519 \mathrm{MPa} / 487 \mathrm{MPa}$ & $585 \mathrm{MPa} / 520 \mathrm{MPa}$ & $589 \mathrm{MPa} / 541 \mathrm{MPa}$ \\
\hline Fracture toughness & $5.1 \mathrm{Klc} / 5.0 \mathrm{Klc}$ & $5.4 \mathrm{~K} 1 \mathrm{c} / 5.2 \mathrm{~K} 1 \mathrm{c}$ & $5.3 \mathrm{Klc} / 5.2 \mathrm{~K} 1 \mathrm{c}$ \\
\hline Stress rupture: & No. pass/No. test & No.pass/No. test & No. pass/No. test \\
$1260 \mathrm{C} / 414 \mathrm{MPa} / 150$ hour & $2 / 4$ & $2 / 4$ & $2 / 4$ \\
$1370 \mathrm{C} / 276 \mathrm{MPa} / 150$ hour & $2 / 4$ & $4 / 4$ & $2 / 4$ \\
\hline
\end{tabular}


TABLE 27. CO-PROCESSED MECHANICAL PROPERTIES FOR DELIVERABLE STATOR SET NO. 3

\begin{tabular}{|l|c|c|}
\hline Process Path $\rightarrow$ & 1 & 2 \\
\hline Component Batch $\rightarrow$ & $\mathbf{7 8 3}, \mathbf{7 8 9}-\mathbf{7 9 4}$ & $\mathbf{7 8 5}$ And 787 \\
\hline \hline Flexural strengths: & Average/Individual & Average/Individual \\
$22 \mathrm{C}$ as processed & $90 \mathrm{MPa} / 72 \mathrm{MPa}$ & $57 \mathrm{MPa} / 48 \mathrm{MPa}$ \\
$1370 \mathrm{C}$ as processed & $64 \mathrm{MPa} / 49 \mathrm{MPa}$ & $58 \mathrm{MPa} / 49 \mathrm{MPa}$ \\
$22 \mathrm{C}$ bulk & $122 \mathrm{MPa} / 93 \mathrm{MPa}$ & $126 \mathrm{MPa} / 102 \mathrm{MPa}$ \\
$1370 \mathrm{C}$ bulk & $81 \mathrm{MPa} / 75 \mathrm{MPa}$ & $85 \mathrm{MPa} / 83 \mathrm{MPa}$ \\
\hline Fracture toughness & $5.4 \mathrm{~K} 1 \mathrm{c} / 0.04 \mathrm{MPa} \cdot \mathrm{m}^{1 / 2}$ & $5.1 \mathrm{~K} 1 \mathrm{c} / 0.05 \mathrm{MPa} \cdot \mathrm{m}^{1 / 2}$ \\
\hline Stress rupture: & No. pass $/ \mathrm{No}$ test & No. pass $/ \mathrm{No}$ test \\
$1260 \mathrm{C} / 414 \mathrm{MPa} / 20$ hour & $0 / 4$ & $1 / 4$ \\
$1370 \mathrm{C} / 310 \mathrm{MPa} / 20$ hour & $0 / 4$ & $0 / 4$ \\
$1370 \mathrm{C} / 276 \mathrm{MPa} / 20$ hour & $2 / 4$ & $0 / 4$ \\
\hline
\end{tabular}

Throughout the 1991 and 1992 engine-quality stator fabrication effort, NAC endeavored to contiriuously improve its prototyping process in terms of both process yields and component quality. As shown in Figure 68, the cumulative process yield for Stator Set No. 1 was only $\approx 10$ percent. NAC experienced high rejection rates due to leading and trailing edge airfoil cracks as well as cleat percent cracks. In addition, as previously discussed under Task 3.2.3, dimensional control was marginal for Set No. 1 with the airfoil chord length specifications being met while the inner platform distance was narrow by $\approx 0.020$ inch.

Based on a comprehensive review of Stator Set No. 1 quality and yields, NAC decided to take two actions. First, the cause of cracking was determined to be related to the stress associated with removal of the airfoil mold insert. NAC decided to change the mold design to alleviate this stress on de-molding. A single splitting seam at the leading edge of the airfoil was replaced by a double splitting seam at the middle of the airfoil perpendicular to the chord length. This revised mold design was implemented for Stator Sets No. 2, No. 3, and No. 4. As shown in Figures 69, 70, and 71 for Sets No. 2, No. 3, and No. 4, respectively, cumulative process yields increased with each subsequent deliverable set from $\approx 35$ to $\approx 45$ to $\approx 55$ percent.

Although this yield improvement was impressive to NAC, quality of the deliverable stators apparently declined in the opinion of GAPD. The placement of the seam perpendicular to the chord length was undesirable to GAPD. In addition, the seam was placed coincident to a high stress region of the airfoil. NAC was unaware of both negative impacts when the design ihange was implemented and in hindsight learned to work more closely with its customers on mold design as related to component quality and stress fields. 


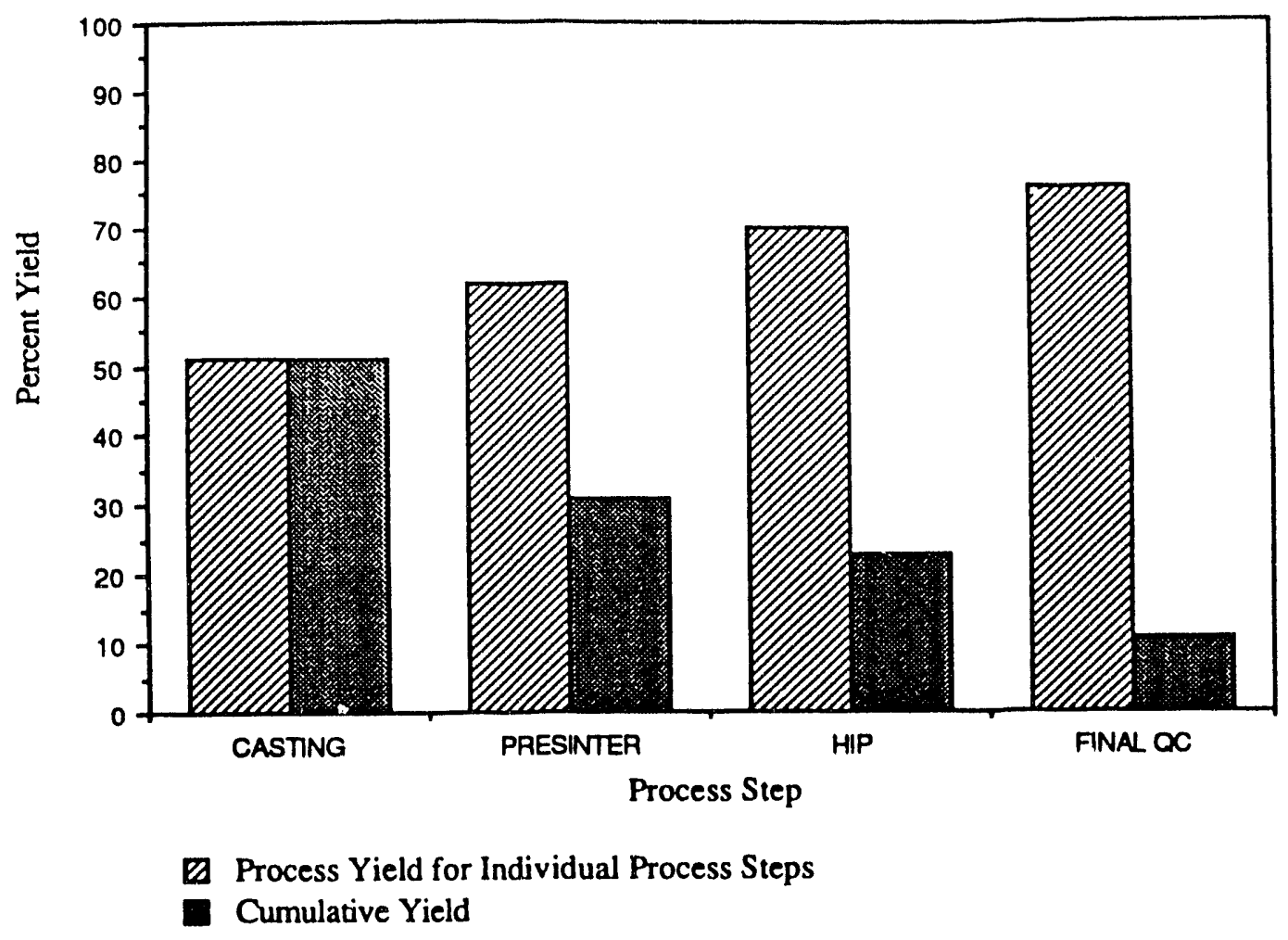

Figure 68. AGT101 Stator Deliverable Set No. 1 Process Yields.

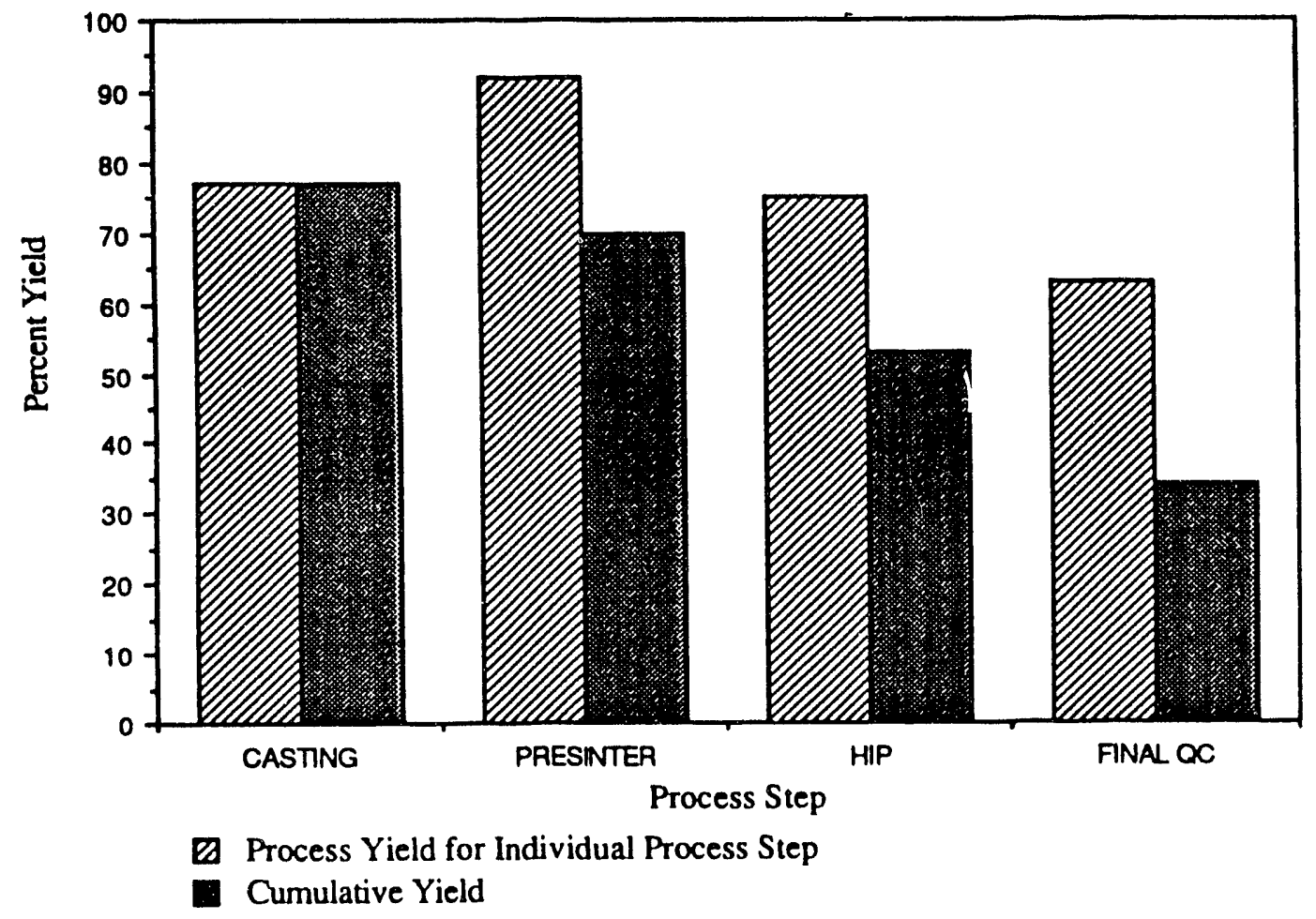

Figure 69. AGT101 Stator Deliverable Set No. 2 Process Yields. 


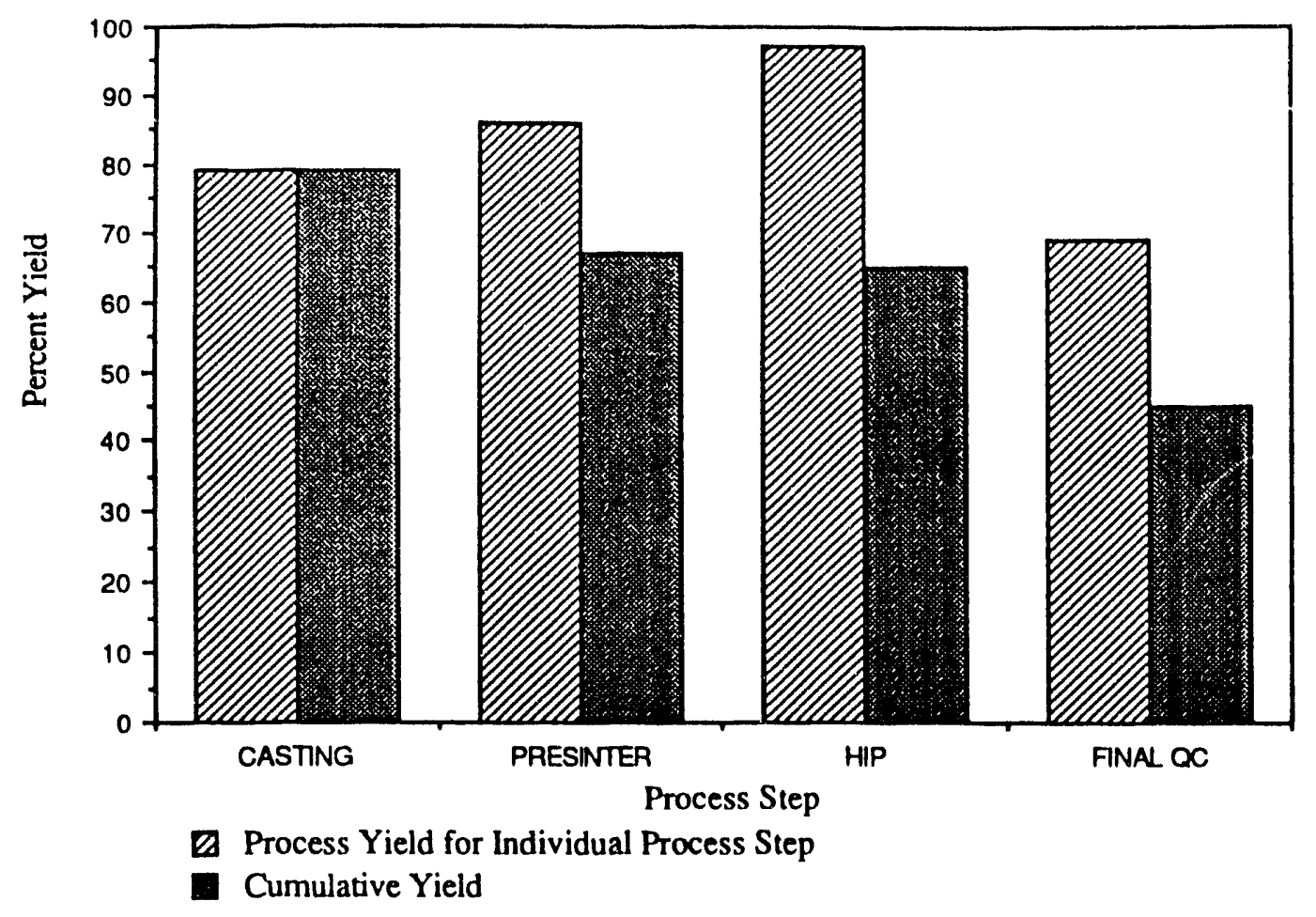

Figure 70. AGT101 Stator Deliverable Set No. 3 Process Yields.

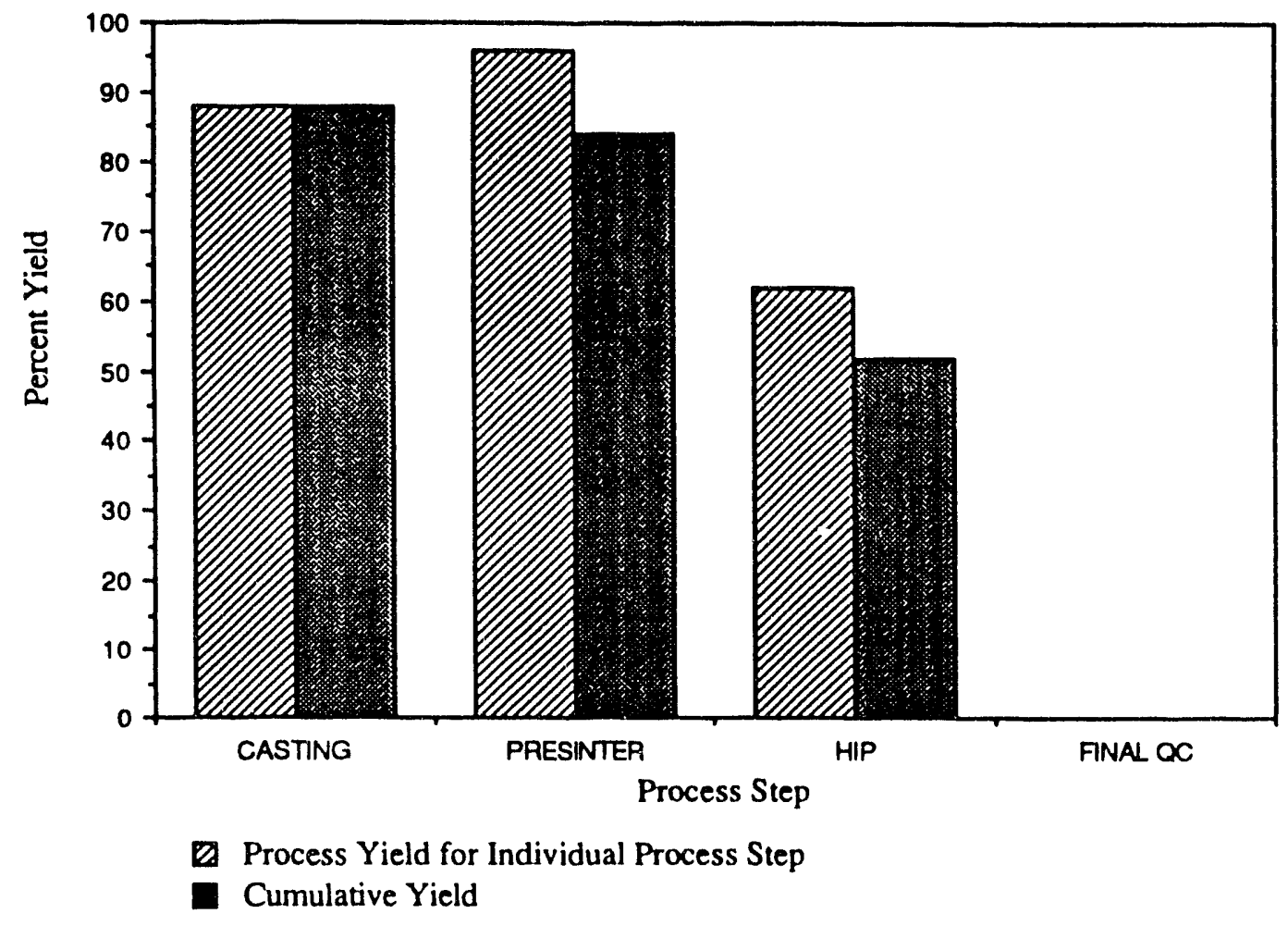

Figure 71. AGT101 Stator Deliverable Set No. 4 Process Yields. 
Based on NAC's comprehensive review of Stator Set No. 1 quality and yields, a second quality improvement action item involved the design and fabrication of a second-generation pattern to improve dimensional conformance of the inner platform distance. As previously shown in Figure 61, the second-generation pattern was designed with generous radii for ease of mold splitting as well as a bi-directional shrink factor to account for the difference in shrinkage between the airfoil chord length (Z-Sections) and inner platform distance (L-sections). NAC performed a comprehensive dimensional analysis of Stator Set No. 3 using a coordinate measuring machine (CMM) to quantify improvement. Figures 72 and 73 show these CMM results for Z-sections and L-sections. The histograms shown reveal that NAC was able to meet the chord length specifications but the inner platform distance was still narrow by $\approx 0.010$ inch. The bi-directional nature of the shrinkage inherent to the mold design and casting plane stack-up was very difficult to control. NAC believes that if the pattern were specified for the aqueous-milled NT154 system then dimensional control would have been achieved. The aqueous-milled NT154 system yields considerably higher green density than its alcohol-milled counterpart. Maximizing green density decreases the amount of shrinkage occurring as well as shrinkage variation due to green density gradients. NAC is successfully using the aqueous-milled version of NT154 on blade and nozzle components for GAPD and other customers and with tight process controls is able to meet print specifications.

Finally, based on GAPD concerns about an apparent degradation in stator quality from Set No. 1 to Set No. 3, NAC completed a comprehensive audit of its inspection records for each key inspection point. These audit results are presented in Figures 74 through 80 . As presented in these figures, NAC's inspection records indicate that quality was equivalent between Set No. 1 to Set No. 3. NAC reviewed GAPD's inspection results as compared to these records and is concerned at the discrepancy between the two organizations. As a result, NAC has heightened the sensitivity of all personnel to the keen quality requirements of GAPD and of the need for improved surface quality. Much of the discrepancy seemed to be centered on surface quality and interpretation of critical defects. NAC is committed to improving its surface quality and working closely with its customers to avoid any discrepancy between inspection results.

NAC believes that the process yield and quality experienced during the production of enginequality AGT101 stators were to be expected for a prototyping process with numerous, complex steps. From this experience, NAC believes that the robustness of the NT154 process can only be improved through simplification and scaleup. 


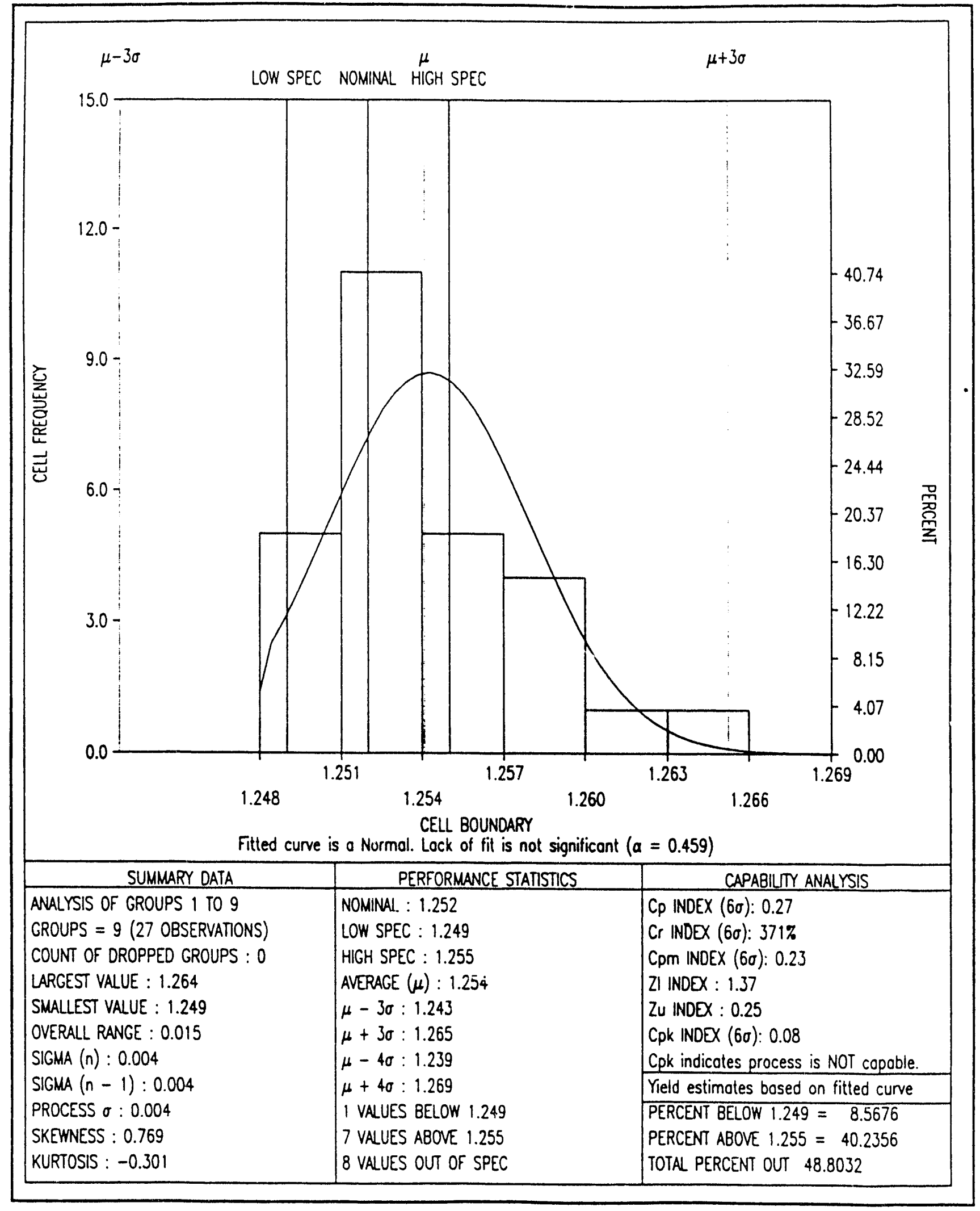

Figure 72. AGT'101 Stator Deliverable Set No. 3 - Histogram Of Z-Section CMM Data. 


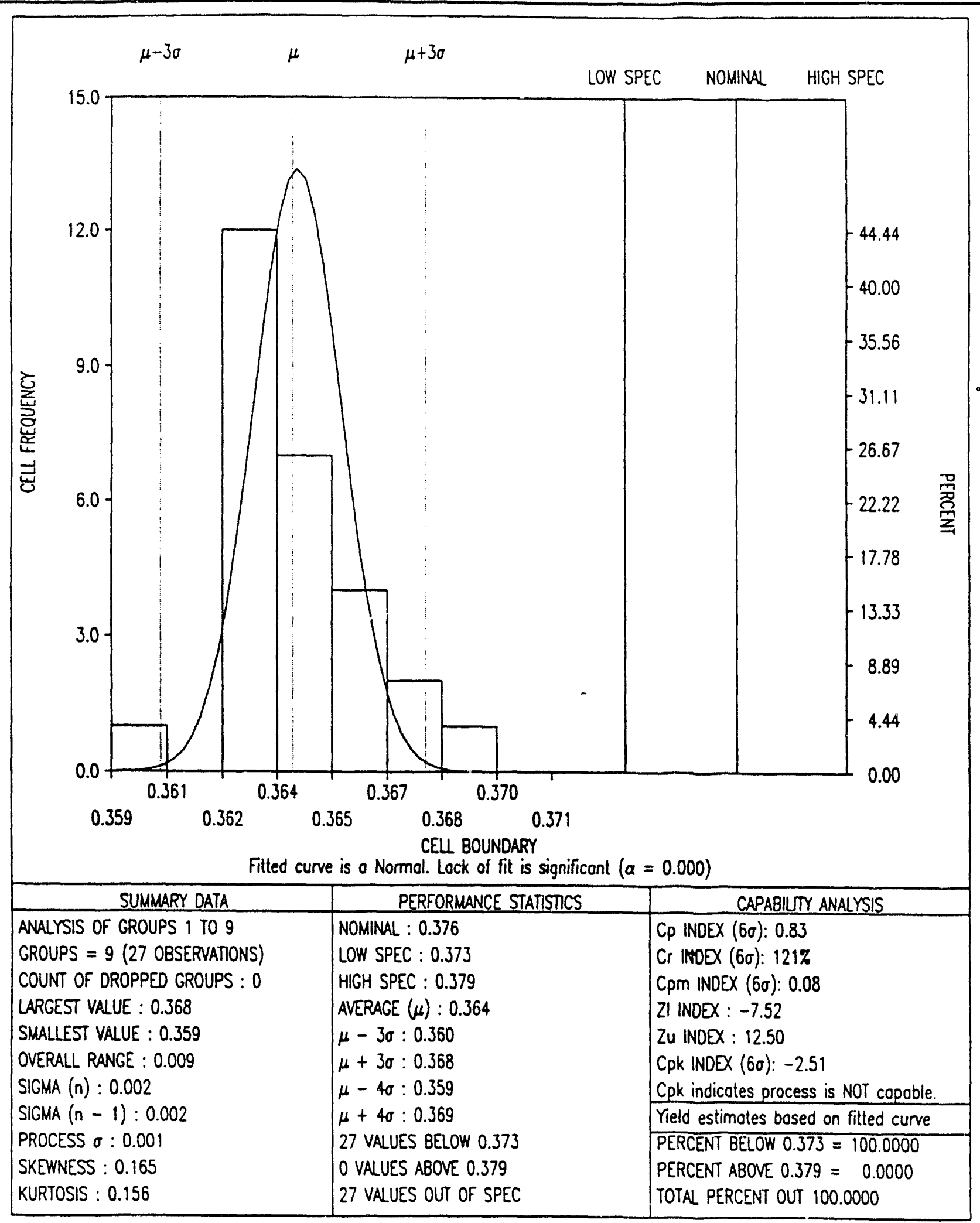

Figure 73. AGT101 Stator Deliverable Set No. 3 - Histogram Of L-Section CMM Data. 


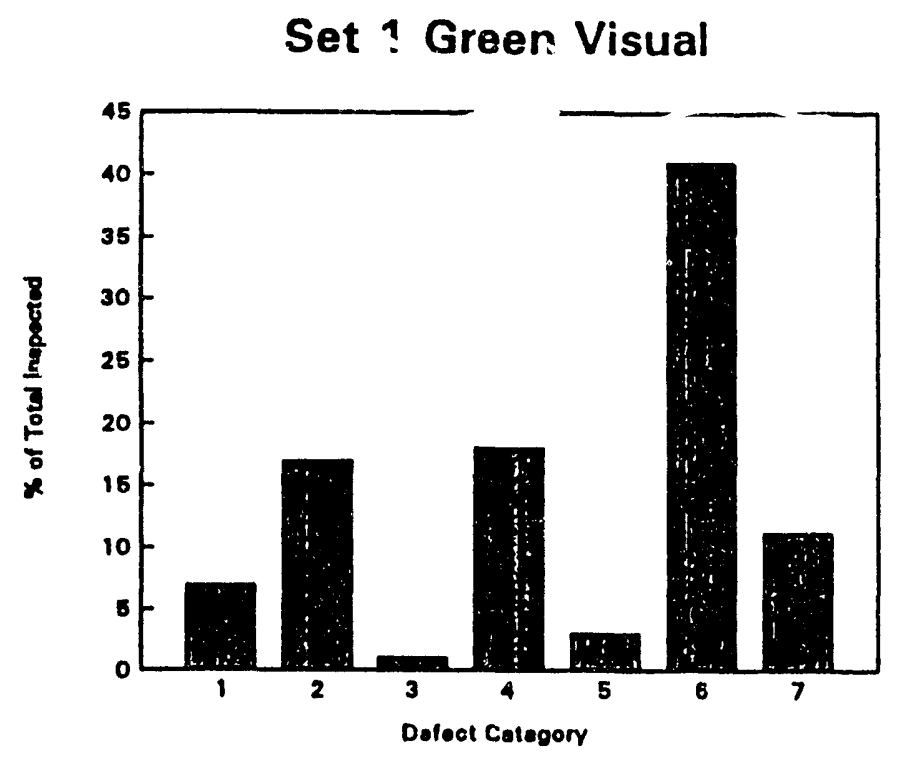

1. Platform Cracks

2. T.E. Airfoil Cracks

3. L.E. Airfoil Cracks

4. Platform Chips

5. Airfoll Chips

6. Pits - Pores - Blemish

7. Broken

\section{Set 3 Green Visual}

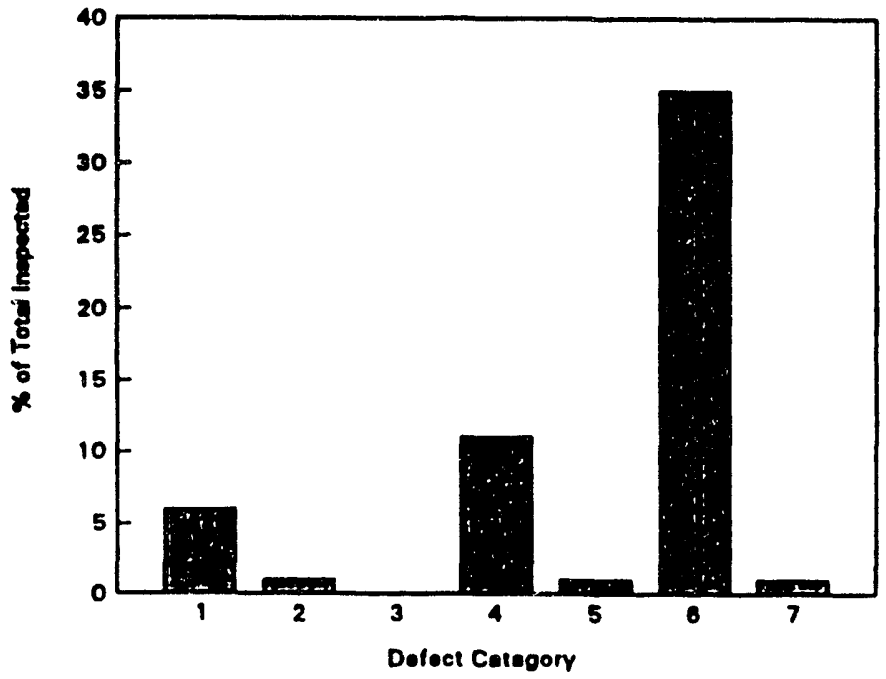

1. Platform Cracks

2. T.E. Alrfoil Cracks

3. L.E. Alrfoil Cracks

4. Platform Chips

5. Alrfoll Chips

6. Pits - Pores - Blemish

7. Broken

Figure 74. AGT101 Stator Set 1 Versus Set 3 Quality Comparison Green Casting Visual Inspection. 
Set 1 Green MFXR

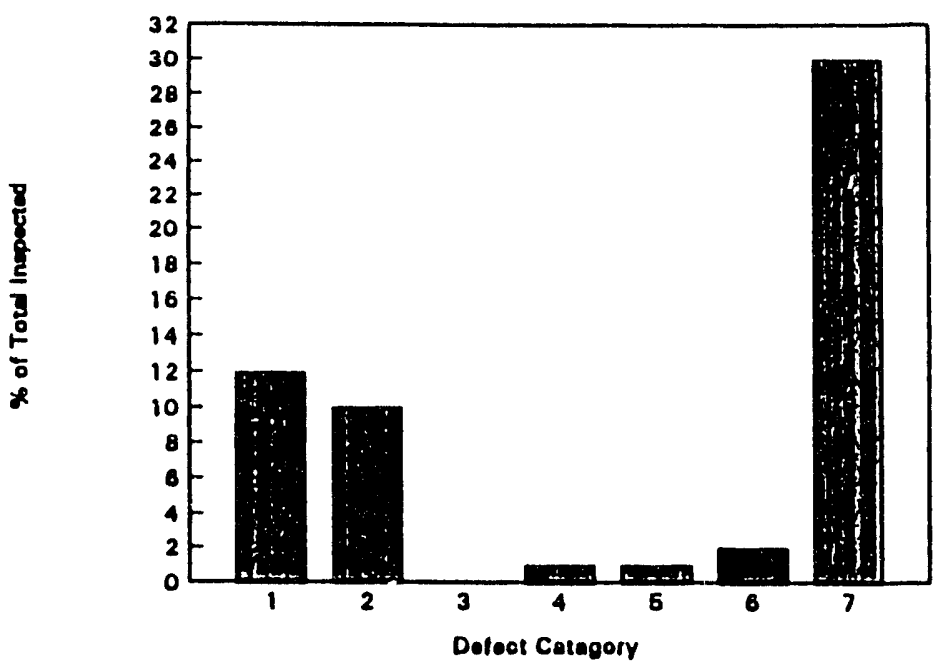

1. Sphericgl LDI - Platform

2. Sperical LDI - Airfoil

3. Linear LDI - Platform

4. Linear LDI - L.E. Alrfoil

5. Linear LDI - T.E. Alrfoil

6. Linear LDI - Other

7. Airfoil Knit Line

Set 3 Green MFXR

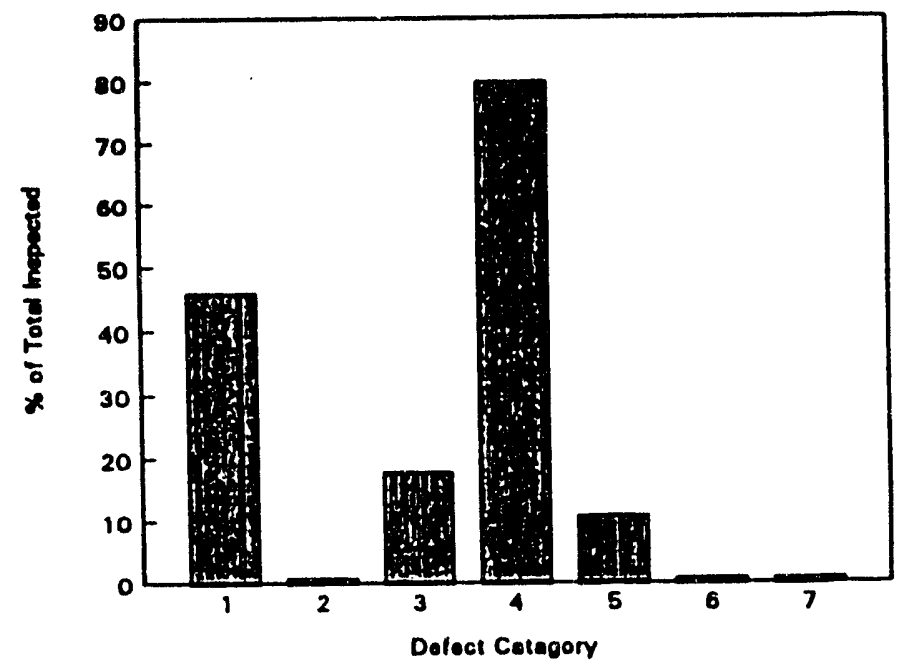

1. Spherical LDI - Platform

2. Sperical LDI - Airfoil

3. Linear LDI - Platform

4. Linear LDI - L.E. Airfoil

5. Linear LDI - T.E. Airfoil

6. High Density Indication

7. Chipped Edges

Figure 75. AGT101 Stator Set 1 Versus Set 3 Quality Comparison Green Casting MFXR Inspection. 
Set 1 Dense Visual

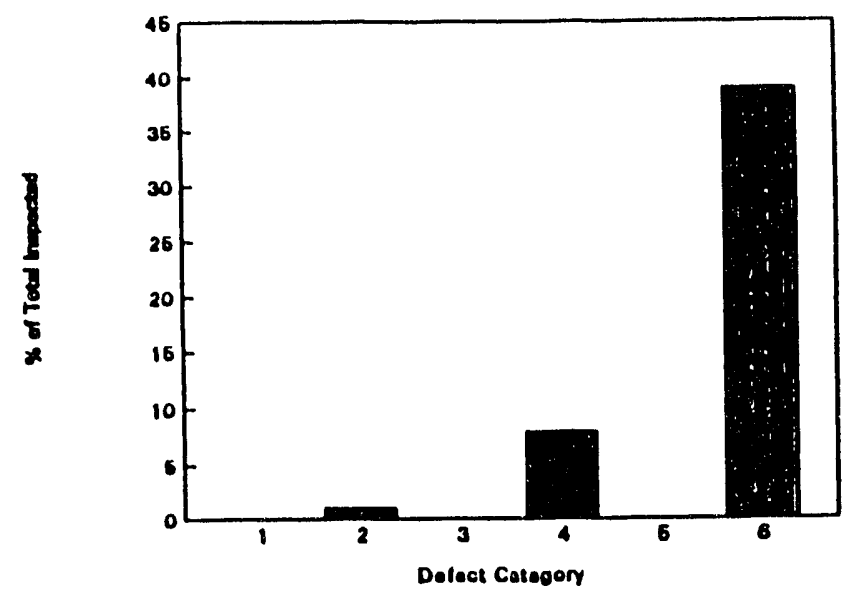

1. Platform Cracks

2. T.E.' Alrfoll Cracks

3. L.E. Airfoll Cracks

4. Chips - Platform

5. Chips - Alrfoll

6. Pits - Pores - Blemish

\section{Set 3 Dense Vísual}

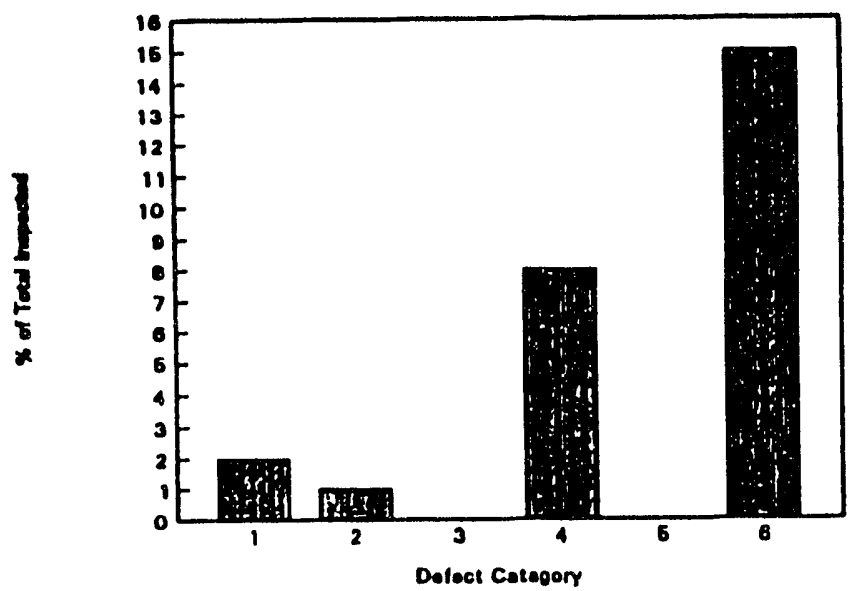

1. Platform Cracks

2. T.E. Airfoil Cracks

3. L.E. Airfoil Cracks

4. Chips - Platform

5. Chips - Alrfoil

6. Pits - Pores - Blemish

Figure 76. AGT101 Stator Set 1 Versus Set 3 Quality Comparison Dense Casting Visual Inspection. 


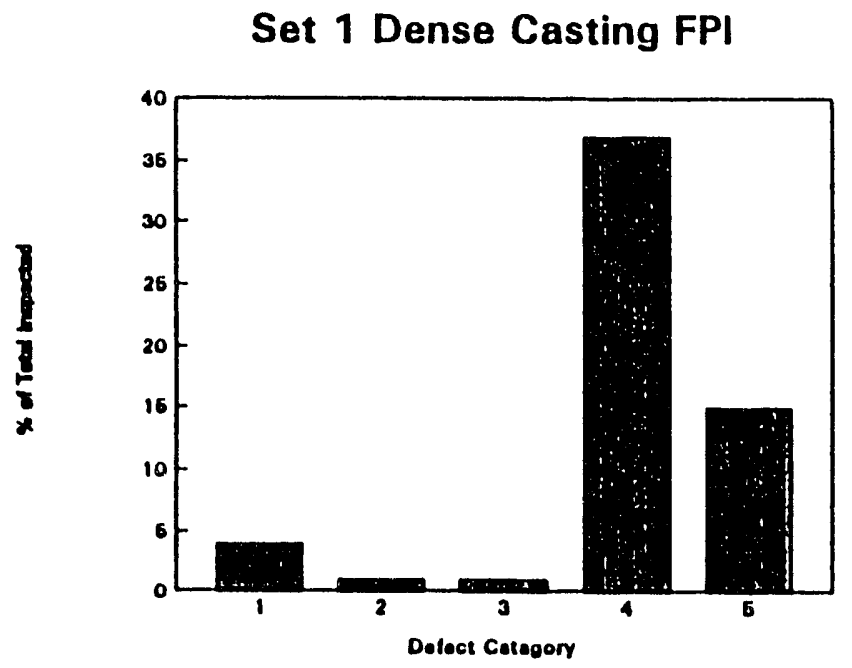

1. Platform Cracks

2. L.E. Airfoil Cracks

3. T.E. Airfoil Cracks

4. Platform Pits/Pores

5. Alrfoil Pits/Pores

Set 3 Dense Casting FPI

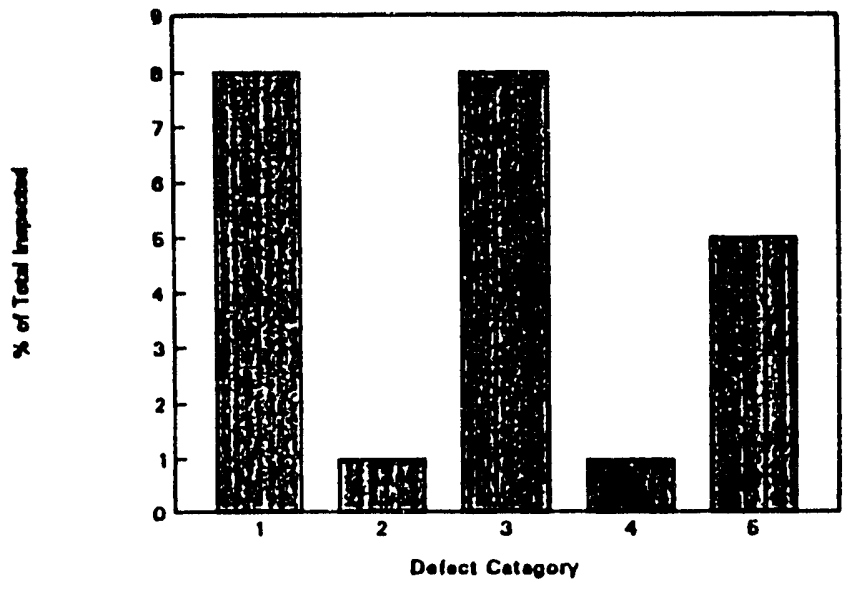

1. Platform Cracks

2. T.E. Airfoil Cracks

3. Platform Pits/Pores

4. Airfoil Pits/Pores

5. Glass

Figure 77. AGT101 Stator Set 1 Versus Set 3 Quality Comparison Dense Casting FPI Inspection. 
Set 1 Dense Machined Visual

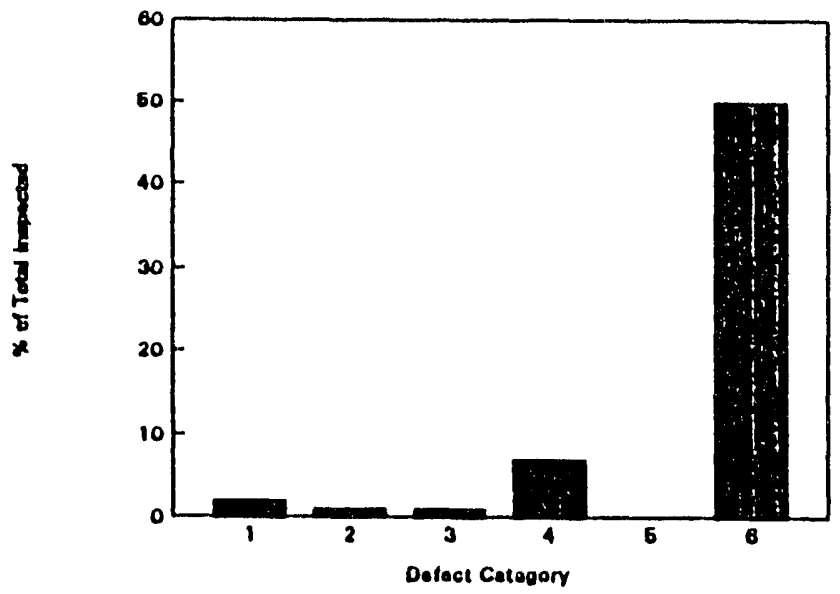

1. Platform Cracks / Chips

2. T.E. Airfoll Cracks

3. L.E. Airfoll Cracks

4. Platform Chips

5. Alrfoll Chips

6. Pits - Pores - Blemish

\section{Set 3 Dense Machined Visual}

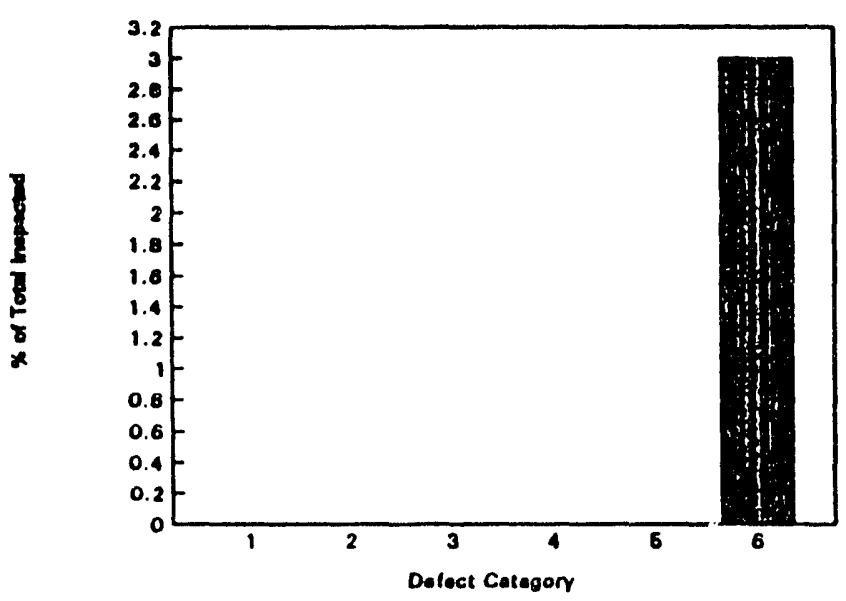

1. Platform Cracks / Chips

2. T.E. Airfoil Cracks

3. L.E. Airfoil Cracks

4. Platform Chips

5. Airfoll Chips

6. Pits - Pores - Blemish

Figure 78. Stator Set 2 Versus Set 3 Quality Comparison Dense Machined Visual Inspection. 
Set 1 Dense Machined FPI

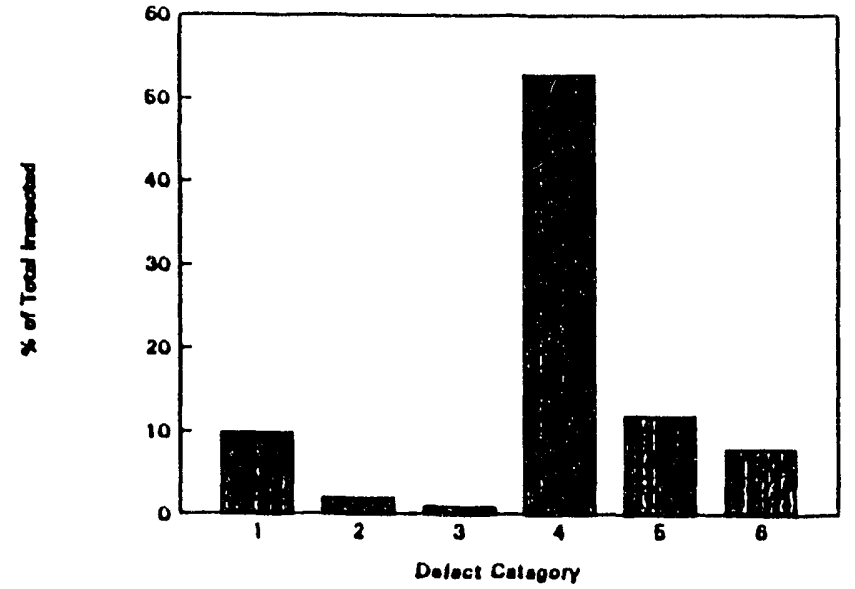

1. Platform Cracks

2. L.E. Airfoil Cracks

3. T.E. Alrfoll Cracks

4. Platform Pits / Pores

5. Airfoil Pits / Pores

6. Open \& Closed Chips

Set 3 Dense Machined FPI

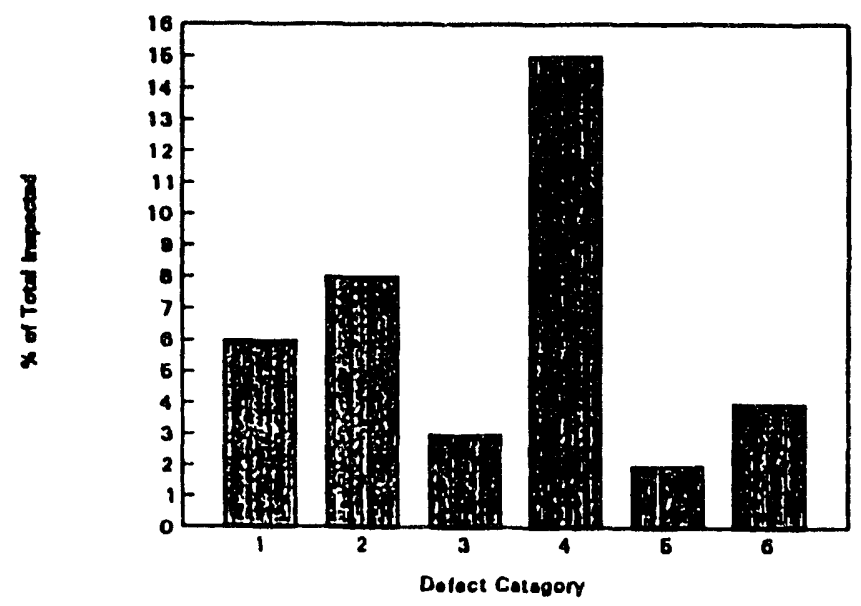

1. Platform Cracks

2. L.E. Airfoil Cracks

3. T.E. Airfoil Cracks

4. Platform Pits / Pores

5. Airfoil Pits / Pores

6. Glass

Figure 79. AGT101 Stator Set 1 Versus Set 3 Quality Comparison Dense Machined FPI Inspection. 


\section{Set 1 Dense Machined MFXR}

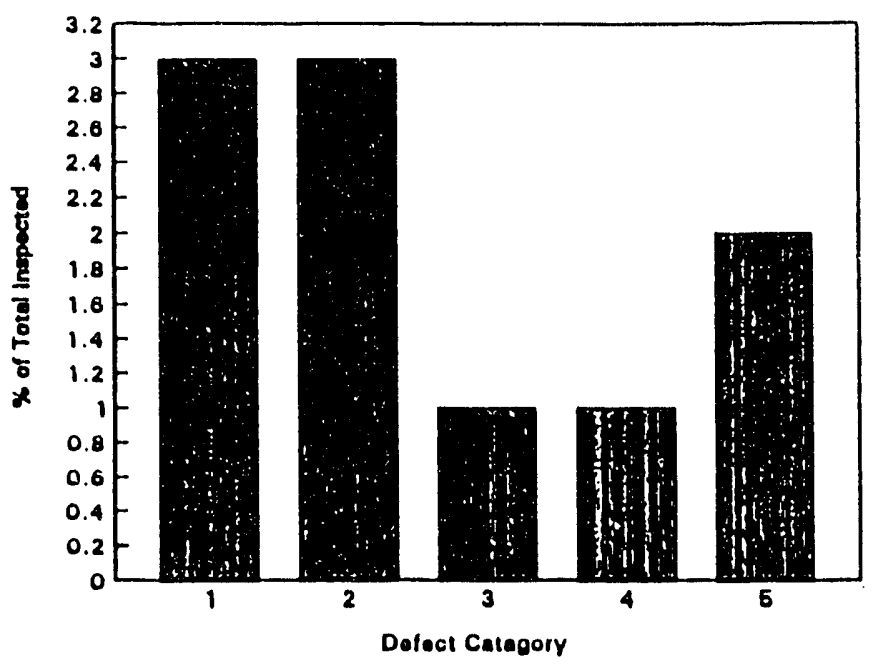

1. Spherical LDI - Platform

2. Spherical LDI - Alrfoil

3. Linear LDI - Platform

4. Linear LDI - T.E. Airfoil

5. Linear LDI - Other

\section{Set 3 Dense Machined MFXR}

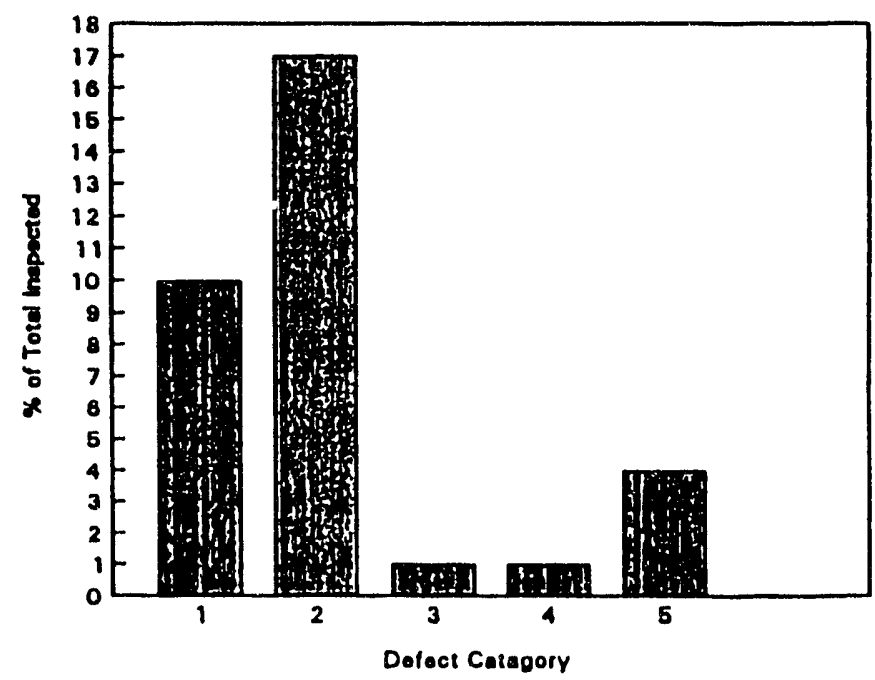

1. Spherical LDI - Platform

2. Spherical LDI - Airfoil

3. Linear LDI - Platform

4. Linear LDI - T.E. Airfoil

5. Chips \& Cracks

Figure 80. AGT101 Stator Set 1 Versus Set 3 Quality Comparison Dense Machined MFXR Inspection. 


\subsection{Project Management And Planning}

NAC successfully fulfilled its requirements specified in Section 5.7 of the ATTAP SOW by providing bimonthly technical progress reports and monthly financial reports. NAC and GAPD maintained close communication throughout the year by effective use of coordination telephone calls. During March of 1992, NAC completed and delivered its 1991 annual report. NAC personnel visited GAPD during April to discuss current technical issues. Tony Taglialavore, Larry Lynch, Bryan McEntire, and Richard Girvin of NAC visited on April 17 with Bob Morey of GAPD. During June, NAC hosted NASA, DOE, GAPD, and Allison personnel for its annual ATTAP review meeting. As discussed under Task 3.3, NAC re-directed technical efforts mid-way through the program year to comply with GAPD budgetary constraints. In October, Mr. Tony Taglialavore and Mr. Larry Lynch of NAC visited GAPD on October 21 to discuss current and future ATTAP program plans. NAC presented 1991-1992 ATTAP results at the annual CCM conference in Dearborn, MI on November 2. NAC has completed all efforts planned under the GAPD ATTAP with the delivery of this 1992 Annual Report. 


\subsection{SUMMARY AND CONCLUSIONS}

Norton Advanced Ceramics (NAC) completed its fifth-year effort of the ATTAP. Process and component development work was completed for both the AGT101 rotor and stator. Development of component specific fabrication operations for engine-quality hardware was completed early in the year. The major focus for 1992 was the fabrication of engine-quality rotor and stator deliverables. NAC successfully produced, proof tested and delivered five engine-quality rotors during 1992 - ten total throughout the entire ATTAP effort. A total of 163 engine-quality stators were also successfully produced and delivered to GAPD during 1992 - 189 total throughout the entire ATTAP effort. In addition, numerous NT154 and NT164 specimens were fabricated and delivered to GAPD for evaluation. A summary of significant accomplishments for the year is given below.

- $\mathbf{N T 1 5 4}$ Silicon Nitride $\left(\mathbf{S i}_{3} \underline{N}_{4}\right)$ - Characterization of NT154 continued during the year. A significant data base of critical mechanical properties for this material continues to be built at NAC, GAPD, other engine builders, and a number of independent laboratories. Flexural strength, fracture toughness, static and dynamic fatigue, creep, and thermal property information are available for engine design and analyses. Overall, properties for this material continue to meet program specifications. Under the 1992 GAPD ATTAP effort, NT154 was utilized to produce engine-quality AGT101 rotors and stators. An aqueous-milled version of NT154 with improved high-temperature fast fracture and stress rupture properties was developed and implemented on Rotor Deliverable Set No. 3.

- NT164 Silicon Nitride $\left(\mathrm{Si}_{3} \underline{N}_{4}\right)$ - Through its experience with NT154, NAC has been able to develop a highly creep resistant $\mathrm{Si}_{3} \mathrm{~N}_{4}$. Designated NT164, this material has approximately four times the creep life of NT154 at 1370C. This evolutionary achievement was realized by a slight change in overall composition, and by selective post-HIP heat-treatments. The NT164 microstructure has no amorphous grain boundary phases. Because of this, NT164 has higher hot strength $(\approx 690 \mathrm{MPa}$ at $1370 \mathrm{C})$ with equivalent fracture toughness and room temperature strength when compared with NT154. During 1992, NT164 was incorporated into the GAPDATTAP program. Under the 1992 GAPD ATTAP effort, NAC optimized a pressure-cast version of NT164 and fabricated numerous test specimens for GAPD evaluation.

- NT230 Siliconized Silicon Carbide (Si-SiC) - A new generation siliconized silicor carbide (Si$\mathrm{SiC}$ ) was developed and introduced. Designated NT230, NAC is used this material to produce transition ducts for GAPD under a parts-supply contract. This material has approximately double the strength of existing $\mathrm{Si}-\mathrm{SiC}$ compositions. At elevated temperatures (up to $1370 \mathrm{C}$ ), its strength is nearly equivalent to NT154. 
- Casting System Development - In an effort to simplify the NT154 process, and as a prerequisite to aqueous-based component casting, development of an aqueous-milled NT154 system was completed. Substitution of water for alcohol in the current process was seen as necessary to improve product quality and reduce cost. An experimental matrix was completed using standard pilot level equipment during the 1991 effort. From water-milled powders, casting trials were conducted for rotors, stators, tensile rods, and test tiles. Flexural and tensile mechanical properties were generated. Casting techniques and properties were found to be equivalent with or superior to the current alcohol-based process. Based on the successful development of the aqueous-milled system, NAC implemented its use on Rotor Deliverable Set No. 3. Additionally, by the middle of 1992, NAC replaced alcohol-milled NT154 with the aqueous-milled system.

- AGT101Rotor Production - NAC performed a comprehensive review of the entire rotor fabrication process used to successfully deliver engine-quality Rotor Set No. 1 during 1991. Based on experience gained from Set No. 1, NAC performed a limited amount of component specific casting development to improve dimensional control and yields. Using fixed and documented processes, NAC successfully cast, densified, machined, characterized, spintested, and delivered to GAPD five AGT101 rotors from Set No. 2. Mechanical properties for these components met program requirements, and were comparable to data acquired from coprocessed test tiles. Based on the successful development of the aqueous-milled NT154 system, NAC implemented its use on Rotor Deliverable Set No. 3. Using fixed and documented processes, NAC successfully cast, densified, and characterized five AGT101 rotors. These rotors were placed on hold prior to machining by GAPD due to budgetary constraints. Under the 1991 and 1992 efforts, NAC successfully spin tested all eleven AGT101 rotors to the proof speed of $105 \mathrm{krpm}$. Nine components were delivered to GAPD. Engine testing of this hardware by GAPD was conducted during 1992. The remaining two rotors were purposefully spun to failure. They failed at speeds of 126.6 and $118.9 \mathrm{krpm}$, or 141 and 132 percent of maximum engine design speed, (i.e., $\approx 90 \mathrm{krpm}$ ).

- AGJ101 Stator Production - At the close of 1991, NAC performed a comprehensive review of the entire stator fabrication process. Corrective action was identified and became part of NAC's 1992 Technical Work Plan. In accordance with this plan, NAC fabricated a secondgeneration casting pattern to improve dimensional control, and increased mold design and casting procedures to improve process yields. While performing these corrective action tasks, NAC completed deliveries on Stator Deliverable Set No. 1. A total of 33 additional stators were delivered bringing the total for Set No. 1 to 57. Mechanical properties for this hardware were evaluated and found to meet ATTAP specifications. Using the identical tooling and 
methods as Set No. 1, NAC fabricated and delivered 50 engine-quality stators for Set No. 2. Mechanical properties for this hardware were evaluated and found to meet ATTAP specifications. Both Set No. 1 and No. 2 met print requirements for machined surfaces, but were out of specification for as-processed dimensions. Although these sets were deemed adequate for engine testing by GAPD, NAC completed its corrective action tasks and implemented a second-generation casting pattern and improved mold design to improve dimensional control and process yields. NAC fabricated and delivered a total of 80 engine-quality stators for Set No. 3. Mechanical properties for this hardware were evaluated and found to adequately meet ATTAP specifications. High-temperature properties, however, were abnormally low for NT154 The degradation in properties was attributed to contamination from the agglomeration process and alcohol milling. Both problem sources have been corrected by NAC. Dimensional control for Set No. 3 was improved over Set No. 1 and No. 2 with airfoil chord length specifications being met. Due to bi-directional shrinkage, however, inner platform distance was still out of specification although better than for the first two sets. Although NAC's improved mold design dramatically improved process yields, surface quality in critical component areas degraded from Sets No. 1 and No. 2 to Set No. 3. NAC has investigated this quality issue and as a result has developed a comprehensive program for 1993 to improve as-processed surface quality. Using the identical tooling and methods as Set No. 3, NAC fabricated and machined a total of 79 engine-quality stators for Set No. 4. Due to budgetary constraints, however, GAPD placed these components on hold after machining. NAC has gained valuable experience in the development of processes and fabrication of engine-quality AGT101 stators for GAPD. Using this experience, NAC has developed and implemented comprehensive plans to improve quality and yields for all NT154 component products.

- HIP Development - NAC performed a limited amount of long-term stress rupture testing for the As-Fired Surface Optimization L16 experiment which was initiated in 1991. Completion of this effort was suspended due to time and budgetary constraints. NAC also performed a limited amount of development work on the improvement of as-processed surface strengths. None of the experimental work performed yielded significant improvements in as-processed properties. NAC recognizes that as-processed surface quality and strength of NT154 must be improved in the future to be commercially viable.

- Process Engineering NDE Development And Quality Assurance - Documentation of the NT154 process and component specific operations was completed in 1991. Revisions of these documents, as necessary, were conducted during 1992. Microfocus X-Ray Radiography (MFXR) and Fluorescent Dye Penetrant Inspection (FPI) are routinely conducted on all 
components. NAC's Quality System was audited by GAPD and found to be in conformance with their internal requirements.

- Deliverables - In addition to delivering 5 engine-quality rotors and 163 engine-quality stators, NAC also supplied numerous NT164 specimens for GAPD evaluation.

NAC's effort under the GAPD ATTAP was completed during 1992. NAC is now using its experience gained under the ATTAP to focus on process simplification and scale-up to commercialization. The ATTAP program has been a vital stepping stone for NAC along the path to high volume production of ceramic engine components. 


\subsection{ACKNOWLEDGMENTS}

Work accomplished by NAC during the 1992 program year represents the combined efforts of a number of individuals. The following principal engineers are gratefully recognized for their key contributions: R. L. Yeckley--Materials Development; P.D. Redington--Machining Development; L. D. Lynch--Design and Drafting; and E. Bright--NDE and Quality Assurance. Additionally, G. Janulewicz, D. Moylan, J. Gulcius, B. McGeary, D. Karsberg, S. FitzGerald, and L. Russell are acknowledged and appreciated for detailed performance of the technical plan. The Characterization and Analysis Groups of Norton Company are acknowledged for their work in chemical analysis, $x-$ ray diffraction, microfocus $x$-ray characterization, mechanical property testing, and electron microscopy. A. M. Schiavitti-Smith, R. T. Foy, and C. Mulcahy are appreciated for cost analysis and accounting services. Special thanks go to Dr. R. R. Wills who constructively reviewed program objectives, plans, and reports; and to J. M. Garwood for government contract administration review and support. B. J. McEntire is gratefully acknowledged for technical contributions and management support. J. Smyth, J. Schienle, J. Minter, and B. Morey of GAPD are acknowledged and thanked for technical guidance, analyses, program direction and support. Finally, appreciation is expressed to Norton Company, TRW, GAPD, NASA, and DOE for financial support. 


\subsection{NOMENCLATURE}

$\begin{array}{ll}\text { ATTAP } & - \text { Advanced Turbine Technology Applications Project } \\ \text { CIP } & - \text { Cold Isostatic-Pressing } \\ \text { CMM } & - \text { Coordinate Measuring Machine } \\ \text { DOE } & - \text { Department Of Energy } \\ \text { FPI } & - \text { Fluorescent Dye Penetrant Inspection } \\ \text { GAPD } & - \text { Garrett Auxiliary Power Division, AlliedSignal Aerospace Company } \\ \text { HIP } & - \text { Hot isostatic Pressing } \\ \text { MFXR } & - \text { Microfocus X-Ray Radiography } \\ \text { MOR } & - \text { Modulus of Rupture } \\ \text { NASA } & - \text { National Aeronautics And Space Administration } \\ \text { NT154 \& NT164 Si3 N } 4 & - \text { HIPped Silicon Nitride } \\ \text { NT230, NT235 and } & \\ \text { NC430 Si-SiC } & - \text { Siliconized Silicon Carbides } \\ \text { NAC } & - \text { Norton Advanced Ceramics } \\ \text { ORNL } & - \text { Oak Ridge National Laboratory } \\ \text { PEEP } & - \text { Pressure-assisted Endothermic Extraction Process } \\ \text { SPC - } & - \text { Statistical Process Control } \\ \text { UDRI } & - \text { University Of Dayton Research Institute } \\ \text { WEEP } & - \text { Water Endothermic Extraction Process }\end{array}$




\subsection{REFERENCES}

1) K.C. Liu and C.R. Brinkman, "Cyclic Fatigue of Toughened Ceramics," Ceramic Technology for Advanced Heat Engines Project - Semiannual Progress Report for October 1989 Through March 1990 (Oak Ridge, TN: ORNL Publication No. ORNL/TM-11239), 359-372.

2) K.C. Liu, H. Pih, C.O. Stevens, and C.R. Brinkman, "Tensile Creep Behavior and Cyclic Fatigue/Creep Interaction of Hot-Isostatically Pressed $\mathrm{Si}_{3} \mathrm{~N}_{4}$," SAE Publication P-243, Proceedings of the 28th Annual DOE Automotive Technology Development Contractors' Coordination Meeting, Dearborn, MI, October 22-25, 1990 (Warrandale, PA: Society of Automotive Engineers, Inc., April 1991).

3) D.W. Richerson, "Fractography of Advanced Silicon Nitride Materials for Turbine Applications," Final Report, Submitted to Naval Sea Systems Command, Contract No. N00024-88-C-5112, Washington, D.C. (Salt Lake City, UT: Ceramatec Report No. 8963201, April 1989).

4) N.L. Hecht, S.M. Goodrich, L. Check, and D.E. McCullum, "Effects of the Environment on the Mechanical Behavior of Ceramics," SAE Publication P-243, Proceedings of the 28th Annual DOE Automotive Technology Development Contractors' Coordination Meeting, Dearborn, MI, October 22-25, $1990 \mathrm{NM}^{\mathrm{r}}$ arrandale, PA: Society of Automotive Engineers, Inc., April 1991).

5) K.C. Liu, H. Pih, C.O. Stevens, and C.R. Prinkman, "Tensile Creep Behavior And Cyclic Fatigue/Creep Interaction Of Hot-Isostatically-Pressed $\mathrm{Si}_{3} \mathrm{~N}_{4}$," SAE Publication P-243, Proceedings Of The 28th Annual DOE Automotive Technology Development Contractors' Coordination Meeting, Dearborn, MI, October 22-25, 1990 (Warrandale, PA: Society of Automotive Engineers, Inc., April 1991).

6) M.L. Torti, J.W. Lucek and G.Q. Weaver, "Densified Silicon Carbide-An Interesting Material For Diesel Applications," SAE Paper No. 780071, Proceedings of the SAE Congress and Exposition, February 27 - March 3, 1978, Detroit, MI (Warrendale, PA: Society Of Automotive Engineers, Inc., 1978).

7) Advanced Gas Turbine (AGT) Technology Project" Final Report, Allison Gas Turbine Division, General Motors Corporation, Report No. DOE/NASA 0168-11, NASA CR-182127, EDR 13295, Prepared For National Aeronautics and Space Administration, Lewis Research Center, for the U.S. Department of Energy, Conservation and Renewable Energy, Office of Transportation Systems (August 1988).

8) G.Q. Weaver, "Process for Forming High Density Silicon Carbide," U.S. Patent No. 3,998,646 (December 21, 1976).

9) G.Q. Weaver and B.A. Olson, "Process for Fabricating Silicon Carbide Articles," U.S. Patent No. 4,019,913 (April 26, 1977). 


\begin{tabular}{|c|c|c|}
\hline 1. & $\begin{array}{l}\text { Report No. } \\
\text { NASA CR-191088 }\end{array}$ & 3. Rectplent's Catalog No. \\
\hline \multirow[t]{2}{*}{4.} & \multirow{2}{*}{$\begin{array}{l}\text { Tite and Subtite } \\
\text { Advanced Turbine Technology Applications } \\
\text { Project (ATTAP) - } 1992 \text { Annual Report }\end{array}$} & $\begin{array}{l}\text { 5. Repon Date } \\
\text { March } 1993\end{array}$ \\
\hline & & $\begin{array}{l}\text { 6. Performing Organization Code } \\
99193\end{array}$ \\
\hline \multirow[t]{2}{*}{7.} & \multirow[t]{2}{*}{$\begin{array}{l}\text { Author(s) } \\
\text { Engineering Staff of Garrett Auxiliary Power Division, } \\
\text { A Unit of Allied-Signal Aerospace Company }\end{array}$} & $\begin{array}{l}\text { 8. Performing Organization Report No. } \\
31-8071(05)\end{array}$ \\
\hline & & \multirow[t]{2}{*}{ 10. Work Unit No } \\
\hline \multirow[t]{2}{*}{ ๑. } & \multirow{2}{*}{$\begin{array}{l}\text { Performing Organtzation Name and Addreas } \\
\text { AlliedSignal Auxiliary Power } \\
2739 \text { East Washington Street } \\
\text { P.O. Box } 52180 \\
\text { Phoenix, Arizona } 85072-2180\end{array}$} & \\
\hline & & $\begin{array}{l}\text { 11. Contrect or Grant No. } \\
\text { DEN3-335 }\end{array}$ \\
\hline \multirow[t]{2}{*}{12.} & \multirow{2}{*}{$\begin{array}{l}\text { Sponsoring Agenoy Name and Addreses } \\
\text { U.S. Department of Energy } \\
\text { Office of Transportation Technologies, Advanced } \\
\text { Propulsion Division, Washington, D.C. } 20585\end{array}$} & $\begin{array}{l}\text { 13. Type of Report and Perlod Covered } \\
\text { Annual Report } 1992\end{array}$ \\
\hline & & $\begin{array}{l}\text { 14. Sponsoring Agency Code } \\
\text { DOE/NASA 0335-5 }\end{array}$ \\
\hline 15. & \multicolumn{2}{|l|}{$\begin{array}{l}\text { Suppleiventary Notce } \\
\text { Annual Report Under Interagency Agreement } \\
\text { Project Manager: T.N. Strom, Propulsion Systems Division } \\
\text { NASA-Lewis Research Center, Cleveland, Ohio } 44135\end{array}$} \\
\hline
\end{tabular}

\section{Abotrect}

This report is the fitth in a series of Annual Technical Summary Reports for the Advanced Turbine Technology Applications Project (ATTAP), authorized under NASA Contract DEN3-335 and sponsored by the U.S. Department of Energy (DOE). The report was prepared by Garrett Auxiliary Power Division (GAPD), a unit of Allied-Signal Aerospace Company, a unit of AlliedSignal, Inc. The report includes information provided by Garrett Ceramic Componenis, and the Norton Advanced Ceramics Company, (formerly Norton/TRW Ceramics), subcontractors to GAPD on the ATTAP. The project is administered by Mr. Thomas Strom. Project Manager, NASA-Lewis Research Center, Clovoland, OH. This report covers plans and progress on coramics dovelopment for commercial automotive applications over the period January 1 through December $31,1992$.

Project effort conducted under this contract is part of the DOE Gas Turbine Highway Vehicle System program. This program is directed to provide the U.S. automotive industry the high-risk, long-range technology necessary to produce gas turbine engines for automobiles with reduced fuel consumption, reduced environmental impact, and a decreased reliance on scarce materials and resources. The program is oriented toward developing the high-risk technology of ceramic structural component design and fabrication, such that industry can carry this technology forward to production in the 1990s. The ATTAP test bed engine, carried over from the previous AGT 101 project, is being used for verification testing of the durability of next-generation ceramic components, and their suitability for service at Reference Powertrain Design conditions.

This document reports the technical effort conducted by GAPD and the ATTAP subcontractors during the fitth year of the project. Topics covered include ceramic processing definition and refinement, design improvements to the ATTAP test bed engine and test rigs, and the methodology development of ceramic impact and fracture mechanisms. Appendices include reports by ATTAP subcontractors in the development of silicon nitride materials and processes.

17. Koy Words (Suggeased by Author(s))

Ceramic-Engine

18. Distribution Statement

Unclassified-Unlimited

Subject Category 85

Ceramic-Technology

DOE Category UC-96

19. Security Claself. (of this report) Unclassified
20. Security Clacelf. (of this pago) Unclassified
21. No. of Pages 140
22. Prlce" A07

For eale by the National Technical Information Sorvice, Springfbld, Virginla 22161

NASA-C-168 (Rov. 10-75) 

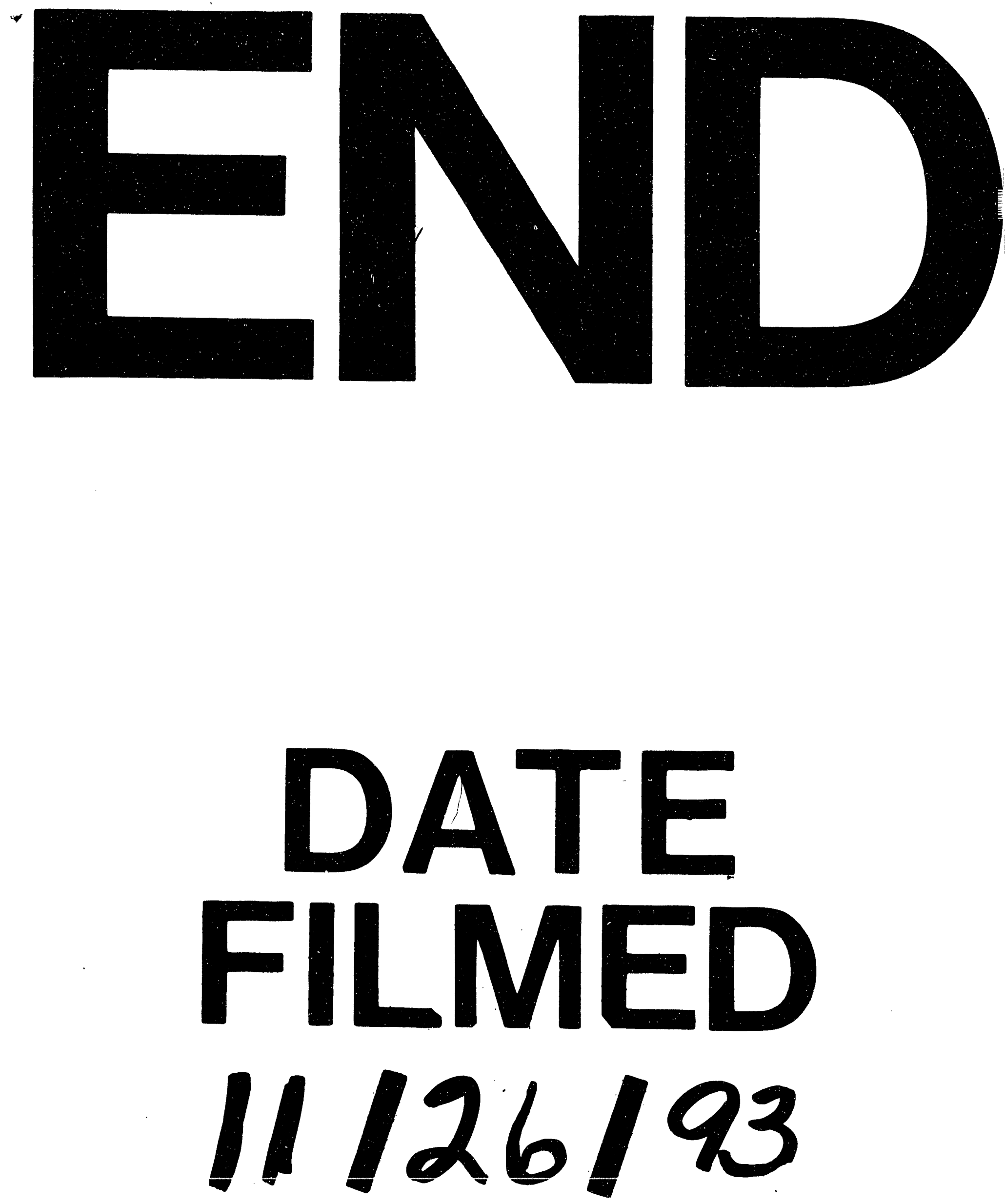


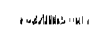

㪯 